Portland State University

PDXScholar

Spring 6-5-2017

\title{
Rural Interprofessional Health Care Education: a Study of Student Perspectives
}

Curt Carlton Stilp

Portland State University

Follow this and additional works at: https://pdxscholar.library.pdx.edu/open_access_etds

Part of the Educational Leadership Commons, Interprofessional Education Commons, and the Rural Sociology Commons

Let us know how access to this document benefits you.

\section{Recommended Citation}

Stilp, Curt Carlton, "Rural Interprofessional Health Care Education: a Study of Student Perspectives" (2017). Dissertations and Theses. Paper 3624.

https://doi.org/10.15760/etd.5516

This Dissertation is brought to you for free and open access. It has been accepted for inclusion in Dissertations and Theses by an authorized administrator of PDXScholar. Please contact us if we can make this document more accessible: pdxscholar@pdx.edu. 
Rural Interprofessional Health Care Education: A Study of Student Perspectives

by

Curt Carlton Stilp

A dissertation submitted in partial fulfillment of the requirements for the degree of

Doctor of Education

in

Educational Leadership: Postsecondary Education

Dissertation Committee:

Candyce Reynolds, Chair

Becky Boesch

Andy Job

Leslie McBride

Portland State University

2017 
(C) 2017 Curt Carlton Stilp 


\begin{abstract}
As the cost for health care delivery increases, so does the demand for access to care. However, individuals in a rural community often do not have access to the care they need. Shortages of rural health care professionals are an ever-increasing problem. The Affordable Care Act of 2010 sought to increase health care access by focusing on teambased care delivery. Thus, the need to educate health care students in the fundamentals of team-based practice has led to an increased emphasis on Interprofessional Education (IPE). While past research focused on urban IPE, a literature gap exists for the effects of a rural team-based educational experience on practice location decisions. This study examined how rural IPE influenced health profession students' perspectives of what it means to be a member of a rural health care team and explored what factors go into making decisions of where to live and provide care. Motivational Theory provided the framework for a mixed methods approach with data from student reflective journaling and a post-experience Q sort. Analysis yielded important understandings about the impact of rural IPE. Accordingly, having a rural IPE experience provided positive motivation for returning after graduation. Further, the time spent in rural IPE generated understandings of what it means to live and provide care to a rural community. One important new discovery gained is the clinical setting is not where most IPE took place. As a result, social interactions with fellow students and community members achieved the goals of rural IPE. Despite these influential findings, noted barriers to genuine rural IPE persisted. In the end, students, educators, and rural health care professionals need to be aware of the multiple factors that guide decisions of where to live and provide care.
\end{abstract}




\section{Acknowledgements}

I would first and foremost like to thank God for his continual strength and provision for my family and me. He sustained us by his grace during the past three years, so that we did not wear out. I would also like to thank my wife, Jodi Stilp, for supporting me before, during, and after this endeavor. She stepped in when I could not and made it possible for life to continue on, without much of a wrinkle. Her love for me and belief that I could finish this program meant everything. I love you! I want to thank my four children, Grant, Katie, Alli, and Paige Stilp. They went into this process knowing that it would require adjustments from them as well. They handled it all with maturity and grew in their knowledge of education right alongside of me. Their understanding was what I needed when sleep was short and I could not always be there to reciprocate the encouragement. Thank you to my friends who began this journey with me, prayed, listened, and cheered all of us on to completion. Thank you for being part of our lives. A big thank you to my dissertation chair, Dr. Candyce Reynolds. Her feedback and suggestions were invaluable. The advice for how to approach a topic or structure an explanation was exactly what I needed to be successful. I also want to thank my dissertation committee. Their recommendations for how to improve my study made this such a better paper in the end. Thank you for reading my entire dissertation in just two weeks. Finally, I want to thank my doctoral classmates who walked this road right along with me. Their support and understanding of what this program takes meant I had an ally in the trenches with me. It was a privilege and honor getting to know you and I cannot wait to see where we all go next. 
Table of Contents

Page

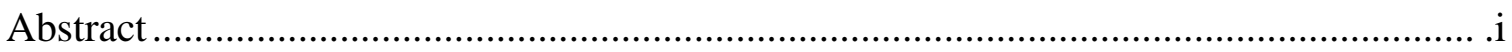

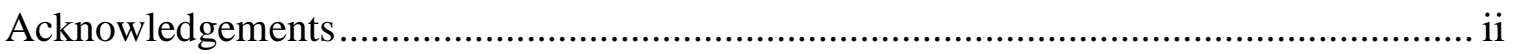

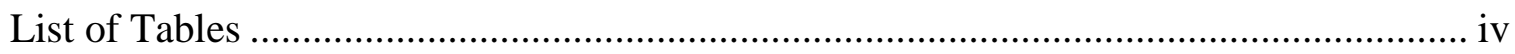

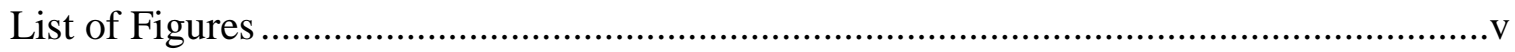

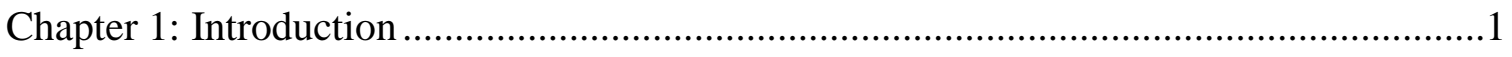

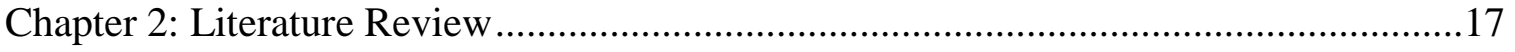

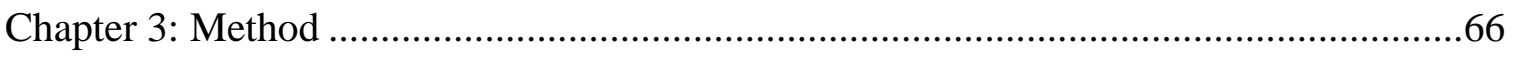

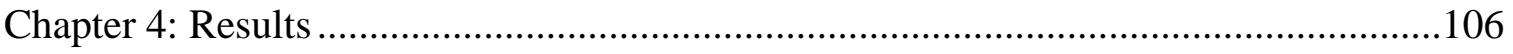

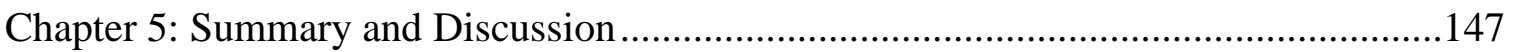

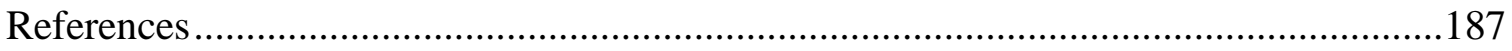

Appendices

Appendix A Informed Consent and Study Information Sheet .........................198

Appendix B The Q-Set Used for the Study ...............................................202

Appendix C Journal Coding Table ............................................................205

Appendix D Values Coding Categorization Table ..........................................226

Appendix E Example of Completed Q Sort and Corresponding Email..............232

Appendix F The Un-Rotated Factor Matrix..................................................234

Appendix G Group A Factor Loadings ..................................................236

Appendix H The Complete Factor Array for the Q Sort ................................238 


\section{List of Tables}

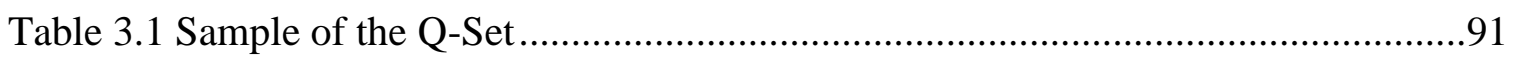

Table 4.1 Descriptive Coding With Examples ......................................................108

Table 4.2 Descriptive Coding Themes...................................................................110

Table 4.3 Values Coding With Examples...............................................................114

Table 4.4 Values Coding Categories .....................................................................116

Table 4.5 Q Sort Demographic Data............................................................... 122 
List of Figures

Figure 3.1 Workflow Design Model for the Study …............................................... 70

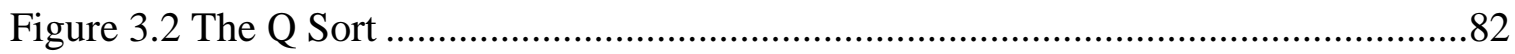

Figure 4.1 Representative Q Sort for Team-Oriented Rural Optimist Perspective .........131

Figure 4.2 Representative Q Sort for Independent Rural Impartial Perspective ............136

Figure 4.3 Representative Q Sort for Team-Willingness Rural Skeptic Perspective ......140 


\section{CHAPTER 1}

\section{INTRODUCTION}

This dissertation is a study of a health science university's attempt to improve the health of rural communities by increasing the numbers of health care professionals living and working in rural communities through a rural Interprofessional Education (IPE) program. Chapter 1 gives a brief overview of the subsequent chapters as well as introduces the problem in practice, theoretical framework, and methods for the study. Chapter 2 is a literature review exploring aspects of rural health care, traditional medical education, team-based learning, and how motivation is influenced through experience. Chapter 3 describes the methods used in the study for data collection and analysis, concluding with some considerations on the implications for rural team-based health care education and delivery. Chapter 4 represents data collected from students who experienced rural IPE as part of their health care training and the respective analysis. Chapter 5 provides interpretation of the data and implications for current and future health care education.

\section{Rural Health Care}

Good health care is a common need shared by every member of society. Individuals encounter illnesses and diseases that require the expertise of medical providers to care for their needs. Therefore, the demand for access to good medical professionals remains constant. The issues of how a person accesses health care, where they access care, and who cares for them have become increasingly more important for 
those living in a rural community. As a result, many Americans try to reconcile the desire to live in a rural community with the need for quality care.

Currently the majority of health care in America is concentrated in large urban settings with nearby access to hospitals, clinics, and specialists. For instance, if a person lives in an urban setting and needs medical attention, they can see a local provider within a few miles of their home. However, those living in rural settings often do not have access to a hospital, clinic, or basic primary care as many rural areas experience a shortage of health care providers from all professions (Jensen \& Royeen, 2002; Mu, Chao, Jensen, \& Royeen, 2004; Smith, Thornberry, Lyons, \& Jones, 2005). For example, $20 \%$ of Americans live in a rural county while only $9 \%$ of physicians practice in such counties (Gazewood, Rollins, \& Galazka, 2006).

The reasons for health care provider shortages in rural areas is multifactorial. An individual's personal or professional views have a significant influence on the decision of where to provide care. As one would imagine, families, spouses, partners, and children have been found to be substantial factors in the choice of where to live (Rabinowitz, Diamond, Markham, \& Hazelwood, 1999). Additionally, where a person was raised and the desire to return or stay in a similar type of setting is shown to be a major contributor to the decision of where to live and provide care (Mayo \& Mathews, 2006). Moreover, individual lifestyle goals and preferences play a significant role in where that person will choose to live (Deutchman, Nearing, Baumgarten, \& Westfall, 2012).

Professional factors such as opportunities for career advancement and access to adequate resources for patient care are among some of the most important elements for 
job satisfaction in health care providers (Hancock, Steinbach, Nesbitt, Adler, \& Auerswald, 2009). Since many rural areas lack the resources necessary to provide fullscope health care, providers are left feeling frustrated they cannot provide the level of care they had desired. Furthermore, the feeling of being professionally overwhelmed when caring for a rural community can lead to feelings of exhaustion when a health care provider does not have fellow professionals to help share the workload of caring for a rural community.

Personal and professional factors are not the only elements that contribute to the decision of where to live and provide care. The rural setting itself offers unique challenges due to the simple geographic location alone. Because several hundred miles isolate rural communities, the influence of a progressive urban city is often not felt within a rural community. This can lead to cultural differences that make it difficult for a health care provider to identify with the rural ethos (Hancock et al., 2009). For example, rural citizens may have a more traditional view of only going to the doctor when they are sick rather than for health screenings or disease prevention visits. Furthermore, learning how to engage with these differences and develop treatment plans that take into account the mindset of a rural community member can prove to be a deterrent to settling in a rural area (Slama, 2004).

The elements that make up a rural setting can also lead to social constructs that leave a health care provider striving for integration into rural community life. A health care provider may be interested in social activities that are frequently not found in many rural towns (Slama, 2004). For instance, many rural towns do not have a health club or 
organized youth events. As a result, health care providers who prefer these types of activities as a way to build relationships with individuals, groups, or families may choose to live elsewhere (Bell, 1992).

All of these contributing factors have the potential to play different roles at different times for the health care provider. Consider how an unmarried health care provider may view living in a rural community without a stable public school system versus how a provider with young children may view raising a family in a community with fewer school options. Or how an early career health care provider trained in a cutting edge hospital would approach providing care to a rural community versus how a provider near the end of her career who has experienced the way care is delivered in a rural area would approach treatment options for advanced disease. What is important to understand is how these factors lead to barriers, which cause health care providers to settle in urban or suburban areas. The end result is a rural health care system that is in desperate need of providers and health care professionals who are prepared for and committed to improving health care access to some of the most underserved areas.

\section{Team-Based Health Care}

In response to a decrease in health care access everywhere, many in the U.S. called for a different model of health care delivery (D. C. Baldwin, 2007). Recently, one of the major pieces of U.S. Government legislation addressing the lack of health care provider access was the Affordable Care Act (ACA) of 2010. When the ACA was signed into law, millions of Americans gained health care coverage they had previously been 
unable to attain. Specifically, the new care delivery model outlined in the ACA is the use of health care teams instead of individual providers to care for patients.

Typically, the health care team is what is called interprofessional, consisting of a medical provider (physician, MD/DO), mid-level health care provider (physician assistant [PA]); nurse practitioner (NP), support staff (medical assistant), nurse, social worker, pharmacist, dentist, and depending on the setting, it may also include someone from rehabilitative medicine. With this new care distribution model, the delivery of health care is changing. The need for teamwork to meet the demands of an aging population with more complex chronic conditions, increasing costs, and fragmented uncoordinated care, is more important than ever before (Smith et al., 2005). This need for collaboration is especially true for those living in a rural community (Illing \& Crampton, 2015).

The limited number of health care providers in a rural setting, including access to specialists, increases the need for collaborative care to address the wide variety of medical problems that exist in a rural community. Therefore, an interprofessional or team-based approach to health care delivery is more important in a rural setting. This is mainly due to limited resources and the lack of health care professionals to help shoulder the responsibility of caring for the health needs of a rural community (Mu et al., 2004). As one looks at rural clinics, health care professionals practice in teams because they have to (D. C. Baldwin, 2007; Jones, Oster, Pederson, Davis, \& Blumenthal, 2000). However, many health care professionals are not prepared for how to work with a health care team upon graduation. 
The need to prepare practitioners for rural team-based care is a challenge facing many in health care education today (Chen, Fordyce, Andres, \& Hart, 2010). The current health care educational system is not doing enough to prepare students for the importance of collaboration and teamwork in the rural setting (Illing \& Crampton, 2015).

Additionally, current health care curriculum does not support the preparation of living and providing care in a rural community (J. A. Henry, Edwards, \& Crotty, 2009). Several challenges exist within current educational models for how health care professionals have historically been trained.

\section{Traditional Health Care Education}

For many years the dominant model of health care education has been one of separate training in discipline specific programs termed "uniprofessional education" (Reeves, Perrier, Goldman, Freeth, \& Zwarenstein, 2013). In other words, traditional health care education involves students learning profession-specific competencies solely in the context of their own program with minimal to no contact with other students (Oandasan \& Reeves, 2005). The end result is individuals acting in separate professional roles within a system that does not foster comprehensive or collaborative health care delivery (D. C. Baldwin, 2007).

Current health care education students have limited awareness of the scope of practice or even the role the other professions play on a health care team. This approach to health care education leads to the reinforcement of traditional profession-specific roles, territorial concerns, and a lack of collaborative coordinated care (Mu et al., 2004). The conventional way of educating health care professionals in silos without horizontal 
integration does not match the real-world nature of team-based health care delivery many are now calling for in rural settings. Additionally, the traditional educational approach has led to training in urban hospitals or clinics for the majority of time to learn at a large tertiary medical center (Wachter, Katz, Showstack, Bindman, \& Goldman, 1998). Therefore, health care training sites have historically been located in areas where increased numbers of providers are not necessarily needed.

The position and standing a healthcare university holds provides a unique opportunity to bring about meaningful change (Hodges, 2014). Through the application of a critical lens, health care education institutions are viewed as central agents in how their students, and ultimately graduates, can play an important role in the equal distribution of health care resources. Furthermore, how these institutions use their position to address health care disparities, such as lack of health access in rural settings and low numbers of primary care providers ready to enter rural practice, is of upmost importance (Rabinowitz et al., 1999).

Several attempts by health care institutions to increase numbers of rural health care providers have been tried. Past efforts have customarily focused on both increasing the recruitment of students from a rural background and increasing the amount of rural experiences students receive in their health care training. For example, one such effort involved the increase of class sizes in hopes that more graduates will choose a rural setting as their destination (Whitcomb, 2005). However, simply increasing class sizes without an emphasis on rural health care or even a curriculum for exposing students to how health care is delivered in rural communities is not enough (Chen et al., 2010). 
Several years ago, health care educators developed postgraduate rural training opportunities and incentives. For instance, the development of Rural Training Tracks (RTTs) sought to expose medical residents to rural settings during the crucial years of clinical training when practice location decisions are made (Rosenthal, 2000).

Additionally, the use of incentive programs such as loan forgiveness or loan repayment aimed to draw students and graduates into rural settings through either paying for a student's tuition or paying off student debt if they choose to practice in rural areas.

It is known that programs designed to expose students to rural settings during their medical training increases the likelihood that they will return to a rural setting to practice (Rabinowitz, Diamond, Markham, \& Wortman, 2008). As a result, students who complete a portion of their training in a rural setting may impact their motivation for them to stay in such a setting after graduation. Therefore, through programs like RTTs, educators can expose more students to rural medical practice, identify motivating factors for choosing to practice in rural settings and examine how a rural experience influences a student's decision to live and practice in a rural community.

While rural experience programs have provided a modest increase to the number of rural providers, they do not provide education in team-based care delivery that is so crucially needed in the rural setting (Geyman, Hart, Norris, Coombs, \& Lishner, 2000). Accordingly, health care educators did recognize the need to instruct students on the concepts of team-based care in the midst of their training programs (Mu et al., 2004). This led to an increased emphasis on what is called Interprofessional Education (IPE). 
Interprofessional Education is a pedagogical approach to health care education that is defined as one or more professions learning from and about each other for the purpose of collaboration and improved care (Centre for the Advancement of Interprofessional Education, 1997). Specifically, IPE can be characterized by students in MD/DO, PA, NP, nursing, pharmacy, dentistry, and Physical Therapy (PT) programs comparatively discussing similarities and differences among their professions while learning how to approach patient care through each other's lens (Hallin, Kiessling, Waldner, \& Henriksson, 2009). To put it succinctly, it asks the question, how can we each contribute and work together to improve patient care?

Interprofessional Education requires students to communicate with purpose in the understanding of each other's roles, and focuses on the contribution that each health care professional makes to collaborative practice. Therefore, the better understanding students have of their role in team-based health care delivery, the better they will perceive their role on the team in a real-world clinical setting. Additionally, having a positive experience with team-based health care training through IPE has the potential to influence a student's decision of whether or not to engage in team-based practice upon graduation. For example, students who spend time together in team-based training often reflect on the educational and professional implications of practice in their own lives. Consequently, these reflections help shape the student's career goals and emphasize the positive experience of IPE and thus influence their choice of where to practice (Mu et al., 2004). 
Initially, IPE was limited to the classroom with students learning about how to deliver care as a team using fictitious patients and simulated patient scenarios. Educators soon realized the need for IPE in an authentic clinical setting (Stew, 2005). Early clinical IPE took place in urban academic health centers where the majority of health care training already occurred. In the meantime, rural communities continued to struggle to find health care providers willing to move to a rural setting prepared to engage in the team-based care delivery that was so desperately needed. Most recently, educational programs designed to combine both a rural experience and team-based training have emerged. However, there is a lack of understanding when it comes to what makes a successful rural IPE program.

\section{Background of Study}

In September 2015 the Oregon Health and Science University (OHSU) launched the Campus for Rural Health in two locations across the state of Oregon. The campuses were not brick and mortar institutions; rather, they represented a place for IPE in the rural clinical setting. The two rural communities reflected geographic locations where a concentration of student clinical experiences already existed across multiple educational programs at OHSU. Through the development of a curriculum designed to purposefully bring students together to learn from and about each other along with exposure to life in a rural community, the OHSU Campus for Rural Health set out to take advantage of an optimal setting for IPE (Spencer, Woodroffe, Cross, \& Allen, 2015). The mission and vision of the OHSU rural campus is to "develop innovative approaches to optimize the health of individuals who reside in rural communities [while] creating an 
interprofessional workforce competent to improve the health of rural populations" (OHSU Office for Rural Health, 2014, p.6-7).

During the developmental phase, key community and university stakeholders came together with a goal to train multiple health care professionals together to learn whether exposing them to a rural clinical setting as a team would lead to an increased number of graduates choosing to return to a rural setting to live and practice. As a result, two rural communities in Oregon were identified by university leadership because they had existing OHSU students training in the community and were viewed as having potential for expansion to include students from multiple schools and programs. Furthermore, the health care delivery systems in these areas recognized a need to hire more health care professionals from various disciplines.

Rural IPE curriculum was created to provide exposure into rural life, collaborative team-based practice, and what it means to be a health care professional outside of an urban or metropolitan area. This newly formed curriculum includes several different aspects of rural IPE. Students from six different health care professions (medicine, PA, dentistry, pharmacy, nursing, and public health) at OHSU spend several weeks learning how to deliver health care while immersed in a rural community. Each campus accommodates up to 14 students at a time and all students live together in community housing provided by the university. Students spend time together in the clinical setting, learning how to care for patients as a team. In addition, they work on a community project together designed to improve public health outcomes. 
As part of the community project, students complete a weekly reflective journal designed to capture their thoughts, observations, and learning while working with other members of the health care team and the community. Weekly debrief sessions are held to discuss the community project as well as the experiences of the students both in and outside of the clinic. In sum, students who spend time doing IPE in the OHSU Campus for Rural Health are exposed to rural team-based care, the life of a health care professional living in a rural setting, and are given the opportunity to reflect on what that means for the future of their clinical practice.

The strength of a rural IPE experience comes as students spend time interacting with the community, environment, fellow students, and complex medical situations. The goal is to prepare students for what rural clinical practice and life will be like. Ultimately, students gain valuable insight into their future professional role. Without such experience students might feel unprepared to enter the health care realm and handle the challenges that a rural setting can bring and lack understanding of what it is like to live and provide care as a team in a rural community. However, very little research has been done on the effectiveness of team-based rural training models for students during, not after, their training in preparing them to consider and in some cases even experience first-hand the factors just outlined. Moreover, no literature has addressed the impact of social interactions outside of curricular IPE requirements.

Having some exposure to a rural setting as a student provides the experience necessary to make informed decisions upon graduation. Thus, having a familiarity for what it means to be a member of a health care team in a rural community has potential 
implications for whether or not a student ends up in a rural setting (Hancock et al., 2009). Understanding the educational effects of a rural team-based experience is therefore directly tied to the motivational aspects of why health care students and graduates make the practice choices they do. In the end, learning what elements go into the decisions of where a health care professional ends up are important matters to investigate (Svinicki, 2004).

\section{Purpose of the Study}

A continuous supply of well prepared, motivated, and skilled health care providers is required to meet the needs of a rural community. The current system of uniprofessional health care education is not preparing students to work as a team in the rural setting where coordinated collaborative care is critical to the heath of a rural community. The use of RTTs has experienced some success in leading more providers to choose a rural setting after graduation (Chen et al., 2010). Additionally, efforts to train health profession students to work as teams in urban settings have shown positive results in preparing providers to deliver team-based care (Ponzer et al., 2004). Furthermore, rural IPE programs have shown an increase in the appreciation for rural IPE and its importance in increasing knowledge of team-member roles (Mu et al., 2004; Stone, 2006). However, there is very little research on how a student's perception of rural team-based care is influenced through a rural IPE experience. Additionally, current research has not investigated the factors that contribute to a student's determination of practice location after a rural team-based care experience and how these factors lead to the development of future rural IPE. Therefore, the purposes of this study are to examine how rural IPE 
influences health profession students' perspectives of what it means to be a member of a health care team while living in a rural setting, examine what factors students consider important in making decisions of where to live and provide care, and how these understandings can help guide future rural IPE pedagogy.

\section{Introduction to Study Design}

In multifactorial research, the use of numerous tools to assess the success of intended outcomes is recommended (Jensen \& Royeen, 2002). Therefore, a mixed methods study design was needed to accomplish this objective. First, qualitative data were collected through student-written reflection journals and coded for attitudes, values, and beliefs about the rural IPE experience. In the OHSU Campus for Rural Health, students keep a weekly journal intended to encourage reflective self-assessment on their perspectives of what it means to live and practice as a health care professional in a rural community. The process of guiding students through reflection in who they are, how they fit into a team, and how they view themselves as a health care provider gives them opportunities to interpret what their rural IPE experience means.

Second, this study also used quantitative Q methodology intended to collect data through a student ranking of subjective statements that represent factors surrounding team-based care in a rural setting. These statements are derived from the current literature on rural team-based care as well as previous student's feedback on a rural IPE experience. The student ranking can be thought of as a representation of each student's viewpoint or perspective on rural life and health care. Through asking students to exercise their opinions about what elements play the most and least important role in 
making post-graduation decisions they think introspectively about their thoughts and feelings. This type of research strategy helps to discern and understand the subjectivity of the individual and how they perceive rural team-based care in light of their rural IPE experience. As a result of this study design, the following research questions were explored:

1. How does working with an interprofessional team shape student views on future work with people in those professions?

2. How does the rural IPE experience influence a student's perspective on working in a rural setting?

3. What factors do students participating in a rural IPE experience consider most important and least important in making a decision to practice team-based care in a rural setting?

\section{Significance of Research}

The development of new educational methods in recent years was originally born out of a greater awareness that the U.S. health care system as it exists now cannot meet the needs of all citizens. As the cost of health care has gone up, educational leaders have been forced to look at how they are training students to care for patients. Consequently, health care educators were required to think beyond the classroom and consider how they can build upon student motives as a way to attract more providers to a rural community (Svinicki, 2004).

By learning more about rural team-based care, health care educators can gain an understanding of what factors go into a rural IPE experience and how it impacts a student's choice of where to practice. Furthermore, learning how a rural IPE experience affects student perspectives of rural team-based practice will help educators create IPE programs designed to put more providers into rural settings. Additionally, learning more 
about the impact of rural IPE, health education institutional leaders can make policy decisions designed to support the development of IPE curriculum. Rural communities themselves will also benefit by knowing how they can partner with health care education institutions, local providers, and students to address barriers to the recruitment of health care professionals. An educational initiative designed to provide rural team-based clinical training is one such program that deserves careful analysis.

Through the years, others have explored similar issues all designed to better understand rural health care training and team-based care delivery. Before this inquiry can engage with questions of how a rural IPE experience impacts a student, a careful look at that literature is needed. The next chapter investigates past research related to the problem in practice and how it can inform this study's research questions and resulting design. 


\section{CHAPTER 2}

\section{LITERATURE REVIEW}

Chapter 2 of this dissertation focuses on a review of the literature surrounding rural health care, health care teams, and motivation. This chapter is divided into three main sections each exploring a different aspect of the problem in practice. The first section discusses rural health care access from the perspective of contributing factors leading to provider shortages. The second section explores team-based care delivery in the rural setting including how critical theory can shed light on a health care institution's role in creating change. The third section discusses motivation as the theoretical framework for what causes a health care provider to decide to live in a rural community and practice team-based health care.

How health care providers are recruited and the factors that lead to their retention have inferences for the issue of health care access in rural communities. Moreover, how health care professionals are trained to deliver care is closely tied to the quality of care in a rural community. Thus, an exploration of these elements through the current literature is important when considering educational implications of a rural IPE experience.

\section{Health Care in America}

Health care in the United States has gotten a lot of attention in the past few years. It is no secret that here in America health care is a major factor in the economy. For example, in the 2015 fiscal year, health care is predicted to account for $20 \%$ of total spending for the U.S. government (Chantrill, 2014). Moreover, the Center for Medicaid 
and Medicare Services predicts that health care spending in the U.S. should increase by an average of $5.7 \%$ from 2013 to 2023 , which would outpace the rise in gross domestic product by roughly $1 \%$ (Howell, 2014).

As the cost for health care delivery increases, so does the demand for access to quality care. The need for quality health care is something all individuals will be faced with during their lifetime. Hence, the issues of how health care is delivered have become more and more important. For many years the traditional model has been care delivery that does not cross professional boundaries (D. C. Baldwin, 2007; Oandasan \& Reeves, 2005). This leads to health care professionals who are trained to provide care independent of one another. Consequently, individual providers act in separate professional roles within a system that does not foster comprehensive or collaborative health care delivery (D. C. Baldwin, 2007; Hammick, Freeth, Koppel, Reeves, \& Barr, 2007).

The scope of practice and the integration of multiple health care providers such as physicians, NPs, and PAs in a rural setting continue to be the subject of much debate (Hart, Salsberg, Phillips, \& Lishner 2002). As a result, there is an increasing demand for good health care professionals to deliver high quality services to a rural population. Nevertheless, who provides the care and the delivery method used can have a significant impact on a rural community and is explored next (Mu et al., 2004).

\section{Rural Health Care in Crisis}

It is important to have a clear understanding of what geographic setting defines a rural population. In the literature, rural can mean many different things to different people. For example, the U.S. Census Bureau (2014) has delineated rural as all 
population and territory that is not an urbanized area, defined as a population density of 500 people per square mile or greater. However, a different study outlined rural as a "geographic area at least 30 miles by road from a city of 50,000 or more" (Crandall \& Weber, 2005, p. 12). For purposes of this study, the Oregon Office of Rural Health's (2016) definition of rural is used, which includes all geographic areas 10 or more miles from a population center of 40,000 people or more. This definition can help in the understanding of isolation that is often present in a rural setting simply related to the number of people within that community and the distance from other more densely populated areas.

As it exists now, the preponderance of health care in the United States is found in urban settings where the access to quality health care is close by (Rosenblatt \& Hart 1999). The current system in America does not reward those who will go to the farthest reaches of this country and care for the marginalized (Huish, 2013). Therefore, multiple areas in the U.S., including rural communities, have a particularly low number of health care professionals and remain perpetually underserved (Petterson, Phillips, Bazemore, \& Koinis, 2013).

The maldistribution of health care providers has affected all professions; thus, this literature review takes into account all health care professions. However, most research focuses on physician training and distribution and is the subject of much of the discussion. For example, physicians continue to prefer urban sites to establish their practice with approximately 305 active physicians per 100,000 in cities with a population more than one million (Geyman et al., 2000). Some even suggest the shortage of health 
care providers in rural settings extends beyond the borders of the U.S. (Huish, 2013; Kazanjian \& Pagliccia, 1996).

Large metropolitan areas provide much needed specialized care and serve the large concentration of people that make up an urban core. However, the more specialized a health care provider is, the greater chance they will choose an urban setting to practice (Rosenblatt \& Hart 1999). Admittedly, the need for such specialists has its place, but what happens when those living in rural settings do not have access to a hospital, clinic, or basic primary care? In short, the high concentration of health care access in urban and suburban settings has led to a significant shortfall of rural health care providers. This shortage and its effect on a rural community's health is investigated next.

\section{Provider Shortages}

Over the past 30 years health care has seen a steady decline in the number of providers choosing to practice in rural settings. For instance, less than $4 \%$ of medical school graduates indicated a desire to provide care to a rural community (Rabinowitz, Diamond, Markham, \& Rabinowitz, 2005). Some suggest the major reason is due to lower numbers of medical students choosing to go into family medicine or general practice (Whitcomb, 2005). Regardless, even when health care is accessible, the delivery of that care in rural areas is influenced by many factors, including geographic distance, insufficient transportation, and the increasing age of many rural populations (Orloff \& Tymann, 1995). Additionally, several impediments exist in rural communities that prevent its citizens from accessing the care they need. In rural settings, increased 
numbers of vulnerable populations such as the elderly, uninsured, undocumented, children, and minority groups are especially susceptible to inadequate health care.

A recent study examined health care access among older adults living in rural areas, and found five main barriers. These included transportation difficulties, limited health care supply, low quality care, social isolation, and financial constraints (Goins, Williams, Carter, Spencer, \& Solovieva, 2005). Of these five, $41 \%$ of rural adults cited lack of physician recruitment and retention, need for more specialists, limited physician choices, and aging of local doctors as factors, while $7 \%$ reported difficulty in scheduling and long wait times as prohibitive. The crisis facing rural communities is not likely to improve. Consequently, rural settings have a higher incidence of chronic disease, higher numbers of under or uninsured, a greater number of geriatric patients, a higher amount of people living in poverty, and more Health Profession Shortage Areas than non-rural areas (Rabinowitz et al., 1999). For example, those communities designated as Health Profession Shortage Areas make up $67 \%$ of the rural settings across the nation (Hart et al., 2002).

Far too often patients in rural communities simply do not receive the care they so desperately need. As a result, their medical conditions go untreated, leading to a higher incidence of morbidity and mortality. For instance, those in rural settings receive fewer regular screening exams, laboratory tests, and diagnostic studies (Kaiser Commission on Medicaid and the Uninsured, 2003). Moreover, rural residents have an increased incidence of arthritis, high blood pressure, asthma, heart disease, diabetes, and psychiatric disorders. In general, the delay in care experienced by many in a rural community has 
been associated with an increase in the diagnosis of late stage breast cancer, malnutrition, heart attacks, and higher death rates in patients with HIV. Additionally, avoidance of health care has been linked to decreased overall cancer screening and increased sexually transmitted infections (Spleen, Lengerich, Camacho, \& Vanderpool, 2014).

The consequences of the lack of health care providers in rural settings are not limited to physical conditions. Slama (2004) has contended rural residents struggle to receive proper care for mental health issues including those with the most persistent psychological illnesses. In short, the proportion of rural residents with chronic disease is higher in nearly every category when compared to urban residents (Bailey, 2013).

These consequences challenge rural communities to create cost containment strategies in the face of limited resources and infrastructure (Pathman, Steiner, Jones, \& Konrad, 1999). Hence, this leaves many rural populations in a position to pay for health care in an already strained economic setting. For instance, a report by the Center for Rural Affairs emphasized that rural Americans are responsible for nearly $22 \%$ more of their total health care costs when compared to people living in urban or suburban areas (Bailey 2013). This is attributed to greater out of pocket cost from higher premiums, an increased reliance on individual health care plans, a lower actuarial value of that plan, and an increased economic burden when hospitalized (Bailey, 2013; Spleen et al., 2014).

When exploring the impact of provider shortages on a rural community, it is important to keep in mind the many elements that go into the recruitment and retention of health care professionals to rural settings. Some would argue retaining rural health care 
providers has the potential to have a significant impact on the health of a rural community (Rabinowitz et al., 2005). Therefore, it is important to understand the many contributing factors and reasons why there is a lack of health care providers in rural settings.

\section{Contributing Factors}

Several reasons for low numbers of health care providers choosing a rural setting to live and practice have been identified in the literature. These range from lack of policy designed to bring attention to rural issues, to a provider's desire to focus on specialized care found only in an urban setting (Hancock et al., 2009). Furthermore, professional and social comforts, along with issues of community life and the providers' personal characteristics have been shown to contribute to recruitment and retention to rural settings (Pathman, Konrad, Dann, \& Koch, 2004).

Issues associated with health care provider access in rural communities can be thought of as modifiable (self-actualization, community engagement, practice type, education) and non-modifiable (familiarity with a rural community, provider background, community characteristics, chosen profession). For example, personal characteristics such as like-mindedness with the rural community or social comforts like desiring to raise children in a suburban setting plays an important role in why a provider stays or does not stay in a rural setting for an extended period of time (Rabinowitz et al., 1999). Additionally, professional challenges including lack of adequate resources, geographic separation from other health care providers, and not as many career advancement 
opportunities have been cited as contributing to a decreased sense of job satisfaction among rural health care providers (Hancock et al., 2009).

It is known that multiple factors play a part when deciding where to live, work, and raise a family. Consequently, the reason why a health care provider would or would not decide to settle in a rural community is a complex topic that deserves careful analysis. Therefore, the next five subsections explore the personal, social, community, professional, and educational contributing factors as they relate to the issues of rural health care provider recruitment and retention.

Personal. Many health care providers make decisions of where to live and work based on personal preferences. This includes familiarity with a rural community, values consistent with that of the provider, lifestyle preferences, leisure interest and a provider's sense of adventure (Deutchman et al., 2012; Kazanjian \& Pagliccia, 1996; Tolhurst, Adams, \& Stewart, 2006). Moreover, the issues of workload, quality of life, educational opportunities for children, and safety have all been identified as personal factors associated with the decision to choose an urban setting rather than a rural setting to provide medical services (Kazanjian \& Pagliccia, 1996; Mayo \& Mathews, 2006).

Several challenges exist to recruiting health care providers to rural settings including the lack of career opportunities for spouses or partners (Whitcomb, 2005). Personal reasons for living in a rural community are multifaceted and often does not take into account a family member's (spouses, partners, children) influence on the provider's choice. Many rural communities are not able to offer similar career opportunities for provider's families; therefore, many will choose not to pursue a rural medical practice. 
For instance, the literature reports that a health care provider's significant other's wishes were an important factor when deciding on a medical practice site (Geyman et al., 2000; Mayo \& Mathews, 2006). Furthermore, some have identified the single most influential personal reason for not choosing a rural community to live and practice as quality of life for the provider's children (Kazanjian \& Pagliccia, 1996). Thus, impediments to the establishment of a rural health care practice such as partners' or spouses' inability to use their skills to find meaningful work, lack of school choice for children, or isolation from family or friends are formidable (J. A. Henry et al., 2009; Kazanjian \& Pagliccia, 1996).

A qualitative study done by Mayo and Mathews (2006) examined spouse satisfaction and contentment with living in a rural community and how these elements contributed to the decision of whether or not to stay in a rural practice location. They found such things as time away from family and the ability to integrate into the community as primary contributors to spouse contentment. These factors were found to be a problem for recruitment since rural medical practice often keeps providers at work due to increased patient loads and frequent on-call shifts. Additionally, the assimilation of a provider's spouse into the community was found to be contingent on such aspects as "employment opportunities, having a rural background or experience in rural communities, proximity to family and friends, maturity, cultural differences, and children" (Mayo \& Mathews, 2006, p. 273). Satisfaction and contentment were therefore, directly tied to a spouse's ability to participate in the things that bring them joy, which may not be found in a rural community. In short, the influence of a spouse is a 
prioritizing factor in deciding where to establish a medical practice (Kazanjian \& Pagliccia, 1996).

Other personal factors that hinder a health care provider from going to a rural setting to live and practice include feeling like you can never get away from your patients. A rural town, by definition, has fewer people when compared to an urban setting. Thus, health care providers are more likely to know those whom they live around. While many in a rural community like the strong bonds that form with those they live around, it forms what Slama (2004) has called the "goldfish bowl affect" (p. 10). As a result, rural providers feel a pressure to conform to the rural culture simply because they conduct their lives in full view of those around them.

As described above, the goldfish bowl affect can lead to providers not sharing aspect of their lives with neighbors or friends for fear they will be judged or perceived as not conforming to the conventional rural mentality (Slama, 2004). As a result, providers may worry about how they are being viewed in the community and when given the choice of living in a fish bowl or blending into a much larger urban setting, many health care providers choose the latter.

Social. Several socially constructed barriers prevent health care providers from choosing or staying in a rural community to practice. Whitcomb (2005) described the social isolation that is often felt by providers in a rural setting as one of the main reasons health care providers choose larger cities to live and practice. Furthermore, engagement in the community is viewed as an important predicative factor for retention of health care providers in rural settings (Hancock et al., 2009). For example, rural communities often 
do not have as many choices for social activities like a health club, organized child care, or youth services (Slama, 2004). For a health care provider who may have done his or her training in a large urban setting, the desire for social engagement outside of church, school, or the local bar may be a significant barrier.

Bell (1992) conducted ethnographic field research of rural communities and identified four main socially constructed rules that lead to either acceptance or rejection of an individual within a rural community. These are described as localism, ruralism, countryism, and communalism (Bell, 1992). These four areas identify such characteristics as length of time living in a rural setting and more specifically the amount of time residing in a specific rural town. Additionally, knowledge of or experience in rural type activities such as farming, hunting, or gardening along with participation in more formal community events like church committees, recreational teams, and local government all produce a rural ethos of empowerment and distinction (Bell, 1992).

This rural lifestyle and pattern of social relationships lead many in rural settings to live a quieter and slower-paced way of life. Individuals who bring a contrasting approach to living into a rural community are seen as "city-slickers, foreigners, or outsiders" are viewed as a threat to the socially constructed solidarity formed around members of a rural community (Bell, 1992, p. 72). For example, a health care provider who brings a low amount of ruralism or localism because they have never lived in a rural setting or grown their own food will have a difficult time being accepted as a member of the community. Furthermore, health care providers who are perceived to have more 
wealth are not viewed as true country people and as a result will have a tough time penetrating the social relationships in a rural community (Bell, 1992).

L. R. Henry and Hooker (2007) explored PAs acceptance into rural communities and found that time and a sustained presence in a community helped build "trust and familiarity" (p. 212). Consequently, if a health care provider does not have the time or interest in the community social isolation can result. Barriers such as these lead to more health care providers choosing to settle in urban settings where they have fewer impediments to forming social relationships with neighbors and community members.

Community. A rural community is often identified by its differences from urban or suburban living. Admittedly, there are fundamental cultural and physical differences between a rural town and a large metropolitan city (Hancock et al., 2009). Often these differences lead to a decision by a health care provider to settle in an area where they identify more with the surrounding cultural ethos. Ethnographic studies centered in rural communities depict a rural culture as one where community minded individuals value resilience and practicality (Philo, Parr, \& Burns, 2003; Slama, 2004). As a result, rural citizens identify themselves as pragmatic, community focused, and able to endure hardship because of their history of dealing with challenges.

This type of rural mentality is viewed as an ideological difference that is hard for outsiders to understand much less overcome. For instance, rural communities have a cultural belief that leads its members to struggle with accepting help for mental health conditions. This creates barriers for health care providers who are not familiar with this rural mindset to know how to treat them (Slama, 2004). Moreover, the customs and 
traditions that are typically attributed to a rural life can differ from town to town. Thus, learning how the specific rituals and practices of a rural community affect its member's actions and thinking can prove to be a critical step in treating rural patients (Slama, 2004).

The ability of a health care provider and their family to integrate into a rural community, build meaningful relationships, and have that community contribute to the overall quality of their life is a major factor in their retention. However, the community's acceptance of the health care provider also played an important role (K. A. Baldwin et al., 1998). One study reported the acceptance of the town PA was directly linked to the PAs willingness to engage in community civic events (L. R. Henry \& Hooker, 2007). In the end, the ethos of a rural community has the potential to create a barrier that affects the choice of whether or not to live and provide care to a rural community (Hancock et al., 2009).

Professional. Providing care to a rural community as a health care professional can be a daunting task. Those who inhabit a rural town often have values and patterns of thinking that create difficulties with making progress toward health and wholeness. Rural citizens tend to have a more conservative view, which can lead to a resistance to try new and unconventional treatment regimens. For example, when treating mental health illness, such as depression, providers can become easily frustrated since rural residents tend hold to the value of self-abnegation, leading to an avoidance of positive selfstatements for fear of being viewed as conceited (Slama, 2004). 
Feeling professionally isolated is found in the literature as a reason why health care providers did not stay in a rural setting to provide care (L. R. Henry \& Hooker, 2007; Lindsay, 2007). For instance, the lack of an older and more experienced health care provider to mentor the newly graduated provider was cited as a reason for not choosing or staying in a rural practice after graduation (Hancock et al., 2009). Feelings of professional isolation lead to frustration, as many health care providers in rural settings cannot take time away from their practices because there was nobody to care for the patients in their absence (Whitcomb, 2005). Additionally, the opportunities for professional advancement, research, and leadership within large health care institutions are not as available in rural settings (Kazanjian \& Pagliccia, 1996).

The burnout of rural health care providers is also a formidable factor in recruitment and retention. For instance, physicians who viewed their work as continual or 24/7, including the feeling of always being on-call had a higher incidence of leaving a rural practice (Pathman, Konrad, Dann et al., 2004). NPs have also reported the negative impact of long hours, professional isolation, and burnout as factors leading them away from rural clinical practice (Anderson \& Hampton, 1999). Additionally, PAs cited elements such as lack of educational and career opportunities, limited family and spouse employment, lower wages, and increased workload as contributing factors for leaving rural practice (Muus et al., 1996).

Kazanjian and Pagliccia (1996) found the issues of "challenge in practice" (p. 31), ranked high in the decision of where to establish a medical practice. These influences included such things as the ability to communicate with specialists about patients, 
continuity of care, feelings of support from peers, overall workload correlated to income, and the opportunity to take time off from professional responsibilities (Kazanjian $\&$ Pagliccia, 1996). Moreover, loss of control over practice characteristics such as hours, provider cross-coverage, and needing to care for the emergent needs of a rural community by providing coverage to the local emergency department are viewed as important factors (Pathman, Konrad, Dann et al., 2004).

Professional isolation and burnout are not the only reasons cited in the literature as contributing to low numbers of rural health care providers. Rosenblatt and Hart (1999) argued the single most important professional factor in the location of a physician's practice is specialty. Granted, the decision of a specialist health care provider to live and provide care in an urban setting is a necessary part of their practice. After all, a specialist physician needs access to high-level hospitals and laboratories along with a big enough population base to support a busy clinical practice (Rosenblatt \& Hart, 1999). Consequently, lower numbers of physicians are choosing to go into family medicine in favor of more lucrative specialties (Whitcomb, 2005). Hence, the increase in specialized physicians has led to a proliferation of providers in metropolitan areas.

This only perpetuates the problem as more and more providers stay in urban centers where career advancement is more readily available (Goins et al., 2005). For instance, trends in PA practice location have indicated a shift toward more urban and less rural locations (Hart et al., 2002). Part of this can be explained by the fact that PAs practice with physician partners in providing care. Consequently, trends seen in physicians will by nature be followed by similar trends in PAs. In fact, Rosenblatt and 
Hart contended "An improvement in the balance of generalist and specialists is a necessary precondition for eliminating rural physician shortages" (Rosenblatt \& Hart, 1999, p. 41). For instance, PAs who practice in rural settings are more likely to deliver primary care services (Cawley, Lane, Smith, \& Bush, 2016). In the end, the family medicine health care provider is the only one likely to settle in a rural area as the nature of their practice permits the flexibility necessary for the diverse needs of a rural community.

As the literature suggests, the decision of where a health care provider chooses to practice is undoubtedly influenced by what specialty area they chose. However, the educational constructs leading a health care provider away from a rural setting should remain in view. For example, health care educational institutions that focus on the needs of the rural health care environment have shown an increase in the numbers of providers who graduate and work in rural communities (Geyman et al., 2000).

In sum, health care education and delivery in America has centered on a solo provider approach with one person in the lead, shouldering the load of patient care. Additionally, the health care landscape for rural settings lacks providers to help meet the needs of some of our nation's most underserved areas. Many reasons exist for why health care professionals do not choose to live and provide care in these communities.

Nevertheless, the nature of care delivery and how health care providers are prepared can have a significant impact on health care in the U.S. 


\section{Team-Based Approach to Care}

The previous section examined the multiple elements that have contributed to the shortage of health care providers in rural settings. Specifically, one of the key contributing factors is the aspect of a solitary provider delivery system. Alternatives to this long held method of care as well as how health care institutions are preparing individuals to function in such unconventional systems is of upmost importance. As a result, aspects of rural health care from a delivery and educational perspective are explored in this section.

\section{History of Team-Based Care}

One of the major weapons the U.S. government used to combat the issue of lack of health care provider access, rural or urban, was the ACA of 2010. Through the creation of health care policy, the U.S. set out to provide primary care access to everyone. When the ACA was signed into law, millions of Americans gained health care coverage they had previously been unable to attain through tax credits and cost-sharing assistance (Bailey, 2013). As a result, the federal government placed a high value on individual health care. The new "universal coverage" was created to give citizens an opportunity to receive care they would otherwise have been denied. The hope was that increased coverage would lead to increased access, which would be met through increased providers ready to deliver the care. Specifically, a main component of the ACA of 2010 is the use of health care teams instead of individual providers to deliver care to patients. While this concept is not revolutionary, the emphasis on this health care delivery model is. 
The origins of team-based health care can actually be traced back to physicians, nurses, and "auxiliaries" in rural parts of India and the United Kingdom (D. C. Baldwin, 2007, p. 32). After World War II the development of community health centers lead to team-based care delivery in urban and inner city settings. For example, some of the first interdisciplinary heath care teams in the U.S. are said to have originated in the late 1940s at Montefiore Hospital in New York (D. C. Baldwin, 2007).

Nevertheless, over the decades that followed, team-based health care delivery saw its share of fits and starts. Legislative funding streams helped develop educational programs such as Health Professions Special Project Grants Program in 1972 and the Health Manpower Education Initiative Awards in 1975 all designed to increase the amount of team-based health care delivery. In the end, programs were phased out due to budget cuts and decisions to focus health care training in other areas (D. C. Baldwin, 2007).

Team-based practice as it stands now is thought of as encompassing more than one health care professional working collaboratively in the care of patients. For instance, the characteristics of team-based practice include clear patient identified goals, a mutual trust among the members, effective communication, and outcomes that are measurable (Golden \& Miller, 2013). Furthermore, vital elements for collaborative team-based practice have been identified in the literature and involve team members discussing and negotiating each other's roles, gained trust of one's own competence and the competence of others, knowing and respecting the unique contribution of the other team members, and motivation to work together (Oandasan et al., 2004). 
Teamwork provides the basis for delivery of more comprehensive and complete care (Ponzer et al., 2004). However, many rural communities do not currently utilize health care teams to deliver care to its members. Therefore, a careful analysis of how a health care team can improve the care patients receive in a rural community is addressed next.

\section{Benefit to Rural Communities}

Many have encouraged the team-based approach to health care because it promotes the collaboration of multiple health care professionals in an effort to improve patient treatment (Mu et al., 2004). Specifically, patient centered benefits include increased patient amenability to the treatment plan, better integration and continuity of care, more comprehensive services, more holistic better-coordinated care delivery, and systems that are attuned to patients' needs rather than to provider convenience (D. C. Baldwin, 2007; Ponzer et al., 2004). Additionally, team-based health care delivery has been attributed to better patient outcomes, improved satisfaction for patients, and lower cost to deliver care (Jensen \& Royeen, 2002).

This is no more apparent than in a rural community where resources are limited and the density of health care providers is geographically more spread out (Pathman et al., 1999). To put it another way, rural communities are uniquely positioned to deliver team-based simply because many different health care disciplines often share the same clinic space because of resource limitations (Croker \& Hudson, 2015). Mu et al. (2004) contended well-coordinated collaborate care "in this type [rural] of setting . . . all disciplines need to work together and oftentimes do, in order to educate patients and take 
care of them more effectively" (p. 129). Furthermore, the rural setting increases the significance of the collaborative nature of the relationships amongst the health care team (Spencer et al., 2015). This approach helps address the disjointed care many patients receive when living in a rural community (Rygh \& Hjortdahl, 2007).

Team-based care in a rural setting also addresses some of the contributing factors of why health care providers do not stay in or choose rural settings to live and work. For instance, a study looked at rural team-based primary care and reported a more evenly distributed workload, improved skills, and a decreased sense of isolation (Taylor, Blue, \& Misan, 2001). Additionally, the burn out experienced by many rural health care providers can be mitigated by having a clear understanding of the role each person plays on the health care team and working to maximize that role in patient care (Minore \& Boone, 2002). To put it another way, the health care team helps address burn out through the expansion of roles and even distribution of responsibilities (Rygh \& Hjortdahl, 2007). Thus, the need for health care teams in the rural setting takes on an increased significance in the recruitment and retention of health care providers.

There is a growing need for care delivery in rural settings that is contiguous and cohesive. The use of health care teams in a rural community stewards limited resources in a way that delivers more complete care to the needs of complex rural patients (Mu et al., 2004). Furthermore, the nature in which care is delivered in a rural setting lends itself to team-based patient centered care (Spencer et al., 2015). Therefore, efforts designed to increase the quality of care delivery in a rural setting should focus on "what kind of team, for what purpose, and under what conditions" (D. C. Baldwin, 2007, p. 31). With the 
growing need for health care teams in rural settings, it is important to consider if tomorrow's health care provider is being educated to this end.

While the government has created policy that gives health care coverage to thousands through the ACA, health care education institutions have largely ignored the need to increase team-based educational experiences for those who are to care for the newly insured population. Consequently, an exploration of the current educational constructs related to the lack of team-based training is next.

\section{Educational Factors}

For many years the dominant model of health care education has been one of separate training for each type of health care professional in discipline specific programs termed "uniprofessional education" (Reeves et al., 2013, p. 7). In other words, traditional health care education involves students learning profession-specific competencies solely in the context of their own program and profession with minimal to no contact with other health profession students (Oandasan \& Reeves, 2005). This conventional pedagogy limits a student's knowledge of the role other members of the health care team play (Croker \& Hudson, 2015).

The long-standing traditions of medical students trained one way, PA students trained another way, and nursing students trained yet a different way have resulted in health care institutions acting like preprogramed machines (Morgan, 1998). This traditional way to educate health care professionals can partly be explained through what Senge (2014) described as "mental models." These mental models are defined ways of thinking that are deeply ingrained and carry with them assumptions about how people are 
supposed to act and think or in this case how health care professional students are educated. This mental model of how medical students and other ancillary or support staff are trained has dominated the curriculum for years. Additionally, the mental model of the physician as the leader having the most authority is still part of the long-held medical educational tradition.

Challenging these engrained patterns of education is not easy. Often those who are the most embedded in an institution's culture are the least likely to embrace change (Marion \& Gonzales, 2014). For example, rural practice is often unfamiliar to medical educators and can even be labeled by some as undesirable (Council on Graduate Medical Education, 1998). Furthermore, in medical schools, educators follow the existing environmental tone and thus reinforce the mental models of uniprofessional education because that is how it's always been done (Senge, 2014).

As previously discussed, team-based care in a rural setting has an increased significance. However, without team-based educational opportunities, students continue to train in professional isolation, thereby missing out on the experience of providing care in the way the ACA calls for. The need to prepare health care professionals on the concepts of team-based care in the midst of their training programs has led to an increased emphasis on what is called IPE. IPE is a pedagogical approach to health care education that is defined as one or more professions learning from and about each other for the purpose of collaboration and improved care (Centre for the Advancement of Interprofessional Education, 1997). Specifically, IPE can be characterized by students comparatively discussing similarities and differences in their profession while learning 
how to approach patient care through their lens (Hallin et al., 2009). It requires students to communicate with purpose in the understanding of each other's roles, and focuses on the contribution to collaborative practice. To put it succinctly, it addresses the question, how can we each contribute and work together to improve patient care?

With the ultimate aim of getting students to see patient care from the perspective of other health care professionals, initial IPE models lacked the follow through application to the real-world clinical setting. Original IPE curriculum focused on the classroom with students sitting side-by-side learning basic medical topics, which did not lead to a better understanding of the different health care provider's roles (Stew, 2005). As a result, a shift in IPE to the clinical setting has been taking place with some moderate success initially noted in the urban hospital setting.

For instance, Ponzer et al. (2004) examined the outcomes of a 2-week clinical IPE experience with students from four different health professions on the inpatient units of an urban teaching hospital. The study found that $64 \%$ of the students reported a greater understanding of their own role on the health care team and all students indicated a more positive attitude toward IPE after the experience. Additionally, the participants noted an increased awareness of the ethical aspects of patient care along with a clearer understanding of the patients' role in the health care plan. However, graduates from medical institutions in recent years are less likely to be prepared for collaborative care delivery and even more unlikely to go into rural settings to practice (Minore \& Boone, 2002). Even with the handful of medical universities who have dedicated rural 
curriculum, the focus has been on single provider delivery of services (Geyman et al., 2000). This kind of educational model does not foster collaborative team-based care.

How information is distributed and shared will be reflected in the institution's culture (Tierney, 1988). For instance, health care education institutions who address such factors as institutional mission, the establishment of a family medicine department, rural clinical experiences that are required, faculty with rural experience who have leadership positions within the university, and the availability of these faculty to help counsel students on rural health care delivery are better positioned to address rural provider shortages (Geyman et al., 2000).

In the case of a medical school, information about different medical specialties is disseminated and shared with the students as they begin the process of deciding on a lifelong career. Information surrounding a primary care career or even the generalist physician may not be shared in a way that equalizes its importance with a surgeon for example. For instance, most medical schools do not have primary care physicians on their admission committees (Geyman et al., 2000). The end result is lower numbers of physicians going into rural areas to practice, since most rural physicians are generalists (Whitcomb, 2005).

Traditional medical education creates power differentials with the physician as the solo provider leaving others feeling as though they do not have a voice. Team-based care eliminates that. The power and prestige of a medical school have traditionally favored urban centered, specialist physicians. As a result, there is a lack of emphasis on the family medical provider and even less of a focus on rural settings. For example, there 
exists a direct correlation between the emphasis a health care education institution places on family medicine training (both undergraduate and graduate) and the numbers of providers choosing rural settings to live and work (Geyman et al., 2000). Furthermore, having the training necessary to provide care to a specific geographic location was viewed as a contributing factor when making practice location decisions (Kazanjian \& Pagliccia, 1996). This kind of approach to health care education leads to a lower number of health care professionals choosing to pursue practice in a rural community (Hancock et al., 2009).

Current medical education focuses on disease treatment rather than the social constructs that could have caused or at least contributed to the problem in the first place. Health care institutions are instrumental in preparing students to be part of the solution rather than applying short-term fixes. Moreover, health care institutions function as social factors that can either foster diversity or further privilege an elite group through practices of admission, teaching, assessment, and research (Hodges, 2014). Therefore, adopting a critical approach means exploring how health care institutions can help in understanding a rural social system is examined next.

\section{Critical Theory}

Applying a critical lens helps in the understanding of the power and prestige of a health care institution and how it could be used as a genesis for change (Hodges, 2014). Specifically, the critical approach encourages educators to teach students the value and importance of distributing medical resources and creating more equity across the landscape of health care. Furthermore, it forces educators to look at the culture of power 
that health care institutions create and ultimately what is done with that power to exert influence.

Health care education as it exists now does very little to encourage critical analysis of the social constructs of power (Waitzkin, 1989). In the case of medical students, social norms and rituals that help reinforce the culture of that medical school are taught from the moment they arrive on campus. How the students are talked to, what they are exposed to and the privileges extended to them reinforce the culture that views them as the future leaders of health care. This is a very important concept when looking at the culture of a health care institution because change can happen through the initiation of several small-scale behaviors aimed at calling attention to relational patterns of social behavior (Cottingham et al., 2008). Consequently, health care education institutions have a unique position to influence the trajectory of many students and potentially make a significant impact in the shortage of health care providers in rural settings (Rabinowitz et al., 1999).

Taking a critical approach also helps in the community's understanding of a health care institution. For instance, health care institutions face an increased pressure to meet their social mission to the communities in which they are located. As a result, rural citizens view health care institutions and its students as partners in addressing the health care disparities that are often present. By placing health care professional students in the rural clinical setting, community members begin to see how an institution can help with such issues as provider shortages, health promotion, disease prevention, and quality of care (Gazewood et al., 2006). 
Community members become critical scholars themselves as they reflect on the previously held beliefs of the health care institution's role in addressing public health problems. Moreover, rural community members can offer ideas and suggestions to educators as they develop curriculum to create greater equity. Ultimately, this can help in the understanding of how rural community members engage with those in the medical community and become participants in the change effort rather than being content with the status quo (Hodges, 2014).

The application of a critical lens here does, however, assume that solutions to social constructs of power are medical in nature. There is a body of literature suggesting those who live in an urban setting have an inherent bias against those who live in rural communities. The term Urban Bias (UB) has been used to describe the perception held by urban citizens that rural towns do not have the ability to support advanced educational or health care activities (Corbridge \& Jones, 2004). As a result, the notion that metropolitan settings are the only place to experience cosmopolitan living leads to a social construct of urban life as far more sophisticated, educated, and healthier. For example, Lipton (1977) explained, "the rural sector contains most of the poverty, and most of the low cost sources of potential advance; but the urban sector contains most of the articulateness, organization and power" (p. 1).

While UB typically is used in the context of agricultural and economic imbalance, this approach can lead to inequitable distribution of resources including human capital (Corbridge \& Jones, 2004). Specifically, UB has been attributed to the migration of health care professionals to urban settings where opportunities to deliver care in dynamic 
health care systems are readily available (Connell, 2011). This results in health care workers who view the rural setting as a place for substandard antiquated care, which proliferates the bias toward living and working in an urban setting (Connell, 2011). For instance, in a qualitative study of young people Glendinning, Nuttall, Hendry, Kloep, and Wood (2003) concluded there are distinct differences between how youth view rural and urban settings leading the belief that rural towns are not good places to be a young adult. This creates a negative bias toward rural communities as socially excluded, lacking opportunities to improve one's life (Glendinning et al., 2003).

The question then becomes, can a critical approach be applied to a rural community without further "medicalizing" it (Waitzkin, 1989)? Assuming the answer to this question is yes, the role medical providers could play in creating change in the social setting of many patients cannot be overlooked. Exposing students to the social aspects of medicine in a rural setting can help them to begin critical analysis about their role as an agent of change through the position of privilege as a health care provider (Deutchman et al., 2012).

In conclusion, this section examined how team-based care delivery has become a major aspect of how patients receive their care. Students learning independent of other health care professions is a long-standing pedagogical approach (D. C. Baldwin, 2007). This method has resulted in health care professionals who are not sufficiently prepared to step into the newly formed health care team. Furthermore, the role of a health care education institution in preparing its students for care delivery to the marginalized citizens that make up a rural community is shown to be a major aspect. 


\section{Motivation}

As previously discussed, training health care students in profession separate clinical settings has been implemented for years. Alternatives to this model have led to a team-based approach to both educating health care providers as well as delivering the quality care people seek. As a result, the aspects of recruitment and subsequent retention of health care providers have been the topics of much literature. Many programs have concentrated on the recruitment aspect by identifying motivating factors for why providers choose to live and practice where in a rural setting. Therefore, how motivation plays a role in why health care providers choose to live, work, and stay in rural communities is the focus of this section.

\section{Motivation Theory}

When discussing motivation one must begin with the classic needs-motivation hypothesis introduced by Maslow (1943) as the hierarchy of needs. Maslow's hierarchy begins with the most basic needs of hunger, thirst, and sleep and then builds up to the most advanced needs of respect, power, and ultimately self-fulfillment when individuals realize their potential. The motivation for these needs comes out of a deprivation rather than a satisfaction of that need.

Clark and Wilson (1961) described motivation as highly individual. People are motivated by different things, which are a matter of personal preference and priorities. Atkinson (1966) defined motivation as "the origin of our impulses to do this or that ... which incites a person to action" (p. 5). Thus, studying what accounts for the direction, 
drive, and perseverance of an individual's action and how it is linked to the consequence of training is important. Ultimately, the study of a person's behavior must take into account the individual's interpretation of what is happening around them at any given time. This of course is influenced by multiple different factors. The idea is to link the movement in particular direction, called behavior, to the cognitive forces that produce them (Atkinson, 1966). This can prove to be difficult if students are not exposed to factors that result in a desired behavior.

The study of motivation helps to explain the reasons why a person acts in a certain way, with how much enthusiasm, and what keeps them moving in this direction (Atkinson, 1966). The environment as it exists may have very little to do with the actual physical surroundings, and much more to do with the very acute reflections and calculations of individuals on the material surroundings in which the individuals find themselves (Atkinson, 1966).

Finding out what motivates a health care student can help in the understanding of the need to expose more students to rural medical practice and the influential role of such an experience on the student's decision to live and practice in a rural community. Numerous elements go into the decision of a medical provider to settle in a rural area. This list includes familiarity with a rural community, values consistent with that of the provider, lifestyle preferences, leisure interest and a provider's sense of adventure (Deutchman et al., 2012; Tolhurst et al., 2006).

Factors such as exposure to rural settings during health care training through rural residency experience or a rural track program, along with participation in a loan 
repayment program are described as predictive of future rural practice (Hancock et al., 2009). As previously discussed, elements such as raising children, opportunities for employment for a spouse or partner, and how a person integrates into the community are all predicative of whether or not a health care provider stays in a rural community to practice (Hancock et al., 2009).

Pathman, Konrad, Dann et al. (2004) suggested the reason for health care provider access difficulties in rural communities is not retention of providers; rather it is due to recruitment of health care professionals in the first place. Concluding "the principal dynamic by which rural shortage areas emerge is simply that too few physicians are recruited" (Pathman, Konrad, Dann et al., 2004, p. 1726). However, simply recruiting more health care providers who do not have some level of familiarity with a rural setting may not be the answer. Some have noted the need to reach out specifically to those who have a rural background of some kind. Arguing the major factor in effective recruitment of rural health care providers involves targeting providers who were raised in a rural setting in the first place (Geyman et al., 2000). However, trends in medical school applicants show an increase in the numbers of urban-raised affluent students and fewer students are being admitted who have rural backgrounds (Hancock et al., 2009).

One of the implications of the ACA's focus on team-based care is that every American will in fact be able to access that care. On the one hand this may not be a problem for many people who live in or near a major metropolitan area; on the other hand it overlooks the barriers to attracting and retaining the providers that make up the health care team in a rural setting. Policies are used as a means to motivate certain sectors, 
people groups, or domains in order to achieve specific results. As a result, the next three sections explore in greater detail the issues of motivation as it relates to rural experience as well as programs designed to specifically encourage health care profession students to choose rural communities to live and practice.

\section{Motivation for Rural}

As previously explored, a student's decision of where to establish a health care career is multifactorial. Through exposure to new ways of thinking and even delivering care, students develop the knowledge necessary to make informed decisions. By exposing them to rural settings and the collaborative nature of team-based practice, students are taught alternatives to traditional medical pedagogy that is grounded in learning theory. This experience is foundational for what motivates a graduate to choose a rural setting or not.

People do not generally choose something if they are not exposed to it. Students bring with them a prior knowledge that influences the decisions they make (Svinicki, 2004). Therefore, misconceptions of what it means to provide medical care in a rural setting can be formidable. Students may already have preexisting understandings about how the world works and educators must learn how to engage with those understandings in order to move students beyond surface level learning (Pellegrino, Bransford, \& Donovan, 1999).

A guiding principle here is the idea that some kind of background knowledge is necessary for comprehension (Willingham, 2009). For example, several studies have shown that when compared to students who did not grow up in a rural setting, students 
who did are more likely to return to that community to practice medicine after graduation (Kazanjian \& Pagliccia, 1996; Pathman, 1996; Rabinowitz, 1988).

Furthermore, qualitative studies examining motivating factors for health care providers to return to a rural setting include being raised in a similar community as a child (Hancock et al., 2009; Kazanjian, \& Pagliccia, 1996; Tolhurst et al., 2006). Specifically, one such study stated the familiarity with a rural community including the family ties that are often still present in that community was a major motivating factor leading a provider to return (Mayo \& Mathews, 2006). Conversely, some suggest more than just a rural background is involved in influencing a provider's choice of where to live and practice. Implying rural upbringing is one of multiple components that come together when deciding to settle in a rural community (Owen, Hayden, \& Bowman, 2005).

Motivation for rural was nicely illustrated through a study conducted by Hancock et al. (2009) which identified exposure to a rural setting through education, recreation, and upbringing actually increased the likelihood a student would choose a rural setting to practice. Through semi-structured interviews of rural practicing physicians, the authors were able to identify four main motivating factors of community engagement, sense of place, self-actualization, and familiarity as central to the reason why they decided to establish a rural medical practice.

Community factors were identified as a desire to help an underserved population and to have close-knit relationships with patients built over a period of time. Forty percent indicated that community specific reasons are what motivated them to choose a rural setting to live and practice. Physicians listed the reason for choosing this domain as 
having a previous experience in a tight-knit community which led to a favorable view of living in such a community after graduation (Hancock et al., 2009).

Sense of place was described as the desire to live in a setting where participants felt a sense of connection to the environment with opportunities for exploring the outdoors and recreation activities. This domain made up $27 \%$ of the physicians reason for choosing a rural setting to live and provide care and was identified as growing over time. Accordingly this was the main reason for wanting to remain in a rural setting as well as the driving force for feelings of health and well-being while spending time there (Hancock et al., 2009).

Thirty-one percent in the Hancock et al. (2009) study listed self-actualization as the main motivating factor for choosing to live and practice in a rural community. In this domain, participants described the rural setting as meeting emotional needs that lead to fulfilling personal and professional lives. Additionally, participants cited the rural community as an ideal place to put down roots. They viewed medical practice in the rural setting as providing ample opportunities for creativity, meaning, variety, and autonomy. Having familiarity from growing up in a small town meant providers wanted to return to something that was well known. This was seen as cognitively less demanding than learning about or integrating into something new or foreign. Thirty-one percent of the physicians in the Hancock et al. (2009) study fell in this domain with $4 \%$ stating this was directly related to the rural experience as a student that resulted in choosing to pursue a rural medical practice. 
Students who have prior experience either living or working in a rural setting could have implications for who decides to stay in such a setting after graduation. For example, the desire for a natural environment found in a rural community has been reported as a motivating factor for returning (Mayo \& Mathews, 2006). Furthermore, students with family members who are more likely to support their choice of rural practice could have a positive impact on an institution's overall mission to rural and underserved settings. Lastly, having a rural experience as a student could lead to an interest in rural practice by increasing the opportunities for finding a clinical setting that matches their values and lifestyle (Tolhurst et al., 2006).

Willingham (2009) contended students need to see themselves as part of a story and every story has a conflict at its center. Indeed, the individual in that story finds an answer, and ultimately the conflict is resolved. Once students understand the lack of health care access in rural settings, then, they will naturally start to work toward possible solutions. Through a rural team-based experience, students may even see themselves as part of the answer.

By exposing students to a rural team-based practice, they gain understanding about how their interests and desires could be met in a rural setting (Tolhurst et al., 2006). For instance, students who spend time together in team-based training often reflect on the educational and professional implications in their own lives. Moreover, these reflections help shape the student's career goals and emphasize the positive experience of team-based exposure and thus influence their choice of where to practice (Mu et al., 
2004). As a result, they may end up thinking, "I could see myself doing the exact same thing."

Programs designed to expose students to rural settings during and after their medical training increases the likelihood that they will return to a rural setting to practice (Rabinowitz et al., 2008). Consequently, several programs have been designed through the years to incentivize health care providers to live and practice in rural settings. These range from federal to state funded initiatives aimed at primary care providers from a variety of professions. This next section explores the literature related to such programs and their outcomes.

Incentive programs. One such policy involves incentivizing health care graduates to serve in rural and underserved areas through loan forgiveness and loan repayment. This type of policy attempts to influence behavior through the distribution of funds designed to draw more providers into rural and underserved areas. Lowi and Ginsberg (1994) considered this type of policy as a distributive technique of control by subsidizing the graduate's educational loans in exchange for a certain number of years of service in a designated Health Care Provider Shortage Area.

For example, in recognition of the difficulties of recruiting health care providers to rural areas, the U.S. Congress developed the first national loan repayment program called the National Health Service Corps (NHSC) approximately 30 years ago (Whitcomb, 2005). This program has experienced a considerable amount of participants with approximately 23,000 clinicians since the program's inception (Pathman et al., 
2006). However, a natural question to ask at this point is do funded programs such as the NHSC actually help?

Research has shown that although such a program has provided much needed care to some of the most rural and underserved areas, the retention of health care providers is less impressive (Geyman et al., 2000). For example, a qualitative study examining contentment with staying in a rural community noted that financial incentive programs do not take into consideration other motivating elements and thus do not make a significant impact in rural health care provider shortages (Mayo \& Mathews, 2006). Furthermore, a study evaluating the effectives of the NHSC program looked at the retention rates of physicians who participated and found that only $21 \%$ were still at the original assigned practice with only $5 \%$ practicing in the same county (Rosenblatt et al., 1996). In addition, a similar study found that only $14 \%$ of NHSC physicians planned to stay in the same practice location for more than five years with only $51 \%$ planning to remain in a rural setting past the 10-year mark (Pathman, Konrad, \& Ricketts, 1994). In supplement to the federal government, states have developed their own distributive policies as described by Lowi and Ginsberg (1994).

State-funded loan repayment programs (SLRP) have a similar purpose to federal policies; however, the specifics of such programs are run through state legislatures. As of 1996, there were 69 such programs across 40 states with an additional 29 programs run jointly with the state and federal government (Pathman, Konrad, King, Taylor, \& Koch, 2004). SLRPs have also experienced some success. For example, the satisfaction of physicians completing SLRPs was high at $83 \%$; with $90 \%$ reporting they would enroll in 
the program again (Pathman, Konrad, King et al., 2004). Some have suggested the broad eligibility criteria of SLRPs leads to a larger number of physicians applying to these programs versus federally funded programs (Pathman, Konrad, King et al., 2000). Additionally, students who have an affinity for a particular geographic area may identify with the local mission of an SLRP choosing to partner with programs designed to help communities within their own state borders (Pathman et al., 2000).

However, one assumption of federal and state distributive policies is that as long as the state or federal government is subsidizing the health care provider's loans they will remain focused on their relationship with the distributing agency and not be concerned with other more enticing offers (Fowler, 2013). This assumption does not take into account other more influential factors such as the provider's family, spouse or partner. Moreover, some suggest having an obligatory commitment to serve in underserved areas sometimes forces healthcare providers to stay in areas that they do not want to serve. There is often resistance on the part of people in these communities when they know somebody is only coming in for a couple of years who is not from the community and not invested in the community (Huish, 2013).

Another assumption of a distributive policy such as loan repayment and loan forgiveness is that human behavior can be influenced through a subsidy such as "cash, goods, or services" (Lowi \& Ginsberg, 1994, p. 389). As previously discussed at the beginning of this section, not all providers are influenced in the same way and multiple factors including familiarity with a rural community, values consistent with that of the provider, lifestyle preferences, leisure interest and a provider's sense of adventure go into 
the decision of a health care provider to settle in a rural area (Deutchman et al., 2012; Tolhurst et al., 2006).

As these studies have shown, the decision of where to live and provide care is multifactorial. These programs alone cannot meet the growing need for health care providers in rural settings (Whitcomb, 2005). Consequently, the increased need for health care teams called for by the ACA in rural settings is in serious jeopardy. However, perceptions such as lack of professional support, fewer career options, and tension between professional health care providers created through a rural experience could lead to an unfavorable view of what it means to live and practice in a rural community (J. A. Henry et al., 2009). Conversely, there is some research to suggest that exposure to rural communities during training increases their likelihood of returning to a rural setting to practice medicine (Tolhurst et al., 2006). Similarly, students with no previous exposure to a rural clinical setting who undergo a prolonged training experience in such a setting were favorably motivated to return to a rural community after graduation (J. A. Henry et al., 2009).

While the government has created policy that gives health care coverage to thousands through the ACA of 2010, institutions have largely ignored the need to increase rural educational experiences for those who are to care for the newly insured population. Therefore, educators have begun to think beyond the classroom and consider how they can build upon motives as a way to attract more providers to a rural community (Svinicki, 2004). Thus, the next section examines the use of rural training to motivate health care providers to live and provide care to a rural community. 
Rural training programs. It is through training in rural settings students begin to construct new knowledge of how a rural community functions and how a health care provider cares for the needs of rural patients. Moreover, during rural training experiences, students also get to observe those whom they look to as possessing the knowledge and expertise they one day hope to have. Throughout this type of learning students develop new ways of thinking and begin to directly do what rural providers actually do (Fink, 2013). Consequently, the question then becomes, how do educators get students to understand what it means to deliver care in a rural setting in a way that motivates them to return to a rural setting to practice?

Recently the American Medical Association called for a $15 \%$ increase in medical school enrollment in an attempt to minimize a projected physician shortage (Norris et al., 2006). However, the literature suggests without an emphasis on educational programs specifically targeted at rural health care provider recruitment and retention, such an increase may benefit urban specialized care even more (Chen et al., 2010; Rabinowitz et al., 2005). Therefore, rural training programs have been created to help bridge the gap in rural health care provider shortages.

Exposure to rural clinical training gives them an opportunity to spend time with a rural medical provider in a setting where they can learn what it means to practice in a rural community. As a result, students learn how to function as a rural health care provider, ultimately gaining the correct perception that would motivate them to return to a rural setting and step into medical practice. For example, medical schools that place a 
high value on rural training opportunities for its learners have a higher percentage of graduates working in rural areas (Chen et al., 2010).

Individuals create knowledge through the social interactions with each other and the culture in which they live and train. Students need to be challenged to construct new ways of thinking about team-based practice while integrating into the rural clinical culture itself. Consequently, rural clinical training has the potential to create a community of practice where students can gain the knowledge, connectivity and experience necessary to practice in a rural community as a team. Furthermore, by having students experience a rural setting they are exposed to the complexities of a rural community where they will see the delivery of health care in new ways. The students become part of that specific medical practice, and in the rural setting, they also become part of that community.

Through a cross-cultural experience students grow in their understanding of themselves and their own culture in light of a rural community (Jensen \& Royeen, 2002). Socializing students into the culture of a team as well as the community of a rural setting happens subjectively as student's progress through a series of experiences interacting with the environment (Jensen \& Royeen, 2002). However, health care education policy has been formed around prioritizing training in large urban medical centers rather than small rural clinics and hospitals. Therefore, very few policies exist to ensure equity of medical training in the rural setting. As a result, a discrepancy exists between the push for equity and the actual delivery of the curriculum. As previously explored, a major 
contributing factor to this inequity is that traditional health care education has not prioritized rural training experiences.

In an attempt to change this tradition, several education institutions have developed rural clinical training programs designed to increase the amount of providers going into these settings (Jones et al., 2000). Some of the longest standing programs have been at the University of Minnesota and Jefferson Medical College (Geyman et al., 2000). The success of programs at these universities has been well documented with $87 \%$ and $79 \%$ retention of physicians in rural settings respectively (Rabinowitz et al., 2008).

To take a case in point, a study looked into one such program at Jefferson Medical College called the Physician Shortage Area Program (PSAP). This program admitted medical school applicants based on their upbringing in a rural community and expressed desire to practice family medicine. Through exposure to rural settings as a student and encouragement to pursue rural personal and professional goals, the PSAP program reported $34 \%$ of graduates were practicing in rural areas, compared with only $11 \%$ who did not participate in the program (Rabinowitz et al., 1999). Additionally, two thirds of PSAP physicians remained in a rural setting for 11-16 years after graduation, which is considerably higher than the national average of 7 years for all rural physicians who do not have a service obligation (Rabinowitz et al., 2005).

The success of a program like the PSAP highlights the impact a rural training program can have. For instance, students who spent time in a rural setting during their medical training gained a greater understanding and appreciation for the challenges many in rural communities face (Deutchman et al., 2012; Mu et al., 2004). Moreover, 
environmental factors such as the educational institutions location within a rural state, amount of federal funding, and a primary care mission have been thought of as crucial when trying to increase the amount of graduates who go into rural settings to practice (Geyman et al., 2000).

Beyond just placing students in a rural setting to train, the amount of time they spend in that setting actually matters (Geyman et al., 2000). For example, postgraduate RTTs, where a physician spends 2 years of their residency in a rural setting, have been implemented in an attempt to equip medical providers with the experiences necessary to gain the skills to care for rural communities (Rosenthal, 2000). A study evaluating RTTs demonstrated that only $30 \%$ of participants intended to stay in a rural setting to practice (Rosenthal, McGuigan, \& Anderson, 2000). However, in a more current study rural trained physicians were three times more likely to practice in a rural setting after graduation (Chen et al., 2010).

In order to better educate a student on the aspects of a rural training experience, institutional programs have been designed to immerse students in a rural setting before the start of their first day (Deutchman et al., 2012). A recent study examined a program where students are given the option to spend a week in a rural community learning and interacting with local government leaders, health care providers, and citizens. This gives the students an opportunity to experience the nonmedical aspects of living in a rural area. Furthermore, by giving students the option to participate in such a rural training program they are able to exercise liberty, which is a major education policy value (Guthrie, 2002). Study results show that students who choose to participate in a rural immersion program 
indicate an increased or reinforced desire to practice in a rural community (Deutchman et al., 2012).

Decisions to fund such programs as the ones described in this section come about after a careful analysis of cost-effectiveness of the policy objective (Levin \& McEwan, 2001). If the objective is to increase the number of providers in rural settings, the decision to invest more time and money on the part of the rural providers on the front end may actually pay dividends in the long run. For example, if more providers end up returning to the rural setting where they did their training, the benefits to the providers who trained them would far outweigh the costs for training. However, the tangible benefit may not be realized until many years after the students' training is completed. As with other areas of the government the benefits of educational changes can sometimes take a while to be noticed (Fowler, 2013).

An important implication here is to consider the amount of time needed to prepare for a curricular change. One study examined the implementation of a new rural medical training program and estimated between three to five years of planning and preparation with continuing administrative work extending beyond the initial accreditation (Rosenthal, 2000). In addition, requirements for the RTT programs currently do not support a year-long continuous training experience in a rural setting. Therefore, examination of accreditation standards to allow a more broad definition of what is considered a rural versus urban experience has been suggested (Geyman et al., 2000). Another significant effect of increased medical training in the rural setting is the amount of valuable data that can be collected and analyzed. By bringing rural health into 
the academic realm the expectation and opportunities for research are created (Rosenthal, 2000). For example, indicators such as determining the number of students who returned to a rural setting to deliver medical care or measuring a student's preparedness for rural practice are valuable methods to judge the policy's effectiveness (Geyman et al., 2000). Through the evaluation of a policy's success, valuable data could lead to the better use of funds and therefore inform future decision-making in a profound way (Cross, 2014).

A student's experience in a rural setting as part of their education prepares them for life in a rural setting and can create the bridge necessary for a graduate to choose a rural setting to continue their practice (Geyman et al., 2000). Furthermore, students who participate in rural medical training have a better awareness and regard for the rural community itself as well as an increased appreciation for the need to collaboratively deliver health care in the rural setting (Mu et al., 2004).

Team-based education in the rural setting has its benefits as well. For example, a study examining an IPE experience in a rural setting showed an increase in the perceived value of interprofessional work, an increased awareness and respect for the rural community along with a realization of the need for collaboration as a necessity in rural clinical practice (Mu et al., 2004). Furthermore, another study looked at a structured rural IPE experience and found that students reported feeling accepted and valued as a member of a rural health care team. As a result, students expressed a more complete understanding of the individual team member roles indicating that IPE should become part of the core health professions training (Stone, 2006). 
Spencer et al. (2015) reported on a rural IPE program involving 14 different professions from medicine, nursing, social services, management, physical medicine, and mental health. Through focus group interviews as well as post-experience surveys, the authors maintain the rural setting is the ideal place for students to learn valuable competencies necessary to function on a health care team. Students in the study commented on how the rural clinical setting provided opportunities to strengthen communication and collaboration skills while learning innovative patient care delivery.

Through the use of the Interprofessional Care Access Network, Wros, Mathews, Voss, and Bookman (2015) indicated students who worked together as a health care team serving the most vulnerable in rural and underserved settings provided opportunities for “authentic learning experiences” (p. 201). Additionally, IPE programs such as Interprofessional Care Access Network have the potential to influence a student's career trajectory through team-based interaction with patients who have some of the highest needs. Ultimately, students who experience a rural team-based educational experience are in the best position to improve the current health care system and the health of a rural community.

In sum, issues of how a rural IPE experience could foster a desire to live in and provide care to a rural community come to the surface. Moreover, the positive effect of a rural team-based educational experience on recruitment and retention cannot be overlooked (Mu et al., 2004). Despite all of the challenges of providing care in a rural setting, "harnessing the potential of rural services to promote students' interprofessional capability" cannot be overlooked (Spencer et al., 2015, p. 390). As a result, the studies 
outlined here could have a profound impact on how health care professionals are trained and prepared to work collaboratively in a rural community.

As this section demonstrated, there is substantial literature on rural health care provider recruitment and retention programs. However, very little research has been done on rural training models and the impact of educational programs designed to prepare students for rural living and team-based care delivery (Geyman et al., 2000). Moreover, some suggest the need for evaluating the effectiveness of rural training programs on health care provider recruitment and retention (Mayo \& Mathews, 2006). In the end, further research has been suggested on how a rural IPE experience provides an ideal opportunity for students to develop their potential as a member of a rural health care team (Spencer et al., 2015).

\section{Summary}

The preceding three major sections carefully explored the literature related to rural health care provider shortages, the benefits of team-based care in rural settings, recruitment and retention of health care providers, and how motivation plays a role in provider decisions. These varied approaches shed light on the need for more team-based health care providers in rural communities and the educational framework to prepare them for such a task. The literature highlighted the history of health care education institutions delivering curriculum with a certain level of success for years. As a result, the rules and polices of how health care education is delivered leads to health care training which does not cross professional boundaries (Morgan, 1998). However, the changing 
landscape of health care delivery as outlined in the ACA of 2010 necessitates a shift in the way tomorrow's health care provider is educated.

The need for more health care providers to practice in rural settings, especially in team-based practice, is not an easy problem to tackle. As previously stated, the use of rural training programs is a way to provide health care professionals with the experiences necessary to gain the skills to care for rural communities (Rosenthal, 2000). Therefore, examining the educational significance of training health care teams in the rural setting is an important topic to explore. As one author exhorts, health care education can play a role in preparing health care providers to care of the needs of rural communities (Huish, 2013).

Nonetheless, without a shared learning experience health profession students are not able to effectively acquire the knowledge, skills, and attitudes required for teambased health care delivery (Ponzer et al., 2004; Smith et al., 2005). In the end, learning about what elements go into having effective rural health care delivery, team-based or otherwise, could have important educational consequences (Kazanjian \& Pagliccia, 1996). With the increased emphasis on team-based practice in a rural setting, educational experiences designed to place students in such practices help them make an informed decision of where to settle after graduation.

The OHSU Campus for Rural Health is an example of an educational program that combines rural training with IPE. By placing students from six different health care professions to live, work, and learn together in a rural community; the OHSU "rural campus" seeks to impact the health care needs of a rural setting through exposing 
students to life in a rural community as a health care professional. This study focused on the evaluation of students who have completed training within the OHSU Campus for Rural Health by asking the following research questions:

1. How does working with an interprofessional team shape student views on future work with people in those professions?

2. How does the rural IPE experience influence a student's perspective on working in a rural setting?

3. What factors do students participating in a rural IPE experience consider most important and least important in making a decision to practice team-based care in a rural setting?

The educational implications for designing the experience are significant.

Through the evaluation of students' experiences in a rural IPE program, health care educators can learn about how students perceive living and working in a rural community. Furthermore, by investigating student's perspectives related to the modifiable and non-modifiable motivating factors previously discussed, health care educators can modify existing programs or design rural team-based training programs with the biggest potential to make a difference in the lives of those in a rural community. Further research is called for exploring the benefits of training health care teams in rural settings. An educational initiative designed to create team-based clinical training in the rural setting is one such program that deserves careful analysis. 


\section{CHAPTER 3}

\section{METHOD}

Chapter 3 of this dissertation explores in detail the methods used to answer the three research questions. The background of the problem in practice is revisited first. Then, the purpose of the study is discussed along with a review of the research questions. Next, a brief description of the research perspective is explored along with the setting for the study. Then, a description of the target population, selection, and procedures used for participant recruitment is examined. The qualitative and quantitative methods used are discussed next, keeping in mind the research questions and how data collection and analysis helped answer each of them. Finally, data security and the role of the researcher are investigated.

\section{Problem in Practice}

The problem of a shortage of health care providers in rural settings is a multifaceted dilemma. The need for quality health care delivery is not isolated to the far reaches of rural America. Nearly every health care profession experiences a shortage of providers in rural areas (Jensen \& Royeen, 2002; Mu et al., 2004; Smith et al., 2005). The new health care delivery model outlined in the ACA of 2010 encourages team-based collaboration in caring for the health needs of a community. Team-based care has proven to be an effective delivery model in urban settings (Jensen \& Royeen, 2002; Ponzer et al., 2004). Regardless, rural communities are positioned to benefit from team-based care as well (Mu et al., 2004; Spencer et al., 2015). 
The focus then becomes the need to adequately prepare tomorrow's health care professionals to step into a changing health care system that is geared toward collaboration and teamwork. Furthermore, the growing need for quality care in rural settings necessitates the need for health care professionals to be ready to deliver teambased care to a rural community. Educational models have begun to address the need for more team-based training in health care institutions through IPE. However, most IPE programs have centered on classroom pedagogy or the urban setting (Ponzer et al., 2004; Stew, 2005).

\section{Purpose of the Study}

Through the years, research on funded programs such as RTT's, loan forgiveness, and loan repayment have focused on outcome data related to the numbers of providers choosing to practice in rural settings. Very little research has been done on how a rural IPE experience has produced meaningful change a team member's perspectives of practice in a rural setting. Additionally, limited research exists on how changes in opinion affect a student's understanding of what it means to live and work in a rural community as a health care provider. Therefore, this study examined student insights of rural life and team-based practice as a result of a rural IPE experience. Additionally, this study explored the factors that students identify as having the highest and lowest significance when making future decisions about where to live and provide care. In order to investigate these issues the following research questions were addressed:

1. How does working with an interprofessional team shape student views on future work with people in those professions?

2. How does the rural IPE experience influence a student's perspective on working in a rural setting? 
3. What factors do students participating in a rural IPE experience consider most important and least important in making a decision to practice teambased care in a rural setting?

As these questions inquire about the experiences students have related to future work environment and work related relationships, Glesne's (2016) belief that research should contribute to the lives of its participants guides the methodological approach for this study. Consider how qualitative research study's methods are chosen based on three principles: The method should help gather data that produce understanding of the topic, bring in different views on the problem, and use time to gather data efficiently (Glesne, 2016). As a result, a mixed methods approach was used, which is discussed further in the following section.

\section{Research Perspective}

The problem of lack of health care access in rural settings and the inadequate health care education system to help meet the need has many layers. Therefore, using several approaches to understand the issue is necessary. The use of different data collection methods that fit together in a compatible way creates a coherent study (Maxwell, 2013). Inquiry that avoids committing to a singular approach and embraces multiple methods, differing worldviews, assumptions, and various ways to collect and analyze data is needed (Creswell, 2009). Furthermore, best practice projects use multiple tools to assess the success of intended outcomes (Jensen \& Royeen, 2002). Consequently, a mixed methods study designed to assess how a rural IPE experience impacts the student's perspective of a health care team as well as a rural community was implemented. To this end, research questions one and two were answered through qualitative methodology and question three was answered with quantitative methodology. 
Through both quantitative and qualitative analyses, researchers can account for alternative explanations of how a rural IPE experience influences students while at the same time increasing validity. To aid in the conceptualization of the study, Figure 3.1 represents an overview of the workflow design used in this study. The next two sections follow the study workflow as outlined in Figure 3.1 and discuss the setting, target population, participant selection, and participant recruitment. The following two sections continue Figure 3.1 workflow design and discuss the qualitative and quantitative research perspective, sample strategy, data collection, instrument (for quantitative approach only), and analyses method used to answer the research questions.

\section{Target Population and Participant Selection}

Students from different health care professions who spent educational time in either rural campus location were targeted for this study. Specifically stratified purposeful sampling by Campus for Rural Health location and health care profession was attempted to ensure an adequate group of participants by both health care profession and rural location. All students who spend between two weeks and six months in either the Coos Bay or Klamath Falls locations of the OHSU Campus for Rural Health were asked to participate in the study via an information sheet and informed consent document. The informed consent and information sheet described the study with clear instructions that if they do not wish to participate they could decline without any effect on their grade (see Appendix A for the informed consent and study information document). 


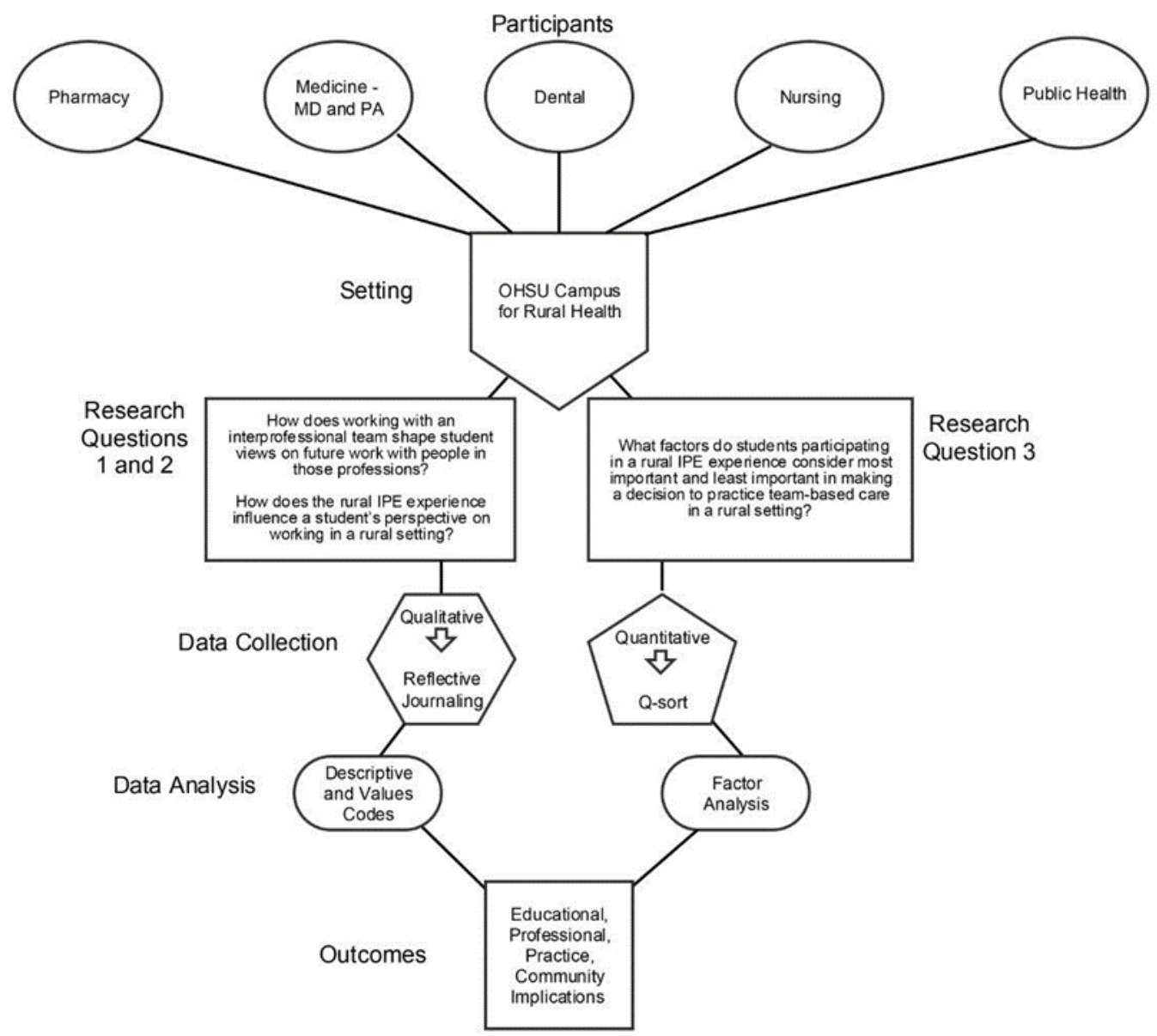

Figure 3.1. Workflow design model for the study. The circles represent the various participants, home plate is the setting for the study, rectangles contain the research questions, the hexagon reflects the qualitative method used to answer research question one and two, the pentagon represents the quantitative method to answer research question three, the ovals denote the type of data analysis for each method, and the square signifies the anticipated outcomes of the study.

In a mixed methods study, participant selection was done to ensure both the qualitative and the quantitative methods have adequate numbers to answer the research questions. On the one hand, selecting participants in qualitative research is rarely done randomly or with populations large enough to produce sweeping generalizations. Rather, qualitative research participants are purposefully selected based on their ability to 
generate rich data germane to the topic in question (Glesne, 2016; Maxwell, 2013). Therefore, qualitative sample sizes tend to be smaller and more reflective of the phenomenon of study. Purposefully selecting individuals who can inform the researcher of key characteristics of the investigation is a common method used in qualitative research (Krathwohl, 2009). For example, selecting participants who are from different health care professions, backgrounds, marital status, age, and location of educational experience are key to this study.

On the other hand, representativeness in a sample for a quantitative study is important if research results are to have generalizability and be free from bias (Krathwohl, 2009). Often this is accomplished through a large enough sample size thought of as representative of the population. This type of approach singles out the respondent as the subject and seeks to gather every potential individual related to the topic of study. Thus, large sample sizes are common in quantitative research studies.

However, participant recruitment in my quantitative method (Q method) was not designed to cast such a wide net that every possible thought, opinion, or consideration was represented. Rather, participant selection in my Q study was reflective of the variety of opinions on the specific topic of interest (Webler, Danielson, \& Tuler, 2009). Moreover, the results that emerge are thought of as "generalizations of the attitudes held by the persons defining the factors" (McKeown \& Thomas, 2013, p. 32).

The individual participants represent the "arrangement of ideas," which makes it possible for the Q researcher to make inferences that are not far from generalizations seen in a large sample randomized control style study. Drawing the comparison to survey 
research, Q study participants are comparable to survey questions. The careful selection of which survey questions are used can be translated to the intentionality of Q study participants. Participant selection in a Q study is primarily based on selecting those who are most closely tied to the goals of the study and those who have the knowledge or experience to help answer the research question (Sexton, Snyder, Wadsworth, Jardine, \& Ernest, 1998). As a result, the recommended number of participants for a Q study is between 15 and 30 (Webler et al., 2009) while others contend a range of 30 to 50 participants is adequate in Q studies (McKeown \& Thomas, 2013). The leading Q Methodologist, Brown (1993), advocates that participant sets (P sets) should not exceed 50 since Q methodology compares patterns within individuals. As a result, large sample sizes are not needed to capture the subjectivity of a select population determined by the focus of the study (McKeown \& Thomas, 2013).

One of the goals of participant selection is to deliberately choose individuals to establish comparisons and illustrate differences (Maxwell, 2013). Given the OHSU Rural Campus has two locations, it was important to select participants from each location to compare and contrast experiences and illuminate the distinctions of each setting. Moreover, given the local practices, values, and circumstantial elements of each rural setting, the need for participant selection from each rural community was foundational to this study.

The variety of perspectives to help answer the research question came from the mix of different participant health care professions and the setting for their IPE experience. Therefore, purposefully sampling research participants was done on the basis 
of those who were directly connected to the dynamics associated with the topic of study (Webler et al., 2009). Furthermore, participants who represented the health care professions students, who experienced central aspects of the study such as team-based care delivery, IPE, and rural community life, were invited to participate. Maxwell (2013) argues selecting participants "that can provide you with the information that you need to answer your research questions is the most important consideration in qualitative selection decisions" (p. 97).

\section{Setting for Study: Campus for Rural Health}

As previously described, OHSU set out to design an education program that would combine team-based health care education with the setting of a rural community. In September of 2015 the OHSU Campus for Rural Health opened in two rural communities with students from six different health care professions (medicine, PA, dentistry, pharmacy, nursing, and public health) to live together, train together, and experience rural life from the vantage point of a health care provider. The mission and vision of the OHSU rural campus is to "develop innovative approaches to optimize the health of individuals who reside in rural communities [while] creating an interprofessional workforce competent to improve the health of rural populations" (OHSU Office for Rural Health, 2014, p.6-7).

Health care profession students from OHSU were assigned by their school or program an experiential clinical rotation in one of the two Campus for Rural Health sites. The medical, PA, and nursing students spent between four and eight weeks in the campus and have the same schedule, thus they arrived and finished at the same time. However, 
nursing students were generally only in the clinical setting three days a week as opposed to five days a week for medical and PA students. The dental students spent four weeks in the Campus for Rural Health and had varying arrival and departure times. The pharmacy students spent a longer period of time in the rural setting by embedding in the community for between two and eight months. Public health students have yet to settle on a regular timetable for participation in Campus for Rural Health activities but generally schedule field placement experiences for three to six months with various start and stop periods.

Once arriving at the Campus for Rural Health, students were given an orientation packet with general information on the rural community, an overview of the IPE goals and objectives, and instructions on the community project along with weekly debrief meeting times. This orientation was done by OHSU Campus for Rural Health staff. Additionally, all students were provided a place to live in a university leased multibedroom unit with a common living space. The housing units at both locations had a capacity for up to seven students at a time with overflow housing units available for an additional five to seven students if needed.

Students were guided through a curriculum that exposes them to team-based care delivery and socialization into a rural community along with opportunities to reflect on how the experience impacted them as a future health care provider. For example, students interacted with the community through a public health focused community project, explored interpersonal emotions through reflective journaling, and discussed how to approach rural health care issues as a team in weekly debriefing sessions. Therefore, the 
OHSU Campus for Rural Health provided a unique opportunity to evaluate how a rural IPE experience impacted health care profession students from an educational perspective.

The next three sections follow the workflow depicted in Figure 3.1 from the point of study setting all the way through outcomes. The first two sections trace the two branches that start with each of the research questions and the method used to answer

them. The individual method used for each question is discussed separately along with a description of data collection and analysis for that method. As the workflow diagram concludes, the branches meet again in the third section with an exploration of the anticipated results.

\section{Research Questions One and Two: Participant Experience}

1. How does working with an interprofessional team shape student views on future work with people in those professions?

2. How does the rural IPE experience influence a student's perspective on working in a rural setting?

\section{Data Collection}

To help answer research questions one and two, participant reflective journals were collected upon completion of their time in the OHSU Campus for Rural Health. All students who participated in the rural IPE experience in the OHSU Campus for Rural Health are asked to keep a weekly journal responding to three or four prompts designed to capture their thoughts, ideas, and feelings from their experience as part of their curriculum. Each student responded to between two and four prompts per week aimed at rural health topic, rural community issues, and team-based care delivery in the rural clinical setting. 
At the completion of the participant's experience in the OHSU Campus for Rural Health, an independent research assistant collected the journal, assigned a random unique identification number to the journal, and uploaded a select portion of the journal to the university secure cloud storage system. The select portion collected for analysis focused on the participant's journal response to two specific prompts. These two prompts directly pertained to research questions one and two and were written accordingly:

- How has working with an interprofessional team of students shaped your views on future work with people in those professions?

- How has the rural IPE experience influenced your perspective on working in a rural setting?

\section{Qualitative Data Analysis}

To help answer research questions one and two, it is important to understand how the participants described the environment of a rural community. As a result, descriptive coding was used since many of the participants described the rural community.

Additionally, it was useful to have general descriptions of what makes these communities unique to the participants.

Descriptive coding was used as an initial approach to describe the "basic topics of a passage" and was beneficial for detailing and examining "material products and physical environments" (Saldaña, 2013, p. 88). This type of coding assisted the qualitative researcher in taking what was seen or heard and drawing general ideas from the data. Furthermore, descriptive coding was a good approach for recording the products participants "experience on a daily basis" (Saldaña, 2013, p. 90).

Additionally, values coding was used to help answer research questions one and two, as it was important to understand the participant's values, attitudes, and beliefs about 
a rural community. Values coding was used to capture the participant's values, attitudes, and beliefs about a rural community. Saldaña (2013) indicated these three concepts are interrelated and affected by the social and cultural environment the participant experiences. As a result, values coding aided in the understanding of how the participants thought and felt about the rural community. Moreover, using all three constructs aided in defining the participant's motivation or philosophy of the topic under study (Saldaña, 2013).

\section{Rationale for Journal Analysis}

Understanding how a participant reflects on a rural community and how those thoughts lead to actions, aided in the understanding of why rural health care providers move to or out of a rural setting. Furthermore, the participants brought with them preexisting understandings about a rural community and researchers must learn how to engage with those understandings in order to gain valuable insight into the values, attitudes, and beliefs (Pellegrino et al., 1999).

Qualitative analysis of data can be done in a variety of different approaches however, the end result should provide the opportunity to discuss, relate, and produce increased understanding of the phenomenon under study. The data produced through qualitative study lack intrinsic meaning in and of themselves. Hence, one of the goals of this qualitative study was to draw significance through continued exploration and analysis (Glesne, 2016).

Reflection through writing has been the vehicle used most often in health care education (Arnold, Shue, \& Jones, 2002; Bradshaw \& Lowenstein, 2013). For example, 
Wassef, Tuomi, Finn, and Sullivan-Bolyai (2015) reported that reflective journaling has been used in nursing education as a way to evaluate how a student's personal ideals and views were explored and even accepted after engaging in a clinical learning experience. As a result, qualitative data collected through reflective tools such as weekly journals helped capture the student's own description about how the rural IPE experience impacted them.

Tolhurst et al. (2006) used a qualitative approach to analyze the effects of a rural educational experience on medical students who grew up in an urban setting. Through the use of focus group interviews, the researchers coded interview transcripts looking for major themes related to why an urban raised student would or would not choose to live in a rural setting after graduation. The authors concluded that previous literature exploring variables for why students choose rural settings has been primarily quantitative and the use of qualitative methods is useful "to investigate the process of the development of an interest in rural practice by urban background students" (Tolhurst et al., 2005, p. 8).

McNair et al. (2005) conducted a quantitative analysis looking at a rural IPE experience for nursing, medical, pharmacy, and physiotherapy students. Through a post experience questionnaire the researchers reported students having an increased interest pursuing a rural-based practice setting upon graduation. However, the researchers also noted that a mixed method approach in the evaluation of a rural IPE experience would be "helpful to develop depth in the analysis, particularly to understand the influence of the immersion experience and reflective process on learning” (McNair et al., 2005, p. 591). 
Mu et al. (2004) used a mixed methods approach to study the effects of a rural IPE experience on students from pharmacy, occupational therapy, and PT. Over a 3-year period pre and post experience quantitative data were collected on the perceptions of teamwork in the rural setting using a validated survey instrument assessing the student's perceptions on how a health care team works together in a clinical setting. Additionally, qualitative data were collected during and after the experience through reflective journaling and weekly debriefings. The researchers determined that "active learning and reflection methods are strongly advocated in interprofessional training, which has been shown to lead to better quality care of patient with improved patient outcomes" (Mu et al., 2004, p. 130).

\section{Research Question Three: Factors Related to Participant Motivation}

3. What factors do students participating in a rural IPE experience consider most important and least important in making a decision to practice team-based care in a rural setting?

To help answer this research question, a quantitative Q method design was used. Q methodology supposes that an individual's subjectivity is a result of their conclusions as they view circumstances around them. Thus, the subjectivity measured in a Q study is the byproduct of a person's internal dialogue rather than a researcher's beliefs of how an external measurement tool can be applied. Consequently, the central unit studied by the Q method is the individual and how they internally make decisions on complex subjects.

Q methodology is not an observation of nature, but "nature exposed to our method of questioning" (Heisenberg, 1962, p. 58). Q methodology is similar in theory and philosophy to the subjectivity that forms the basis of qualitative research. In this regard, it is almost a hybrid approach as its purpose is to objectively measure subjectivity. 
One of the primary reasons for doing a Q study is to shed light on shared perspectives surrounding a particular topic or field of study (Brown, 1993; Webler et al., 2009). Thus, when attempting to answer research question three, Q methodology allowed for the measurement of the shared perspectives students have concerning the rural IPE experience and the multilayered decision making that goes into deciding where to live and provide care.

\section{Q Sort}

In this Q study, participants were asked to sort a set of statements that represent factors surrounding team-based care in a rural setting. This ordering of a participant's opinions with the Q sample items is known as a Q sort. Instructions to the participants included the notion that each Q sample statement should be interpreted in the context of all the other statements in the set.

Participants were instructed first to read through all of the statements in the Q-set. This is thought to give them time to gather the wide range of opinions on the topic and sets the context. Next, the participants were asked to pile the statements into three distinct categories that represent most agreement, most disagreement, and somewhere in the middle as it relates to the statement. Next, participants further refined the sort by placing each statement under a provided distribution scale with most agree $(+5)$ to most disagree $(-5)$ and neutral $(0)$ in the middle. The resulting frequency distribution represented the typical bell curve, and thus, participants were restricted to placing the statements into frequency patterns that reflect such a curve. 
The forced distribution described in a Q sort is not as prescriptive as it may seem. Research participants were asked to assign statements in each rank but were completely free to decide which statements belong under which rank. However, they were only allowed to place a certain number of statements within each rank. Consequently, the Q study participants may have spent extra time carefully thinking through each statement and how they responded to it. This moves the analysis toward the purely subjective nature of the participant's Q sort and away from the serial scoring of a scale-type evaluation. Thus, the forced distribution is thought of as exclusively statistical in that all of the Q sorts have the same mean and standard deviation (McKeown \& Thomas, 2013). To help understand this process, Figure 3.2 illustrates the Q-sorting procedure used in this study.

An independent research assistant administered the Q sort during the final week of that participant's rural IPE experience. The Q sort was completed and collected via the Flash Q® software in an electronic format. The completed Q sorts were de-identified and given a unique participant identification number. This unique identification number was not the same number given to the participants involved in the qualitative data collection. Additionally, demographic data were collected including participant age, gender, if they had a rural background, if they had children, if they were married/partnered, health care profession of study, and location of the OHSU Campus for Rural Health they participated in. 


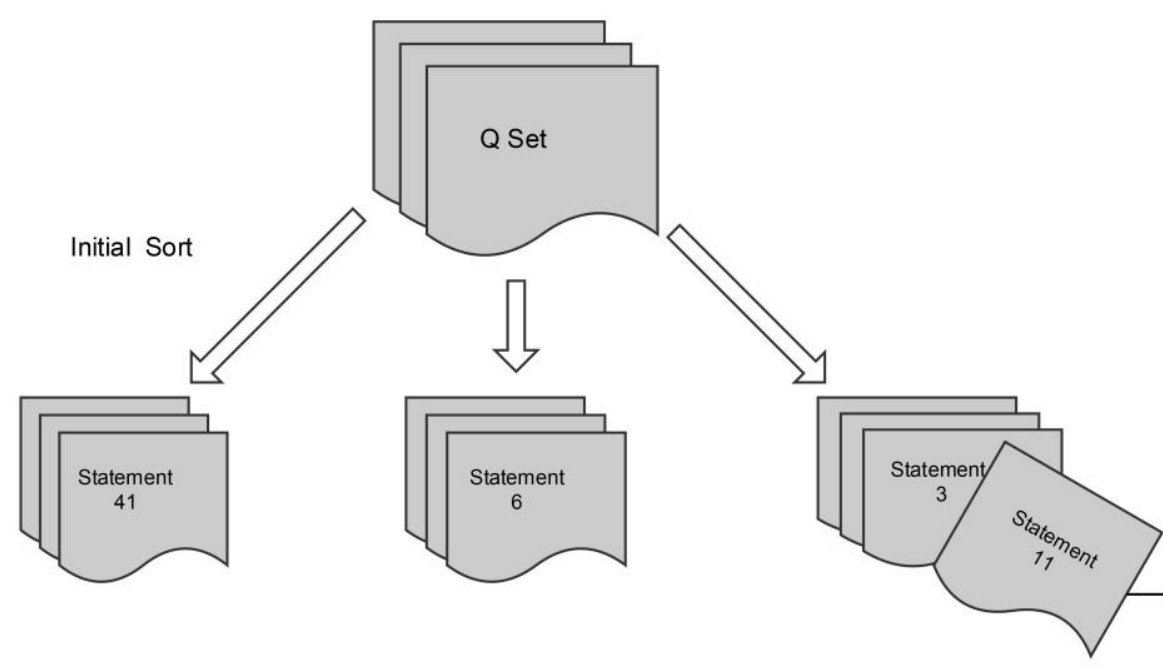

$\begin{array}{lll}\text { Most Disagree Neutral } \quad \text { Most Agree } & \text { Nat }\end{array}$

Refined Sort

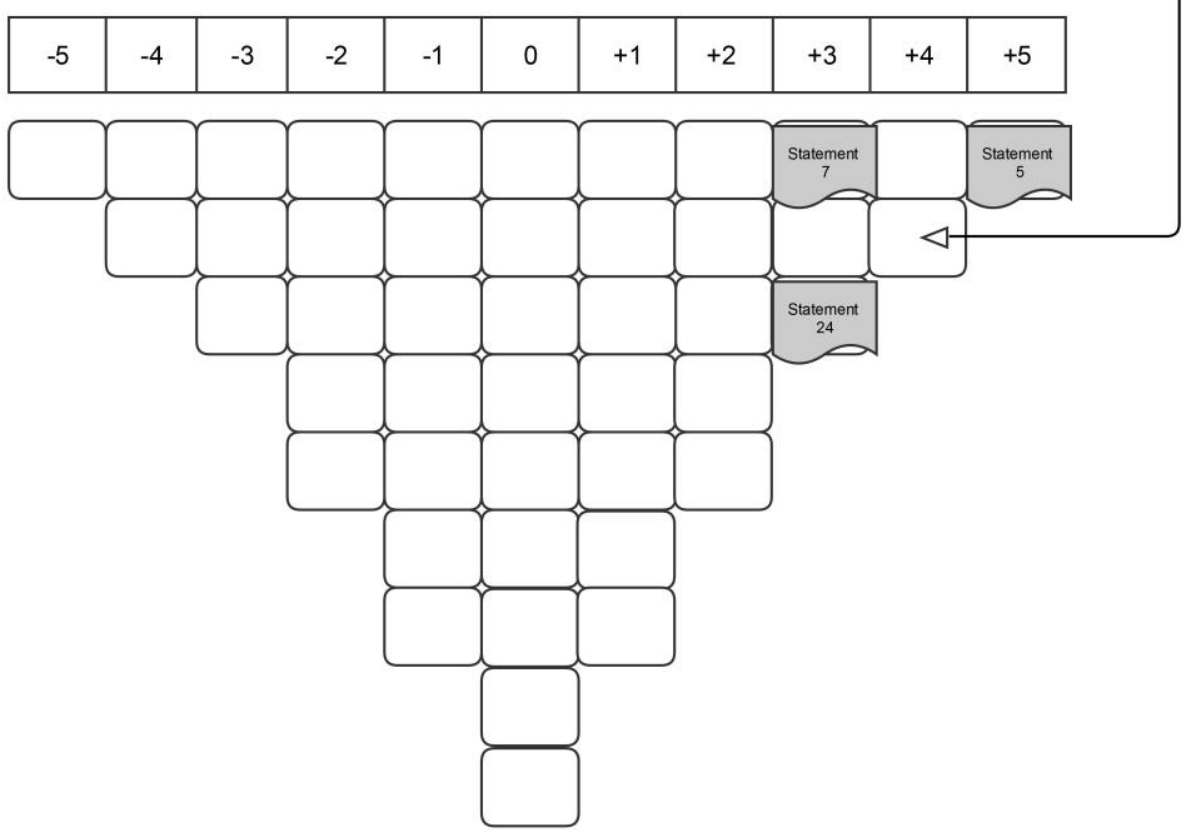

Figure 3.2. The $\mathrm{Q}$ sort. A representation of how the $\mathrm{Q}$ sort is performed.

When research participants enter into a $\mathrm{Q}$ sort they assign meaning to the $\mathrm{Q}$ sample items as they compare and relate the items based on self-reflection. This approach 
is reflective of what people do in situations of everyday life-changing channels on the television, selecting a meal from a menu, and deciding where to vacation. Everyone makes judgments on the value or nonvalue of particular things as they relate to not only their own but everyone's internal ranking system.

The Q sort can be thought of as a representation of each participant's vantage point on the topic. In the analysis of the completed Q sorts, shared perspectives emerge that may actually represent participant rather than researcher bias. As a result, bias is not imposed as it potentially would in a survey (Brown, 1993). Furthermore, validity becomes less of a factor as there is no outside benchmark used to measure the participant's own viewpoint. Performing a Q sort is another way of asking the participants to exercise their opinions about the Q statements through the sorting of these statements according to how they feel about them (Webler et al., 2009). The purest sense of subjectivity comes in when the participant sorts these statements because there is no right or wrong way to think about a point of view and thus participants are free to express that point of view any way they want through the Q sort.

In contrast to a rating scale type analysis ("most" to "least"), the Q method gathers a participant's subjective views by a forced distribution on a most to most range ("most like me" to "most unlike me"). Thus, the zero point or the middle is thought of as nondescript and does not carry as much weight or emotion compared to the end points. For some people these statements are in a zone of neutrality. This results in a linear distribution that is unlike the typical most to least scale because it maintains the zero point as central. Consequently, the items in a $\mathrm{Q}$ sort sit in close relationship emanating 
out from a central point of unimportance to the negative and positive extremes of an individual's contextual reaction to statements on the given topic (Stephenson, 1953).

\section{Q Methodology History}

The origins of Q methodology can be traced back to psychologist and physicist William Stephenson, who in 1935 introduced Q methodology as a way to study operant subjectivity (Webler et al., 2009). The Q came to be because it represents an alternative to the usual $\mathrm{R}$ method that is used to find statistical patterns in participant responses typically through a correlation coefficient. The letter Q was used to distinguish this method as a different approach to studying patterns or traits in participants (Webler et al., 2009). The main advantage as outlined by Stephenson is the participants are the ones who do the measuring for the researcher as opposed to being the ones being measured. Furthermore, the core of Q methodology represents a shift from the measurement of external observations to the self-ascribed meaning that individuals give to the environment presented to them.

Q methodology is a way to measure the subjective nature of human behavior as it relates to a particular subject or phenomenon. Individual subjectivity, also referred to as a person's point of view, is captured through communication on topics of importance. A central component of Q methodology is that the observation and extent of an individual's point of view can only be made themselves (Stephenson, 1972). As Brown (1993) stated, "subjectivity is ubiquitous, and Q methodology provides for its systematic measure" (p. 110). 
Sexton et al. (1998) studied the subjective benefits of an early childhood education program using Q methodology. The researchers sought to determine related and distinct perspectives about a new educational program's effect on families. Q methodology was specifically chosen to determine if certain elements were associated with the unique viewpoints expressed. The study concluded that Q methodology is "extremely useful when early interventionists are interested in assessing the characteristics or predilections of individuals they serve or the shared perspectives held by consumers, teachers, and so on" (Sexton et al., 1998, p. 106).

Pruslow and Owl (2012) employed Q methodology to evaluate how graduate students in education make significant connections between the classroom and the field. In other words, the Q approach was used to engage students in meaningful reflection about their field experiences and how it is connected to classroom instruction. It was believed the Q method opened the student's minds to how theory might actually be tied experiential factors that may otherwise have been disregarded when completing curricular requirements. Q methodology was so successful for Pruslow and Owl that they began to recommend it to other instructors "who seek to better integrate classroom instruction with their students' field experiences" (p. 388).

In sum, the central aspect of a Q study is to maintain the subjective nature of the individual by elevating them as the only one that can correctly discern his or her experience. Moreover, the participant's subjective experience is rooted in self-reference and shared through external and internal communication. Therefore, Q methodology 
attempts to align with that stream of communication within an individual and measure their agreement or disagreement with representative statements known as a $\mathrm{Q}$ sample.

\section{Concourse to Q Sample}

Individuals exchange a wide range of beliefs, ideas, and opinions about various subjects and topics through the course of their everyday lives. This stream of communication is representative of the volume of discussion on the topic and is referred to as a concourse (Stephenson, 1980). The concourse can be thought of as a sample from the universe of subjective statements on the topic under study. More than one individual's thoughts, feelings, and emotions about a particular subject or experience are important when conceptualizing the concourse.

In previous Q studies, multiple different sources have been described as contributing to the concourse. In-person interviews, statements from individuals central to the area of study, written narratives, professional literature, and even nonlinguistic areas such as the arts or music have been suggested (McKeown \& Thomas, 2013). For example, Brown (2006) used written narratives from students as they reacted to stories about the subject of study as the basis for statements that made up the Q sample. Conversely, McKeown and Thomas (2013) stated that published research can easily take the place of an in-person concourse gathering technique as it provides viewpoints that are naturalistic.

Stephenson (1978) asserted "all subjective communication is reducible to concourses, whether in the sciences, the arts, or any other domain" (p. 24). The concourse makes up the building blocks of the subjective nature used in a Q study. Similarly, 
research using discourse analysis relies heavily on the discourse itself as a central component. Therefore, Q researchers look to the concourse in the same way. The concourse is foundational to developing the Q sample just as the conversation is to the discourse analysis.

The concourse for my study came from two main sources - the extensive literature review done as part of this paper and previous de-identified reflection journals and feedback originating from health care profession students who had experienced rural IPE at some point in their training. Thus, Q statements used to compile the Q sample for this study are believed to be representative of the topics of rural, rural health care, teambased health care, and rural IPE. The concourse of my literature review and prior student reflections provided extensive communication from which to draw from when developing the Q statements.

Approximately half of the Q sample was developed using structured sampling made up of statements culled from the literature review. This ensured Q samples contained statements already found to be central to the topic of study. For instance, issues of rural health care, team-based care delivery, IPE, motivation, and the elements associated with the recruitment and retention of health care professionals to rural settings were included. As a result, participants were given a wide array of statements that they may have found difficult to express or perhaps have not even considered.

For the remaining half of the Q sample I used an unstructured sampling technique with statements coming from the previous journals and feedback on rural IPE. Through the use of these statements, the Q sample was partially made up of the "student voice" of 
those who have had a rural IPE experience. Thus, it is a representative sample of the exact population that ultimately made up my study. Webler et al. (2009) contended that gathering statements directly from those being studied ensures the concourse reflects people's subjective understanding of the topic. By using statements from individuals as the concourse, the Q sample reflected the actual phrasing of the individual as closely as possible. This helped ensure the subjective nature of the Q sample is representative of the actual context.

McKeown and Thomas (2013) described the two methods of Q sample composition: unstructured and structured sampling. Unstructured sampling takes communication that is not produced as the result of explicit experimental design but yet is part of a bigger discussion whereby theoretical principles have yet to be produced. The argument against using unstructured sampling is that it will potentially miss areas of the conversation resulting in a concourse that is either over or under sampled (McKeown \& Thomas, 2013).

On the other hand, structured sampling quiets these concerns, as the concourse from which the Q sample is derived is the product of comprehensive and theoretical design and thus representative of the communication surrounding the issue at hand. As a result, the Q samples from a structured sampling technique are believed to minimize researcher bias since the only influence is on what statements are eventually selected and not what words make up those statements. In the end, both structured and unstructured sampling in Q sample development have been deemed valid (McKeown \& Thomas, 2013). 
For the creation of my Q sample, eight categories were used to organize the statements. The categories are Social, Personal, Professional, Team, Education, Community, Familiarity, and Motivation. These categories represent the main topical areas found in the literature surrounding rural health care, perspectives of rural communities, and health care education. Approximately 7-10 statements were placed into each of the eight categories resulting in a total of 70 statements.

It is recommended that Q sample statements are independent sentences that have just enough variety in their interpretation but not too much that it becomes difficult to compare the subsequent perspectives. Moreover, the use of a standardized preset Q sample is not recommended as it takes away from the subjective foundation of this type of methodology (Webler et al., 2009). The goal is to have a Q sample that is as natural to the language of those involved in the discourse but broad enough to include the multiple viewpoints thereby maintaining the subjective representation of the topic studied (McKeown \& Thomas, 2013).

\section{Instrument: Q-Set}

The Q-set for this study was created after carefully reviewing the completed Q sample searching for duplicative statements and those not germane to the research questions. This resulted in the revision or elimination of some of the Q sample statements and served as the basis for the development of the Q-set. Furthermore, an independent researcher in health care education well versed in Q methodology reviewed the initial 70 statements to ensure the statements accurately represented the concourse but did not contain excess meaning. Ultimately four to five statements were chosen from each of the 
eight categories believed to represent a wide range of communication about the topic of study (see Appendix B for the final Q-set).

Krathwohl (2009) explained the validity of a research instrument is increased with evidence that its content is measuring what it intends to measure. Furthermore, the instrument can be analyzed to show that it does in fact representatively sample the intended subject matter. For example, in the development of a Q-set, two sources of evidence for validity are reported (Webler et al., 2009).

First, Q samples are intended to have multiple meanings and interpretations to allow for the subjective measurement of the participant's viewpoints. The objective measurement of the participant's subjectivity is a hallmark of Q methodology (Brown, 1993; Stephenson, 1972). Second, statements should be representative of the total concourse related to the topic of study. This is achieved through the structured and unstructured sampling approach to determine the Q sample previously discussed. Consequently, the Q-set emerges by choosing a certain number of Q sample statements from each of the categories created (Webler et al., 2009). This ensures the Q-set is a representative sample of the topic of study, thus providing evidence for instrument validity (Krathwohl, 2009).

Webler et al. (2009, p. 10) suggested that a Q-set be made up of a "small number" of Q sample statements. While an explicit number is generally not prescribed, if a Q-set is drawn from a $\mathrm{Q}$ sample that includes roughly eight categories, choosing four to five statements from each category would result in approximately 32-40 statements in a Q-set. 
Hence, eight categories each producing a range of 32-40 statements served as a guide for creating my study's Q-set.

Table 3.1 represents a sample of the Q-set used for this study. The first column contains the Q sample statements. The organizational categories make up the middle column. The final column contains the source where the statement was found.

Table 3.1

Sample of the Q-Set

\begin{tabular}{lcc}
\hline \multicolumn{1}{c}{ Statement } & Category & Source \\
\hline $\begin{array}{l}\text { Time and sustained presence in a } \\
\text { community helped build trust and } \\
\text { familiarity. }\end{array}$ & Social & L. R. Henry and Hooker (2007) \\
\hline $\begin{array}{l}\text { Working together in the clinic } \\
\text { serves as great "peer" support that } \\
\text { is needed. }\end{array}$ & Team & Student reflection journal \\
\hline $\begin{array}{l}\text { Rural communities have limited } \\
\text { funds which restrict what care can } \\
\text { be provided. }\end{array}$ & Community & Student reflection journal \\
\hline $\begin{array}{l}\text { IPE leads to a greater } \\
\text { understanding of my own role on } \\
\text { the health care team. }\end{array}$ & Team & Ponzer et al. (2004) \\
\hline $\begin{array}{l}\text { The availability of outdoor } \\
\text { activities attracts me to the rural } \\
\text { setting. }\end{array}$ & & Student reflection journal \\
\hline $\begin{array}{l}\text { The most effective rural IPE } \\
\text { allows for engagement in the } \\
\text { community. }\end{array}$ & Personal & Deutchman et al. (2012) \\
\hline
\end{tabular}

\section{Q Sort Analysis}

The end goal of the Q researcher is to evaluate the fundamental meaning of why participants sorted the Q statements the way they did and if there are any similarities 
amongst the Q sorts. In Q methodology this is called factor analysis. This is achieved through comparing completed Q sorts searching for patterns of agreement and disagreement. In Q methodology, factor analysis is the process used to accomplish this goal. To put it another way, factor analysis is the statistical description of the way in which participants group themselves when they do a Q sort. In a Q study, factor analysis can be broken down to a statistical lens applied to the similarly (or dissimilarly) of Q sorts (McKeown \& Thomas, 2013). Complete Q factor analysis involves a four-step process using correlation, factor rotation, factor scores, and a factor array (McKeown \& Thomas, 2013). This four-step process is employed using the PQMethod, version 2.35, software program developed by Schmolck (2014a) specifically for the analysis of Q sorts. It allows the researcher to enter the exact Q sort of each participant directly into the program. The software calculates inter-correlations among the Q sorts along with participant Q sort patterns that emerge (Schmolck, 2014b). This correlational matrix forms the basis for Q methodology factor analysis using the four-step process described in detail next.

Correlational analysis. First, completed Q sorts are entered into the software program and analyzed looking for similar sorts in an attempt to identify patterns that emerge. When a pattern of participants sorting in a similar way emerges, there is believed to be a high correlation among those Q sorts. A high correlation of similar Q sorts is thought to represent an important variable or perspective of the topic of study. In Q methodology this variable is also called a factor. Thus, the first statistical output is the production of multiple perspectives or factors of correlated Q sorts. The PQMethod 
program displays this in what is termed an un-rotated correlational matrix. This matrix identifies Q sort patterns, groups them together into perceived shared viewpoints or factors, and gives the correlation coefficient for each participant in relation to that factor. It is from this initial un-rotated correlational matrix the $\mathrm{Q}$ researcher identifies the factors with high correlation to examine in greater detail.

Factors that emerge from the un-rotated correlational matrix are scrutinized to see which ones have a high number of participants who correlate to that factor. Again, the correlation coefficient by the PQMethod software represents how similar each participant's sorting pattern is in relation to the other participant's sorting pattern when grouped around a single factor. The decision of how many factors to retain and rotate is determined by the Q researcher using a correlation coefficient cut-off.

Brown (1993) described using a correlation coefficient cut-off in Q methodology by first calculating the standard error using the equation $1 / \sqrt{ }(\mathrm{N})$, where $\mathrm{N}$ is the number of statements in the Q sort. Since there are $36 \mathrm{Q}$ statements, the standard error in this study is $.16(1 / \sqrt{ } 36=.16)$. Further, correlations are generally considered statistically significant if they are 2.5 times the standard error (Brown, 1993; McKeown \& Thomas, 2013). As a result, the cut-off for correlation coefficient statistical significance is greater than or equal to $.40(2.5 \times .16=.40)$. In order to avoid having factors that are driven by just one or two participant Q sorts, the cut-off was used to decide how many factors to preserve and rotate. Typically, two to five factors are retained to undergo further analysis through rotation (Webler et al., 2009). 
Factor rotation. McKeown and Thomas (2013) maintained the best way to identify a particular factor is to slightly change its meaning or rotate it within the correlational matrix to obtain higher correlations. To put it another way, "what rotation effects is a change in the vantage point from which the data are viewed" (McKeown \& Thomas, 2013, p. 55). This is done to maximize the saturation of as many participant Q sorts on one or other of the factors initially produced.

Using the previously described correlation coefficient cut-off the Q researcher identifies which factors are to be retained and instructs the PQMethod software to rotate only those factors. In the end, the greater the number of participants who correlate to a particular factor at a significant level, the greater chance that factor will represent the shared perspective of the group. It is common for a Q researcher to identify different groups of factors to rotate in an attempt to find the highest number of participants who load on a single factor while at the same time minimizing the number of participants who load across multiple factors (McKeown \& Thomas, 2013).

Factor scores. Next, once the correct number of factors is identified and rotated, the software program produces factor scores. Factor scores represent the previously described saturation or loading of a participant's Q sort on a particular factor. In other words, participants who load highly on that factor are believed to be representative of that shared perspective (McKeown \& Thomas, 2013). The Q researcher must determine how high a factor loading should be to be considered significant. Webler et al. (2009) suggested the statistical significant cut-off for factor loading be calculated by the equation $2.58 / \sqrt{ } \mathrm{N}$, where $\mathrm{N}$ is the number of $\mathrm{Q}$ statements. Therefore, factor scores 
greater than $+/-.43(2.58 / \sqrt{ } 36=.43)$ are considered statistically significant for loading on a single factor in this study.

Participants who have statistically significant factor loadings on only one factor are then grouped together with other participants who load on only that same factor. This produces a cohort of participants who share the factor, or in other words, share the perspective. The Q researcher then identifies what participants significantly load on a single factor and instructs the software program to group these participant Q sorts together for the final stage of analysis, the construction of factor arrays.

Factor array. The PQMethod program produces a factor array by using all of the participant Q sorts who loaded at a significant level on that one factor. The resulting factor array is actually a reconstructed Q sort representative of the group's shared perspective. To put it another way, the factor array is considered to be a generalization of the participant's subjective belief surrounding that particular issue. Therefore, the factor array can give the $\mathrm{Q}$ researcher clues into the group's shared perspective though the inspection of the representative Q sort itself and the examination of the participants who make up that group.

In order to move into the interpretation, the factor array is assessed to identify where along the sorting grid each Q statement is placed in accordance with each factor or perspective. Through the examination of how the statements are sorted, the researcher begins to identify the elements within the sort that are most important and least important to this factor or shared perspective. Additionally, the researcher begins to define the perspective in a way that would have been difficult to extract without this analysis. This 
shared perspective along with the elements that go into identifying it, are the cornerstone of Q methodology interpretation. As a result, the researcher through looking at participant demographics, the factor array, and the idealized Q sort defines the shared perspective themselves, not the software program. Further, the researcher using key Q statements and their corresponding placement on the factor array creates a sketch of the factor. The researcher then uses this information to paint a picture of the typical participant found in the factor group through a first-person fictional account of their experience called a factor monologue. This process is used to discuss the Q method results in Chapter 4.

\section{Q Method Significance}

It is important to keep in mind that whatever perspective is under scrutiny, the contextual significance should be viewed within the context of the research problem. McKeown and Thomas (2013) noted that special attention be given to the wider context and how the pattern is situated within the particular system under study. Critics such as Comrey and Lee (1992) have suggested that Q methodology inquiry is little more than an inverted factor analysis. However, the factoring in a $\mathrm{Q}$ study compares person to person instead of person to traits or variables. Stated differently, Q methodology places the emphasis on the "factoring of persons [and is] premised on a common unit of measurement, namely, self-significance” (McKeown \& Thomas, 2013, p. 49).

That which a Q study participant centers on is the importance of a particular statement to the individual alone. As a result, the effect of one statement rated greater than another now takes on meaning for quantitative purposes. This approach aids in 
analyzing patterns within the participants rather than from participant to participant (Brown, 1993). In sum, interpretation of the factors and factor arrays is noted to be the most difficult part of a Q study. How a researcher makes sense of the data is contingent upon their familiarity with the current theories and hypotheses found in the larger conversation surrounding the subject of study (McKeown \& Thomas, 2013).

\section{Data Security}

The use of informed consent gave the opportunity to disclose all the information necessary for study participants to make the choice about whether or not to participate (Glesne, 2016). The students were informed that their feedback and reflections were being used in a research study to evaluate their experience in the OHSU Campus for Rural Health. Additionally, reassurance was provided that feedback and reflections would not be analyzed until after the student had completed their experience and the course had formally ended.

Two independent Research Assistants who de-identified the data before sending it to the researcher conducting the study did all data collection. The only possible identifying information was the demographic data collected (age, gender, rural background, children, marital status, health care profession of study, and location of rural experience). All collected data are kept on a university secured cloud storage system (OHSU box.com). Only the researcher had access to the data via the password-protected storage system. Data were kept until completion of the study, which is anticipated to be one year. Once the study has concluded, all data will be permanently deleted and destroyed from any electronic storage system. 
How data are secured during a research study is a key consideration during the proposal process. Krathwohl (2009) has suggested that to ensure confidentiality of research data "steps must be taken from the outset of data collection to make sure that participants are not at risk" (p. 214). Furthermore, anonymity or the protection of a participant's identity must be confirmed from the beginning of a study. Breaches to data security can cause serious violations of privacy and have the potential to induce legal consequences.

\section{Role of the Researcher}

The role of the researcher is somewhat defined by the context of the study itself. Things like methodology, participants, and the researchers own characteristics determine what type of position and function the researcher will take (Glesne, 2016). A welldesigned study seeks to acknowledge the researcher's own beliefs and assumptions surrounding the field of inquiry. Furthermore, exploring how these values and expectations influence study design and conclusions is a major part of a research study (Maxwell, 2013). Consequently, this section assesses the role of the researcher in this study as a participant observer in the field of health care education at the participating institution.

Glesne (2016) described a continuum on which the participant observer sits at any given point in the research process. This continuum is made up of the researcher whose full participation is central to the research process on one end, while the other end contains the researcher who almost exclusively observes the phenomenon of study from the outside. Different parts of the study necessitated the researcher to move up or down 
the continuum as data were collected and analyzed. As a result, the study's environment has a direct impact on the researcher's location on the continuum (Glesne, 2016).

\section{Dynamic Environment}

The context of this study involved health care students from three different professions (medicine, PA, dentistry) all from the same university. The environment involved two different rural communities in southern Oregon with unique characteristics. The clinical settings varied depending on the type of student, clinic, hospital, or community agency. The amount of time each student spent in the rural setting was also dependent on the profession specific education requirements. Thus, the context tended to be varied and continually changing.

As a health care educator for the last 10 years, I have experience in training health care providers in a variety of settings. The last 4 years have been devoted solely to clinical training of PAs in urban and rural communities. Moreover, I have spent a significant amount of time in rural settings interacting with key stakeholders who serve as clinical educators for my students. My involvement in the OHSU Campus for Rural Health Leadership Committee has given me a unique perspective into the development of a rural IPE program and the factors associated with its maintenance. This experience has given me a view of health care in a rural community and the perceived impact of clinical training as a team in the rural setting. As a result, I found myself more on the participant end of the continuum. 
On the other hand, I am also involved with student assessment and evaluation experiences in the rural setting through on-line teaching methods. I have spoken to multiple students about their experiences in the OHSU Campus for Rural Health as well as other rural communities. I serve as an advisor for a group of four PA students who have all spent extensive time in rural clinical training as well as rural IPE. Additionally, my role as the coordinator of the PA student clinical training has given me a perspective of how PA clinical training pedagogy has evolved over the course of the last four to five years. Consequently, these experiences have necessitated more of an observer role in how rural clinical training and IPE impact students.

\section{Researcher Bias and Reactivity}

One of the biggest threats to a study's validity is researcher bias. As previously discussed, all researchers bring with them a set of beliefs and assumptions that influence the lens by which they view the study. However, understanding and acknowledging how the researcher's subjectivity translates into potential biases is an important part of mixed methods research. Furthermore, reducing or suspending researcher bias is a central component of this research study (Maxwell, 2013).

The other component to reducing validity threats is that of reactivity. The term reactivity refers to the influence of the researcher on the setting and participants in the study (Maxwell, 2013). The extent to which reactivity plays a role in validity depends on how involved the researcher is in the components of the actual environment. The participant observer continuum is again important here as the researcher seeks to understand where they find themselves when evaluating reactivity. The goal is not 
necessarily to eliminate reactivity in a mixed methods study. Rather, the researcher seeks to understand how to use their role, as dynamic as it may be, in a productive way (Maxwell, 2013).

My role as an educator with experience in IPE and rural health care training has led to theories and expectations about the impact of a rural IPE experience on health care professionals. Having seen the impact of a rural training experience on a student, may have led to the assumption that students involved my study will have a favorable response to a rural IPE experience. Furthermore, my involvement with students who have experienced IPE has also lead to the belief that team-based training results in a more favorable view of the work environment and health care delivery system. Lastly, my own professional experience as a PA, having worked as part of a health care team for nearly 16 years, influenced my perception of how team-based care delivery positively impacts patient care and health care provider burnout.

My role as an advisor to a group of PA students as well as coordinator of PA student clinical activities may have led to the PA students feeling as though they were required to participate for fear of receiving a poor grade or future clinical placement. Moreover, participating PA students may have been influenced to tell me what I wanted to hear when doing reflective journaling or the Q sort since I am in a position of authority. The role I have as a member of the OHSU Campus for Rural Health Leadership Committee also has the potential to impact the context or environment of the study. Through my involvement in the development of the rural IPE program, I have been 
able to lend my voice to how the clinical experiences are structured and which types of evaluation mechanisms are in place.

In general, my experience of growing up in a region of the U.S. where many of the rural behaviors outlined in Chapter 2 of this paper (hunting, fishing, pragmatic lifestyle) were accessible to me may have led to a bias toward viewing a rural community as a desirable place to live. Moreover, much of my childhood involved hours of leisure and recreational activities situated in rural communities in my home state. As a young adult, I viewed rural life as a place where one could interact with the environment and experience the beauty of nature in its most pristine form. Consequently, my background of placing a high value on those activities that are often found only in a rural setting has created a bias that rural communities offer a life that is more desirable.

This had potential to influence how I analyzed the data collected in this study. As a result of my upbringing, I have a more favorable view of rural life. I may have been more likely to interpret a student reflection journal as a positive experience in a rural community or be drawn to influential factors that would lead to a student choosing rural over urban living. Furthermore, my bias toward a rural life could have led to conclusions or recommendations from that do not reflect the participants' true judgment of what it is like to live and provide care to a rural community.

As previously stated, the goal of the researcher is not to completely eliminate bias or reactivity, but to minimize the amount of influence each and understand the potential effect on data collection and interpretation (Maxwell, 2013). To address the potential of reactivity, all participant data were de-identified so the students felt free to 
share their experiences in the data collection phase. I feel the benefits of the gathered demographic data outweighed the potential for researcher reactivity in this area. Additionally, the informed consent clearly stated that the student's decision whether or not to participate would have no influence on their grade or subsequent educational experiences.

In order to address potential researcher bias, respondent validation through member checks was done. Using some of the participants themselves, or what Glesne (2016) has called "member checking" (p. 212), verified the interpretation of the qualitative data was in-line with what the participants had intended. The process of asking the study participants to provide feedback on my interpretation of the data was an important way to ensure I was not misrepresenting what the participants said. Moreover, member checking aided in the identification of my biases and errors in what I have observed (Maxwell, 2013). In sum, the role of the researcher was an important consideration when designing this study. How that role was defined and what the potential outcomes of that role were on the study's participants and data interpretation is a central component of this study.

\section{Conclusion}

This chapter examined the methods used to answer the research questions posed as part of this study. The three research questions are:

1. How does working with an interprofessional team shape student views on future work with people in those professions?

2. How does the rural IPE experience influence a student's perspective on working in a rural setting? 
3. What factors do students participating in a rural IPE experience consider most important and least important in making a decision to practice teambased care in a rural setting?

This study employs a mixed-methods design evaluating the experience of health care professions' students as they engage in rural IPE. Stratified purposeful sampling was used to ask Health care professions' students who spend between one and four weeks in either the Coos Bay or Klamath Falls locations of the OHSU Campus for Rural Health to participate in this study. Literature was explored related to qualitative and quantitative data methodology. Specifically, prior research outlining the benefits of using reflective journaling as well as Q methodology was discussed.

Qualitative data were collected as part of participants' reflective journaling as they processed their rural IPE experience. Specifically, journaling data were collected in response to the following two prompts:

- How has working with an interprofessional team of students shaped your views on future work with people in those professions?

- How has the rural IPE experience influenced your perspective on working in a rural setting?

Journaling data were then coded using descriptive and values codes to shed light on how the rural IPE experience molds the views and perspectives of health care professions' students. For instance, how does being educated alongside other health care profession students influence a student's decision of whether or not to return to the rural setting to live and work. Participant's Q sort data were also collected to help identify what unique elements are given high and low consideration when a health care profession student graduates and is choosing where to settle and provide care. 
The next chapter of this dissertation presents the data collected as part of the mixed-methods approach just described. Results of journal coding and completed Q sorts are examined using the analytic approaches discussed in this chapter. Lastly, Chapter 4 moves into interpretation of the data results and sets the stage for dissertation conclusions and recommendations. 


\section{CHAPTER 4}

\section{RESULTS}

Chapter 4 contains the results and initial analysis of the data collected as part of this study. To review, this dissertation analyzed the health care profession student experience through a mixed method approach designed to answer the following research questions:

1. How does working with an interprofessional team shape student views on future work with people in those professions?

2. How does the rural IPE experience influence a student's perspective on working in a rural setting?

3. What factors do students participating in a rural IPE experience consider most important and least important in making a decision to practice team-based care in a rural setting?

Participants' reflective journaling was used to help answer research questions one and two. These data were coded using descriptive and values coding. A Q sort performed by the participants at the conclusion of their rural IPE experience was used to explore research question three. Factor analysis was performed on the completed Q sorts to determine which elements play an important role when making decisions of where to live and provide care.

The participants for the study were from one of two rural campus locations and from one of four health care professions (medicine, PA, pharmacy, and dentistry). Sixtythree students spent between one and five weeks of their clinical training in either of the two rural campus locations between June and December 2016. A total of 30 students 
consented to participate in the qualitative data portion and a total of 45 students

consented to participate in the Q method data segment. Given there were 63 students who were in either location of the OHSU Campus for Rural Health during the data collection period, a minimum of 12 participants supplied data for both the qualitative and the quantitative aspects. It is entirely possible that number was higher, but corresponding data were not collected that would have linked the two participant data sets together.

\section{Research Questions One and Two Analysis}

Participant journals were collected specifically in response to the following two prompts:

- How has working with an interprofessional team of students shaped your views on future work with people in those professions?

- How has the rural IPE experience influenced your perspective on working in a rural setting?

Only the portion of the journal corresponding to these two prompts was collected. Once the participants finished their rural IPE experience, an independent Research Assistant at each rural campus location collected their reflective journaling via an on-line course management system, de-identified the journal, and uploaded it to a secure cloud storage system where I retrieved them for coding and analysis. All health care profession students who were in Coos Bay or Klamath Falls between June 26 and December 16, 2016, were asked to participate in the qualitative data collection. A total of 30 students consented to participate in the qualitative data collection at which time data collection ended.

A journal coding table was created to organize each participant's journaling and provide space for coding (see Appendix C). No demographic data were collected as part of the journaling. If a participant identified themselves by a certain health care profession 
or by location of experience, it was entirely of their own accord and was not required as part of the journaling exercise. Some portions of the participant journals were actually responses to classmates' journal postings as part of an on-line discussion board. These particular journal entries are indicated through the use of italics in the coding table. First and second pass approach was used to verify all possible descriptive and values codes were captured. Codes in qualitative data analysis can provide the necessary groundwork for meaningful reflection on what the data means. Therefore, choosing the types of codes to use for this study was done with purpose and intention to help answer the research questions.

\section{Descriptive Coding}

The first type of qualitative coding used was descriptive coding. This type of coding was used to draw general ideas for how participants described material products or the physical surroundings. Special attention was given to how they uniquely described the environment of a rural community. Terms or expressions used to depict what the participants tangibly worked with, saw, and experienced on a regular basis formed the foundation for this type of coding. Descriptive words and phrases were marked with a superscript " 1 " to indicate a descriptive code was derived from the journaling. Marked words, terms, expressions, or phrases were then entered into the journal coding table previously described (Appendix C). An example of the descriptive coding applied to study participants is found in Table 4.1 .

Table 4.1

Descriptive Coding With Examples 


\begin{tabular}{|c|c|}
\hline Descriptive Code & Participant Journal \\
\hline $\begin{array}{c}\text { Warm } \\
\text { Earnest } \\
\text { Welcoming }\end{array}$ & $\begin{array}{l}\text { Participant 3: I do think that the experience of working in the rural setting has } \\
\text { been very eye-opening (in a good way). I was pleasantly surprised at how } \\
\text { warm and earnest }^{1} \text { the people in this town have been, and have been } \\
\text { impressed with how welcome they have made me feel. }{ }^{1}\end{array}$ \\
\hline $\begin{array}{c}\text { Small } \\
\text { Charming town } \\
\text { Gorgeous }\end{array}$ & $\begin{array}{l}\text { Participant 17: Before this rotation, I assumed my future career would be in a } \\
\text { large suburb because I have always lived in that type of setting. However, the } \\
\text { incredible patient interactions and relations I have built with other } \\
\text { professionals in this small }{ }^{1} \text { and charming town }{ }^{1} \text { of Coos Bay has made me } \\
\text { reconsider where I would like to work. I genuinely enjoy my time here, and } \\
\text { the gorgeous }{ }^{1} \text { coastline makes it even easier to stay another rotation longer. }\end{array}$ \\
\hline $\begin{array}{l}\text { Collaborative } \\
\text { Informative } \\
\text { Miles from anyone else } \\
\text { Nice people } \\
\text { Smaller community } \\
\text { Beautiful }\end{array}$ & $\begin{array}{l}\text { Participant 22: The rural IPE course further showed me that the PA/MD } \\
\text { relationship is more collaborative than hierarchical }{ }^{1} \text {. Between IPE and the } \\
\text { ICAN program, this was the first time I had worked with dental students. It } \\
\text { was great to hear them explain the importance of dental health and show the } \\
\text { client how to use their equipment }{ }^{1} \text {. I talked with patients who were ranchers, } \\
\text { farmers, who worked in slaughterhouses, who hunted, and who lived miles } \\
\text { from anyone else. }{ }^{1} \text { I did not have any of these experiences growing up outside } \\
\text { of Washington, DC. The people were nice }{ }^{1} \text { and had no problem answering my } \\
\text { questions about living out here. I also liked how many of the providers knew } \\
\text { each other given that it was a smaller community, }{ }^{1} \text { and I felt there were more } \\
\text { collaborative relationships. It didn't hurt that the lakes and parks were } \\
\text { beautiful }{ }^{1} \text { too. Overall, the Klamath rural experience increased the likelihood } \\
\text { that I would work in a rural setting. }\end{array}$ \\
\hline
\end{tabular}

\section{Descriptive Coding Themes}

Participant descriptions of the rural IPE experience, rural community, and environment were reviewed multiple times searching for repeated words or phrases. However, I did not simply count up repeating words in an attempt to generate a theme. In other words, I was not just looking for patterns but how those patterns could tell me something about the themes and categories that were emerging. I wanted to get a sense for how the rural environment was viewed from the participant's perspective. As a result, I developed a descriptive coding table (Table 4.2) according to the themes I saw developing along with the actual descriptive codes used to create those themes. Overall I noticed both a humanistic perspective as well as a health care provider perspective evolving from four subthemes. 
Table 4.2

Descriptive Coding Themes

\begin{tabular}{|c|c|c|c|c|}
\hline \multirow{2}{*}{$\begin{array}{c}\text { Major Themes } \\
\text { Subthemes }\end{array}$} & \multicolumn{3}{|c|}{ Humanistic Perspective } & \multirow{2}{*}{$\begin{array}{c}\begin{array}{c}\text { Health Care } \\
\text { Provider } \\
\text { Perspective }\end{array} \\
\text { Interprofessional }\end{array}$} \\
\hline & Cold & Neutral & Warm & \\
\hline Descriptive Codes & $\begin{array}{c}\text { Small } \\
\text { Remote } \\
\text { Isolated } \\
\text { Inadequate } \\
\text { Outsider } \\
\text { Struggle }\end{array}$ & $\begin{array}{c}\text { Nature } \\
\text { Interconnected } \\
\text { Vast } \\
\text { Informative }\end{array}$ & $\begin{array}{c}\text { Earnest } \\
\text { Welcoming } \\
\text { Tight-knit } \\
\text { Sincere } \\
\text { Resolute } \\
\text { Beautiful }\end{array}$ & $\begin{array}{c}\text { Silos } \\
\text { Absent } \\
\text { Collaborative } \\
\text { Supportive } \\
\text { Freedom }\end{array}$ \\
\hline
\end{tabular}

\section{Descriptive Coding Theme Discussion}

Participants described the environment of the rural community in terms that were generally positive with a warm thematic tone. They felt the rural community was genuinely excited they were there and displayed a sense of openness and acceptance toward them. Participants remarked about the close nature of relationships within families and community members. This was viewed as the basis for enduring hardships and the difficulties rural communities face. "To me, that community cohesion is the strength of this community; people know each other well enough to enquire and hold one another to account" wrote Participant 18. A general feeling of resolve leading to strength not found in larger communities was also described. Participants saw rural citizens as resourceful and genuine with a sense of togetherness. However, there was also an undercurrent that those who live in a rural setting are this way because they have to be.

Some participants described the rural setting with negative connotations leaving more of a cold thematic impression. Although not very prominent, some participants 
described feeling like at an outsider creating an "Us vs. Them" type of mentality. Feeling like the town was disconnected and physically far away from everyone else was also described. The participants referred not only to the geographic location of a rural community but also in contrast to the more unified impression described in the previous paragraph, noted feelings of isolation. Some participants noticed rural communities have a dichotomy of social interdependence up against the face of secluded citizens with little or no contact with others.

Participants observed people from rural communities dealing with extremely difficult circumstances leading to suffering and even despair. As a result, participants viewed the rural community as having a lot of needs with very limited resources. Poverty was described multiple times as a main contributor to difficulties faced by rural citizens. Lack of adequate health care resources and lack of access to the local health care system was noted as contributing to, or as a result of, the cold thematic expressions discussed. For example, Participant 10 wrote, "Back on the hill in Portland, it's relatively easy to find resources, whether for patients or for working on community projects. However, in rural communities, where such resources and services are not as abundant, it felt like we had to spend significantly more energy tracking resources."

Experiences were also described using words or phrases that could either be viewed as warm, cold, or somewhere in the middle depending on the person's unique perspective. For instance, relational interconnectedness was portrayed as a helpful aspect of living in a small town. However, this was also explained as leading to feelings of everyone knowing your business and not having much privacy. The geographically 
spread out nature of a rural area was depicted by some as one of the main benefits of living there. However, being physically disconnected from others was also described as contributing to feelings of isolation.

Several narratives of the IPE experience or the local health care system lead to the health care provider thematic perspective. Participants described the team-based approach to care as not only prevalent but also needed in a rural community. The IPE environment was generally depicted as encouraging and cooperative in nature, leading to an overall sense of professional equity. However, some called out the professional silos that still exist in within the rural health care system leading to a more negative sense of the IPE experience. Furthermore, many participants noticed a lack of IPE in the actual clinical setting remarking that most of the interprofessional learning took place outside of formal IPE time. This notion is described more in the values coding analysis section.

Lastly, many participants explained the rural health care environment as a place where you have a large amount of professional liberty to work at the top of one's license. This was described through observations of providers filling many roles within the clinic. For instance, Participant 11 wrote, "Here the pharmacists get to do it all which makes for an excellent learning environment in terms of what I'm exposed to."

Overall one could gather participants described the rural environment as having a lot to offer along with a general appreciation for the hardships facing rural Americans. A variety of descriptions were used, but for the most part participants used positive words to describe the rural community. Additionally, rural IPE was portrayed in a positive way as participants articulated an appreciation for how they could fit into a team-based 
clinical practice. However, it seemed IPE was most conducive to the non-clinical environment, as participants did not witness robust team-based care while in the clinic or hospital.

\section{Values Coding}

The second type of qualitative coding used was values coding. This was thought to represent the participant's perspective or worldview of a rural community and IPE. Thus, it was felt values coding would assist in answering research questions one and two. Focus was given to what values, attitudes, and beliefs participants had toward the rural setting, team-based care delivery, and IPE. Coding for all three was considered useful for determining participant motivation for making certain decisions (Saldana, 2013). Value, attitude, or belief words and phrases were marked with a superscript "2" indicating it was a values code. Then, a V, A, or B was used to signify if the word or phrase was a value, attitude, or belief. Each word or phrase was then identified in a separate column in the journaling coding table previously described (Appendix C). Examples of values coding applied to study participants are found in Table 4.3. 
Table 4.3

\section{Values Coding With Examples}

\begin{tabular}{|c|c|}
\hline Values Code & Participant Journal \\
\hline $\begin{array}{l}\text { B: IPE is valuable } \\
\text { V: Matching skill sets } \\
\text { A: Excited for future work } \\
\text { A: Learned about rural } \\
\text { B: Lack of privacy }\end{array}$ & $\begin{array}{l}\text { Participant } 8 \text { : Working with my interprofessional colleagues has } \\
\text { been an incredibly valuable experience. }{ }^{2} \text { I came to understand that } \\
\text { individuals from varying health professions have a } \\
\text { general biomedical sciences knowledge base that helps facilitate } \\
\text { group work. }{ }^{2} \text { Most importantly, though, are the complementary } \\
\text { knowledge, expertise, experience and skill-sets that created a very } \\
\text { productive environment. }{ }^{2} \text { After having worked on this project, I will } \\
\text { be even more eager to have interprofessional projects and } \\
\text { interactions in the future. } \\
\text { The rural IPE experience has opened my eyes to the many aspects of } \\
\text { working in rural setting. I became aware that each rural setting has } \\
\text { a distinct demographic composition, and that cultural and } \\
\text { socioeconomic differences are magnified in a place with such as } \\
\text { small population. }{ }^{2} \text { Furthermore, it became apparent to me that in an } \\
\text { area with a small population, individuals are more socially } \\
\text { interconnected, and this may have implications in terms of privacy } \\
\text { and healthcare delivery. }\end{array}$ \\
\hline $\begin{array}{l}\text { B: Minimal professional } \\
\text { interaction } \\
\text { V: Professional learning } \\
\text { A: Expanded mindset } \\
\text { B: Rural IPE is motivating } \\
\text { B: Engaged teachers enhance } \\
\text { rural learning } \\
\text { V: Making a difference }\end{array}$ & $\begin{array}{l}\text { Participant 12: Unfortunately we did not have much interaction with } \\
\text { students from other professions. }{ }^{2} \text { We briefly met a pharmacy student } \\
\text { and a dental student, but we didn't really get the opportunity to do } \\
\text { the big activities with them. I wish it would've worked out } \\
\text { differently because it would have been interesting to get their input } \\
\text { and ideas. } \\
\text { Given that I didn't get to work with students from other professions, } \\
\text { I can't really say that rural IPE influenced or changed my } \\
\text { perspective about working in a rural setting. }{ }^{2} \text { Working in Coos Bay } \\
\text { for a month was more eye opening and motivating. }{ }^{2} \text { I already had a } \\
\text { desire to work with underserved and rural communities, and after } \\
\text { seeing the impact a good and engaged provider }{ }^{2} \text { can have on the } \\
\text { community I am leaving more motivated to work in an area where I } \\
\text { can make an impact with the individual patient and with the } \\
\text { community as a whole. }\end{array}$ \\
\hline $\begin{array}{l}\text { A: Positive } \\
\text { A: Appreciation } \\
\text { V: Whole group contribution } \\
\text { B: Need other providers for good } \\
\text { care } \\
\text { B: Team-based care is needed in } \\
\text { rural } \\
\text { B: Greater impact in rural } \\
\text { A: Gratified } \\
\text { V: Making a difference }\end{array}$ & $\begin{array}{l}\text { Participant } 28 \text { : Working on this project with PA's and Med students } \\
\text { has been great. My teammates are smart and insightful people who I } \\
\text { know will make a great difference in healthcare. }{ }^{2} \text { It really is a team } \\
\text { effort for total health and we can all feed off of each other and offer } \\
\text { support for each other in complex cases. }{ }^{2} \text { And sure I think the oral } \\
\text { cavity is a very important section of the human anatomy, but I can't } \\
\text { cure it all and not even } 1 / 10 \text { of someone's body. So it's important to } \\
\text { work in teams especially in rural communities. }{ }^{2} \text { I love smaller } \\
\text { communities because when you want to make a difference, it } \\
\text { actually seems to help a lot more than if it were a large town and } \\
\text { what you actually accomplished was a rain drop in the ocean. Here it } \\
\text { seems to matter more. }{ }^{2} \text { Overall my rural experience with Klamath } \\
\text { Advantage has been amazing. I am really proud of the work I've } \\
\text { achieved here. }{ }^{2} \text { I was able to be a part of the standard of care and } \\
\text { help set that bar }{ }^{2} \text { be a larger drop of water in the ocean. }\end{array}$ \\
\hline
\end{tabular}


Initially I went through the data and marked specific values codes pulling the exact words from the participants. Subsequently, I went through the data a second time and revised each values code to a single word or short phrase. For example, on first pass I coded, "Now that I know this nice little community exists, I will seriously consider working out here after I graduate” as A: I will now consider working here. On second pass I revised the attitude code to A: Open to rural. Additionally, I coded, “. . . reviewing the community health problems during our first assignment really opened my eyes to the need that exists here in ..." as B: The project really opened my eyes to the needs of a rural community. Upon the second pass I revised this code to B: Rural has needs.

\section{Values Coding Categorization}

Word, terms, and phrases that were given values codes were put into categorical components according to values, attitudes and beliefs to allow for reflection of their shared importance and interconnection. Similarities between the participant's values, attitudes, and beliefs were marked with different colored highlights and assigned a word or phrase depicting the associated theme (see Appendix D for complete values coding theme table). Each time I went through the categorization list, I saw new connections between the data, adding codes to each of the themes. Seven themes were drawn out of

the values coded data. These seven themes are Social Connectedness, Role Appreciation, Collegiality, Rural Appeal, Patient Centered, Education, and Challenges. Table 4.4 lists the seven themes with a sample of the values codes from each of the three coding categories. These similarities and resulting themes provide the foundation for interpretation of the values codes. 
Table 4.4

\section{Values Coding Categories}

\begin{tabular}{|c|c|c|c|}
\hline \multicolumn{4}{|c|}{ Values Coding Category } \\
\hline Theme & Values & Attitude & Belief \\
\hline Social Connectedness & $\begin{array}{c}\text { Hanging out } \\
\text { Living together } \\
\text { Close relationships } \\
\text { Social interactions }\end{array}$ & $\begin{array}{l}\text { Happiness } \\
\text { Respect } \\
\text { Inclusive }\end{array}$ & $\begin{array}{l}\text { Personal interaction } \\
\text { are key to IPE } \\
\text { Shared housing is the } \\
\text { best for IPE } \\
\text { Organic } \\
\text { conversations yielded } \\
\text { the most }\end{array}$ \\
\hline Role Appreciation & $\begin{array}{l}\text { Working with other } \\
\text { professionals } \\
\text { Learn about other } \\
\text { professions } \\
\text { More clinical IPE }\end{array}$ & $\begin{array}{l}\text { Expanded mindset } \\
\text { Appreciation of } \\
\text { differences } \\
\text { Respect }\end{array}$ & $\begin{array}{c}\text { IPE increases } \\
\text { understanding } \\
\text { The different } \\
\text { professions are } \\
\text { needed } \\
\text { PAs and MDs are } \\
\text { very similar }\end{array}$ \\
\hline Collegiality & $\begin{array}{c}\text { Collaborative } \\
\text { environment } \\
\text { Working together in } \\
\text { clinic } \\
\text { Whole group } \\
\text { contribution }\end{array}$ & $\begin{array}{l}\text { Teamwork is fun } \\
\text { Teachable } \\
\text { Uncompetitive } \\
\text { Open-minded }\end{array}$ & $\begin{array}{c}\text { Team increases } \\
\text { impact } \\
\text { Medicine is a team } \\
\text { effort } \\
\text { Collaboration leads to } \\
\text { better care }\end{array}$ \\
\hline Rural Appeal & $\begin{array}{l}\text { Making a difference } \\
\text { Community project } \\
\text { Rural learning } \\
\text { environment }\end{array}$ & $\begin{array}{l}\text { Jumping in with both } \\
\text { feet } \\
\text { Increased motivation for } \\
\text { rural } \\
\text { Enjoy the setting }\end{array}$ & $\begin{array}{l}\text { Urban care is more } \\
\text { fragmented } \\
\text { Rural practice is } \\
\text { rewarding } \\
\text { Greater impact in } \\
\text { rural } \\
\end{array}$ \\
\hline Patient Centered & $\begin{array}{l}\text { Engaged provider } \\
\text { Patient's point of view } \\
\text { Available resources }\end{array}$ & $\begin{array}{c}\text { Eye-opening } \\
\text { Excited for future work }\end{array}$ & $\begin{array}{c}\text { Sparse resources } \\
\text { Local hospital is } \\
\text { needed } \\
\text { IPP improves care } \\
\text { Impacted my future } \\
\text { practice }\end{array}$ \\
\hline Education & $\begin{array}{l}\text { Mentor's involvement } \\
\text { Interprofessional } \\
\text { preceptors } \\
\text { Feedback }\end{array}$ & $\begin{array}{c}\text { Gratefulness for the } \\
\text { experience } \\
\text { Confirming } \\
\text { Self-realization }\end{array}$ & $\begin{array}{l}\text { Structure is necessary } \\
\text { Rural IPE is not } \\
\text { influential } \\
\text { Communication is } \\
\text { learning }\end{array}$ \\
\hline Challenges & $\begin{array}{l}\text { More time } \\
\text { More clinical IPE } \\
\text { Whole group } \\
\text { contribution }\end{array}$ & $\begin{array}{l}\text { Frustration } \\
\text { Out of place }\end{array}$ & $\begin{array}{c}\text { Structure is necessary } \\
\text { Schedules are a } \\
\text { barrier } \\
\text { Asynchronous timing } \\
\text { is difficult }\end{array}$ \\
\hline
\end{tabular}




\section{Values Coding Categorization Discussion}

Social Connectedness was a theme highly valued by many participants. They wrote about how a rural community provided opportunities for them to engage outside of the clinical environment. Moreover, participants commented on the shared student housing as a major contributor toward feeling like there was a place for them to learn from, with, and about each other. For example, Participant 2 wrote, “. . . we ended up having a really fun time hanging out around the house and around town together." The opportunity to interact with other students separate from curricular requirements was repeatedly described in a positive light, leading to an appreciative and grateful attitude. Many participants noted the organic conversations that occurred outside of the clinical walls as the cornerstone and the most rewarding aspect of the rural IPE experience.

The Role Appreciation theme was also highly valued among the participants and found to be a prevailing attitude and belief throughout the journals. Participants noted the increased appreciation they had for what their fellow students were learning and how their skills were a valuable contributor to the health care team. Several participants described observing their preceptors in the clinic and coming away with a renewed sense of appreciation for the many roles providers hold. They noted the importance of having formal curriculum designed to get them together to discuss the unique contribution each of them could bring to the health care system.

Collegiality theme was a very strong belief within the data. The sense that working together as a team was not only needed in a rural setting, but the rural IPE experience provided opportunities to see this in action. "I did enjoy working within a multidisciplinary clinic and seeing my preceptor not hesitate to utilize the expertise of 
those around her," wrote Participant 25. Others explained the collaborative nature of the rural health clinic as the glue that holds it all together. They believed the team-based approach improved patient care was generated by the openness felt by every member of the team when it came to making suggestions.

The Rural Appeal theme was a common attitude and belief among the participants. Many participants described an appreciation for what the rural environment could bring. Having the opportunity to make an impact on the health needs of a rural community was a common belief. Health care disparities were apparent to many participants leading to a feeling of wanting to return to the rural setting to provide much needed care. Others described the rural clinical setting as the perfect place to see interprofessional practice in action. Some reflected on how the rural IPE experience reinforced or even motivated them to want to live there after graduation. Specifically noting the opportunity to take advantage of the natural beauty of the outdoors readily available in the rural setting.

The Patient Centered theme was not only valued but also a large part of the participant's beliefs. Many noted improved patient care as a direct result of the collaborative team-based environment. Participants explained they valued providers who were dedicated to their patients and communities. Participants believed the rural teambased environment was an essential part of making limited resources go further. Finally, some participants reflected that the impact in patient care was a motivating reason why they would choose to live in a rural community. 
The Education theme was found in participants' values and belief about rural IPE. Many of the participants wrote about the importance of having such an experience as it informed them about rural life and rural health care. Others reflected on the belief that the educational experience did not influence their postgraduate decision at all. Some of these participants did note they had already planned to return to a rural setting after graduation. Many described the value of having a preceptor who was interested in teaching and gave frequent feedback as an important aspect of their experience.

The Challenge theme was a common curricular related aspect seen throughout the data. Different student schedules were believed to prevent cohesive learning and pose a barrier to IPE. Having students continually coming and going from the community led to feelings of frustration. For instance Participant 27 reflected, "I do think that having different schedules created some inconsistency, especially when it came to working on the IPE project." The inability to find consistency amid the student cohorts made it difficult to achieve the curricular goals and objectives. The challenge of not having teambased care modeled in the clinic was also noted. Students found it difficult to engage in clinical IPE with fellow students when the clinic they were assigned to did not reflect a collaborative team-based approach to care delivery.

From this initial analysis, one could get the sense rural IPE was highly valued among study participants although some challenges related to differing schedules and clinical environments were described. A general appreciation and gratefulness for the rural IPE experience seemed to permeate the journals. Participants came to understand the complexities of rural care and the belief that a team-based approach to caring for 
complex patient conditions is needed in the rural setting. Furthermore, an overall value for the rural environment appeared to be shared among the participants. In the end, there did seem to be a high value placed on the non-clinical aspect of the rural IPE experience, noting that organic IPE generally took place in non-educational social settings.

\section{Research Question Three Analysis}

All health care profession students who were in Coos Bay or Klamath Falls between June $26^{\text {th }}$ and December $16^{\text {th }}, 2016$, were asked to participate in the quantitative data collection. An independent Research Assistant at each rural location obtained consent and administered the $\mathrm{Q}$ sort of 36 statements using the Flash $\mathrm{Q}{ }^{\circledR}$ software program (Hackert \& Braehler, 2007) at the conclusion of their rural IPE experience. As previously described, no correlational data were collected to link the $\mathrm{Q}$ sort participants to the journaling participants. Therefore, the $\mathrm{Q}$ sort participants represent a separate and potentially different group of students.

Once Q sorts were completed by the study participants they were de-identified and emailed directly to me along with participant answers to several demographic questions. The completed Q sorts were given a unique participant identification number and stored in a secure cloud storage system provided by the university. A sample of a completed Q sort and corresponding email I would receive is found in Appendix E.

The 36 statements that made up the entire Q-set were entered into the PQMethod software program by number corresponding to the exact number used in the Q sort. This allowed for correlation of the Q-set statement number to its position in the grid of each 
participant's completed Q sort. Then, all of the participant's completed Q sorts were transferred into PQMethod statistical program. Completed Q sorts for each participant were entered by hand. Because all 36 statements of the Q-set were entered into the PQMethod program, the software was able to catch any errors of omission or duplication when entering the completed Q sorts. In other words, the program would not go any further until all Q-set statements were entered and entered only once for each completed Q sort. This ensured accuracy when entering participant Q sorts for statistical analysis. In general, most study participants sorted the Q statements in a way that reflected a positive perspective of a rural community, rural IPE, and team-based care delivery.

\section{Demographic Data Analysis}

Demographic data were collected at the conclusion of each Q sort using the Flash $\mathrm{Q}$ ( software program. This included participant age, gender, if they had a rural background, if they had children, if they were married/partnered, health care profession of study, and rural campus location. This information was organized by participant and is found in Table 4.5 and is analyzed in the following paragraph. 
Table 4.5

\section{Q Sort Demographic Data}

\begin{tabular}{|c|c|c|c|c|c|c|c|}
\hline Participant & Age & Gender & $\begin{array}{l}\text { Rural } \\
\text { Backgound }\end{array}$ & Children & $\begin{array}{l}\text { Married/ } \\
\text { Partnered }\end{array}$ & Profession & Location \\
\hline 1 & 30 & Female & Yes & No & No & PA & $\mathrm{CB}$ \\
\hline 2 & 28 & Male & No & No & No & MD & $\mathrm{CB}$ \\
\hline 3 & 32 & Male & No & No & Yes & PA & KF \\
\hline 4 & 29 & Female & No & No & Yes & $\mathrm{PA}$ & KF \\
\hline 5 & 26 & Female & No & No & No & Not Identified & $\mathrm{CB}$ \\
\hline 6 & 24 & Female & Yes & No & No & PA & $\mathrm{CB}$ \\
\hline 7 & 26 & Female & Yes & No & Yes & PA & $\mathrm{CB}$ \\
\hline 8 & 28 & Female & Yes & No & No & PA & $\mathrm{CB}$ \\
\hline 9 & 24 & Male & No & No & No & MD & KF \\
\hline 10 & 31 & Male & No & No & Yes & PA & KF \\
\hline 11 & 24 & Female & No & No & No & MD & $\mathrm{KF}$ \\
\hline 12 & 32 & Male & No & No & No & Dent & $\mathrm{CB}$ \\
\hline 13 & 28 & Female & Yes & No & No & PA & $\mathrm{KF}$ \\
\hline 14 & 28 & Female & No & No & Yes & PA & $\mathrm{CB}$ \\
\hline 15 & 29 & Female & No & No & Yes & MD & $\mathrm{CB}$ \\
\hline 16 & 29 & Male & Yes & No & Yes & $\mathrm{PA}$ & $\mathrm{CB}$ \\
\hline 17 & 32 & Male & Yes & No & No & PA & $\mathrm{CB}$ \\
\hline 18 & 29 & Female & No & No & Yes & MD & $\mathrm{CB}$ \\
\hline 19 & 27 & Male & No & Yes & Yes & MD & $\mathrm{KF}$ \\
\hline 20 & 33 & Male & No & No & No & MD \& Dent & $\mathrm{KF}$ \\
\hline 21 & 31 & Male & No & No & Yes & MD & $\mathrm{CB}$ \\
\hline 22 & 32 & Male & No & Yes & Yes & PA & $\mathrm{KF}$ \\
\hline 23 & 29 & Male & Yes & No & Yes & MD & $\mathrm{KF}$ \\
\hline 24 & 25 & Female & Yes & No & Yes & PA & CB \\
\hline 25 & 31 & Female & Yes & No & Yes & PA & $\mathrm{CB}$ \\
\hline 26 & 31 & Male & No & No & No & PA & CB \\
\hline 27 & 29 & Female & Yes & No & Yes & MD & $\mathrm{KF}$ \\
\hline 28 & 26 & Female & Yes & No & Yes & MD & $\mathrm{KF}$ \\
\hline 29 & 26 & Male & Yes & No & Yes & Dent & CB \\
\hline 30 & 27 & Male & Yes & No & No & $\mathrm{MD}$ & $\mathrm{CB}$ \\
\hline 31 & 28 & Female & Yes & No & Yes & PA & $\mathrm{CB}$ \\
\hline 32 & 29 & Female & No & No & Yes & PA & CB \\
\hline 33 & 29 & Female & No & No & Yes & PA & CB \\
\hline 34 & 26 & Male & No & No & No & MD & CB \\
\hline 35 & 26 & Male & No & No & No & Dent & CB \\
\hline 36 & 32 & Male & Yes & No & No & PA & CB \\
\hline 37 & 29 & Female & No & No & No & Dent & KF \\
\hline 38 & 34 & Female & Yes & No & Yes & PA & KF \\
\hline 39 & 31 & Male & Yes & No & Yes & PA & KF \\
\hline 40 & 25 & Female & No & No & No & MD & KF \\
\hline 41 & 25 & Male & No & No & No & MD & CB \\
\hline 42 & 28 & Male & No & No & Yes & MD & KF \\
\hline 43 & 31 & Male & No & No & No & PA & CB \\
\hline 44 & 26 & Female & No & No & No & PA & CB \\
\hline 45 & 31 & Male & No & No & Yes & PA & $\mathrm{CB}$ \\
\hline
\end{tabular}

Note Participant $=$ participant number; Rural Background $=$ rural background; Location $=$ location of experience; $\mathrm{MD}=$ medical student $\mathrm{PA}=$ physician assistant student; Dent $=$ dental student $\mathrm{CB}=\mathrm{Coos}$ Bay; KF = Klamath Falls 
A total of 45 participants consented to completing the demographic questions. The youngest participant was 24 years old and the oldest was 34 years old. The mean age was 28.5 years old. Twenty-two participants were female and 23 were male. Of the 45 participants, 18 were from a rural background and 27 were not. Only two participants had children and 24 were married or partnered, leaving 21 participants not married or partnered. Of the three health care professions represented, 24 were PA students, 15 were medical students, four were dental students, one was a medical and dental student, and one did not identify themselves with any health care profession of study. Twenty-eight of the participants did their experience in Coos Bay while 17 experienced rural IPE in Klamath Falls. On average, study participants tended to be PA students, in their late twenties, married or partnered, did not have children, and did their rural IPE experience in the coastal town of Coos Bay. The average Q sort participant can be summarized in the following demographic bullet points:

- Late twenties (mean 28.5).

- Majority PA students (24).

- Near even split - female (22) and male (23).

- Majority married/partnered without children (24).

- Majority not from a rural background (27).

- Majority were in Coos Bay (28).

\section{Factor Analysis}

As described in Chapter 3, the evaluation of completed Q sorts involves factor analysis. Factor analysis for this study essentially involves searching for groups of 
participants who completed the Q sort in a similar way and therefore share a perspective about rural IPE. Ultimately, the shared perspective, and what elements went into defining the perspective, is of central importance to answering research question three. This is accomplished through the previously discussed four-step process of analyzing correlation, factor rotation, factor scores, and a factor array.

Correlational analysis. Completed participant Q sorts were entered into the statistical PQMethod software program. This produced an un-rotated correlational matrix for each completed Q sort (see Appendix F for the complete matrix). As previously discussed, this matrix represents how strongly each participant's Q sort correlated to identified patterns amongst the completed Q sorts. Remember, these patterns represent possible shared perspectives called factors. The default number of factors the PQMethod software produced was eight. When looking at the matrix it was important to remember the closer the correlation coefficient was to 1 the stronger the linear relationship of the participant Q sort to that factor. Thus, I examined the correlational coefficients to determine how many factors to retain for further analysis.

As discussed in Chapter 3, I used the correlation coefficient cut-off of .40 to decide what factors to preserve. Recall, this correlation coefficient cut-off was determined by the equation 2.5 times the standard error $(2.5 \times .16=.40)$. This cut-off showed 40 out of the 45 total participants had a positive correlation coefficient $>.40$ in the first four out of the eight factors. This means $89 \%$ of participants' Q sorts were significantly similar to one of four identified perspectives or patterns of sorting. Therefore, factors one, two, three, and four were retained for further analysis, which is in 
line with the typical number of factors kept for rotation described in the literature (Webler et al., 2009).

Factor rotation and factor scores. As previously described in Chapter 3, factor rotation is done to increase the correlation of as many participant Q sorts to the factors identified as significant for further analysis. Factors one, two, three, and four were retained and rotated using the varimax rotation method in the PQMethod software. Varimax rotation was done to maximize the factor score of each participant's Q sorts around one of the four factors. Remember, factor scores signify how closely correlated or how much the participant Q sort loads on a particular factor. To put it another way, Q sorts with high loading on a particular factor are thought to share the perspective represented by that factor.

In order to maximize the factor scores, I rotated two different groupings of the factors to determine the best possible factor loading distribution. The two groups of factors used in the varimax rotation were Group A - consisting of factors one, two, and three and Group B — consisting of factors one, two, three, and four. I examined the factor scores for each group using the statistically significant cut-off of greater than .43 . Recall in Chapter 3, Webler et al. (2009) suggested the factor score cut-off be calculated by the equation 2.58 divided by $\sqrt{ } \mathrm{N}$ (where $\mathrm{N}$ is the number of $\mathrm{Q}$ statements); thus, for my study, $2.58 / \sqrt{ } 36=.43$.

My goal with rotation of Groups A and B was to maximize the number of participants who significantly loaded (greater than .43) on only one factor and minimize those who loaded on more than one factor or did not load on any factor at all. This aided 
in defining each factor since the final description of the factors was based on the weighted average of the statistically significant factor loadings. In other words, the higher the number of participants who loaded on a single factor the easier it is to define each factor. Using this approach, Group A had 35 participants loaded on a single factor while Group B had only 30 . The decision was made to use Group A since it contained more single loaded participants.

Group A resulted in 23 participants single loading on factor one, 8 participants single loading on factor two, and 4 participants single loading on factor three at a statistically significant level. A total of 10 participants had significant loading on more than one factor or no factor at all. These participants were termed Confounders and were not considered as contributing to defining the factor. The entire factor loading table for Group A showing the single statistically significant factor loadings (> .43) is found in Appendix G.

Factor array. The last step taken in the Q method analysis involves the creation of a factor array. It is one of the most important steps in the factor analysis of a Q study, because it is from the factor array, the meaning of each perspective is brought to life. As discussed in Chapter 3, the Q sorts with significant factor loadings (> .43) on only one of the three retained factors was used to create the factor array. I did this by marking the significant Q sort factor loadings for the PQMethod program to use when constructing the factor array (Appendix G). As a result, the PQMethod software produced a representative Q sort or factor array, for each of three factors as they relate to all $36 \mathrm{Q}$ statements (see Appendix $\mathrm{H}$ for the complete factor array). To put it another way, each 
unique perspective (factor) is represented by a Q sort in, which the $36 \mathrm{Q}$ statements are placed on the sorting grid. From this I could see what statements the perspective most agreed with (+5), what statements the perspective most disagreed with $(-5)$, what statements the perspective was neutral on (0), and everything in between.

\section{Factor Array Interpretation}

The most significant part of Q methodology is the interpretation of each unique perspective as it relates to the topic of study. The factor array is the primary means by which I accomplished this task and ultimately how I answered research question three. The factor array shaped what the perspectives where and what elements went into defining this perspective. In other words, it helped me determine what was important and what was not. Furthermore, the meaning of each perspective was derived from the variables found in the Q statements themselves. For instance, where Q statements related to team-based care were placed on the sorting grid in the factor array, gave me clues as to how participants in the shared perspective felt about team-based care in the rural setting. In the end, predominant patterns in the factor array's relationship — whether the perspective most agreed, most disagreed, or was neutral— to the Q statements was used as the basis for the final step in $\mathrm{Q}$ method interpretation, defining each perspective. For the purposes of my Q study, these three perspectives are what is important when evaluating the student experience in rural team-based education.

In the following subsections, the factor array interpretation reaches its climax. Each factor perspective is named and defined first using factor demographics, followed by a factor sketch, and then a factor monologue. Specifically, the factor's perspective is 
explained for each factor in the opening section. Next, factor demographics describe the characteristics of the participants who loaded on the factor along with a representative Q sort created from the factor array. Then a factor sketch is discussed, which is a summary of important Q statements along with their corresponding factor array ranksmost agree to most disagree - to substantiate the factor interpretation. This is done in the format, Q statement number, followed by the placement on the sorting grid according to the factor array. For example 4:+3 means Q statement number four is placed in the +3 position for that perspective. Lastly, the factor monologue is given, which represents a description of the perspective given from a first person point of view to provide a personalization of the factor and its corresponding perspective.

As described in Chapter 3, each factor represents a shared perspective among the participants. Defining or naming the perspective is an important job of the researcher. Therefore each factor was given a name reflective of the perspective it represents. Specifically, Factor 1 is named the Team-Oriented Rural Optimist perspective, Factor 2 is called the Independent Rural Impartial perspective, and Factor 3 is termed the TeamWilling Rural Skeptic perspective. Finally, an explanation of the confounding sorts along with consensus Q statements that were shared by two or more factors will conclude this section.

\section{Factor 1: Team-Oriented Rural Optimist Perspective}

Team-Oriented Rural Optimists are community minded people with an interest in rural practice that involves other health care professionals. They share the perspective that rural health care delivery should be done with humility and pure intentions. They felt 
accepted and supported by other members of the health care team and well received by the community. They felt rural IPE was instrumental in aiding their decision to want to return to the rural community to live and practice. They also favored a sustained educational experience in a rural setting to help in the understanding of what is involved with rural health care.

Team-Oriented Rural Optimist perspective demographics. Factor 1, TeamOriented Rural Optimist, was the dominant perspective of the study. Twenty-three of the 45 total participants loaded on this factor. The age range was $24-34$ with the average age at 28.8 years old. Factor 1 was the only group that had participants with children (two) while 21 did not have children. This group was almost evenly split on married (12) and not married (11), as well as site of rural IPE experience (10 Coos Bay, 13 Klamath Falls). A slightly greater percentage did not have a rural background (52\%) versus those who did identify as having a rural upbringing (48\%). The same percentages occurred for males and females in this group ( $52 \%$ males, $48 \%$ females). For health care profession, all the participants were either PA students or medical students (57\% PA and 43\% medicine). No participants in this group were dental students.

Team-Oriented Rural Optimist perspective sketch. The Factor 1 sketch represents a composite of the key Q statements used to name the factor. Each key Q statement is paraphrased with its number and corresponding Factor 1 array ranking. In other words how much participants in this factor agreed with (positive number) or disagreed with (negative number) with each key Q statement. Team-Oriented Rural Optimists desire a lengthy clinical rotation in a rural community $(4:+3)$ and believe the 
rural setting is a great place for IPE (33:-3). They desire spending time in a rural setting to better understand what it means to live in such a community (14:-4). Coming from outside a rural town they prefer a good intentioned, open-minded, and teachable approach to learning $(12:+5)$. Team-Oriented Rural Optimists do not view the social challenges of rural patients as barriers to providing good care (2:-2), thus they are progressive when coming up with alternatives to care based on the patient's means and abilities (15:0). For them a rural community is an ideal place for creative solutions that allow for variety in providing care $(18:+4)$. They approach rural IPE with a positive perspective knowing that it can open the mind of a health care professional to the advantages of living in a rural city $(21:+4)$.

Team-Oriented Rural Optimists have a favorable view of the rural setting $(20:+2)$ and how other health care professionals fit into the rural health care landscape prior to their rural IPE experience (23:-4). They view rural health care delivery as professionally supported (24:-3) and balanced with personal goals and opportunities (25:-3). Even if they held a different world-view they did not feel judged by their patients (29:-5). They support engagement in the community as an effective mechanism for enhancing rural IPE $(31:+3)$ and proliferating a connection to rural life that makes it likely they will return $(36:+2)$. Living together with other health care profession students was not a major factor in their positive rural IPE experience (27:-1). They view the rural health care landscape as an ideal place to delivery team-based care $(8:+3)$. Figure 4.1 contains the representing Q sort for the Team-Oriented Rural Optimists. 


\section{Factor 1 Array}

Most Disagree

Most Agree

\begin{tabular}{|l|l|l|l|l|l|l|l|l|l|l|}
\hline-5 & -4 & -3 & -2 & -1 & 0 & +1 & +2 & +3 & +4 & +5 \\
\hline
\end{tabular}

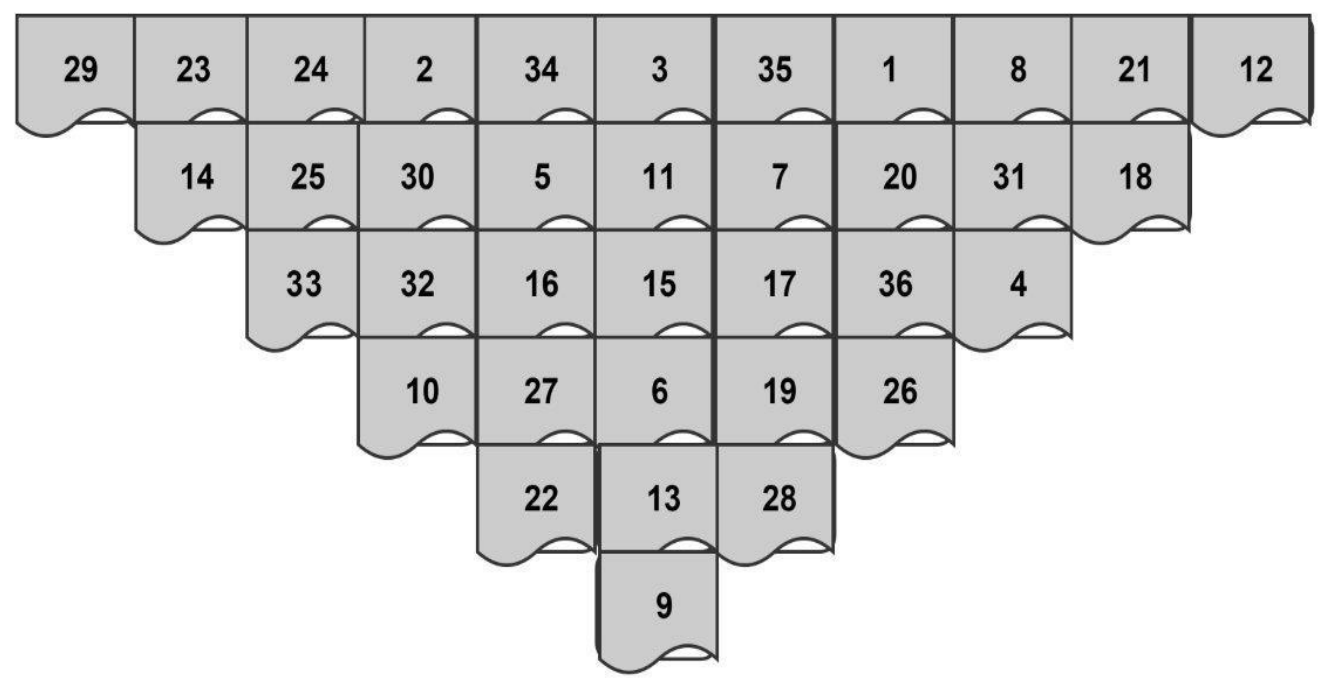

Figure 4.1. Representative Q sort for Team-Oriented Rural Optimist perspective.

Team-Oriented Rural Optimist perspective monologue. As previously

described, the Factor 1 monologue represents a first person rendering of this factor to give a personal summary of the perspective. This monologue was developed by the researcher as a way to describe the perspective further: I really enjoyed my time in the rural setting. In fact, I wish I could spend a longer period of time here. The longer I am here, the more I could see myself fitting into the health care landscape of this community. I have only been here for a month and I feel the more time I spend here the more I learn about what it means to live in a small town. I have always seen myself as a healthcare provider who has close relationships with my patients and the community I am a part of. I 
feel I have only begun to scratch the surface of how my aspirations could be met through living and raising my family here.

Even though I am not from here, I have felt welcomed and accepted. I just try to approach each patient with an unpretentious and sincere attitude. That has seemed to work best for getting to really know the people I have cared for. Make no mistake; there are significant challenges people in a rural community face. I have seen how limited funds and social problems make it difficult to provide care the same way they do in a large city. However, I do not perceive this as a major barrier to providing good quality care. Sometimes you just need to be creative and I really like the variability each day brings. It helps me think outside the box and call on other people to help me solve problems.

People can say what they want about the isolation of a rural town. I think it drives you to rely more on each other to get by. The nature of proving care to a rural area means you have to depend on members of your health care team and trust they have got your back. I saw several of my preceptors asking team-members to do things I would have typically thought the providers would do themselves. I even saw a few providers take time off to go on a vacation. I did not think you could do that when a whole community looks to you to take care of them.

I really enjoyed getting to know the other students. We would often spend time talking about patients and what we had seen that day in clinic. I learned a lot about the way each health profession approached a patient and the role they play on a health care team. The nature of the rural town makes it so that you have to know what the other 
team-members are capable of and how they can help you provide care. Having this educational experience with my fellow students was perfectly situated in this rural setting. If I were at the university hospital I do not believe I would have learned as much about what the other members of the team did and how they could improve patient care. I guess to sum it all up I felt a connection to this community and saw the benefits of spending time here with my fellow classmates. I was already leaning toward living in a small town, but this experience solidified my desire to return. In short, participants sharing this perspective had a positive outlook on rural IPE and had a preference for team-based practice as well as living in a rural community.

\section{Factor 2: Independent Rural Impartial Perspective}

Independent Rural Impartial are individuals who prefer to approach patient care alone and are somewhat ambivalent when it comes to living in a rural community. They value spending a sustained amount of time in a rural setting and have an affinity toward certain aspects of the rural lifestyle. However, they value the proximity of family and friends and view the isolation of a rural setting as a major barrier. Participants in this group did not see the advantage of doing IPE in the rural setting. They did not perceive how the rural setting lends itself to team-based care or IPE. They preferred to remain separate from community engagement activities and felt team learning curriculum did not enhance the educational experience.

Independent Rural Impartial perspective demographics. The Independent Rural Impartial factor made up the next largest factor-loading group in the study. A total of eight participants loaded on this factor when doing the $\mathrm{Q}$ sort. The age range of this 
group was 26-32 with the average age at 28.7 years old. However, this group had the largest percentage $(50 \%)$ over the age of 30 . None of the participants in the Independent Rural Impartial group had children. The number of males was five and the number of females was three. This was the same distribution for the number of participants who had a rural background versus those who did not (five did not and three did). The number of participants who did their IPE experience in Coos Bay was much higher (six participants or $75 \%$ ) compared to those who were in Klamath Falls (two participants or $25 \%$ ). The group of married participants was almost equal to the group of non-married (five and three respectively). The PAs made up the largest portion of this group (four participants or $50 \%$ ). However, this group contained two dental students and only one medical student. One participant in this group did not identify a specific health care profession of study.

Independent Rural Impartial perspective sketch. As previously mentioned, the Factor 2 sketch displays key Q statements used in the formation of the factor. Each Q statement number with the corresponding Factor 2 array rankings- how much participants in this factor agree with (positive number) or disagree with (negative number) key Q statements — are given to demonstrate the correlation between the Q statement and the factor description. Participants in the Independent Rural Impartial group had mixed perspectives about the rural community. They agreed that spending an extended period of time in a community increases trust and understanding (4:+3 and 14:4). On the other hand, they did not feel this would lead to a desire to return to a rural setting to live and provide care (10:-3). They viewed the remote nature of a rural town as 
an obstacle to remaining connected to family and friends $(30:+5)$ and a factor toward not choosing to live in a rural setting. Participants in this group could see the benefits of how their hobbies could be met in a rural location $(26:+4)$ but did not view their experience as helpful in understanding how being a member of a health care team was benefitted the rural health care landscape (19:-3 and 8:0). They remained neutral in how the rural IPE experience created an interest in returning to a rural town to live and provide care $(20:+1)$ and did not have strong feelings toward the perceived professional isolation that comes with living in a remote health care setting (24:0).

With respect to IPE in a rural setting, participants in the Independent Rural Impartial group did not feel engagement in the community was a prominent role for the health care provider (16:-4). They did share a perspective that effective rural IPE should involve some community engagement $(31:+4)$ but did not feel a public health project was the way to do it (5:-5). They remained neutral on the advantages of team-based care in a rural setting (6:0) and did not view the rural clinical as a place to engage in learning about other health care professions (32:-3) or provide advantages to increasing their knowledge of patient care (34:-2). They did not view the team approach to patient care provided a significant support structure to the many responsibilities of caring for a rural community (7:-1 and 8:0). Finally, individuals in this group did not walk away from the rural IPE experience feeling they had a greater understanding of how they fit into the rural health care team (9:-2). Figure 4.2 contains the representing sort for the Independent Rural Impartial factor array. 
Factor 2 Array

Most Disagree Most Agree

\begin{tabular}{|l|l|l|l|l|l|l|l|l|l|l|}
\hline-5 & -4 & -3 & -2 & -1 & 0 & +1 & +2 & +3 & +4 & +5 \\
\hline
\end{tabular}

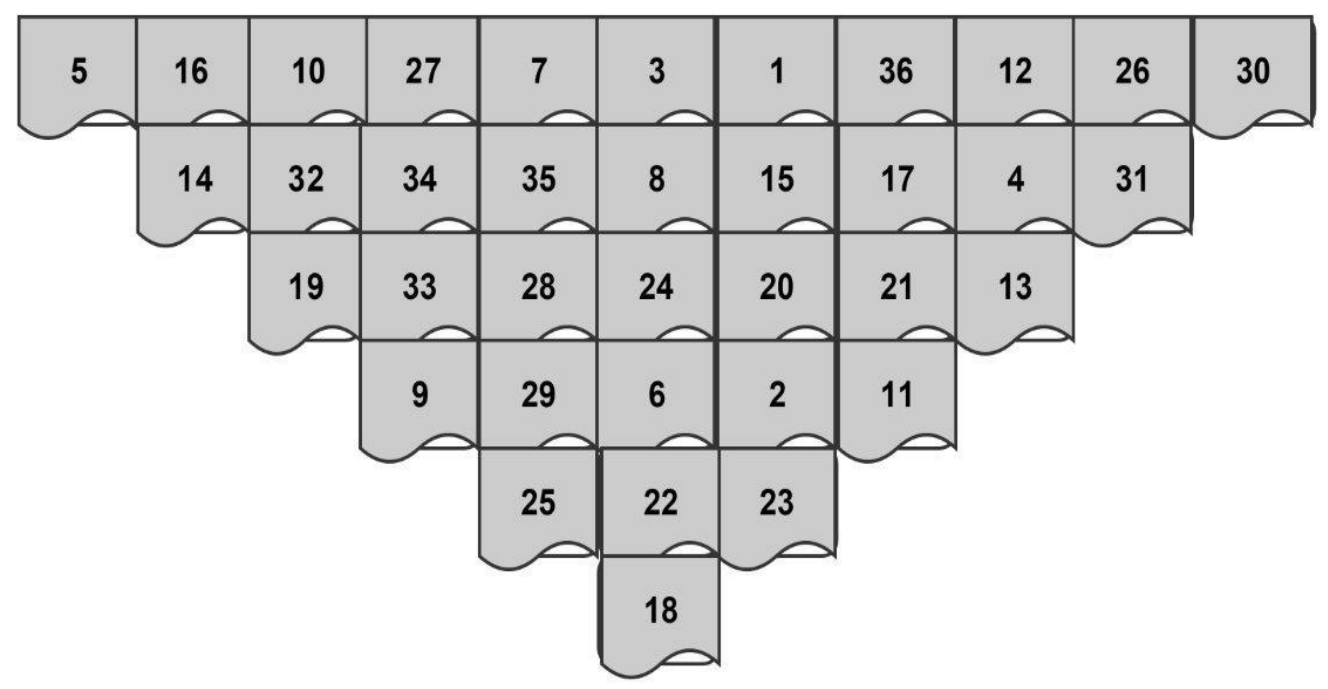

Figure 4.2. Representative Q sort for Independent Rural Impartial perspective.

Independent Rural Impartial perspective monologue. As previously described,

the Factor 2 monologue is a first-person account of an Independent Rural Impartial individual might reflect on their experience created by the researcher: I have mixed emotions to living in a rural town. On the one had I saw so many opportunities to go fishing, which I really love. On the other hand, I do not know that I could stand being so far away from my brother and his kids. I love being an uncle and driving 10 minutes across town to go to birthday parties and family gatherings. This is a big reason why I would not live outside of the metro area. I do not know, I probably would make some friends in a rural town, but it just would not be the same. I did see people who are 
relationally connected and have strong social support systems, but I also saw many individuals who are lonely and do not have a lot of family close by.

Maybe with enough time in a rural area I would learn to appreciate the distance from the hustle and bustle of city life but I do not know. I am not the kind of person who readily engages in the community around them just for the sake of getting to know those I live by. For instance, my fellow students and I needed to work on a community project together while on our rural rotation and I thought it was a huge waste of time and did not add much to learning about the community or learning about the health care professions of my friends. I can see the value in having us students get out of the clinic and learn about the surrounding area but I was overwhelmed with just learning how to care for patients. I saw the doctors in my clinic barely keeping up with daily demands. They had little extra time for volunteering at health fairs or blood pressure screenings at the local super market.

I have always viewed my clinical practice as more of a solo endeavor with a small support staff that runs the clinic the way I like it. I already had a good idea of my role and how I fit into the health care system. I did try to approach my rural educational experience with an open mind thinking I could really learn something here. Unfortunately, the environment was just not conducive to IPE or team-based care. Perhaps I would eventually learn to appreciate the value of having a group of health care professionals to help carry the load of caring for a rural community. I guess I just did not see the need for it when I was in clinic. Everyone was busy, but not to the point of burn out or exhaustion. At least I have a frame of reference if I were ever to decide that I want 
to spend more time on a river or lake. Overall, it could be said participants with this shared perspective were not in favor of IPE or team-based practice. They were not opposed to living in a rural community but would not generally favor it.

\section{Factor 3: Team-Willing Rural Skeptic Perspective}

Team-Willing Rural Skeptics are individuals who would not particularly choose to settle in a rural area. They value time in a rural setting in the sense that it solidified their understanding of what rural life was like. However, this is where their appreciation of the rural IPE experience ends. Team-Willing Rural Skeptics do not see the rural setting as a place to raise a family or experience community. They have moderate feelings against team-based care but their perspective about IPE favors a more urban setting as the ideal place to learn and practice this type of model. This group did not feel the IPE experience lead to an increased understanding of the other health care team members.

Team-Willing Rural Skeptic perspective demographics. The Factor 3 perspective, Team-Willing Rural Skeptic had a lower number of participants who loaded on this factor when compared to the other two groups. At total of four participants were in this group with equal male and female representation (two respectively). The age range was 26-31 with the average age at 28.7 years old. Only one participant was over the age of 30 and no participants were under the age of 25. No participants in the Team-Willing Rural Skeptic group had children or were from a rural area. Three participants were married, leaving one participant in this group not married. There were no PA students in this group only three medical students and one dental student. All of the participants in this group did their rural experience in Coos Bay. 
Team-Willing Rural Skeptic perspective sketch. The Factor 3 sketch is a summary of the factor array ranking of the central Q statement that aided in naming this factor. Each key Q statement number is given with the Factor 3 array ranking or how much participants in this factor agreed with (positive number) or disagreed with (negative number) the Q statement. Individuals in the Team-Willing Rural Skeptic group had a strong negative perspective about the rural setting (1:-5). They did not view it as a setting where they would want to raise their children (28:-4). They desired closeness and proximity to their family and friends and felt living in a rural location would be socially isolating (30:+4). They did not have strong feelings toward the perceived advantages of living in a rural community $(26:+1)$ and remained neutral on their perspective of rural minded people as resilient and practical (17:0 and 3:+1).

Individuals in this group had a positive perspective on how their time spent in a rural setting helped them understand what rural life was like (14:-4). The rural IPE experience helped answer questions they had about what it was really like to live and provide care to a rural community $(19:+5)$. They did not see familiarity with a rural town as a reason for returning after graduation (10:-3) but also felt having no idea about what it meant to live in a rural community was a disadvantage to making a decision of where to live and practice $(13:+3)$. Team-Willing Rural Skeptics viewed some health professions as having more of a responsibility to help rural communities $(22:+3)$ while maintaining the rural IPE experience did not aid in their understanding of the other profession's role or responsibility on the health care team (23:-2). 
The perspective of Team-Willing Rural Skeptics is that the rural setting is not a good setting for IPE (33:-3). They viewed the rural clinic as a place to learn about rural life $(21:+3)$ but not necessarily learn much about the other health care professions $(32:-1)$. They did not appear particularly motivated to return to a rural community after graduation (20:-2) although having a connection to the community increased the chance they would choose a rural setting to live and work $(36:+2)$. In the end, they did not have strong feelings against team-based care (6:0) even though they did not view IPE as the best modality for furthering their overall education (34:-3). Figure 4.3 contains the representing sort for the Team-Willing Rural Skeptics.

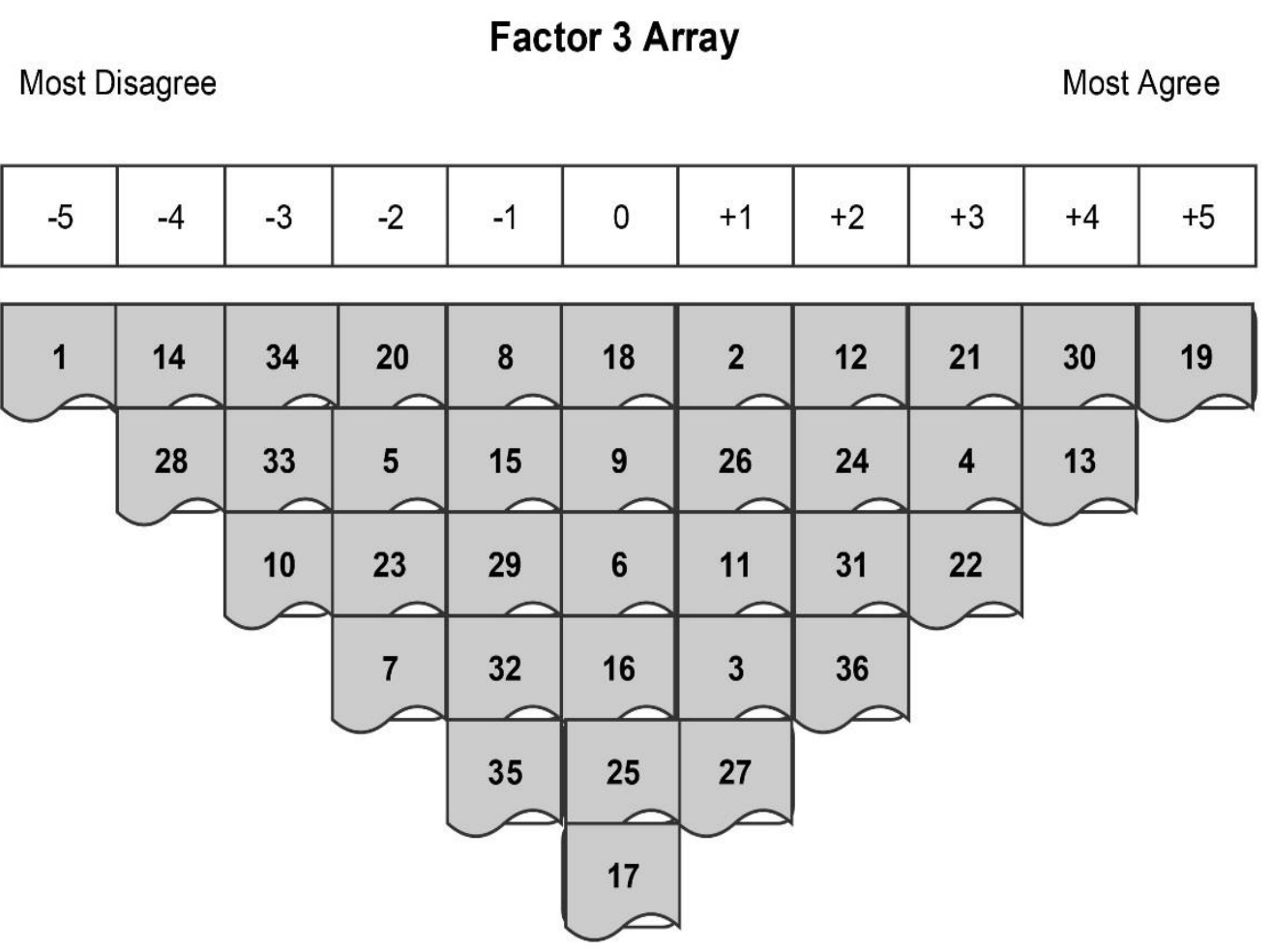

Figure 4.3 Representative Q sort for Team-Willing Rural Skeptic perspective. 
Team-Willing Rural Skeptic perspective monologue. The Factor 3

monologue is a reflection of how a Team-Willing Rural Skeptic might describe their rural IPE experience: I have never viewed myself as a person who would live out in the sticks. I have such close ties with my family that being far away concerns me. I am glad I was able to spend a month in a rural town. It helped me see rural life just is not for me. At least I have a frame of reference for what people live like in a rural town. I do not think I would have the time or energy to learn about a whole new way of life on top of establishing a clinical practice. I am confident the more time I spend in a rural community the more I would realize I want to be in a big city. I have always felt more content and relaxed within an urban area.

I found being in clinic with a bunch of other students got in the way of me learning what I need to know to pass my exams. However, it was nice to have another student who I could go to with basic questions and not feel stupid. The people I worked with talked a lot about how it can be very isolating when you do not have a strong referral network and most health care is done independent of others. Doctors are probably the best suited for a rural clinic. They tend not to need the help of anyone. Actually, now that I think about it, I do not know if I agree with that. I saw plenty of examples of other health care providers lending their expertise to complex patients and providing solutions to the problems providers face. In this sense, having fellow team members you can rely on might be kind of nice. Actually, I do think I could get this same support in an urban clinic. 
Most people I saw and talked to appeared to be happy although I did see patients who were really struggling to make ends meet. These patients tended to be parents with young kids. Maybe it is related to lack of education or just general social know-how. I am not even sure what to say about the schools in this town. Many of the younger kids I saw in clinic were so far behind in reading and math. The older ones did not really have a great idea of where they were headed in life and honestly, there is not much opportunity for them. I did not see this as a major obstacle to providing the best care I could, but some of the more advanced treatment methods like a behavioral psychologist just is not available. This place is so far removed from progressive approaches that the people living here do not have many options. Personally, I want my own kids to have as many options and opportunities as possible. In general, participants in this group shared the perspective that rural IPE is not their first choice and team-based practice is sometimes necessary but they would prefer a different type of practice delivery. Further, participants in this group were generally resistant to living in a rural community.

\section{Confounded Sorts}

Confounded sorts are defined as participants who did not significantly load on a single factor rather they significantly loaded on more than one factor or no factor at all. In other words, they did not fit into any one of the three defined perspectives. Of the 45 total participants, 10 of them were confounding, which made up the second largest group of overall quantitative participants. As previously described, Appendix G displays the factor loadings used in the analysis. Of the 10 Confounders, 6 were female and 4 were male. 
Seven of the confounding sorts were from PA students, with one dental student, one medical student, and one dental and medical student combination. The age range was 2433 years old with two participants over the age of 30 and two below the age of 25 . The average age was 27.8 years old. Three of the Confounders were married and seven were not. Four confounding sorts were from a rural background while six did not have a rural upbringing. A majority of Confounders spent their experience Coos Bay (80\%) while $20 \%$ were located in Klamath Falls.

Each of the 10 confounding sorts represented a blended perspective. Two of the Confounders cross-loaded on Factors 1 and 2 (Participants 16 and 31) at a statistically significant level. Two more cross-loaded at a significant level on Factors 2 and 3 (Participants 20 and 24). Two participants (37 and 43) cross-loaded on Factors 1 and 3 at a significant level. Of the remaining four Confounders, Participant 14 cross-loaded on all three factors at a statistically significant level sharing perspectives with participants in these categories. Participants 6, 41, and 44 did not load on any of the factors at a statistically significant level.

In sum, Confounders represented a blending of multiple perspectives across the described factors. They identified with perspectives both in favor or rural, IPE, and team along with views that were negative toward these elements. Since the Confounders made up the second largest overall Q participant group it can be understood that a significant portion of study participants held multiple and sometimes paradoxical perspectives toward rural living, rural IPE, and team-based care delivery. 


\section{Consensus Statements}

Consensus statements aid in the consideration of what elements are common to all study participants. For example, based on the consensus statements, one could determine the rural IPE experience is beneficial for understanding rural life. Their significance is found in the uniformity of the factor array. In other words, the variables found in the consensus statements that have the same array do not help distinguish what elements are most important and least important amongst the factor groups. If all factor groups agree or disagree with the statement, the statements do not help define the perspective. For example, the combined efforts of team-based care in the rural setting remain neither a positive or negative element when deciding to return.

Of the $36 \mathrm{Q}$ statements, four did not distinguish between any of the three factors with all four having a complete consensus on all the factors. The four consensus statements along with their category and corresponding factor array ranking are:

- Feeling a connection to a rural community makes it more likely to return after graduation. (Motivation, $+2,+2,+2$ )

- Time spent in a rural setting does not lead to a greater understanding of rural life. (Familiarity, -4, -4, -4)

- Seeing patients together combines our knowledge and strength to provide care. (Team, 0, 0, 0)

- Time and sustained presence in a community helped build trust and familiarity. (Social, $+3,+3,+3$ )

\section{Member Checking}

As described in Chapter 3, member checking was done to guard against researcher bias when interpreting the qualitative data. Five PA students who participated in the study were asked to review the qualitative data coding themes and asked for their 
input on how they felt it captured the perspectives of students in the OHSU Campus for Rural Health. All participants asked to do a member check agreed with the coding themes as an accurate representation of the participant's descriptions, values, attitudes, and beliefs about their rural IPE experience.

\section{Summary}

Chapter 4 contained the results from both the qualitative and quantitative data collection methods. These results were presented in an effort to answer the following research questions:

1. How does working with an interprofessional team shape student views on future work with people in those professions?

2. How does the rural IPE experience influence a student's perspective on working in a rural setting?

3. What factors do students participating in a rural IPE experience consider most important and least important in making a decision to practice team-based care in a rural setting?

Descriptive statistics were included along with the results of basic demographic data. Qualitative data from the participant's reflective journaling while on their rural IPE experience was presented along with the descriptive and values codes assigned to each journal entry. A more advanced analysis of the codes revealed themes related to the participant's experience.

Results of the Q study along with factor analysis of the participant's Q sorts were presented. Three factors were extracted and described in detail including basic 
demographic statistics and a more detailed analysis of each factor's representative Q sort along with a sample monologue of someone who identifies with the particular factor. Finally, participant sorts that did not identify at a statistically significant level with one single factor were described and analyzed. The next chapter explores the implications of the data results and analysis described in this chapter. Furthermore, limitations of this study as well as areas for improvement are also investigated. 


\section{CHAPTER 5}

\section{SUMMARY AND DISCUSSION}

As previously discussed, this study set out to explore the health care professions' student experience while engaging in rural Interprofessional Education (IPE). This chapter provides an examination of the study's results along with conclusions, limitations, and recommendations for future education and research. To begin, a review of the research problem, research questions, and the study's methodology is discussed. Following this, a summary of the study results is reviewed. Then, the study's conclusion related to educational practice is examined. Lastly, limitations from the study along with opportunities for future education and research conclude this dissertation.

\section{Research Problem and Methodology Review}

As explained in Chapter 2, difficulties accessing health care in rural and remote areas of the U.S. is a long-standing problem (Jensen \& Royeen, 2002; Mu et al., 2004; Smith et al., 2005). Individuals who call rural America home often have to choose between going to the doctor to receive care or leaving medical conditions untreated. Significant barriers exist in rural communities when it comes to accessing the local health care system. Many struggle to find adequate transportation, health insurance, or support when needing care (Bailey, 2013). Consequently, the health of rural populations has suffered (Spleen et al., 2014).

The ACA of 2010 pledged to reduce health disparities through improved access to those living in rural and medically underserved areas. This federal legislation was aimed 
at giving health care coverage to millions who previously were not able to afford it or even be eligible. However, increasing health care for the newly insured assumed there would be an adequate supply of health care providers to care for them. A major strategy proposed by the ACA placed an emphasis on the use of health care teams to deliver care for the individuals now covered.

Until recent years, health care educational models reflected historical soloprovider approaches to delivering care. Academic health centers had not caught up with the transforming health care delivery systems the ACA was calling for. Moreover, health care education was not providing the curricular framework of training students in teams where it mattered most—rural communities. As a result, graduates from health care universities were not motivated to live and work as part of a collaborative team in rural settings.

The decision of where to establish a practice is one that every health care provider faces upon graduation. Since many factors go into that decision, moving into a deeper understanding of how individuals process an educational experience and how that process influences their behavior is valuable (Maxwell, 2013). Furthermore, knowing what motivates a health care profession graduate to choose a rural community to live and work has educational implications for how and where they are trained. The conclusions drawn in this chapter help in that understanding.

In order to better comprehend the impact of a rural team-based experience on a student's decision of where to live and provide care, a mixed-methods study was conducted to evaluate the experience of a health care profession student while 
participating in rural IPE. Motivation Theory provided the framework to inform the study design and analysis. As a result, the following three research questions were posed:

1. How does working with an interprofessional team shape student views on future work with people in those professions?

2. How does the rural IPE experience influence a student's perspective on working in a rural setting?

3. What factors do students participating in a rural IPE experience consider most important and least important in making a decision to practice team-based care in a rural setting?

Medical, PA, dental, and pharmacy students who spent 2-5 weeks engaged in IPE in two distinct rural locations were asked to participate in this study to better understand their experience. First, qualitative data were collected in the form of reflective journaling in response to two prompts designed to answer research questions one and two. Then quantitative data were gathered by asking participants to complete a Q sort at the conclusion of their experience to address research question three. In general, data results provided a glimpse into health care profession students' perspectives on rural life, teambased care delivery, and the decision-making process of where to live and work after graduation. The following section provides a general-to-specific summary of the study results setting the stage for a more in-depth interpretation of what the results mean in the final section.

\section{Brief Review of Results}

As discussed, participant's reflective journaling was used to address research questions one and two: How does working with an interprofessional team shape student views on future work with people in those professions? How does the rural IPE experience influence a student's perspective on working in a rural setting? The qualitative 
journaling included a total of 30 health care profession students from medicine, PA, dental, and pharmacy. Forty-five study participants from medicine, PA, and dental provided Q sort data to address research question three: What factors do students participating in a rural IPE experience consider most important and least important in making a decision to practice team-based care in a rural setting? Data were not collected to correlate participants who provided both qualitative and quantitative data, although it was assumed some participants provided both. A discussion of the reflective journaling and Q sort data results is provided next.

\section{Discussion of the Results}

This segment of the dissertation moves into a more detailed discussion of what the results of this mixed-method study mean for health care students, educators, and practicing health care professionals. First, each method's conclusions are delineated in two or three succinct statements followed by a more detailed look at how the data aided in the subsequent formation of the supposition. Then, study limitations are discussed including what I learned from conduction the analysis. These lessons form the basis for the last section, recommendations for future rural IPE and research, which brings this dissertation to a close.

\section{Study Conclusions}

In general, rural IPE is a worthwhile experience for health care professions' students. Participants had a genuine appreciation for the time spent learning from rural preceptors and engaging in the community. They felt the rural IPE experience helped them decide if they enjoyed team-based care and rural life to the point they would be 
motivated to return. Further, spending an extended period of time in a rural setting aided in the understanding of rural living. Overall, participants felt a sustained presence helped build trust and familiarity with both patients and providers.

Universally, participants felt the rural clinic was an ideal place to learn about team-based collaborative care. This supports a similar view held by many health care education researchers idealizing the rural setting for IPE (Mu et al., 2004; Spencer et al., 2015; Wros et al., 2015). Engagement in the community was agreed upon by all participants to be an important aspect of the IPE experience. Having a connection to a community was viewed as an important reason for why a health professions' graduate would return to a rural community to live and work.

However, as previously noted, the perceived benefits of team-based care were not widely shared. Perspectives of neutrality toward the combined knowledge and strength of a team were found in this study. Many participants were neither overly positive nor extremely negative concerning how a collaborative team enhanced the care of a rural community. This goes against the widely held belief that a rural community benefits from a team-based approach to care (Croker \& Hudson, 2015; Minore \& Boone, 2002; Taylor, Blue, \& Misan, 2001). The ambiguity toward rural collaborative health care teams may in fact be linked to another widely held perspective found in the data - the clinical setting is not where most IPE took place.

Many participants seemed to favor the non-curricular "social" interactions outside of the clinic or hospital for achieving the goals of IPE. Time spent outside of prescriptive IPE was viewed as one of the most important elements in learning about other health care 
professions. Furthermore, these interactions formed the basis for learning how one could be an integral part of a team, embedded within a health care community serving the needs of a rural area. Of importance, this conclusion is not found in the current IPE literature. Therefore, a more in-depth look at this new idea will take place in the following section.

\section{Research Questions One and Two Conclusions}

Reflective journaling provided the space for participants to discuss their thoughts and feelings of living and providing care in a rural setting. Overall participants described their engagement in the community as the primary means to see if the rural setting was a place where they could live and work. Additionally, interacting with their patients, learning about their successes, struggles, and way of living was central to participants making decisions about where to live after graduation. Out of these general conclusions three main suppositions emerged from the journaling data analysis. As discussed in Chapter 4, several different Descriptive and Values coding themes were described. Within each conclusion I specifically name the key coding themes that were felt to be of importance.

\section{Conclusion 1: Social interaction outside of the clinical experience is a useful}

method for learning about other health care professions. Participants repeatedly wrote about the importance of interacting with their fellow classmates outside of formal clinic time. They stressed the significance of living together as the main mechanism for achieving IPE_-learning from and about each other for the purpose of collaboration and improved care (Centre for the Advancement of Interprofessional Education, 1997). For 
instance Participant 1 wrote, "The time in the house hanging out and talking with the other students and being able to talk about their experiences and training did more to get me to know them than the actual project. I could see how if the project wasn't here people could go through their rotations without ever really communicating ${ }^{1}$ with or getting to know their roommates." Further, Participant 15 remarked, "I was able to get some IPE experience from the fact that I had the opportunity to live in the same complex as a pharmacy student and a dental student." The shared living space is therefore foundational to a rural IPE experience. This is highlighted in the Social Connectedness Values coding theme described in Chapter 4.

Closely related to this new conclusion is what Hancock et al. (2009) described as the Community domain. Recall the previously described need for a rural health care provider to feel a sense of connection with other health care professionals and the community in which they serve. This connection functions as the basis for not only successful recruitment of rural health care providers but also retaining them for years into the future. In the same way, students in this study have a deep need for relationship formation that is found outside of the prescribed curricular domain of current rural IPE. "Living and spending time with an interprofessional team of students provided the best views of these people beyond the mandatory projects we had to collaborate on together" reflected Participant 17.

Students felt a genuine connection to each other and the rural community through informal conversations, excursions, and down time while in the shared living space. Casual social time at the end of the day or on weekends provided the most organic and 
fruitful time for achieving the goals and objectives of an IPE experience. Students learn to appreciate the other members of the health care team through conversations around the kitchen table, while on a hike, or in the midst of a community outing. Through organic interactions outside of formal curricular constructs, true IPE took place. The success experienced through non-curricular IPE begs the question, what are the barriers to achieving the goal of IPE in the current delivery method?

Conclusion 2: Achieving genuine IPE has significant challenges. Many times, students wrote about the challenges to working together as part of the IPE curriculum. This conclusion was clearly identified within the Values coding Challenges theme. Specifically, different academic schedules were described as a consistent barrier. Students commented on the struggle to have steady team members present to work on group assignments. For example, Participant 24 wrote, "I completely agree. Having other students coming and going while working on the project did make some details difficult." Students were coming and going from the rural community at different times.

Consequently, there was rarely a consistent group to work on curricular requirements and provide continuity toward educational objectives. The inconsistency with team members made it challenging to build trust within the team. Without this foundational element, the benefits of a collaborative health care team are difficult to achieve (Golden \& Miller, 2013).

A second challenge derived from the data analysis had to do with the student's schedule after arriving in the rural setting. Some participants had traditional clinic hours of Monday through Friday, while others did not. This made it difficult to interact during 
formal IPE time since many of them were not in the clinic or hospital at the same time. Some of this can be explained through the differing nature of the type of health care educational experiences required for each student. For instance, a medical student may be in a rural clinical setting for a surgical experience that involves evening surgeries, on-call hours, and weekend emergencies. Conversely, a PA student might be in the same rural setting for a pediatrics experience with more traditional "business" hours. Furthermore, these two students might not even be in the same clinic space making it difficult to achieve curricular IPE goals. Participant 16 remarked, "In all honesty it was difficult really getting to know the other students on rotation because of the scheduling differences with my rotation. I only got to interact with them a few times and when we were together it was nice getting to know a little bit about their education and what their profession looks like." This specific challenge stresses the importance of the previously described non-curricular organic interactions as the most meaningful way to connect IPE students.

A third challenge found was the clinical environment did not always reflect a collaborative team-based approach to care. This was highlighted in the Descriptive coding Interprofessional subtheme. Moreover, modeling the benefits of a team-based approach to care in a rural community was a belief described by students. It was clear the desire for a supportive clinical atmosphere was highly valued among the students. "I will be honest, I think that working with a team of interprofessional students sounds like a really neat idea and I wish I had had the chance to spend some time in clinic with students from other professions... the way I experienced it, left something to be desired by way of having interprofessional clinical experiences" wrote Participant 21. 
Additionally, Participant 19 commented, "I think this experience was better for getting to know other types of professionals on a personal level. Although we didn't actually end up working together as students at the clinic frequently..." Without an educational setting that actually demonstrates what a collaborative team does to enhance patient care, students will not attain true IPE (Oandasan et al., 2004; Ponzer et al., 2004)

\section{Conclusion 3: Time spent in a rural IPE experience is useful for}

\section{understanding the challenges and rewards of being a rural health care provider.}

Engaging with rural practicing providers is central to learning what rural life and rural health care is really about. The value of clinical time with preceptors as a way to see how they handled challenges and celebrated the rewards of providing rural care cannot be overstated. For instance, students engaged in rural IPE were able to see how health care providers can make a significant difference in the lives of their patients. To put it another way, through time spent with their preceptors' students were able to get a sense for how they could impact the health of the entire rural community through providing much needed care. Consider Participant 28 wrote, "I love smaller communities because when you want to make a difference, it actually seems to help a lot more than if it were a large town and what you actually accomplished was a rain drop in the ocean. Here it seems to matter more." This supports research that suggests through hearing the narratives of others, students begin to understand what it means to work in a rural community (Deutchman et al., 2012; Fink, 2013; Mu et al., 2004; Tolhurst et al., 2006; Willingham, 2009). 
The rural IPE experience was also useful for exposing students to the challenges of providing care to a rural community. Students reflected on the difficulties inherent to a rural clinical practice through their interactions with their preceptors. For example, students viewed their preceptors wearing multiple different hats during a busy clinic day, which sometimes made it difficult to concentrate on patient care. However, without time spent in the clinic, interacting with the preceptor and experiencing the many different roles they would need to play, this perspective would not have been possible. To take a case in point, Participant 9 remarked, "The beautiful thing about rural medicine is that there are so few providers that they have to work together more cohesively and get to know each other well in order to provide good healthcare for their patients... In the rural setting primary care providers often have a heavier patient load due to understaffing, they also provide a wider range of services due to lack of specialists and they spend so much time and energy tracking down resources. They are stretched really thin" and Participant 23 stated, “... since there were fewer specialists, I felt the primary care providers took on additional responsibilities and had a broader scope." As a result, the student's view of rural health care delivery was shaped through exposure to practicing rural health care providers.

Recognition of this challenge led students to reflect on the importance of having a team of health care professionals to rely on for expertise, collaboration, and support. Moreover, students moved into an understanding of the need for a team to care for a rural community. Consider how Participant 4 reflected, "In a rural setting with limited resources utilizing the skills of your colleagues is critical to providing exceptional patient 
care." This conclusion supports a major aspect of the rural IPE experience; students growing in their understanding of how a collaborative team approach benefits both providers and the rural community (Croker \& Hudson, 2015; Minore \& Boone, 2002; Taylor et al., 2001). Consequently, as student's transition to graduates, they may only be motivated to return to the rural setting if they know they will be part of a collaborative team.

\section{Research Question Three Conclusions}

The factors identified as part of the Q sort analysis represent shared perspectives about rural life, rural IPE, and the motivation for choosing to live in a rural community after graduation. The $\mathrm{Q}$ sort analysis produced factor arrays reflective of the shared perspectives of study participants. It is important to remember these shared perspectives about the topic rarely match any one participant's viewpoint completely. Some of the students landed closer to the shared perspective and other did not. Overall, students either favored or were open to being part of a health care team, living in a rural setting, or both. Of note, no group of participants held the perspective that was positive on team but negative on rural. This specific finding is addressed in the recommendations section later in this chapter.

One thing we can be sure of, the rural IPE experience is useful for understanding rural life. Additionally, a sustained presence coupled together with some kind of community engagement is beneficial to rural IPE. In general, there does seem to be a connection between getting involved in the rural community and the decision to return after graduation. From these overall deductions, three main conclusions arose from the Q 
sort analysis along with the most important and least important factors associated with that conclusion. Each of these conclusions is directly related to the factor arrays and interpretation done in Chapter 4. Specifically, Conclusion 1 is derived from the Factor 1: Team-Oriented Rural Optimists Perspective, Conclusion 2 comes from the Factor 2: Independent Rural Impartial Perspective, and Conclusion 3 results from the Factor 3: Team-Willing Rural Skeptic perspective.

\section{Conclusion 1: Having a rural IPE experience motivates health care} professions' students to return to a rural setting to practice team-based care. Most important factors: Being part of a team, age, type of health care profession, length of time in a rural setting, and approaching care with humility and good intention. Least important factors: Living with other students during the rural IPE experience, limited resources, working as a team on a community project, familiarity with the rural environment, and connection to the community.

A longer period of time in the rural IPE environment is one of the most important factors for the majority of health profession students. Students did not feel their experience was a waste, rather it appeared to help them with decision making about where to live after graduation. They favored a sustained presence in a rural setting to learn all they could about rural life and providing care to the community. Through a longer period of time, they felt accepted and even part of the community itself. The rural IPE experiences aided in the understanding of how they could be part of that community and contribute as a member of the health care team. Specifically, this conclusion reflects literature supporting a sustained presence by a health care professional in a rural setting 
leads to increased retention (Geyman et al., 2000; J. A. Henry et al., 2009;

Rabinowitz et al., 2008; Tolhurst et al., 2006).

Certain health care professions that by nature practice as part of a team, are more likely to have a positive IPE experience. This included PAs whose scope of practice is defined by a team-based relationship with other practicing health care providers. In contrast, health care professions such as physicians and dentists who traditionally practice in solo-provider clinics were less likely to have a positive rural IPE experience. Of note, purposeful structures of the rural IPE experience do not play a major role in student motivation. For example, a community project, living together, and community engagement were not found to be important considerations for the students.

\section{Conclusion 2: Feelings of isolation and geographic remoteness during a rural}

\section{IPE experience decrease the likelihood a graduate will return to a rural setting.}

Most important factors: Being far away from family and friends, natural resources of a rural landscape, length of time in a rural setting, independent learning environment, and familiarity with the rural setting. Least important factors: Working together on a community project, community engagement, team-based approach to care, and health care profession.

For some, the rural IPE experience produced an outlook of separation from the rest of society resulting in a neutral view of living in a rural community. Not having family or close friends nearby may lead some health care profession students to choose practice locations close to those they have existing relationships with. This is consistent with barriers to rural health care provider recruitment and retention described in the 
literature (J. A. Henry et al., 2009; Kazanjian \& Pagliccia, 1996; Mayo \& Mathews, 2006). Community engagement is not perceived as a way to build relational capital; however, spending time in a rural community is considered valuable in making future practice decisions. Even if the end result favors urban or suburban living, the experience students have in a rural community is useful for helping them make future practice decisions.

Contrary to what some might believe, feelings of isolation and remoteness are not diminished through participation as a member of a health care team. Further, working together with other students on shared curricular activities was not viewed as useful for fostering a sense of "teamness" designed to benefit a rural community. The resulting student perspective does very little to support current literature that focuses on the benefits of team-based care to a rural area (Croker \& Hudson, 2015; Minore \& Boone, 2002; Taylor et al., 2001). It is important to note, this perspective was not held by one particular health care profession, rather, it was found in medical, dental, and PA students alike.

\section{Conclusion 3: Having a rural heritage leads to a greater likelihood a student} will return to the rural setting after graduation. Most important factors: Having a first-hand experience in a rural setting, not raising children in a rural setting, location of experience, length of time, and familiarity with the rural setting. Least important factors: Challenges faced by patients, health care profession, recreational activities, clinical environment, and community engagement. 
Students with a rural upbringing understand the benefits and hardships of growing up in such a setting. They can appreciate the advantages of living in a tight-knit community while knowing what struggles are present in rural areas. Undoubtedly, some who are raised in a rural community will move away and not to return. However, it appears those who have a rural heritage are more likely to return than those who do not. It is interesting to note that one of the most important factors was not rearing children in a rural area. Consequently, it can be speculated those who know what it is like to be a child in a rural town are less likely to want to raise their own children there.

The other domain at work here is that of familiarity. Students who are familiar with the challenges faced by rural individuals did not appear to be deterred by facing them as a health care provider. Rather, meeting those challenges and moving past them may actually be a motivating factor. They may have faced similar financial constraints or barriers to health care and learned how to overcome them. This conclusion supports existing research that having familiarity of a rural area is a motivating factor in choosing to live there as a health care provider (Geyman et al., 2000; Hancock et al., 2009; Kazanjian \& Pagliccia, 1996; Mayo \& Mathews, 2006; Owen et al., 2005; Pathman, 1996; Rabinowitz, 1988; Svinicki, 2004; Tolhurst et al., 2006).

In the end, a frame of reference or some kind of familiarity with a rural setting makes it more likely they will choose to return after graduation. This can also work in the opposite direction. A student who does not have good memories of growing up in a rural area similar may deem their experience as an important factor is deciding not to choose that exact area after graduation. Of note, while having an understanding of the natural and 
community resources may be useful, according to this study it was not found to be an important element when making practice location decisions.

\section{Limitations}

A few limitations with this study were noted and will be discussed in this section. Each limitation is stated in italics and then explained in detail. Study limitations are explained in a way that leads to potential suggestions for future educational programs and research. As a result, when possible the limitations are addressed in the subsequent recommendations section.

\section{Participant Reflective Journaling was in an Open Forum}

Study participants entered their on-line journal entries on a discussion board through the universities web-based course management system. Fellow classmates could read other participant's journaling and respond if desired. Thus, some participants may not have felt as comfortable sharing openly knowing their fellow classmates were going to read and potentially respond. This could have led to participants not sharing their true perspectives for fear of offending a fellow classmate who may have felt differently.

Conversely, responding to fellow classmates may have actually enhanced the depth of the journaling. I saw participants responding to each other with phrases like, "that is a really good point" or "I appreciate that perspective." In this way, participants may not have thought of certain aspects of their experience and by reading how others responded may have made them aware of thoughts or feelings they had not considered. Additionally, participants might have felt more open to share about a negative experience if they read about a similar experience from a fellow student. Perhaps this lead to 
participant's expressing their thoughts and opinions knowing others were doing the same thing.

\section{Q Statement Development}

The Q statements used in this study were derived from my own understanding of rural IPE literature and my interpretation of previous health care professions' student journaling. As a result, the Q statements used in this study have the potential to be biased by my own beliefs of rural life, rural IPE, and team-based care delivery. In general, using a standardized set of Q statements is not recommended (Webler et al., 2009). However, despite the use of structured and unstructured methods for Q statement development described in Chapter 3, there is potential I did not have the most diverse set of $Q$ statements representative of the wide perspectives of rural living, rural IPE, and teambased care delivery.

\section{Potential for Qualitative Coding Bias}

When coding the participant journals I would sometimes need to choose between a values code that might be viewed as both a belief and a value. For instance, if a participant journal entry stated, "I was able to be a part of the standard of care and help set that bar: be a larger drop of water in the ocean." I had to choose between a belief code of "Engagement makes an impact" or a value code of "Making a difference." In order to aid in the quandary, I needed to remind myself of the goals of this study along with the research questions I was seeking to answer. This recalibration helped me make the decision of how to code when faced with this dilemma. 
My experience as a health care provider had the potential to bias how I was interpreting and coding the qualitative data as well. As previously discussed, I hold a favorable view of rural life through several rural-based experiences as a child. These views combined with my experience in IPE as one of the health care professions involved in this study, may have led to a more positive interpretation or code given to participant data. However, Cameron (2014) suggests variations within interpretation of qualitative data are unavoidable and a natural consequence of the knowledge, background, and expertise of the researcher. In the end, as long as these variations are acknowledged and taken into consideration when interpreting that data, valuable conclusions can still result (Cameron, 2014).

As described in Chapter 3, member checking was done with my study conclusions. PA student participants were asked to review the study conclusions to see if they reflected their general perspective. While this aided in the protection against researcher bias, no other health care professions' were used in member checking. Thus, the study conclusions are subject to researcher bias from my perspective as a health care provider, health care educator, and participants from my own health care profession.

\section{No Demographic Data Collected for Research Questions One and Two}

Another limitation was the lack of demographic data collection as part of the reflective journaling. I did not collect demographic data like I had with the Q sort. Therefore, I was not able to correlate participant journaling to a health care profession, age, rural heritage, marital status, children, or gender. For instance, correlating the warm, cold, or neutral themes to a participant's upbringing would have given me insight into 
how the dimension of familiarity plays a role in forming perspectives of rural life or team-based care.

I was able to connect the location of the rural IPE experience to each participant's reflective journal based on the location of the Research Assistant who collected the data. Additionally, some participants volunteered their health care profession of study in the midst of their journaling. When possible, these demographic data were used during the journaling analysis.

\section{No Educational Sequence Data Collected}

I did not collect data related to when in the sequence of the participant's education the rural IPE experience actually occurred. Stated another way, when data collection took place I did not know if the participant was one month away from graduating or 10 months away. It can be speculated that if a participant were near the end of their training they might have had a different perspective than if that same participant was completing the Q sort or reflective journaling early in their training.

\section{No Coordination Between Qualitative and Quantitative Participants}

As previously stated, it was assumed a certain number of participants supplied both qualitative and quantitative data. However, there was no formal correlation between what was gathered as part of the reflective journaling and the Q sort. As a result, I could not analyze how a participant sorted Q statements with how that same participant reflected on similar topics through their journaling.

This was simply a missed opportunity and an oversight on my part. The correlational data would have provided understanding into how participant's perspectives 
on team-based care and rural life was reflected in both the journaling and the Q sort. Furthermore, it may have produced similarities or potential differences in the participant's perspectives, which would shed light on the validity of the data collection methods used. For instance, a participant whose Q sort reflected factors positive of a rural community and journaling contained statements placing a high value on rural life, strengthens the validity that both data collection methods are capturing the same thing.

\section{Limited Variation of Health Care Professions}

As previously stated, over the 6 months of data collection, a total of 63 health care professions' students spent time in the OHSU Campus for Rural Health. As a result, I was limited to the health care professions contained within that group of 63 students. Unfortunately, this group only contained four out of the possible six health care professions in the Campus for Rural Health. Thus, I was not able to collected data from nursing or public health. With these limitations, I was not able to analyze how a nursing or public health student felt about rural life or team-based care. These are important professions as they bring valuable perspectives outside of the traditional health care provider role found in most health care setting, rural or urban.

\section{Participant Selection Bias}

Another limitation to my study is how participants were selected to have a rural IPE experience in the first place. Some participants volunteered to go and others were not given the choice but were assigned to do a rural IPE experience as part of their education. This has the potential to create a selection bias with those who volunteered to go and those who did not. For example, some participants may have chosen to do the rural IPE 
experience because they were already interested in rural living. These participants could have already favored rural life and were planning to live in a rural setting after graduation. Thus, the rural IPE experience may have had very little to do with changing their perspective about rural living.

Conversely, students who were assigned a rural IPE experience without any interest in going might have brought a negative perspective to the data, potentially producing a bias against rural life or team-based care. This bias may have had nothing to do with the constructs of IPE or even a team-based approach but with the student's perceived prejudice against a rural setting. Therefore, not knowing a student's reason for being part of a rural IPE experience in the first place limits the amount of credit given to the rural IPE experience with motivating them to return after graduation.

\section{Recommendations}

The recommendations from this study are generated from a combination of data analysis, conclusions, and limitations. Specifically, many of the recommendations in this section address the limitations identified in this study. However, some recommendations address concerns identified in the data analysis and interpretation. Further, certain recommendations represent logical next steps in the continued investigation of a rural IPE experience. In order to draw a clear connection to the reason behind the recommendation, each one begins with a statement of where it stemmed from. The recommendations are divided into two categories: educational and research. Educational recommendations speak to what approaches health care educators can take when designing future rural IPE 
experiences. Research recommendations address specific methodological changes to be made with future study of rural IPE.

\section{Educational Recommendations}

The educational recommendations in this section are listed in order of importance.

All of the educational recommendations are significant; however, certain recommendations are felt to have a higher impact on IPE, rural IPE, and the pedagogy surrounding health care education. Therefore, the education recommendations start with the most important and move to the least important.

Recommendation 1: Support non-curricular IPE learning opportunities. As previously noted in this chapter, students highly valued the organic interactions outside of formal curricular time as a major contributor to achieving the goals of IPE. However, some curricular structure is needed when attempting to increase motivation for rural living through IPE (Chen et al., 2010). The literature also stresses the importance of a supportive team-based clinical space is central to IPE curriculum (Croker \& Hudson, 2015). As previously noted, there is a gap in the literature describing the significance of informal IPE time to developing student understanding of team and similarly rural life.

Therefore, I recommend future rural IPE experiences contain purposeful nonclinical IPE that includes down time, shared living space, and community engagement activities. The rural setting provides the unique opportunity to house students together and provide non-curricular time for social IPE to take place. Students are often looking for opportunities to engage with fellow classmates and the community around them in order to push against feelings of isolation that are sometimes present with a rural 
educational experience. In a setting where the clinical environment is difficult to control, supporting the learning that exists outside of the clinic is central to successful rural IPE.

\section{Recommendation 2: Conduct IPE experiences in hospitals and clinics where}

collaborative team-based practice is modeled. As described in the values coding Challenges theme, participants expressed the paucity of IPE in the clinical setting and suggested the goals and objectives of IPE were actually accomplished outside of the clinical realm. The push for IPE to move into the field necessitates clinics and hospitals practice the collaborative team-based approach educators are seeking. Without the environment to support IPE, students are less likely to learn the valuable roles they and others can play as part of a health care team (Croker \& Hudson, 2015).

As discussed the previous recommendation, the importance of non-clinical and non-curricular time for students is an important factor in IPE. However, the significance of an atmosphere where health care team members practice what they are teaching cannot be overstated. This concurs with Ponzer et al. (2004) and Smith et al. (2005) who contended the quality of the clinical environment and those who serve in preceptor roles are one of the most important elements in IPE. Consequently, the need for a collaborative team-based clinical environment to serve as a role model and support student learning is an essential component of achieving the goals and objectives of IPE.

Recommendation 3: Conduct formal urban IPE experiences. As noted in the introductory section of the research question three conclusions, I did not identify a shared perspective that was positive on team but negative on rural. It can be speculated this is 
because I did not have any groups in my study who were part of an urban IPE cohort. To put it another way, participants' negativity for rural pulled down their affinity for team. Because they were not motivated to live in a rural area, they were not as motivated to practice team-based care. Hence, if I had a comparable urban IPE cohort to include in the study, I might see their team affinity be stronger because they are more positive about the setting in which the IPE takes place.

As it stands now, the only formal clinically based IPE component for students at the university is in a rural setting. Rural clinics and hospitals are not the only places team-based practice occurs. In fact, urban hospitals have been described as a suitable place for IPE (Ponzer et al., 2004). Using an urban IPE experience for students may actually expose them to how a team can function in a high-need setting regardless of geographic location. This approach would elevate the benefits of a team-based approach to care described in the literature (Golden \& Miller, 2013; Oandasan et al., 2004). Moreover, students who experience both rural and urban IPE would have the opportunity to see how team-based practice is delivered in a variety of settings. This will further inform their decision of where to live and provide care after graduation.

\section{Recommendation 4: Group IPE cohorts according to clinical rotation type.}

The above recommendation cited the challenges identified in both the journal coding and the conclusions section. Specifically, student schedules while doing various rural clinical experiences was described by study participants. It is important to note that the need for diverse clinical experiences in the rural setting is an essential aspect to a well-rounded rural IPE experience. Students need to spend time with rural primary care providers, 
general surgeons, dentists, social workers, pharmacists, and emergency room personnel. However, these different health care professionals often have varying schedules meaning students assigned to these disciplines have difficulty finding common times to interact.

Linked to the previous recommendation, I propose the IPE cohorts be grouped together according to clinical rotation type. This will still allow multiple health care professions to be in the same cohort, but will provide the opportunity for a student who is doing shift-work in the Emergency Department to interact with a student with nontraditional hours while on a general surgery rotation. Accounting for different daily schedules allows students to interact in non-clinical ways and supports the overall IPE goals outlined by Oandasan et al. (2004); team members discussing and negotiating each other's roles, gained trust of one's own competence and the competence of others, and respecting the unique contribution of the other team members.

\section{Recommendation 5: Develop a common IPE experience calendar. As}

discussed in the research questions one and two conclusion section, noted barriers to accomplishing IPE exist in the rural clinical setting. Through my journaling analysis, the Challenge theme highlighted the issue of not having a consistent group of students to accomplish curricular goals and objectives. Attempts at bringing together all programs and schools at OHSU into one unified academic calendar have been tried. Unfortunately curricular redesign and the specific needs of each program of study have gotten in the way. 
Thus, I recommend the rural IPE experience contain unified start and stop times for participating programs and schools. Health care educators could actually fill in offsetting days or weeks with rural IPE activities designed to prepare students for the rural IPE experience. Specifically, this supports research done by Deutchman et al. (2012) that outlined the importance of preparatory work on the part of the student in creating a meaningful rural IPE experience. Ensuring all students are arriving and departing at the same time will build a consistent IPE cohort where shared work and trust can flourish.

\section{Recommendation 6: Conduct reflective journaling in a closed forum. As}

discussed in the study limitations, students wrote their journals on an open forum via the university course management system. Therefore, next time I would have all the participants' journal either anonymously or not share their journaling with classmates. This would provide consistency for all participants and may actually increase the depth of sharing. Furthermore, this approach removes potential barriers to the transformative process that reflection brings and sets the study up for the best chance of success (Jensen \& Royeen, 2002). This may result in participants feeling open to express thoughts or feelings they would otherwise not share. Providing a safe space for students to reflect on their experiences would enable them to compare the various settings where they have worked, discuss community issues, and brainstorm about solving problems they have encountered (McNair et al., 2005). 


\section{Research Recommendations}

Recommendation 1: Conduct a one-way structured $\mathbf{Q}$ sort. As explored in the conclusions section of this chapter, several suppositions were derived from the analysis. A suitable approach to test those conclusions would be to administer a one-way structured Q sort in a future rural IPE study. A one-way structured Q sort specifically tests individual theories or conclusions generated from previous research (Kerlinger, 1986). First, an equal number of Q sort statements are chosen from the major categories or tenants of the conclusion in question. Then, participants are selected to specifically represent the major categories of the conclusion. If the conclusion is valid, the participant's Q sort will be in-line with the conclusion in question. In other words, the participants sort the statements according to their expected values.

For example, if I wanted to test my conclusion that having a rural IPE experience motivates health care professions' students to return to a rural setting to practice teambased care, I would use a one-way structured Q sort to help validate this hypothesis. In this case I may want to focus in on the health care profession as the central aspect to this conclusion. Thus, I would write the Q statements specifically to represent the different health care professions' values as a motivating factor for returning to a rural setting.

The Q sort would contain five statements representing nursing values, five statements representing pharmacy values, five statements representing medicine values, and so on. Therefore, when selecting participants for the study, it would be important to have representatives of all health care professions found in the hypothesis. This underscores the importance of having the full variety of participants is essential to 
validating the conclusion in question. As previously discussed, only three health care professions were part of the Q sort; thus, not representing a complete picture of all students in the OHSU Campus for Rural Health. Further, this approach was not used because I did not have an existing theory or hypothesis from prior research to test in my study.

\section{Recommendation 2: Include equal numbers of health care professions'}

participants. As previously stated in the limitations section, not all of the health care professions' that have a rural IPE experience in the OHSU Campus for Rural Health were represented in my study. As a result, I recommend future rural IPE research include as many different health care professions' perspectives as possible. Additionally, in order to achieve research recommendation one, more health care professions are needed to test conclusions related to specific perspectives of the different health care professions.

Research analysis would therefore focus on connecting outcomes to the value system of each health care profession and correlating that back to the conclusion or hypothesis being tested. This manner of analysis stresses the importance of having participants with known attitudes or roles to perform the Q sort (Kerlinger, 1986). Thus, participant sampling would need to ensure health care profession students from a wide variety of roles and approaches are represented. Specifically for my study, data collection would need to be extended until participant representation included an equal number of all six health care professions at the OHSU Campus for Rural Health.

\section{Recommendation 3: Compare the results of this study with the results of}

future similar studies. The limitations section of this study described several areas for 
potential bias. One approach to address potential researcher bias is to compare my results to the results of future rural IPE research. For example, using the arrays from my study as a basis for comparing future rural IPE Q sort arrays helps increase the trustworthiness of hypotheses and theories born out of rural IPE research. Sexton et al. (1998) suggested comparing Q sort results at different points in time with different cohorts looking for similarities increases reliability. Furthermore, correlating the Q sorts of new rural IPE participants can aid in the study of "attitude, value, belief, and perception (or judgment) change" (Kerlinger, 1986, p. 517). This type of comparison aids in the understanding of how perceptions of health professions' students vary from year to year, location to location, or even university to university. Additionally, by comparing my research to that of future similar studies, decreases the influence of any potential bias introduced in this study.

Recommendation 4: Conduct pre- and post-experience $Q$ sorts. In the limitations section, it was noted there was no demographic data collected on when in the student's education the rural IPE experience took place. Moreover, the research question three analysis section contained a conclusion that prior rural experiences influences future practice location. One approach to analyze in what way prior experience impacts current learning involves the use of pre and post-experience Q sorting. Therefore, I recommend expanding the Q sort beyond just the post rural IPE experience timeframe.

A noted strength of Q methodology is the ability to study the complexities of the participant perspectives through objectively measuring subjectivity. In order to dive deeper into this analysis I would have students complete the Q sort before and after the 
rural IPE experience. This would allow for specific exploration of attitudinal modification of the student as it relates to the rural IPE program (Kerlinger, 1986). Specifically in my study, many of the participants did not have a rural upbringing. Thus, is would be useful to capture the potential change in perception of what it means to live and work in a rural community for these students. This would draw particular attention on the impact of a rural IPE experience as a motivating factor.

\section{Recommendation 5: Collect additional demographic data on all participants.}

As described in the limitations section, no demographic data were collected for the reflective journaling participants. As a result, I recommend future rural IPE research gather similar demographic data on each participant and expand the type of demographic data collected. This would increase the understanding beyond how participant characteristics impact factors when making practice decisions to include analyzing how those characteristics influence descriptions, values, attitudes, and beliefs about rural IPE.

As noted in the limitation section, no demographic data were collected on how far along each participant was in their education. Therefore, I recommend gathering information such as how close a student is to graduation, how long their rural IPE experience was, and what institution they are enrolled in. This would shed light on other elements that play into motivation level for choosing rural or not. For example, correlating an individual's Q sort to the type of academic institution could provide useful information on how a particular university's rural mission plays out in the lives of its students. 
Furthermore, collecting information on when in the sequence of their education the rural IPE experience occurred — knowing if it is early or late in their education-would give insight into what perspectives they might have about team-based care. For instance, a student that has already had 7 months of clinical training with different health care teams may have a more positive perspective than a student who is doing a rural IPE experience early in their training without any previous exposure to team-based practice. Thus, knowing how far along a student is in their education will help researchers take into account previous health care education exposure. Additionally, if a student is just weeks away from graduating and they spent the last three months in rural IPE, how they reflect on their experience may vary from a student who is several months away from graduation. Analyzing those participants who fell into a particular factor may be easier since I would know if other elements such as nearness to graduation or pressure to find a job are influencing their decision of where to practice.

Recommendation 6: Collect qualitative data during the $\mathbf{Q}$ sort. As noted in the introductory section of the research question three conclusions, the shared perspectives produced from the Q sort analysis seldom match any one participant's viewpoint exactly. In order to gather insight into how individual participant perspectives guide the completion of a Q sort, I recommend future research include logging participant comments as they perform the Q sort. To accomplish this, either the Research Assistant or I would be present during the Q sort to encourage participants to verbalize their thinking as they sort the Q statements. Recording participant thoughts, insights, and 
perspectives on rural life, IPE, and team-based care would yield valuable contextual information as well as participant opinions of the Q statements themselves.

Webler et al. (2009) suggested using participant comments made during the Q sort to aid in the understanding of "why people who load on a certain factor placed a certain statement where they did" (p. 33). For instance, knowing why a PA student ranked a purely team-based statement very high but a rural team-based statement much lower would give insight into their perspective of health care delivery in a rural setting. Furthermore, understanding how participants interpret the Q statements in relation to other statements in the context of the environment under study is an important consideration when describing participant perspectives (Webler et al., 2009).

Gathering participant comments during the Q sort can help guard against researcher bias during the factor analysis. Applying participant comments to the Q sort interpretation keeps the factor interpretation away from simply re-creating what the researcher believes is true and more on the participant's perspective (Webler et al., 2009). In the end, collecting additional qualitative data during the Q sort would shed light on the multiple components that motivate a decision of where to live and provide care.

\section{Recommendation 7: Correlate participant journaling and the $\mathbf{Q}$ sort. As}

noted in the limitations section, the participant journaling was not linked to the same participant's Q sort. Correlating the participant Q sorts to their reflective journaling is another recommendation for future research. As described in Chapter 4, reflective journaling gave valuable insight into the students' thoughts, feeling, and emotions of the rural IPE experience. Linking the same participant data to their completed Q sort would 
aid in the understanding of why they sorted Q statements the way they did or conversely, why they described a belief or value in a particular way.

Pruslow and Owl (2012) suggested the value of assessing shared perspectives comes from looking at how students interpreted factors in a Q sort in light of their experiential learning reflections. In other words, linking the data gathered from a reflective journal to the completed Q sort is invaluable to understanding the complexities of individual perspectives. This leads the student to a deeper level of engagement as completing the Q sort requires students to interpret their thoughts and feelings generated from the field experience as recorded in the journal (Pruslow \& Owl, 2012). Thus, linking the qualitative and the quantitative on the same participant becomes an essential next step in future rural IPE research.

\section{Model IPE Program}

At this point in the dissertation an obvious question to ask is, so what do we do based on the information gathered, studied, and interpreted? Centered on my recommendations, I suggest this is where the results might lead us: The creation of an experiential IPE program designed to provide rural and urban team-based health care training with a purposeful curriculum intended to prepare and motivate students to return to these settings after graduation.

There is no doubt that rural health care training is a worthwhile endeavor and the clinical setting can provide the ideal place for IPE. However, a framework that allows for flexibility, creativity, and collaboration is the foundational. The three different perspectives defined as part of the Q sort, helped me understand that students are 
generally in favor of rural life and team-based care or at the very least open to it. For example, each perspective included language reflecting a willingness or optimism toward the rural setting and team-based care. For some, this experience is only the beginning to considering how living and providing care to a rural community might be the place for them. However, my model begins with interprofessional students in both the rural and urban clinical setting. As a result, the following five pillars form the framework for an ideal experiential IPE program.

\section{Pillar 1}

\section{Interprofessional students from different backgrounds with different career}

\section{goals, divided up into clinical rotation type cohorts with the same start and stop}

times. First, students need to be from different health care professions for this to be IPE.

Second, I suggest students who are from both rural and urban backgrounds - some with an interest in rural and urban care, others without. This gives the opportunity to expose some students to rural and urban care, while also allowing the student with prior experience in these settings to solidify their resolve to return after graduation. Students should be divided up into rotation type to allow for students with similar clinical schedules to engage in IPE both inside and outside the clinic. For instance, all students who are on a surgical rotation would be grouped together separate from students doing primary care experiences to provide for IPE that might be dependent on student schedule. Lastly, in order to minimize the disruption to the cohorts, students within these rotation type groups would have the same start and stop times of their IPE experience. 


\section{Pillar 2}

\section{Minimum of 4-week clinical experiences in settings that practice}

collaborative team-based care. Length of time spent in these settings does matter.

Therefore, a minimum of 4 weeks to allow for a sustained presence in the community is needed. Students should only be sent to clinical environments where team-based care is actively practiced. This will require some clinics to undergo some level of practice transformation in order to become eligible to host cohorts of interprofessional students. The need for collaborative team-based modeling and the student mentoring that comes from this type of setting is of upmost importance.

\section{Pillar 3}

Conduct clinical and social IPE. Following closely with Pillar 2, IPE must take place in and outside of the clinic itself. When engaged in clinical training, interprofessional students should be learning how to care for patients in the midst of a practicing healthcare team. In order for students to understand what collaborative teambased care delivery is all about, they need to be involved as it is happening. Additionally, the need for interprofessional students to interact in less formal social settings is essential to IPE. Learning from, with, and about other health care professionals is often done through organic conversations over a meal or on a bike ride. To this end, the cohorts of students must live together. Interacting with students from other professions in the nonclinical environment sets the stage for social IPE. 


\section{Pillar 4}

Provide opportunities for community and environmental engagement. It is

clear interacting with the community itself is a central component to experiential IPE. Moreover, allowing time for students to get out and experience the natural environment is also needed. Therefore, my ideal IPE program builds in time for students to go on a hike together, meet with community members, and fully understand the place they are considering calling home.

\section{Pillar 5}

Allow time for inter- and post-experience reflection. Finally, I would require students to write down what they are seeing, learning, and experiencing through dedicated reflective journaling times each day or week. This would be done individually and not for other students, mentors, or educators to see. Students could share their reflections with others if they choose, but at the very least, it gets the students to think about what this experience means for them. The process of reflecting on the impact of rural or urban IPE may be the most effective tool in motivating them to return.

\section{Dissertation Summary}

This dissertation set out to explore health care professions' student perspectives of a rural IPE experience at two locations in the state of Oregon. Students assigned to the OHSU Campus for Rural Health in Coos Bay or Klamath Falls voluntarily consented to be part of the study to further understand what motivates them to make future practice location decisions. A mixed method study design was employed to answer the following three research questions: 
1. How does working with an interprofessional team shape student views on future work with people in those professions?

2. How does the rural IPE experience influence a student's perspective on working in a rural setting?

3. What factors do students participating in a rural IPE experience consider most important and least important in making a decision to practice team-based care in a rural setting?

Data from two main sources were collected to answer the research questions for this study. Research questions one and two utilized qualitative data from student reflective journaling completed during their rural IPE experience. Research question three used quantitative data from a post-experience Q sort. The theoretical lens of Motivation Theory was applied to explore how a student's perspective of a rural IPE experience could motivate them to return or not return to the rural setting to live and provide care. My data analysis set out to understand student perspectives, while at the same time learning about how those views are shaped by experiences before and during rural IPE. Therefore, the end result provided the opportunity to discuss, relate, and produce enlightenments to living in a rural setting and providing team-based care to a rural community.

The use of descriptive and values coding helped me define the participant's motivation or philosophy for rural living and team-based health care delivery (Saldaña, 2013). Specifically, understanding how a participant reflected on a rural community and how those thoughts lead to actions, aided in the understanding of why rural health care providers move to or out of a rural setting. The attitudes and beliefs of the participants gathered through the reflective journals brought an understanding of student perspectives about rural communities and the practice of team-based care. To put it another way, 
participants each brought with them their description of what it meant to be a health care provider in a rural town. However, qualitative analysis alone provided only partial understanding. As a result, Q methodology set out to study participant subjectivity in an objective way.

Q methodology helped students who may profess uncertainty about particular topic areas to think introspectively about their thoughts and feelings regarding teambased collaborative practice and rural life. Moreover, it encouraged participants to articulate their thoughts, feelings, and emotions about rural IPE even though they may not have been able to journal a well-crafted response to a set of prompts. Q sort analysis gave me information about representative patterns that emerged out of the participant's perspectives in the form of factor arrays. These arrays represented significant associations between viewpoints from participant to participant. In the end, the shared perspectives reflected "inter-subjective orderings of beliefs that are shared among people" (Webler et al., 2009, p. 8). Ultimately, the Q sort analysis revealed how the elements of a rural experience and team-based care delivery impact student perspectives of rural life and rural care and what elements were most important and least important in shaping their outlook.

In conclusion, the theoretical framework of how motivation plays a role into the decision of where a health care provider lives and works also aided in the understanding of the effects of a rural IPE experience. Viewing student perspectives of rural IPE through the theoretical lens of motivation has an impact on how and where future health care professions' students are educated. The data gathered from this study helped inform 
educators, students, health care providers, patients, and community members about a rural IPE program and how it affected the thoughts, attitudes, and beliefs of those who experienced it. 


\section{REFERENCES}

Affordable Care Act of 2010 (The Patient Protection and Affordable Care Act), Pub. L. No. 111-148, 124 Stat. 119 (2010).

Anderson, D. M., \& Hampton, M. B. (1999). Rural health policy: Physician Assistants and Nurse Practitioners: Rural urban settings and reimbursement for services. The Journal of Rural Health, 15(2), 252-263.

Arnold, L., Shue, C. K., \& Jones, D. (2002). Implementation of geriatric education into the first and second years of a baccalaureate: MD degree program. Academic Medicine, 77(9), 933-934.

Atkinson, J. W. (1966). An introduction to motivation. Princeton, NJ: D. Van Nostrand Company.

Babbie, E. R. (1995). The practice of social research ( $7^{\text {th }}$ ed.). Belmont, CA: Wadsworth Publishing Company.

Bailey, J. (2013). Making health insurance affordable: Assistance to individuals and families in the Affordable Care Act. Retrieved from http://www.cfra.org/node/4733

Baldwin, D. C. (2007). Some historical notes on interdisciplinary and interprofessional education and practice in health care in the USA. Journal of Interprofessional Care, 21(S1), 23-37. doi:10.1080/13561820701594728

Baldwin, K. A., Sisk, R. J., Watts, P., McCubbin, J., Brockschmidt, B., \& Marion, L. N. (1998). Acceptance of nurse practitioners and physician assistants in meeting the perceived needs of rural communities. Public Health Nursing, 15(6), 389-397.

Bell, M. M. (1992). The fruit of difference: The rural-urban continuum as a system of identity. Rural Sociology, 57(1), 65-82.

Bradshaw, M., \& Lowenstein, A. (2013). Innovative teaching strategies in nursing and related health professions. Burlington, MA: Jones \& Bartlett.

Brown, S. R. (1993). A primer on Q methodology. Operant subjectivity, 16(3/4), 91-138.

Brown, S. R. (2006). Modern perspectives on JR Kantor and interbehaviorism. Reno, NV: Context Press.

Cameron, D. (2014). Working with spoken discourse. Thousand Oaks, CA: Sage. 
Cawley, J. F., Lane, S., Smith, N., \& Bush, E. (2016). Physician assistants in rural communities. Journal of the American Academy of Physician Assistants, 29(1), $42-45$.

Centre for the Advancement of Interprofessional Education. (1997). Interprofessional education: A definition. CAIPE Bulletin, 13, 19.

Chantrill, C. (2014). Government spending pie chart. Retrieved from http://www. usgovernmentspending.com/year_spending_2015USbt_16bs2n_10\#usgs302

Chen, F., Fordyce, M., Andes, S., \& Hart, L. G. (2010). Which medical schools produce rural physicians? A 15-year update. Academic Medicine, 85(4), 594-598. doi:10.1097/ACM.0b013e3181d280e9

Clark, P. B., \& Wilson, J. Q. (1961). Incentive systems: A theory of organizations. Administrative Science Quarterly, 6(2), 129-166.

Comrey, A. L., \& Lee, H. B. (1992). A first course in factor analysis (2 ${ }^{\text {nd }}$ ed.). London, England: Psychology Press.

Connell, J. (2011). A new inequality? Privatisation, urban bias, migration and medical tourism. Asia Pacific Viewpoint, 52(3), 260-271.

Corbridge, S., \& Jones, G. A. (2004). The continuing debate about urban bias: The thesis, its critics, its influence, and implications for poverty reduction. London England: London School of Economics and Political Science, Department of Geography and Environment.

Cottingham, A. H., Suchman, A. L., Litzelman, D. K., Frankel, R. M., Mossbarger, D. L., Williamson, P. R., \& Inui, T. S. (2008). Enhancing the informal curriculum of a medical school: A case study in organizational culture change. Journal of General Internal Medicine, 23(6), 715-722.

Council on Graduate Medical Education. (1998). Tenth report: Physician distribution and health care challenges in rural and inner-city areas. Washington DC: U.S. Department of Health and Human Services.

Crandall, M., \& Weber, B. (2005). Defining rural Oregon: An exploration (Working Paper). Retrieved from http://ir.library.oregonstate.edu/xmlui/handle/1957/9262

Creswell, J. (2009). Research design: Qualitative, quantitative, and mixed methods approaches. Thousand Oaks, CA: Sage.

Croker, A., \& Hudson, J. N. (2015). Interprofessional education: Does recent literature from rural settings offer insights into what really matters? Medical Education, 49(9), 880-887. 
Cross, C. T. (2014). Political education: Setting the course for state and federal policy. New York, NY: Teachers College Press.

Deutchman, M. E., Nearing, K., Baumgarten, B., \& Westfall, J. M. (2012). Interdisciplinary rural immersion week. Rural and Remote Health, Retrieved from http://www.rrh.org.au

Fink, L. D. (2013). Creating significant learning experiences: An integrated approach to designing college courses. San Francisco, CA: Jossey-Bass.

Fowler, F. C. (2013). Policy studies for educational leaders: An introduction. Upper Saddle River, NJ: Pearson.

Gazewood, J. D., Rollins, L. K., \& Galazka, S. S. (2006). Beyond the horizon: The role of academic health centers in improving the health of rural communities. Academic Medicine, 81(9), 793-797.

Geyman, J. P., Hart, L. G., Norris, T. E., Coombs, J. B., \& Lishner, D. M. (2000). Educating generalist physicians for rural practice: How are we doing? The Journal of Rural Health, 16(1), 56-80. doi:10.1111/j.1748-0361.2000.tb00436.x

Glendinning, A., Nuttall, M., Hendry, L., Kloep, M., \& Wood, S. (2003). Rural communities and well-being: A good place to grow up? The Sociological Review, 51(1), 129-156.

Glesne, C. (2016). Becoming qualitative researchers: An introduction ( $5^{\text {th }}$ ed.). Upper Saddle River, NJ: Pearson.

Goins, R. T., Williams, K. A., Carter, M. W., Spencer, S. M., \& Solovieva, T. (2005). Perceived barriers to health care access among rural older adults: A qualitative study. The Journal of Rural Health, 21(3), 206-213. doi:10.1111/j.17480361.2005.tb00084.x

Golden, A., \& Miller, K. P. (2013). Championing truly collaborative team-based care. Annals of Internal Medicine, 159(9), 640-642.

Guthrie, J. W. (2002). Education policy, United States. In J. W. Guthrie (Ed.): Encyclopedia of education (pp. 668-676). New York, NY: MacMillan.

Hackert, C, \& Braehler, G. (2007) Flash Q [Computer software]. Retrieved from http://www.hackert.biz/flashq/home/

Hallin, K., Kiessling, A., Waldner, A., \& Henriksson, P. (2009). Active interprofessional education in a patient based setting increases perceived collaborative and professional competence. Medical Teacher, 31(2), 151-157.

doi:10.1080/01421590802216258 
Hammick, M., Freeth, D., Koppel, I., Reeves, S., \& Barr, H. (2007). A best evidence systematic review of interprofessional education: BEME Guide no. 9. Medical Teacher, 29(8), 735-751. doi:10.1080/01421590701682576

Hancock, C., Steinbach, A., Nesbitt, T. S., Adler, S. R., \& Auerswald, C. L. (2009). Why doctors choose small towns: A developmental model of rural physician recruitment and retention. Social Science and Medicine, 69(9), 1368-1376.

Hart, L. G., Salsberg, E., Phillips, D. M., \& Lishner, D. M. (2002). Rural health care providers in the United States. The Journal of Rural Health, 18(5), 211-231.

Heisenberg, W. (1962). Physics and philosophy: The revolution in modern science. New York, NY: Harper \& Row.

Henry, J. A., Edwards, B. J., \& Crotty, B. (2009) Why do medical graduates choose rural careers? Rural and Remote Health, 9, 1083. Retrieved from http://www.rrh.org.au.proxy.lib.pdx.edu

Henry, L. R., \& Hooker, R. S. (2007). Retention of physician assistants in rural health clinics. The Journal of Rural Health, 23(3), 207-214.

Hodges, B. D. (2014). When I say . . c critical theory. Medical Education, 48(11), 10431044. doi:10.1111/medu. 12474

Howell, T. (2014). Health care spending expected to pick up, grab bigger share of GDP. The Washington Times. Retrieved from http://www.washingtontimes.com/news/ 2014/sep/3/health-care-spending-expected-spike-coming-years/

Huish, R. (2013). Where no doctor has gone before: Cuba's place in the global health landscape. Waterloo, Ontario, Canada: Wilfrid Laurier University Press.

Illing, J. C., \& Crampton, P. E. (2015). Collaborative relationships and learning in rural communities. Medical Education, 48(9), 850-858. doi:10.1111/medu12784

Jensen, G. M., \& Royeen, C. B. (2002). Improved rural access to care: Dimensions of best practice. Journal of Interprofessional Care, 16(2), 117-128.

doi:10.1080/13561820220124139

Jones, A. R., Oster, R. A., Pederson, L. L., Davis, M. K., \& Blumenthal, D. S. (2000). Influence of a rural primary care clerkship on medical students' intentions to practice in a rural community. The Journal of Rural Health, 16(2), 155-161. doi:10.1111/j.1748-0361.2000.tb00449.x

Kaiser Commission on Medicaid and the Uninsured. (2003). The uninsured in rural America. Retrieved from https://kaiserfamilyfoundation.files.wordpress.com/ 2013/01/the-uninsured-in-rural-america-update-pdf.pdf 
Kazanjian, A., \& Pagliccia, N. (1996). Key factors in physicians' choice of practice location: Findings from a survey of practitioners and their spouses. Health and Place, 2(1), 27-34.

Kerlinger, F. N. (1986). Foundations of behavioral research (3rd ed.). Orlando, FL: Holt, Rinehart and Winston.

Krathwohl, D. R. (2009). Methods of educational and social science research: The logic of methods (3rd ed.). Lake Grove, IL: Waveland Press.

Levine, H. M., \& McEwan, P. J. (2001). Cost effectiveness analysis ( $2^{\text {nd }}$ ed.). Thousand Oaks, CA: Sage.

Lindsay, S. (2007). Gender differences in rural and urban practice location among midlevel health care providers. The Journal of Rural Health, 23(1), 72-76.

Lipton, M. (1977). Why poor people stay poor: A study of urban bias in world development. London, England: Temple Smith.

Lowi, T. J., \& Ginsberg, B. (1994). American government (brief $3^{\text {rd }}$ ed.). New York, NY: Norton.

Marion, R., \& Gonzales L. D. (2014). Leadership in education: Organizational theory for the practitioner (2nd ed.). Long Grove, IL: Waveland Press.

Maslow, A. H. (1943). A theory of human motivation. Psychological Review, 50(4), 370396.

Maxwell, J. A. (2013). Qualitative research design: An interactive approach ( $\left.{ }^{\text {rd }} \mathrm{ed}.\right)$. Thousand Oaks, CA: Sage.

Mayo, E., \& Mathews, M. (2006). Spousal perspectives on factors influencing recruitment and retention of rural family physicians. Ottawa, ON, Canada: Society of Rural Physicians of Canada.

McKeown, B., \& Thomas, D. B. (2013). Q methodology (Vol. 66). Thousand Oaks, CA: Sage.

McNair, R., Stone, N., Sims, J., \& Curtis, C. (2005). Australian evidence for interprofessional education contributing to effective teamwork preparation and interest in rural practice. Journal of Interprofessional Care, 19(6), 579-594.

Minore, B., \& Boone, M. (2002). Realizing potential: Improving interdisciplinary professional/paraprofessional health care teams in Canada's northern aboriginal communities through education. Journal of Interprofessional Care, 16(2), 139147. 
Morgan, G. (1998). Images of organization: The executive edition. San Francisco, CA: Sage.

Mu, K., Chao, C. C., Jensen, G. M., \& Royeen, C. B. (2004). Effects of interprofessional rural training on students' perceptions of interprofessional health care services. Journal of Allied Health, 33(2), 125-131.

Muus, K. J., Geller, J. M., Ludtke, R. L., Pan, S., Kassab, C., Luloff, A. E., \& Hart, L. G. (1996). Comparing urban and rural primary care PAs: Implications for rural recruitment. Journal of the American Academy of Physician Assistants, 9, 49-52.

Norris, T. E., Coombs, J. B., House, P., Moore, S., Wenrich, M. D., \& Ramsey, P. G. (2006). Regional solutions to the physician workforce shortage: The WWAMI experience. Academic Medicine, 81(10), 857-862.

Oandasan, I., D’Amour, D., Zwarenstein, M., Barker, K., Purden, M., Beaulieau, M. D., Reeves, S., Nasmith, L., Bosco, C., Ginsburg, L., \& Tregunno, D. (2004). Chapter 3: Key elements of collaborative practice and frameworks: Conceptual basis for interdisciplinary practice. In I. Oandasan, D. D’Amour, M. Zwarenstein, K. Barker, M. Purden, M. Beaulieu, S. Reeves, L. Nasmith, C. Bosco, L. Ginsburg, \& D. Tregunno (Eds.), Interdisciplinary education for collaborative, patientcentered practice: Research and findings report (pp. 64-99). Ottawa, Ontario, Canada: Health Canada.

Oandasan, I., \& Reeves, S. (2005). Key elements for interprofessional education. Part 1: The learner, the educator and the learning context. Journal of Interprofessional Care, 19(S1), 21-38. doi:10.1080/13561820500083550

Oregon Office of Rural Health (2014). Retrieved from http://www.ohsu.edu/xd/outreach/oregon-rural-health/about/rural-healthconference/upload/2014-Fri-JM-Rural-pleanary-oct-17FINAL.pdf

Oregon Office of Rural Health. (2016). Rural definitions. Retrieved from http://www.ohsu.edu/xd/outreach/oregon-rural-health/data/ruraldefinitions/index.cfm

Orloff, T. M., \& Tymann, B. (1995). Rural health: An evolving system of accessible services. Washington, DC: National Governor's Association.

Owen, J. A., Hayden, G. F., \& Bowman, R. C. (2005). Influence of places of birth, medical education, and residency training on the eventual practice locations of family physicians: Recent experience in Virginia. Southern Medical Journal, 98(6), 674-676.

Pathman, D. E. (1996). Medical education and physicians' career choices: Are we taking credit beyond our due? Academic Medicine. Retrieved from http://journals.lww. 
com/academicmedicine/Fulltext/1996/09000/Medical_education_and_physici ans_career_choices_.10.aspx

Pathman, D. E., Fryer, G. E., Phillips, R. L., Smucny, J., Miyoshi, T., \& Green, L. A. (2006). National Health Service Corps staffing and the growth of the local rural non-NHSC primary care physician workforce. The Journal of Rural Health, 22(4), 285-293.

Pathman, D. E., Konrad, T. R., Dann, R., \& Koch, G. (2004). Retention of primary care physicians in rural health professional shortage areas. American Journal of Public Health, 94(10), 1723-1729.

Pathman, D. E., Konrad, T. R., King, T. S., Taylor, D. H. Jr., \& Koch, G. G. (2004). Outcomes of states' scholarship, loan repayment, and related programs for physicians. Medical Care, 42(6), 560-568.

Pathman, D. E., Konrad, T. R., \& Ricketts, T. C. (1994). The National Health Service Corps experience for rural physicians in the late 1980s. Journal of the American Medical Association. 272(17), 1341-1348.

Pathman, D. E., Steiner, B. D., Jones, B. D., \& Konrad, T. R. (1999). Preparing and retaining rural physicians through medical education. Academic Medicine, 74(7), 810-820.

Pathman, D. E., Taylor Jr., D. H., Konrad, T. R., King, T. S., Harris, T., Henderson, T. M., Bernstein, J. D., Tucker, T., Crook, K. D., Spaulding, C., \& Koch, G. G. (2000). State scholarship, loan forgiveness, and related programs: The unheralded safety net. Journal of the American Medical Association, 284(16), 2084-2092.

Pellegrino, J. W., Bransford, J. D., \& Donovan, M. S. (1999). How people learn: Bridging research and practice. Washington DC: National Academies Press.

Petterson, S. M., Phillips Jr, R. L., Bazemore, A. W., \& Koinis, G. T. (2013). Unequal distribution of the U.S. primary care workforce. American Family Physician, 87(11), Retrieved from http://europepmc.org.proxy.lib.pdx.edu/search; jsessionid=DKPISCk9PVehqEp0hyz0.0?page=1\&query=JOURNAL:\%22Am+Fa $\mathrm{m}+$ Physician\% 22

Philo, C., Parr, H., \& Burns, N. (2003). Rural madness: A geographical reading and critique of the rural mental health literature. Journal of Rural Studies, 19(3), 259281.

Ponzer, S., Hylin, U., Kusoffsky, A., Lauffs, M., Lonka, K., Mattiasson, A. C., \& Nordström, G. (2004). Interprofessional training in the context of clinical practice: Goals and students' perceptions on clinical education wards. Medical Education, 38(7), 727-736. doi:10.1111/j.1365-2929.2004.01848.x 
Pruslow, J. T., \& Owl, R. R. (2012). Demonstrating the application of Q methodology for fieldwork reporting in experiential education. Journal of Experiential Education, 35(2), 375-392.

Rabinowitz, H. K. (1988). Evaluation of a selective medical school admissions policy to increase the number of family physicians in rural and underserved areas. New England Journal of Medicine, 319(8), 480-486. Retrieved from http://doi.org/10.1056/NEJM198808253190805

Rabinowitz, H. K., Diamond, J. J., Markham, F. W., \& Hazelwood, C. E. (1999). A program to increase the number of family physicians in rural and underserved areas: Impact after 22 years. Journal of the American Medical Association, 281(3), 255-260.

Rabinowitz, H. K., Diamond, J. J., Markham, F. W., \& Rabinowitz, C. (2005). Long-term retention of graduates from a program to increase the supply of rural family physicians. Academic Medicine, 80(8), 728-732.

Rabinowitz, H. K., Diamond, J. J., Markham, F. W., \& Wortman, J. R. (2008). Medical school programs to increase the rural physician supply: A systematic review and projected impact of widespread replication. Academic Medicine, 83(3), 235-243. doi:10.1097/ACM.0b013e318163789b

Reeves, S., Perrier, L., Goldman, J., Freeth, D., \& Zwarenstein, M. (2013). Interprofessional education: Effects on professional practice and healthcare outcomes (update). Cochrane Database of Systematic Reviews. doi:10.1002/14651858.CD002213.pub3

Rosenblatt, R. A., \& Hart, L. G. (1999). Physicians and rural America. In T. C. Ricketts (Ed.), Rural health in the United States (pp. 38-51). New York, NY: Oxford Press.

Rosenblatt, R. A., Saunders, G., Shreffler, J., Pirani, M. J., Larson, E. H., \& Hart, L. G. (1996). Beyond retention: National Health Service Corps participation and subsequent practice locations of a cohort of rural family physicians. The Journal of the American Board of Family Practice, 9(1), 23-30.

Rosenthal, T. C. (2000). Outcomes of rural training tracks: A review. The Journal of Rural Health, 16(3), 213-216. doi:10.1111/j.1748-0361.2000.tb00459.x

Rosenthal, T. C., McGuigan, M. H., \& Anderson, G. (2000). Rural residency tracks in family practice: Graduate outcomes. Family Medicine, 32(3), 174-177.

Rygh, E. M., \& Hjortdahl, P. (2007). Continuous and integrated health care services in rural areas. A literature study. Rural and Remote Health, 7(3). Retrieved from http://www.rrh.org.au/articles/subviewnew.asp?ArticleID=766 
Saldaña, J. (2013). The coding manual for qualitative researchers $\left(2^{\text {nd }}\right.$ ed). Thousand Oaks, CA: Sage.

Schmolck, P. (2014a). PQMethod (Version 2.35) [Software program]. Retrieved from http://schmolck.userweb.mwn.de/qmethod/downpqwin.htm

Schmolck, P. (2014b). PQMethod Manual. Retrieved from http://schmolck.userweb.mwn.de/qmethod/pqmanual.htm

Senge, P. M. (2014). The fifth discipline fieldbook: Strategies and tools for building a learning organization. New York, NY: Crown Business.

Sexton, D., Snyder, P., Wadsworth, D., Jardine, A., \& Ernest, J. (1998). Applying Q methodology to investigations of subjective judgments of early intervention effectiveness. Topics in Early Childhood Special Education, 18(2), 95-107.

Slama, K. (2004). Rural culture is a diversity issue. Minnesota Psychologist, 53(1), 9-12.

Smith, T., Thornberry, T., Lyons, M., \& Jones, P. (2005, March). The challenge of evaluating rural undergraduate multi-professional education. Paper presented at the Australian National Rural Health Conference, Alice Springs, Australia.

Spencer, J., Woodroffe, J., Cross, M., \& Allen, P. (2015). “A golden opportunity”: Exploring interprofessional learning and practice in rural clinical settings. Journal of Interprofessional Care, 29(4), 389-391.

Spleen, A. M., Lengerich, E. J., Camacho, F. T., \& Vanderpool, R. C. (2014). Health care avoidance among rural populations: Results from a nationally representative survey. The Journal of Rural Health, 30(1), 79-88.

Stephenson, W. (1953). The study of behavior: Q-technique and its methodology. Chicago, IL: University of Chicago Press.

Stephenson, W. (1972). Applications of Communication Theory: Substructure of Science. The Psychological Record. 22, 17-36.

Stephenson, W. (1978). Concourse theory of communication. Communication, 3(1), 21 40.

Stephenson, W. (1980). Consciring: A general theory for subjective communicability. In D. Nimmo (Ed.), Communication yearbook, 4 (pp. 7-36). New Brunswick, NJ: Transaction.

Stew, G. (2005). Learning together in practice: A survey of interprofessional education in clinical settings in South-East England. Journal of Interprofessional Care, 19(3), 223-235. doi:10.1080/13561820500138685 
Stone, N. (2006). The rural interprofessional education project (RIPE). Journal of Interprofessional Care, 20(1), 79-81.

Svinicki, M. D. (2004). Learning and motivation in the postsecondary classroom. Bolton, MA: Anker Publishing.

Taylor, J., Blue, I., \& Misan, G. (2001). Approach to sustainable primary health care service delivery for rural and remote South Australia. Australian Journal of Rural Health, 9(6), 304-310.

Tierney, W. G. (1988). Organizational culture in higher education: Defining the essentials. The Journal of Higher Education, 59(1), 2-21.

Tolhurst, H., Adams, J., \& Stewart, S. (2006). An exploration of when urban background medical students become interested in rural practice. Rural and Remote Health. 6(452). Retrieved from http://hdl.handle.net/10453/15689

United States Census Bureau. (2014). Retrieved from https://www.census.gov/geo/reference/urban-rural.html

Wachter, R. M., Katz, P., Showstack, J., Bindman, A. B., \& Goldman, L. (1998). Reorganizing an academic medical service: Impact on cost, quality, patient satisfaction, and education. Journal of the American Medical Association. 279(19), 1560-1565.

Waitzkin, H. (1989). A Critical Theory of medical discourse: Ideology, social control, and the processing of social context in medical encounters. Journal of Health and Social Behavior, 30(2), 220. Retrieved from http://doi.org/10.2307/2137015

Wassef, M. E., Tuomi, M. O., Finn, T., \& Sullivan-Bolyai, S. (2015). A theoreticallybased coding system to guide assessment and evaluation of affective learning. Journal of Nursing Education and Practice, (6)1, 45. doi:10.5430/jnep.v6n1p45

Webler, T., Danielson, S., \& Tuler, S. (2009). Using Q method to reveal social perspectives in environmental research. Greenfield, MA: Social and Environmental Research Institute.

Whitcomb, M. E. (2005). The challenge of providing doctors for rural America. Academic Medicine, 80(8), 715-716.

Willingham, D. T. (2009). Why don't students like school?: A cognitive scientist answers questions about how the mind works and what it means for your classroom. San Francisco, CA: Jossey-Bass. 
Wros, P., Mathews, L. R., Voss, H., \& Bookman, N. (2015). An academic-practice model to improve the health of underserved neighborhoods. Family and Community Health, 38(2), 195-203. 


\section{APPENDIX A \\ Informed Consent and Study Information Sheet}

\section{Introduction}

You are being asked to participate in a research study that is being done by Candyce Reynolds, PhD, who is the Principal Investigator and Curt Stilp, MS, PA-C, from the Graduate School of Education, at Portland State University in Portland, Oregon. This research is studying the student experience in a rural interprofessional health care education program.

You are being asked to participate in this study because you are participating in the Oregon Health \& Science University (OHSU) Campus for Rural Health clinical rotation. This form will explain the research study, and will also explain the possible risks as well as the possible benefits to you. We encourage you to talk with your family and friends before you decide to take part in this research study. If you have any questions, please ask one of the study investigators.

\section{What will happen if I decide to participate?}

If you agree to participate, the following things will happen:

Your weekly reflection journals will be collected and analyzed for your views, attitudes, and thoughts of Interprofessional Education (IPE) in a rural clinical setting. You will be asked to submit your journals to the OHSU Campus for Rural Health Education Coordinator for your location. Your data will be de-identified so that neither we nor any other researcher, preceptor, or faculty would be able to identify you. We will also include "member check" prior to sharing our findings to ensure that you also believe we have protected your identity. We will not communicate any of your data to those who are grading or evaluating you. Additionally, at the conclusion of your clinical rotation you will be asked to do a ranking of subjective statements that represent factors surrounding team-based care in a rural setting ( $\mathrm{Q}$ sort). The $\mathrm{Q}$ sort will also ask you for basic demographic information to indicate your health profession of study, gender, age, rural or urban background, if you have children, marital status, and which location of the OHSU Campus for Rural Health you attended. Your de-identified completed Q sort will automatically be emailed to us when you finish. At the conclusion of the study, all of the data will be permanently deleted.

\section{How long will I be in this study?}


Participation in this study will take a total of 4 hours over a period of 1 to 4 weeks. Your participation in the study will continue until the study's conclusion which is estimated to be one year.

\section{What are the risks or side effects of being in this study?}

There are risks of stress, emotional distress, inconvenience and possible loss of privacy and confidentiality associated with participating in a research study.

For more information about risks and discomforts, ask the investigator.

\section{What are the benefits to being in this study?}

You will not directly benefit from being in this study. However, by serving as a participant, you may help health care preparation institutions learn how to better design rural IPE programs in the future thereby improving future students' experiences. Furthermore, the information provided may aid rural communities in the recruitment and retention of health care professionals.

\section{How will my information be kept confidential?}

All reflection journals, Q sorts, and demographic information will be de-identified so there is little chance of breach of confidentiality. All data will be kept on the secure OHSU box.com cloud storage system and permanently deleted once the study has concluded. The study investigators will protect the security of all your personal information, but we cannot guarantee confidentiality of all study data.

Information contained in your study records is used by study staff. The Portland State University Institutional Review Board (IRB) that oversees human subject research and/or other entities may be permitted to access your records, and there may be times when we are required by law to share your information. It is the investigator's legal obligation to report child abuse, child neglect, elder abuse, harm to self or others or any lifethreatening situation to the appropriate authorities, and; therefore, your confidentiality will not be maintained.

Your name will not be used in any published reports about this study.

\section{Will I be paid for taking part in this study?}

No.

\section{Can I stop being in the study once I begin?}


You do not have to join this or any research study. If you do join and later change your mind, you may quit at any time. If you decide not to join or withdraw early from the study, there will be no penalty or loss of any benefits to which you are otherwise entitled. Whether or not you participate will have no effect on your preceptor evaluation or grade for your community based project course; in fact, there will be no communication between the researcher and the preceptor.

Whom can I call with questions or complaints about this study?

If you have any questions, concerns or complaints at any time about the research study, Curt Stilp, or his associates will be glad to answer them at 503-494-4639.

If you need to contact someone after business hours or on weekends, please call 503-9890153 and ask for Curt.

\section{Whom can I call with questions about my rights as a research participant?}

If you have questions regarding your rights as a research participant, you may call the PSU Office for Research Integrity at (503) 725-2227 or 1(877) 480-4400. The ORI is the office that supports the PSU Institutional Review Board (IRB). The IRB is a group of people from PSU and the community who provide independent oversight of safety and ethical issues related to research involving human participants. For more information, you may also access the IRB website at https://sites.google.com/a/pdx.edu/research/integrity.

\section{CONSENT}

You are making a decision whether to participate in this study. Your signature below indicates that you have read the information provided (or the information was read to you). By signing this consent form, you are not waiving any of your legal rights as a research participant.

You have had an opportunity to ask questions and all questions have been answered to your satisfaction. By signing this consent form, you agree to participate in this study. A copy of this consent form will be provided to you.

$\overline{\text { Name of Adult Subject (print) }} \overline{\text { Signature of Adult Subject }} \overline{\text { Date }}$

\section{INVESTIGATOR SIGNATURE}

This research study has been explained to the participant and all of his/her questions have been answered. The participant understands the information described in this consent form and freely consents to participate.

Name of Investigator/ Research Team Member (type or print) 


\section{APPENDIX B}

The Q-set used for the study

\begin{tabular}{|c|c|c|c|}
\hline & Statement & Category & Source \\
\hline 1. & $\begin{array}{l}\text { The rural setting makes me feel } \\
\text { comfortable and at ease. }\end{array}$ & Social & $\begin{array}{l}\text { Hancock et al., } \\
2009\end{array}$ \\
\hline 2. & $\begin{array}{l}\text { The social challenges rural patients face } \\
\text { make it hard for me to provide care }\end{array}$ & Social & $\begin{array}{l}\text { Student } \\
\text { reflection journal }\end{array}$ \\
\hline 3. & $\begin{array}{l}\text { I noticed the people seem happy in spite } \\
\text { of significant disadvantages. }\end{array}$ & Social & $\begin{array}{l}\text { Student } \\
\text { reflection journal }\end{array}$ \\
\hline 4. & $\begin{array}{l}\text { Time and sustained presence in a } \\
\text { community helped build trust and } \\
\text { familiarity. }\end{array}$ & Social & $\begin{array}{l}\text { L. R. Henry \& } \\
\text { Hooker, } 2007\end{array}$ \\
\hline 5. & $\begin{array}{l}\text { Working on a community project } \\
\text { provides the most suitable platform for } \\
\text { learning how to communicate with other } \\
\text { members of the health care team. }\end{array}$ & Team & $\begin{array}{l}\text { Student } \\
\text { reflection journal }\end{array}$ \\
\hline 6. & $\begin{array}{l}\text { Seeing patients together combines our } \\
\text { knowledge and strength to provide care. }\end{array}$ & Team & $\begin{array}{l}\text { Student } \\
\text { reflection journal }\end{array}$ \\
\hline 7. & $\begin{array}{l}\text { Working together in the clinic serves as } \\
\text { great "peer" support that is needed. }\end{array}$ & Team & $\begin{array}{l}\text { Student } \\
\text { reflection journal }\end{array}$ \\
\hline 8. & $\begin{array}{l}\text { The nature in which care is delivered in } \\
\text { a rural setting lends itself to team-based } \\
\text { patient-centered care. }\end{array}$ & Team & $\begin{array}{l}\text { Spencer et al., } \\
2015\end{array}$ \\
\hline 9. & $\begin{array}{l}\text { IPE leads to a greater understanding of } \\
\text { my own role on the health care team. }\end{array}$ & Team & $\begin{array}{l}\text { Ponzer et al., } \\
2004\end{array}$ \\
\hline 10. & $\begin{array}{l}\text { Returning to something that is familiar } \\
\text { is the most important reason I would } \\
\text { choose a rural community. }\end{array}$ & Familiarity & $\begin{array}{l}\text { Hancock et al., } \\
2009\end{array}$ \\
\hline 11. & $\begin{array}{l}\text { Knowledge and experience with rural } \\
\text { recreational activities lead to acceptance } \\
\text { by the community. }\end{array}$ & Familiarity & Bell, 1992 \\
\hline 12. & $\begin{array}{l}\text { As an outsider to a rural community, the } \\
\text { best approach is through humility, } \\
\text { curiosity, and good intention. }\end{array}$ & Familiarity & $\begin{array}{l}\text { Student } \\
\text { reflection journal }\end{array}$ \\
\hline 13. & $\begin{array}{l}\text { Having no familiarity with a rural } \\
\text { community is a disadvantage when } \\
\text { providing care. }\end{array}$ & Familiarity & $\begin{array}{l}\text { Student } \\
\text { reflection journal }\end{array}$ \\
\hline
\end{tabular}




\begin{tabular}{|c|c|c|c|}
\hline 14. & $\begin{array}{l}\text { Time spent in a rural setting does not } \\
\text { lead to a greater understanding of rural } \\
\text { life. }\end{array}$ & Familiarity & $\begin{array}{l}\text { Student } \\
\text { reflection journal }\end{array}$ \\
\hline 15. & $\begin{array}{l}\text { Rural communities have limited funds } \\
\text { which restrict what care can be } \\
\text { provided. }\end{array}$ & Community & $\begin{array}{l}\text { Student } \\
\text { reflection journal }\end{array}$ \\
\hline 16. & $\begin{array}{l}\text { The most important role of a health care } \\
\text { provider is community engagement. }\end{array}$ & Community & $\begin{array}{l}\text { Student } \\
\text { reflection journal }\end{array}$ \\
\hline 17. & $\begin{array}{l}\text { Rural culture is one where community- } \\
\text { minded individuals value resilience and } \\
\text { practicality. }\end{array}$ & Community & Philo et al., 2003 \\
\hline 18. & $\begin{array}{l}\text { A rural community provides ample } \\
\text { opportunities for creativity, meaning, } \\
\text { variety, and autonomy. }\end{array}$ & Community & $\begin{array}{l}\text { Hancock et al., } \\
2009\end{array}$ \\
\hline 19. & $\begin{array}{l}\text { The rural IPE experience helped me } \\
\text { answer questions about rural life. }\end{array}$ & Motivation & $\begin{array}{l}\text { Deutchman et al., } \\
2012\end{array}$ \\
\hline 20. & $\begin{array}{l}\text { My exposure to rural practice had } \\
\text { generated an interest in a rural } \\
\text { community. }\end{array}$ & Motivation & $\begin{array}{l}\text { Tolhurst et al., } \\
2006\end{array}$ \\
\hline 21. & $\begin{array}{l}\text { By being exposed to a rural clinical } \\
\text { experience, I gained understanding } \\
\text { about how my interests and desires } \\
\text { could be met in a rural setting. }\end{array}$ & Motivation & $\begin{array}{l}\text { Tolhurst et al., } \\
2006\end{array}$ \\
\hline 22. & $\begin{array}{l}\text { Certain health professions come with a } \\
\text { responsibility to care for a rural } \\
\text { community. }\end{array}$ & Professional & $\begin{array}{l}\text { Student } \\
\text { reflection journal }\end{array}$ \\
\hline 23. & $\begin{array}{l}\text { The rural IPE experience did not expand } \\
\text { my understanding of the respective } \\
\text { health care professions. }\end{array}$ & Professional & $\begin{array}{l}\text { Student } \\
\text { reflection journal }\end{array}$ \\
\hline 24. & $\begin{array}{l}\text { Feeling professionally isolated is } \\
\text { common in a rural community. }\end{array}$ & Professional & Lindsay, 2007 \\
\hline 25. & $\begin{array}{l}\text { Rural healthcare practice does not allow } \\
\text { time away from your patients. }\end{array}$ & Professional & Whitcomb, 2005 \\
\hline 26. & $\begin{array}{l}\text { The availability of outdoor activities } \\
\text { attracts me to the rural setting. }\end{array}$ & Personal & $\begin{array}{l}\text { Student } \\
\text { reflection journal }\end{array}$ \\
\hline 27. & $\begin{array}{l}\text { The most important aspect of rural IPE } \\
\text { is living together with other health } \\
\text { professions students. }\end{array}$ & Personal & $\begin{array}{l}\text { Student } \\
\text { reflection journal }\end{array}$ \\
\hline 28. & $\begin{array}{l}\text { I want my children to grow up in a rural } \\
\text { area. }\end{array}$ & Personal & $\begin{array}{l}\text { Kazanjian \& } \\
\text { Pagliccia, } 1996 \\
\end{array}$ \\
\hline 29. & $\begin{array}{l}\text { I felt judged for not having views and } \\
\text { beliefs similar to my patients. }\end{array}$ & Personal & Slama, 2004 \\
\hline 30. & $\begin{array}{l}\text { Isolation from family and friends is a } \\
\text { major reason for not choosing to live in }\end{array}$ & Personal & $\begin{array}{l}\text { J. A. Henry et al., } \\
2009\end{array}$ \\
\hline
\end{tabular}




\begin{tabular}{|c|l|c|l|}
\hline & a rural community. & & \\
\hline 31. & $\begin{array}{l}\text { The most effective rural IPE allows for } \\
\text { engagement in the community. }\end{array}$ & Education & $\begin{array}{l}\text { Deutchman et al., } \\
2012\end{array}$ \\
\hline 32. & $\begin{array}{l}\text { The rural clinical setting provides the } \\
\text { best opportunity to learn about other } \\
\text { health care professions. }\end{array}$ & Education & $\begin{array}{l}\text { Student } \\
\text { reflection journal }\end{array}$ \\
\hline 33. & $\begin{array}{l}\text { The rural setting is not a good place to } \\
\text { apply the IPE model. }\end{array}$ & Education & $\begin{array}{l}\text { Student } \\
\text { reflection journal }\end{array}$ \\
\hline 34. & $\begin{array}{l}\text { Seeing patients together with another } \\
\text { student provided a great way for me to } \\
\text { learn. }\end{array}$ & Education & $\begin{array}{l}\text { Student } \\
\text { reflection journal }\end{array}$ \\
\hline 35. & $\begin{array}{l}\text { The rural IPE experience harnessed the } \\
\text { potential of rural services to promote my } \\
\text { interprofessional capability. }\end{array}$ & Education & $\begin{array}{l}\text { Spencer et al., } \\
2015\end{array}$ \\
\hline 36. & $\begin{array}{l}\text { Feeling a connection to a rural } \\
\text { community makes it more likely to } \\
\text { return after graduation. }\end{array}$ & Motivation & $\begin{array}{l}\text { Hancock et al., } \\
2009\end{array}$ \\
\hline
\end{tabular}




\section{APPENDIX C}

\section{Journal Coding Table}

\begin{tabular}{|c|c|c|c|}
\hline Reflective Journal Text & $\begin{array}{l}\text { Health } \\
\text { Care } \\
\text { Profession } \\
\text { (if given) }\end{array}$ & $\begin{array}{l}\text { Descriptive } \\
\text { Code }^{1}\end{array}$ & Values Code ${ }^{2}$ \\
\hline $\begin{array}{l}\text { Participant 1: Working with people of different } \\
\text { professions during the rural project definitely } \\
\text { effects the way you will work with people in those } \\
\text { professions in the future. For me living in the same } \\
\text { house and getting to know the different people and } \\
\text { this being my second rotation in Klamath and } \\
\text { participating in the IPE project both times gives } \\
\text { me a good perspective on it as well. The time in } \\
\text { the house hanging out and talking with the other } \\
\text { students and being able to talk about their } \\
\text { experiences and training did more to get me to } \\
\text { know them than the actual project. }{ }^{2} \text { The project did } \\
\text { make us have to meet outside of the Monday class } \\
\text { though. }{ }^{1} \text { I could see how if the project wasn't here } \\
\text { people could go through their rotations without } \\
\text { ever really communicating }{ }^{1} \text { with or getting to } \\
\text { know their roommates. }{ }^{2} \text { I was lucky enough to } \\
\text { work with most of the different medical } \\
\text { professions }{ }^{2} \text { at the rural campus including medical } \\
\text { students, pharmacy students, and dental students, } \\
\text { as well as my fellow classmates of the PA } \\
\text { program. }\end{array}$ & $\begin{array}{l}\text { Physician } \\
\text { Assistant }\end{array}$ & $\begin{array}{l}\text { Professional } \\
\text { siloes } \\
\text { Inherently } \\
\text { isolated }\end{array}$ & $\begin{array}{l}\text { V: Social time } \\
\text { A: Lucky } \\
\text { B: Structure is } \\
\text { necessary } \\
\text { V: Multiple } \\
\text { professions }\end{array}$ \\
\hline $\begin{array}{l}\text { Participant 2: Working interprofessionally with } \\
\text { other students has been a great way to learn }{ }^{2} \text { about } \\
\text { the training and scope of practice of different } \\
\text { fields, as well as how these different health } \\
\text { professions interact in the clinical setting. I feel } \\
\text { like I have a much better understanding }{ }^{2} \text { of the role } \\
\text { of each profession in patient care. Working on this } \\
\text { project all together was a great way to get us all } \\
\text { introduced to each other }{ }^{2} \text { and we ended up having } \\
\text { a really fun time hanging out around the house and } \\
\text { around town together. } \\
\\
\text { I was considering rural practice before I came } \\
\text { down here and have enjoyed being involved in the } \\
\text { community project. }{ }^{2} \text { I think it was a great way to } \\
\text { learn about a specific problem that this community } \\
\text { faces and I would like to be involved in projects } \\
\text { that impact my community in my future practice. }\end{array}$ & & $\begin{array}{l}\text { Small } \\
\text { Rural } \\
\text { Whole } \\
\text { community } \\
\text { Smallish } \\
\text { community }\end{array}$ & $\begin{array}{l}\text { V: IPE } \\
\text { B: Better } \\
\text { understanding } \\
\text { B: Project } \\
\text { provides context } \\
\text { V: Hanging out } \\
\text { A: Enjoyed } \\
\text { being part of the } \\
\text { project } \\
\text { V: Community } \\
\text { project } \\
\text { B: Great way to } \\
\text { learn } \\
\text { B: Made an } \\
\text { impact } \\
\text { A: Enjoy rural } \\
\text { practice }\end{array}$ \\
\hline
\end{tabular}




\begin{tabular}{|c|c|c|c|}
\hline $\begin{array}{l}\text { I think the neat thing about being in a small rural } \\
\text { area }{ }^{1} \text { is that the intervention made by the outcome } \\
\text { of a project can have a positive impact on the } \\
\text { whole community, }{ }^{1,2} \text { whereas similar projects in a } \\
\text { bigger city would most likely focus a small subset } \\
\text { of the population. So, I would summarize by } \\
\text { saying that I have really enjoyed getting to know } \\
\text { this smallish community }{ }^{1} \text { and think I would enjoy } \\
\text { rural practice }^{2} \text { in the future. }\end{array}$ & & & \\
\hline $\begin{array}{l}\text { Participant 3: I did very much like working with } \\
\text { other students from other professions }{ }^{2} \text { on the Rural } \\
\text { Community Project, and getting to live and } \\
\text { interact with them on a daily basis as well. }{ }^{2} \text { I think } \\
\text { that it led to a greater appreciation for them as } \\
\text { people. }{ }^{2} \text { However, I don't know if it really } \\
\text { expanded my knowledge or appreciation for their } \\
\text { individual professions, }{ }^{2} \text { as it was not really in that } \\
\text { capacity that we were interacting during the } \\
\text { project. }{ }^{2} \text { I think that the times where I have learned } \\
\text { the most about other professions has been when I } \\
\text { have been working alongside them in the clinical } \\
\text { setting, shoulder-to-shoulder, with the common } \\
\text { goal of excellent patient care. } \\
\text { I do think that the experience of working in the } \\
\text { rural setting has been very eye-opening }{ }^{2} \text { (in a good } \\
\text { way). I was pleasantly surprised at how warm and } \\
\text { earnest }{ }^{1} \text { the people in this town have been, and } \\
\text { have been impressed with how welcome they have } \\
\text { made me feel. }{ }^{1} \text { I would certainly consider Klamath } \\
\text { as somewhere I could come back and work and } \\
\text { live. }{ }^{2}\end{array}$ & & $\begin{array}{l}\text { Warm } \\
\text { Earnest } \\
\text { Welcoming }\end{array}$ & $\begin{array}{l}\text { V: Working with } \\
\text { other professions } \\
\text { V: Community } \\
\text { project } \\
\text { V: Living with } \\
\text { others students } \\
\text { A: Greater } \\
\text { appreciation } \\
\text { B: Learning } \\
\text { happens side-by- } \\
\text { side } \\
\text { A: Eye-opening } \\
\text { A: Contemplate } \\
\text { rural }\end{array}$ \\
\hline $\begin{array}{l}\text { Participant 4: IPE has been a wonderful learning } \\
\text { experience }{ }^{2} \text { and has made me more excited }{ }^{2} \text { by the } \\
\text { possibility of working with individuals from a } \\
\text { variety of professions in the future! In a rural } \\
\text { setting with limited resources }{ }^{1} \text { utilizing the skills } \\
\text { of your colleagues }{ }^{2} \text { is critical to providing } \\
\text { exceptional patient care. I am grateful for the } \\
\text { opportunity to experience a collaborative } \\
\text { interprofessional work environment during my } \\
\text { education }{ }^{2} \text { and look forward }{ }^{2} \text { to working in rural } \\
\text { healthcare with colleagues from a variety of } \\
\text { professional backgrounds in the future. }\end{array}$ & & $\begin{array}{l}\text { Limited } \\
\text { resources }\end{array}$ & $\begin{array}{l}\text { A: Delightful } \\
\text { B: Enthusiastic } \\
\text { B: Rely on } \\
\text { others } \\
\text { A: Thankful } \\
\text { V: Collaborative } \\
\text { environment } \\
\text { A: Anticipate the } \\
\text { future }\end{array}$ \\
\hline $\begin{array}{l}\text { Participant 5: Working with our team }{ }^{1} \text { was a lot } \\
\text { of fun. }{ }^{2} \text { Everyone had something unique to bring } \\
\text { to the table }{ }^{2} \text { (extensive experience on the project, a } \\
\text { passion for rural health, etc.). This experience just } \\
\text { confirms by beliefs that working with a team } \\
\text { (whether big or small) produces greater outcomes }\end{array}$ & Medicine & $\begin{array}{l}\text { Team } \\
\text { Challenging }\end{array}$ & $\begin{array}{l}\text { A: Teamwork is } \\
\text { fun } \\
\text { V: Distinctive } \\
\text { B: Team > } \\
\text { Individual } \\
\text { B: Team }\end{array}$ \\
\hline
\end{tabular}




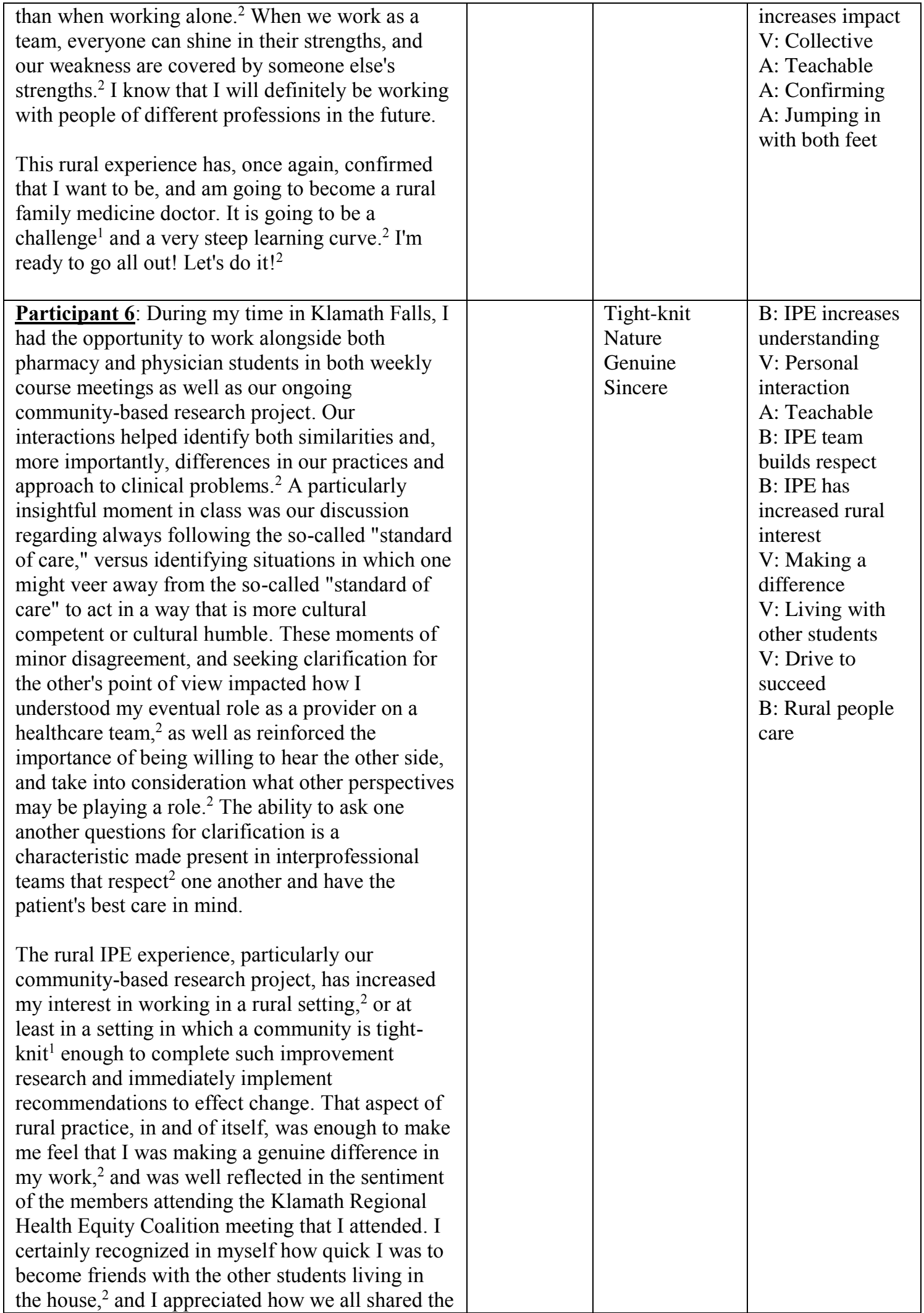




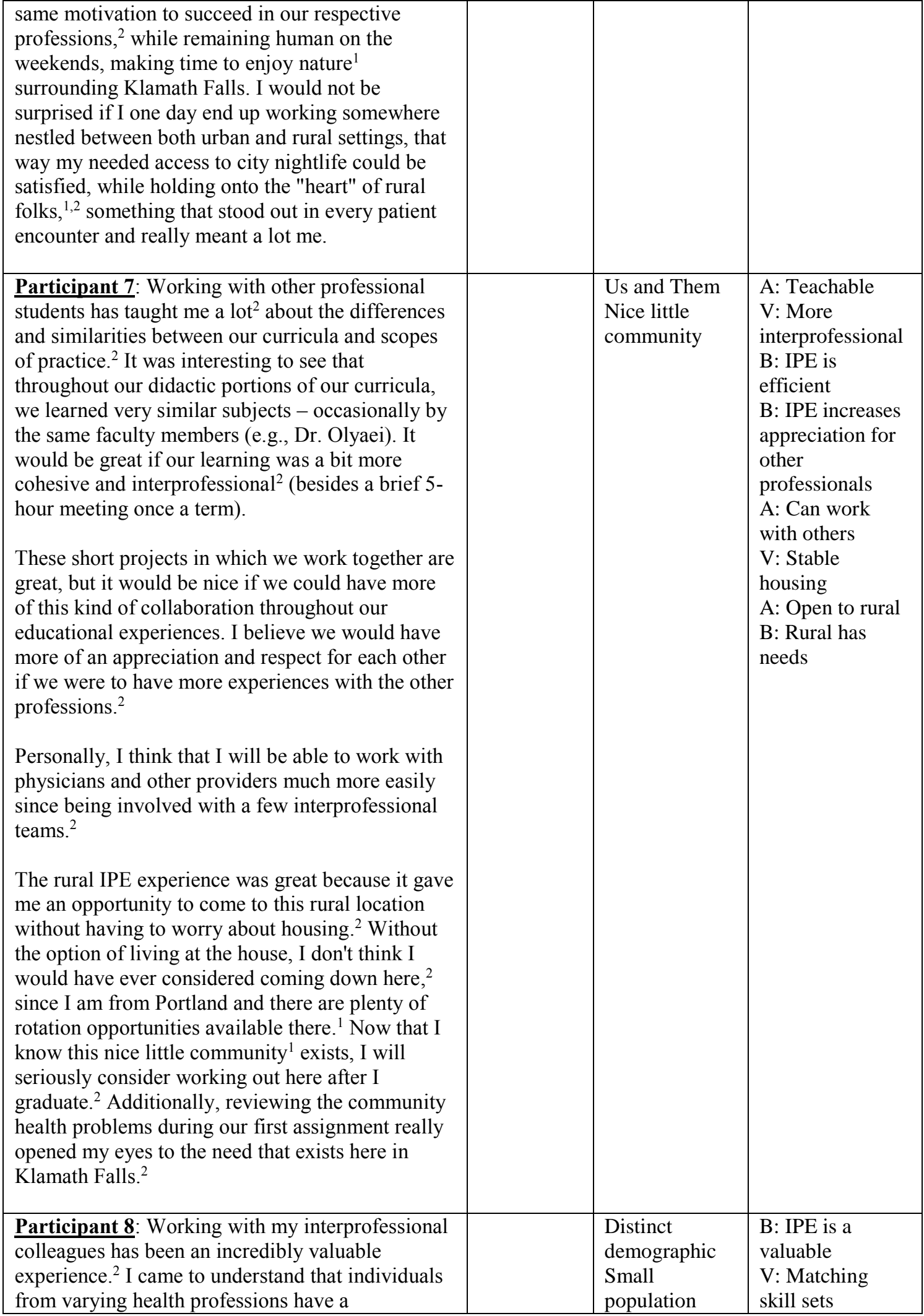




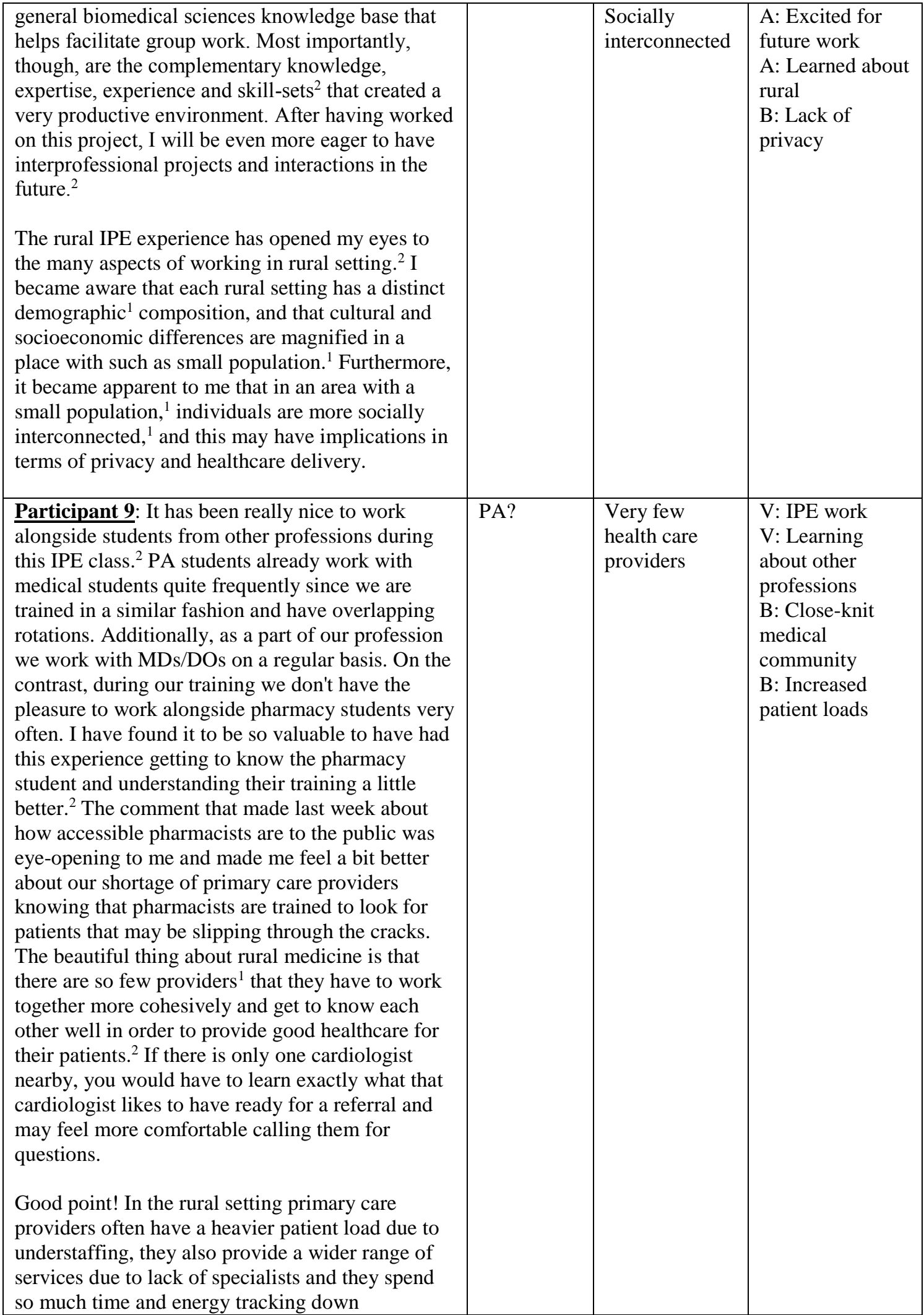




\begin{tabular}{|c|c|c|c|}
\hline resources. ${ }^{2}$ They are stretched really thin. & & & \\
\hline 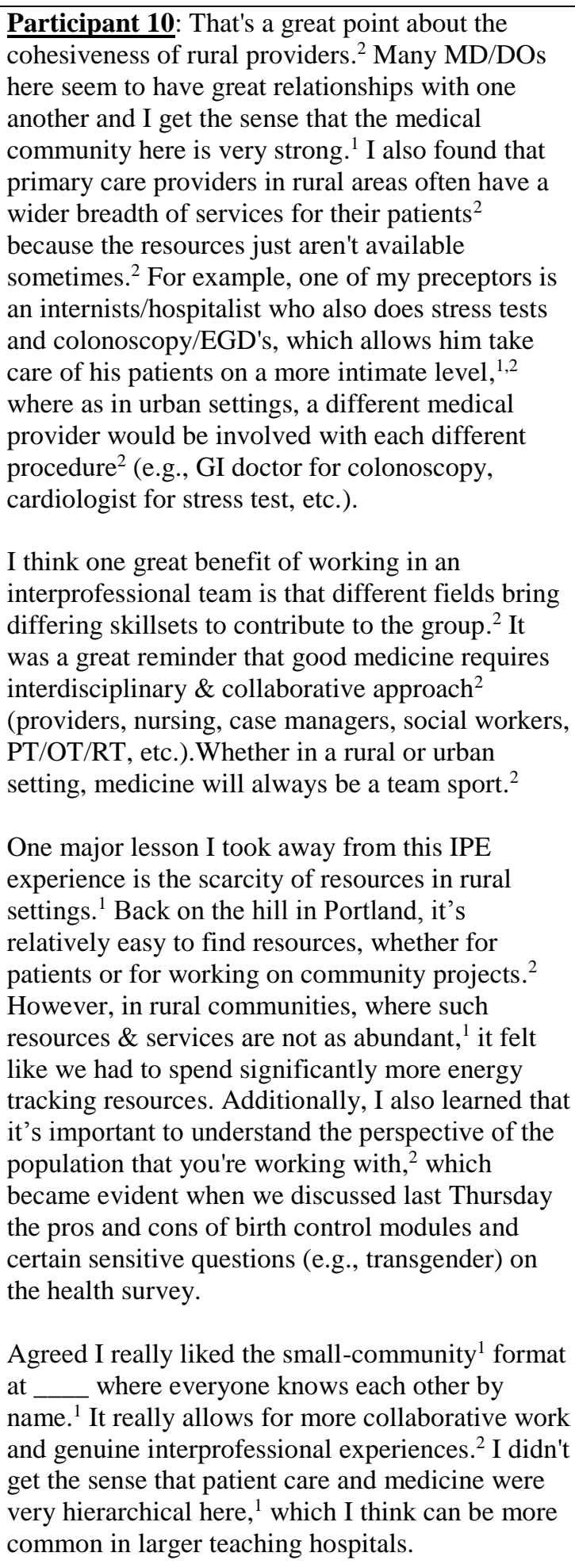 & & $\begin{array}{l}\text { Good } \\
\text { relationships } \\
\text { Strong medical } \\
\text { community } \\
\text { Care is on a } \\
\text { deeper level } \\
\text { Resource } \\
\text { limited } \\
\text { Small } \\
\text { community } \\
\text { Know } \\
\text { everyone's } \\
\text { name } \\
\text { Lack of power } \\
\text { relationships at } \\
\text { work }\end{array}$ & $\begin{array}{l}\text { B: Medically } \\
\text { interconnected } \\
\text { B: Sparse } \\
\text { resources } \\
\text { V: Deeper level } \\
\text { of care } \\
\text { B: Urban care is } \\
\text { more fragmented } \\
\text { B: IPP highlights } \\
\text { individual } \\
\text { contributions } \\
\text { B: Good care is } \\
\text { collaborative } \\
\text { B: Medicine is a } \\
\text { team effort } \\
\text { V: Available } \\
\text { resources } \\
\text { V: Patient's } \\
\text { point of view } \\
\text { B: Rural is great } \\
\text { for IPE }\end{array}$ \\
\hline Participant 11: I agree. In rural areas, medical & Pharmacy & Outsiders & B: Professional \\
\hline
\end{tabular}




\begin{tabular}{|c|c|c|}
\hline 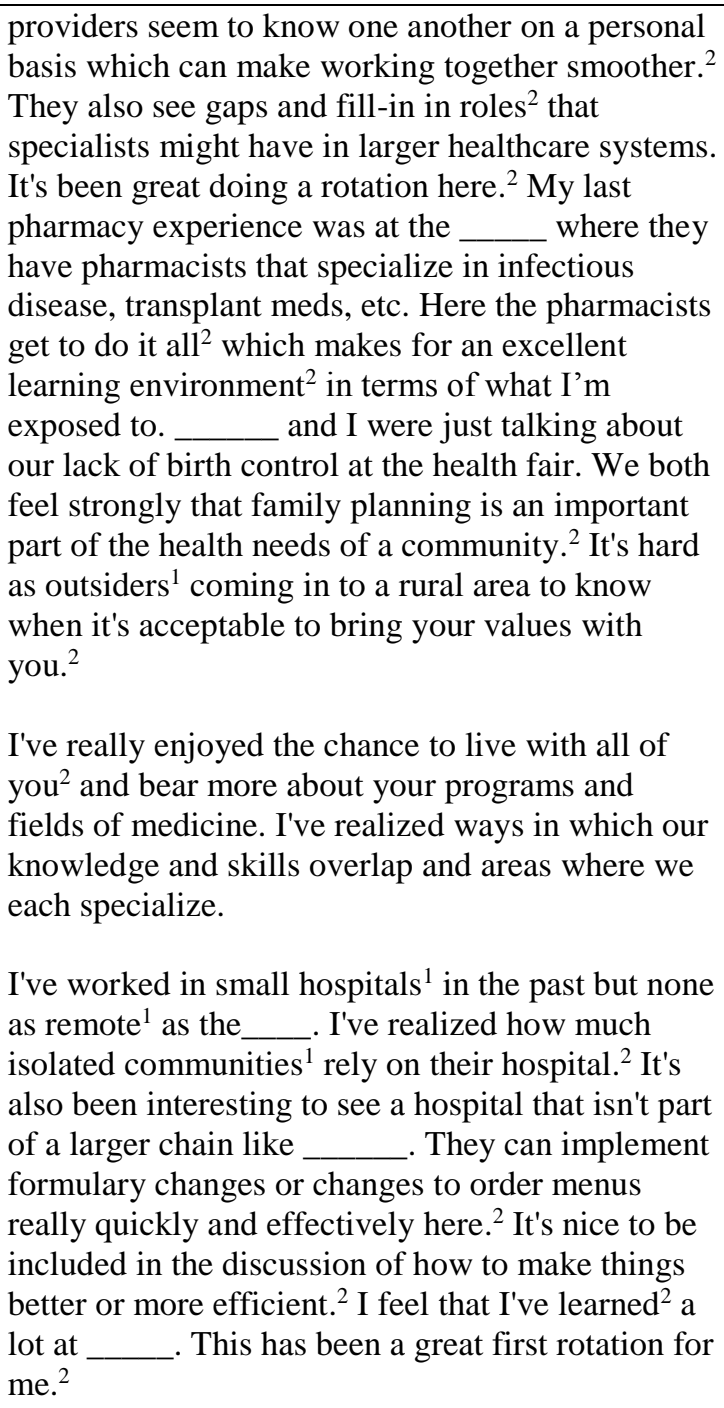 & $\begin{array}{l}\text { Small } \\
\text { hospitals } \\
\text { Remote } \\
\text { Isolated }\end{array}$ & $\begin{array}{l}\text { familiarity } \\
\text { B: Generalist } \\
\text { providers } \\
\text { A: Enjoyment } \\
\text { B: Large scope } \\
\text { of practice } \\
\text { V: Rural learning } \\
\text { environment } \\
\text { V: Family } \\
\text { planning } \\
\text { A: Out of place } \\
\text { V: Living } \\
\text { together } \\
\text { V: Learned about } \\
\text { others } \\
\text { A: Appreciative } \\
\text { B: Local hospital } \\
\text { is needed } \\
\text { B: Rural } \\
\text { hospitals are } \\
\text { more adaptable } \\
\text { A: Inclusive } \\
\text { B: Learned a lot } \\
\text { B: Worthy } \\
\text { experience }\end{array}$ \\
\hline $\begin{array}{l}\text { Participant 12: Unfortunately we did not have } \\
\text { much interaction with students from other } \\
\text { professions. }{ }^{2} \text { We briefly met a pharmacy student } \\
\text { and a dental student, but we didn't really get the } \\
\text { opportunity to do the big activities with them. I } \\
\text { wish it would've worked out differently }{ }^{2} \text { because it } \\
\text { would have been interesting to get their input and } \\
\text { ideas. } \\
\text { Given that I didn't get to work with students from } \\
\text { other professions, I can't really say that rural IPE } \\
\text { influenced or changed my perspective about } \\
\text { working in a rural setting. }{ }^{2} \text { Working in Coos Bay } \\
\text { for a month was more eye opening and } \\
\text { motivating. }{ }^{2} \text { I already had a desire to work with } \\
\text { underserved and rural communities, and after } \\
\text { seeing the impact a good and engaged provider }{ }^{2}\end{array}$ & $\begin{array}{l}\text { Whole } \\
\text { community }\end{array}$ & $\begin{array}{l}\text { B: Minimal } \\
\text { professional } \\
\text { interaction } \\
\text { V: Professional } \\
\text { learning } \\
\text { A: Expanded } \\
\text { mindset } \\
\text { B: Rural IPE is } \\
\text { motivating } \\
\text { B: Engaged } \\
\text { teachers enhance } \\
\text { rural learning } \\
\text { V: Making a } \\
\text { difference }\end{array}$ \\
\hline
\end{tabular}




\begin{tabular}{|c|c|}
\hline $\begin{array}{l}\text { can have on the community I am leaving more } \\
\text { motivated to work in an area where I can make an } \\
\text { impact with the individual patient and with the } \\
\text { community as a whole. }{ }^{1,2}\end{array}$ & \\
\hline $\begin{array}{l}\text { Participant 13: It is difficult for me to answer } \\
\text { how working with an interprofessional team of } \\
\text { students shaped my views because I have been } \\
\text { working with a group of all PA students. }{ }^{2} \text { One } \\
\text { dental student joined us this last week, and our } \\
\text { only contact thus far has been at the social. With } \\
\text { that, I have no problems working with any } \\
\text { particular profession in the future. }{ }^{2} \\
\text { This rural experience influenced my perspective } \\
\text { on working in a rural setting by reinforcing my } \\
\text { views. }{ }^{2} \text { I grew up in a rural setting, and therefore } \\
\text { already had a pretty good idea of what it would be } \\
\text { like to work in one. } \\
\\
\text { I think it is awesome that you are leaving more } \\
\text { motivated to work in an underserved area! I agree } \\
\text { with you, this experience has re-enforced how I } \\
\text { felt about working in a rural community, }{ }^{2} \text { and it is } \\
\text { great to see the difference an engaged provider can } \\
\text { make. }\end{array}$ & $\begin{array}{l}\text { B: Not much IPE } \\
\text { A: Inclusive } \\
\text { B: Reinforced } \\
\text { my views } \\
\text { B: Previous } \\
\text { experience } \\
\text { influences } \\
\text { current view } \\
\text { A: Increased } \\
\text { motivation for } \\
\text { rural } \\
\text { V: Engaged } \\
\text { provider } \\
\text { B: Impact } \\
\text { through } \\
\text { dedication }\end{array}$ \\
\hline $\begin{array}{l}\text { Participant 14: I totally agree with Participant } 15 . \\
\text { It is always nice to interact with these other } \\
\text { professions, }{ }^{2} \text { but actually working with them in a } \\
\text { professional setting is a learned skill in which I } \\
\text { still need practice. Ultimately, I respect the } \\
\text { professions more by talking with these other } \\
\text { students, }{ }^{2} \text { but in order to gain respect of the } \\
\text { individuals in clinical practice, I would have to } \\
\text { actually work with them in a clinical setting. } \\
\text { Talking with my preceptors about rural health care } \\
\text { was definitely a great opportunity and } \\
\text { strengthened my desire to work in a rural } \\
\text { community. } \\
\\
\text { Although our group of students was built up of } \\
\text { solely PA students until the last couple weeks, it } \\
\text { was still nice to work with other professionals in a } \\
\text { nonmedical environment. }{ }^{2} \text { It is always nice to see } \\
\text { that two minds is better than one, }{ }^{2} \text { and building } \\
\text { strong relationships with peers is important }{ }^{2} \text { in any } \\
\text { environment. No one person can know all things, } \\
\text { so having other minds to help out is great. }{ }^{2} \text { I did } \\
\text { enjoy the time talking with the dental student, } \\
\text { because I learned a lot more about his profession. }{ }^{2} \\
\text { Every time I learn more about these professions, I } \\
\text { appreciate them more and respect them more. }{ }^{2} \text { I }\end{array}$ & $\begin{array}{l}\text { V: Professional } \\
\text { interaction } \\
\text { B: Team-based } \\
\text { practice is a skill } \\
\text { B: Personal } \\
\text { interactions are } \\
\text { key to IPE } \\
\text { V: Personal } \\
\text { mentorship } \\
\text { V: Nonclinical } \\
\text { interactions } \\
\text { B: Multiple } \\
\text { opinions } \\
\text { improves care } \\
\text { B: IPE involves } \\
\text { interaction } \\
\text { V: Strong } \\
\text { professional } \\
\text { relationships } \\
\text { A: Respect } \\
\text { B: Rural IPE is } \\
\text { not influential }\end{array}$ \\
\hline
\end{tabular}




\begin{tabular}{|c|c|c|c|}
\hline $\begin{array}{l}\text { don't think the rural IPE experience swayed me } \\
\text { one way or another about working in a rural } \\
\text { setting. I I was very interested in working in a rural } \\
\text { setting before this course, and I continue to be } \\
\text { interested moving forward. }\end{array}$ & & & \\
\hline $\begin{array}{l}\text { Participant 15: Participant } 13 \text { is a great team } \\
\text { player from my experience, so I believe she would } \\
\text { be great in an interprofessional team! } \\
\text { I was able to get some IPE experience from the } \\
\text { fact that I had the opportunity to live in the same } \\
\text { complex as a pharmacy student and a dental } \\
\text { student. I enjoyed the opportunity to talk to them } \\
\text { about their professions and answer any questions } \\
\text { they had about the PA profession. It would have } \\
\text { been ideal to have actually worked together with } \\
\text { other professions on providing healthcare to the } \\
\text { community }{ }^{2} \text {--like a community, interprofessional } \\
\text { health clinic--hopefully that is an opportunity that } \\
\text { can be available in the future. My mentors at clinic } \\
\text { have had the greatest impact }{ }^{2} \text { on the joys and } \\
\text { challenges of working in a rural setting. I } \\
\text { appreciated the time they spent to tell me their } \\
\text { own anecdotes and make each patient I } \\
\text { encountered a learning experience on the } \\
\text { intricacies of rural medicine. }\end{array}$ & PA & & $\begin{array}{l}\text { V: Collegiality } \\
\text { B: Shared } \\
\text { housing is the } \\
\text { best for of IPE } \\
\text { A: Enjoyment } \\
\text { B: Meaningful } \\
\text { IPE involves the } \\
\text { clinic } \\
\text { V: Mentor's } \\
\text { involvement } \\
\text { A: Thankful }\end{array}$ \\
\hline $\begin{array}{l}\text { Participant 16: In all honesty it was difficult } \\
\text { really getting to know the other students on } \\
\text { rotation because of the scheduling differences with } \\
\text { my rotation. }{ }^{2} \text { I only got to interact with them a few } \\
\text { times and when we were together it was nice } \\
\text { getting to know }{ }^{2} \text { a little bit about their education } \\
\text { and what their profession looks like. I will say that } \\
\text { I have always had a respect for other health care } \\
\text { professionals }{ }^{2} \text { and I don't feel like this rotation } \\
\text { made that respect any stronger. I have been } \\
\text { involved with the healthcare environment for } \\
\text { many years, even before dental school and have } \\
\text { worked with physicians, nurses and PAs and I feel } \\
\text { that each profession is invaluable }{ }^{2} \text { to the next and } \\
\text { we all have our place and can benefit populations, } \\
\text { especially in a rural setting. }{ }^{2} \text { As far as influences } \\
\text { on my perspective working in a rural setting I } \\
\text { would have to say that my experience in Coos Bay } \\
\text { outside of the IPE activities is what has really } \\
\text { shaped a better understanding of what working in } \\
\text { this type of population }{ }^{1} \text { entails. }{ }^{2} \text { I think that the } \\
\text { overall IPE project would have enhanced my } \\
\text { perspective, but it was difficult coming in at such a } \\
\text { late stage and offset from my cohort and honestly }\end{array}$ & Dental & $\begin{array}{l}\text { Community } \\
\text { Certain } \\
\text { populations }\end{array}$ & $\begin{array}{l}\text { A: Frustration } \\
\text { V: Learning } \\
\text { about other } \\
\text { professions } \\
\text { A: Regard for } \\
\text { other professions } \\
\text { B: The different } \\
\text { professions are } \\
\text { needed } \\
\text { B: Assistance to } \\
\text { rural } \\
\text { V: Experience } \\
\text { separate from } \\
\text { IPE } \\
\text { B: Asynchronous } \\
\text { timing is } \\
\text { challenging } \\
\text { A: Increased } \\
\text { openness } \\
\text { A: Enjoyment } \\
\text { V: Working } \\
\text { together in clinic }\end{array}$ \\
\hline
\end{tabular}




\begin{tabular}{|c|c|c|c|}
\hline $\begin{array}{l}\text { being able to get a bunch of useful experience out } \\
\text { of it. }{ }^{2} \text { I will say that I am more open now to } \\
\text { working in a rural setting after having spent some } \\
\text { time in the community. }{ }^{1,2} \text { I have grown to like this } \\
\text { area }^{2} \text { and wouldn't be opposed to working here for } \\
\text { several years in the future. } \\
\text { I totally agree it would have been great to have } \\
\text { spent some time actually working together. }{ }^{2} \text { We } \\
\text { spoke about this one night and I know it might not } \\
\text { be the easiest thing to make happen, but it wouldn't } \\
\text { be impossible either, especially at OHSU. I feel } \\
\text { that the best way to learn about other professions } \\
\text { is to spend time with them while they are } \\
\text { practicing that profession. }{ }^{2} \text { Hopefully someday } \\
\text { this will be possible. }\end{array}$ & & & \\
\hline $\begin{array}{l}\text { Participant 17: Living and spending time with an } \\
\text { interprofessional team of students provided the } \\
\text { best views of these people beyond the mandatory } \\
\text { projects we had to collaborate on together. }{ }^{2} \text { I had a } \\
\text { wonderful experience }{ }^{2} \text { hearing stories and } \\
\text { experiences from a different health care profession } \\
\text { training, and it made me realize that we are } \\
\text { generally more similar than different. } \\
\text { The IPE rural experience has surprisingly opened } \\
\text { my eyes to the idea of practicing in a rural setting. } \\
\text { Before this rotation, I assumed my future career } \\
\text { would be in a large suburb because I have always } \\
\text { lived in that type of setting. }{ }^{2} \text { However, the } \\
\text { incredible patient interactions and relations I have } \\
\text { built with other professionals }{ }^{2} \text { in this small }{ }^{1} \text { and } \\
\text { charming town }{ }^{1} \text { of Coos Bay has made me } \\
\text { reconsider where I would like to work. }{ }^{2} \text { I } \\
\text { genuinely enjoy my time here, }{ }^{2} \text { and the gorgeous }{ }^{1} \\
\text { coastline makes it even easier to stay another } \\
\text { rotation longer. }\end{array}$ & & $\begin{array}{l}\text { Small } \\
\text { Charming } \\
\text { town } \\
\text { Gorgeous }\end{array}$ & $\begin{array}{l}\text { V: Living with } \\
\text { classmates } \\
\text { A: IPE is } \\
\text { delightful } \\
\text { B: Health care } \\
\text { professions are } \\
\text { similar } \\
\text { A: Realized rural } \\
\text { is a possibility } \\
\text { B: Past } \\
\text { experience } \\
\text { influences } \\
\text { choices } \\
\text { A: Treasured } \\
\text { V: Close } \\
\text { relationships } \\
\text { A: Gratitude }\end{array}$ \\
\hline $\begin{array}{l}\text { Participant 18: I hear about scheduling } \\
\text { differences; last week I worked only nights and so } \\
\text { I would only see my housemates for } 30 \text { minutes in } \\
\text { their evening/my morning after they would get } \\
\text { back from work and before I'd be off to mine. }{ }^{2} \\
\text { I agree that I think we're more similar than } \\
\text { different }^{2} ; \text { I do wish that the PA students and MD } \\
\text { students at OHSU could interact more during our } \\
\text { training. } \\
\text { I also agree that the coastline is gorgeous, }{ }^{1} \text { I really } \\
\text { have loved spending time }{ }^{2} \text { at Cape Arago! } \\
\text { Living with and working with non-MD team }\end{array}$ & MD & $\begin{array}{l}\text { Gorgeous } \\
\text { Significant } \\
\text { poverty level } \\
\text { Lack of health } \\
\text { care providers } \\
\text { This } \\
\text { community } \\
\text { suffers } \\
\text { immensely } \\
\text { Lack of } \\
\text { Primary Care } \\
\text { Provider } \\
\text { (PCP) access } \\
\text { Great }\end{array}$ & $\begin{array}{l}\text { B: Schedules are } \\
\text { a barrier } \\
\text { V: Building } \\
\text { professional } \\
\text { relationships } \\
\text { A: Appreciation } \\
\text { of differences } \\
\text { V: Diversity } \\
\text { A: Enjoyed the } \\
\text { setting } \\
\text { B: PAs and MDs } \\
\text { are very similar } \\
\text { A: Respect for } \\
\text { other professions }\end{array}$ \\
\hline
\end{tabular}


members has given me an appreciation for the different backgrounds and contributions ${ }^{2}$ that Health care workers of all stripes bring to patient care. While I am being trained in one discipline, I note that the PA students around me and the NP I've worked with at NBMC bring equal clinical skills with a slightly different perspective on planning and care. ${ }^{2}$ In all honesty, I've noticed that PAs and MDs bring many of the same skills to a patient encounter and often will give very similar care. $^{2}$ One big difference, to my mind, is perhaps that MDs have done some more rotations in different services than PAs have and so may have a little better understanding of what other practitioners do.

Regardless of those (albeit minor) differences, I think that for the vast majority of patients in a given specialty MDs and PAs will provide care at a very similar level. Being able to respect one another and work together as part of a care team is key to providing a high level of patient care. ${ }^{2}$ I've seen instances in which NPs, PAs and MDs have consulted with one another and all had a different view of the patient. We all bring the same clinical knowledge, but with different philosophies and the healthcare team is best served when we respectfully acknowledge and seek to understand each other's care philosophies. ${ }^{2}$

My experience here has been a very interesting one! Admittedly, I did not know anything about this community before arriving here. But over the course of the last couple of weeks I've been able to see its good and bad sides. Being a rural community with a significant poverty ${ }^{1}$ level and profound lack of healthcare providers, ${ }^{1} \mathrm{Coos}$ County suffers immensely. ${ }^{1}$ I saw many people in the urgent care setting who had very simple ailments, but who could not get in to see their PCP or who did not have PCPs. ${ }^{1}$ I also saw people who had great difficulty ${ }^{1}$ filling prescriptions, were not well informed about their conditions, ${ }^{1}$ and many with diseases that we commonly associated with poverty. ${ }^{1}$

And yet, I also was struck by the tight knit nature of the community ${ }^{1}$ here. Not infrequently, providers would walk into a room and casually greet the patient- knowing them socially, already knowing their illnesses and much of their history! ${ }^{2}$ I could never imagine such a thing happening in Portland. To me, that community cohesion ${ }^{1}$ is the

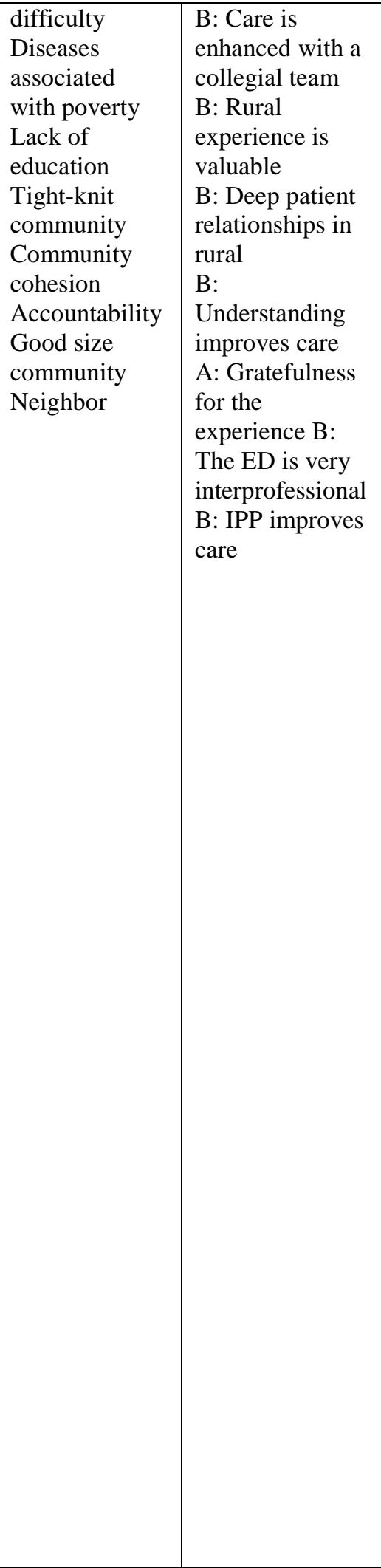


strength of this community; people know each other well enough to enquire and hold one another to account ${ }^{1}$ when something isn't right. I see that as a huge strength for community health if it could be leveraged in the right way by the local physician community. $^{2}$

For me, Coos Bay is a good-sized ${ }^{1}$ community in which to practice medicine. The physicians know one another, work together frequently, and there are enough specialists to be able to get an answer or a referral quickly for most cases. I can see the attraction of working here! ${ }^{2}$

I think it might have been the setting I was in; the Emergency Department is a very interprofessional space where you are working all the time with nurses, RTs, PAs etc. The team was really tight, and it happened really frequently that somebody knew the patient or a patient would be somebody's neighbor ${ }^{1}$ or something like that.

I also got to see PAs working with MDs in the Emergency Department at BAH, and it was very seamless. Really impressive! ${ }^{2}$

The PA there essentially holds the same position as the MD in their 'fast track' urgent care clinic, operating independently and making all the same decisions (workup, orders, dispo) as the MDs. Sometimes when the department was overwhelmed, the PA would join the MDs working with sicker patients to help speed up the flow of people through the department. I got to work under the PA and I learned a lot from hershe had a background in ortho so she taught me about her knee exam, for instance. It was a great example of different professionals working together.

\section{Participant 19: I think the lack of time was} honestly the biggest challenge here. ${ }^{2}$ A month is just not long enough as it is, and two weeks is even less time. I ended up learning a lot of interprofessional communication just by watching the providers here ${ }^{2}$ rather than by actually interacting with my cohort in the clinic. ${ }^{2}$

I would have loved something like a team-building simulation, where we could have acted out our various roles together in a clinical setting. The members of this cohort were delightful and I would have enjoyed spending time with them

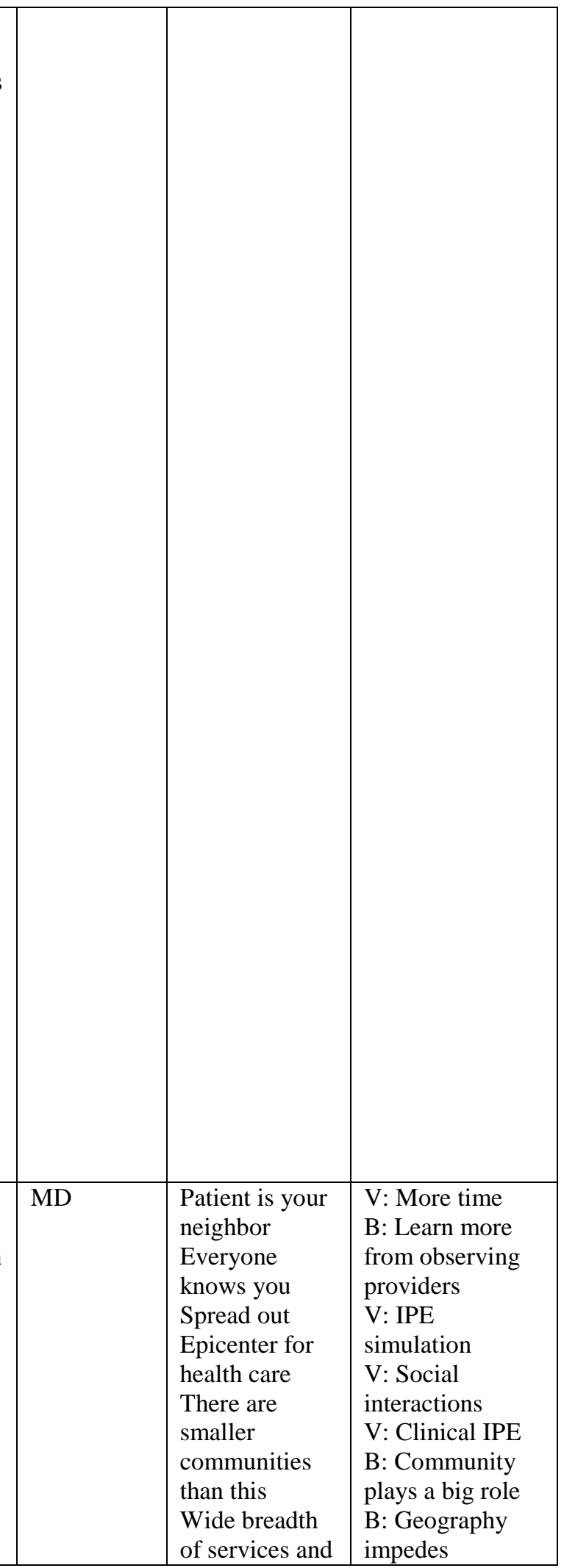


together in a social setting ${ }^{2}$ regardless of their profession, but what I'd really like to see is how we would work together when we're in our ultimate jobs. ${ }^{2}$

It's interesting that you bring up the community portion of it, because that's one of the things I was kind of expecting and didn't see as much. There were certainly elements of this- my physician was the next door neighbor of one of her patients, ${ }^{1}$ for example, and somebody did say that they saw my picture in the newspaper. ${ }^{1}$ But I didn't get the sense that "everybody knows everybody" that I was expecting.

This could be because I spent probably too many nights passing out at 8:00 after long days at the clinic (oops), but I kind of think that the spread of the rural community ${ }^{1}$ contributes to this. ${ }^{2}$ Coos Bay is more of a local epicenter for health care ${ }^{1}$ than, say, Port Orford, so people were coming from many different regions. I got kind of a Portland-y vibe for that reason, with people traveling pretty substantial distances to get care in a community they weren't necessarily part of. ${ }^{2}$ I think I'd like to go to an even smaller community ${ }^{1}$ for a while and see how that differs. I'd like to spend more than a month there, ${ }^{2}$ though . . .

It was really great to get to know colleagues ${ }^{2}$ in the PA program by living with them and spending time with them on weekends and evenings. ${ }^{2} \mathrm{We}$ had a lot of interesting discussions about the intricacies of their program and how it differed from the med school program. I've worked with PAs in prior rotations who have really taken an interest in medical education - in some rotations, I spent more time with the PA supervisors than the actual physicians and learned a lot more from them. ${ }^{2}$ I think this experience was better for getting to know other types of professionals on a personal level. ${ }^{2}$ Although we didn't actually end up working together as students at the clinic frequently, it was definitely interesting seeing the way that NPs and PAs are working in NBMC.

I was intending to work in a rural setting before I came to Coos Bay, so I was considering this experience more of a way to learn how rural medicine works than anything else. I didn't expect this rotation would persuade me to move to a rural area, since I didn't need persuading!

\begin{tabular}{|l|l|} 
specialties & closeness \\
Long wait list & B: People travel \\
Impoverished & from far \\
Not much time & receive care \\
working & V: More time \\
together in the & A: Enjoyment \\
clinic & V: \\
& Interprofessional \\
& preceptors \\
& B: Personal \\
& interactions were \\
& most beneficial \\
& A: Surprised \\
& B: Rural areas \\
& need health care
\end{tabular}

specialties Long wait list for your PCP Not much time together in the clinic closeness from far distances to $\mathrm{V}$ : More time A: Enjoyment $\mathrm{V}$ : preceptors : Persona most beneficial A: Surprised need health care 


\begin{tabular}{|c|c|c|c|}
\hline $\begin{array}{l}\text { I was certain surprised by some aspects of } \\
\text { medicine here. I didn't realize the breadth of } \\
\text { services and specialties available }{ }^{1} \text { in Coos Bay, } \\
\text { despite its population of less than } 50,000 \text { people. I } \\
\text { was expecting a lot more variation in procedures } \\
\text { and quality in rural areas, }{ }^{2} \text { and I didn't really find } \\
\text { that any more than I did in the giant Portland } \\
\text { metropolis. } \\
\text { Some things weren't a surprise, and usually those } \\
\text { weren't good things. I wasn't surprised to see that } \\
\text { most of the adult medicine doctors had a } \\
\text { significant wait list. }{ }^{1} \text { I wasn't surprised to see a } \\
\text { population that was generally much more } \\
\text { impoverished }{ }^{1} \text { than the population I've seen at } \\
\text { other institutions. But this reinforces for me that } \\
\text { rural areas are where I need to be when I } \\
\text { graduate. }\end{array}$ & & & \\
\hline $\begin{array}{l}\text { Participant 20: I didn't know what to expect } \\
\text { coming into this rotation, but I can easily say it's } \\
\text { been one of my most rewarding experiences of my } \\
\text { PA life so far. }{ }^{2} \text { I've loved working with my } \\
\text { interdisciplinary/collaborative }{ }^{1} \text { /transdisciplinary/in } \\
\text { terprofessional classmates. }{ }^{2} \text { I've come away from } \\
\text { this experience feeling a real sense of creativity } \\
\text { and opportunity. }{ }^{2} \text { I've been truly amazed how } \\
\text { welcoming }{ }^{1} \text { the Coos Bay community has been. } \\
\text { There's so much opportunity here and that's really } \\
\text { exciting. } \\
\text { The rural IPE experience really affirmed my } \\
\text { interest in rural health. }{ }^{2} \text { That was one of my } \\
\text { primary interests to begin with, but to be honest I } \\
\text { had started to doubt it a bit toward the end of this } \\
\text { last academic year. Having this opportunity to } \\
\text { learn here has reminded me of why I wanted to } \\
\text { serve as a provider in a more rural community. }{ }^{2} \text { I'll } \\
\text { be sad to leave Coos Bay and all you guys! }\end{array}$ & PA & $\begin{array}{l}\text { Collaborative } \\
\text { Welcoming }\end{array}$ & $\begin{array}{l}\text { A: Satisfied } \\
\text { A: Respected } \\
\text { A: Inspired } \\
\text { A: Astonished } \\
\text { B: Plenty of } \\
\text { opportunity } \\
\text { A: Exhilarated } \\
\text { B: Reinforced } \\
\text { desire for rural } \\
\text { A: Nostalgic }\end{array}$ \\
\hline $\begin{array}{l}\text { Participant 21: I will be honest, I think that } \\
\text { working with a team of interprofessional students } \\
\text { sounds like a really neat idea and I wish I had had } \\
\text { the chance to spend some time in clinic with } \\
\text { students from other professions. }{ }^{2} \\
\text { I really appreciated the chance to live with some } \\
\text { other students. It was surprising }{ }^{2} \text { to see how much } \\
\text { we shared in terms of knowledge and drive, but } \\
\text { equally surprising to see the differences in } \\
\text { perspective that each of our professions brought. } \\
\text { I can see working in a rural setting as being }\end{array}$ & & & $\begin{array}{l}\text { V: More clinical } \\
\text { IPE } \\
\text { V: Living with } \\
\text { other students } \\
\text { A: Amazed } \\
\text { B: Rural care } \\
\text { requires more } \\
\text { collaboration } \\
\text { B: Course did } \\
\text { not add much to } \\
\text { IPE }\end{array}$ \\
\hline
\end{tabular}




\begin{tabular}{|c|c|c|c|}
\hline $\begin{array}{l}\text { something that requires close coordination } \\
\text { between the available providers and specialties; }{ }^{2} \\
\text { this was modeled for me daily by my preceptors }{ }^{2} \\
\text { and the clinical scenarios in which I worked. But I } \\
\text { would say that my IPE class was not the main } \\
\text { driver of this realization. }^{2} \text { I don't mean to sound } \\
\text { harsh or down on the IPE class, because I think it } \\
\text { has the potential to be really something special, } \\
\text { but the way I experienced it, left something to be } \\
\text { desired by way of having interprofessional clinical } \\
\text { experiences. }\end{array}$ & & & \\
\hline $\begin{array}{l}\text { Participant 22: I had worked on a team with a } \\
\text { med student before, and it was a great experience. } \\
\text { While on my inpatient medicine rotation at OHSU, } \\
\text { our team consistent of an MD student, PA student, } \\
\text { intern, first year resident and an attending. I had } \\
\text { wondered if there was going to be some air of } \\
\text { competition or showmanship between the MD } \\
\text { student and myself but that was never the case. We } \\
\text { helped each other through the rotation and had } \\
\text { many of the same responsibilities and } \\
\text { expectations. The rural IPE course further showed } \\
\text { me that the PA/MD relationship is more } \\
\text { collaborative than hierarchical. }{ }^{1}{ }^{2} \text { Between IPE } \\
\text { and the ICAN program, this was the first time I } \\
\text { had worked with dental students. It was great to } \\
\text { hear them explain the importance of dental health } \\
\text { and show the client how to use their equipment. } \\
\text { After this, I took a little bit of extra time during } \\
\text { complete physicals to do a quick assessment of } \\
\text { dentition and I recommended more dental visits to } \\
\text { the patients I saw in clinic this past week. }{ }^{2} \text { I knew } \\
\text { little about rural life before this rotation but I was } \\
\text { able to get a better sense of it by the end. }{ }^{2} \text { I talked } \\
\text { with patients who were ranchers, farmers, who } \\
\text { worked in slaughterhouses, who hunted, and who } \\
\text { lived miles from anyone else. }{ }^{1} \text { I did not have any } \\
\text { of these experiences growing up outside of } \\
\text { Washington DC. The people were nice }{ }^{1} \text { and had no } \\
\text { problem answering my questions about living out } \\
\text { here. I also liked how many of the providers knew } \\
\text { each other }{ }^{2} \text { given that it was a smaller } \\
\text { community, }{ }^{1} \text { and I felt there were more } \\
\text { collaborative relationships. }{ }^{2} \text { And since there were } \\
\text { fewer specialists, I felt the primary care providers } \\
\text { took on additional responsibilities and had a } \\
\text { broader scope. }{ }^{2} \text { It didn't hurt that the lakes and } \\
\text { parks were beautiful }{ }^{1} \text { too. Overall, the Klamath } \\
\text { rural experience increased the likelihood that I } \\
\text { would work in a rural setting. }{ }^{2}\end{array}$ & PA & $\begin{array}{l}\text { Collaborative } \\
\text { Informative } \\
\text { Miles from } \\
\text { anyone else } \\
\text { Nice people } \\
\text { Smaller } \\
\text { community } \\
\text { Beautiful }\end{array}$ & $\begin{array}{l}\text { V: Prior IPE } \\
\text { A: } \\
\text { Uncompetitive } \\
\text { A: Collaborative } \\
\text { B: Positive effect } \\
\text { on my patient } \\
\text { care } \\
\text { B: Better } \\
\text { comprehension } \\
\text { of rural } \\
\text { V: Open } \\
\text { communication } \\
\text { with patients } \\
\text { V: Professional } \\
\text { collaboration } \\
\text { B: Collaboration } \\
\text { leads to better } \\
\text { care } \\
\text { B: Larger scope } \\
\text { for primary care } \\
\text { A: Increased } \\
\text { desire for rural }\end{array}$ \\
\hline Participant 23: I had not previously had the & MD? & Unified goals & A: Gratified \\
\hline
\end{tabular}




\begin{tabular}{|c|c|c|}
\hline $\begin{array}{l}\text { chance to work with PA and DMD students before } \\
\text { and I enjoyed my time }{ }^{2} \text { on this and the ICAN } \\
\text { project. In the context of this community project it } \\
\text { became apparent that if we worked together we } \\
\text { could create a much tighter safety net for our } \\
\text { patients. }{ }^{2} \text { For example, a dentist or PA may see a } \\
\text { patient more often in certain contexts and it makes } \\
\text { sense to have unified goals. }{ }^{1} \text { I also found these } \\
\text { individuals to be a pleasure to work with }{ }^{2} \text { and it } \\
\text { was bittersweet to return to Portland. I hope to } \\
\text { maintain my newfound connections with the PA, } \\
\text { dental, and nursing students and I think that future } \\
\text { collaboration in the future only makes sense. }{ }^{2} \text { In } \\
\text { general I think that rural practice lends itself well } \\
\text { to collaboration }{ }^{2} \text { in this context and this } \\
\text { experience strengthens my view that it is } \\
\text { the preferential way to conduct my future } \\
\text { practice. }\end{array}$ & & $\begin{array}{l}\text { B: Team leads to } \\
\text { better patient } \\
\text { care } \\
\text { A: Satisfied } \\
\text { V: IPP } \\
\text { collaboration } \\
\text { B: Rural is the } \\
\text { best place for } \\
\text { collaboration } \\
\text { B: Impacted my } \\
\text { future practice }\end{array}$ \\
\hline $\begin{array}{l}\text { Participant 24: I have really enjoyed }{ }^{2} \text { living in } \\
\text { interprofessional housing throughout this rotation } \\
\text { and getting to know students from other } \\
\text { professional programs. } .^{2} \text { I think it is always helpful } \\
\text { to learn more about the training of other healthcare } \\
\text { professionals. }{ }^{2} \text { It's nice to compare and contrast } \\
\text { our chosen fields, which is helpful for envisioning } \\
\text { what our future professional collaboration may } \\
\text { look like. }{ }^{2} \text { However, I wouldn't say that working } \\
\text { on the project itself shaped my views. }{ }^{2} \text { While } \\
\text { working on the project, we all just felt like fellow } \\
\text { students. It is similar to looking on a project with } \\
\text { students of various majors in undergrad-something } \\
\text { I we are all very familiar with. I think it was the } \\
\text { time we spent outside of that just hanging out as } \\
\text { peers that was beneficial. } \\
\end{array}$ & $\begin{array}{l}\text { Barriers to } \\
\text { accessing care } \\
\text { Overcome } \\
\text { Strong sense } \\
\text { of community } \\
\text { Rewarding } \\
\text { Isolated } \\
\text { Support } \\
\text { Resourceful }\end{array}$ & $\begin{array}{l}\text { A: Enjoyment } \\
\text { V: Living with } \\
\text { other students } \\
\text { B: Beneficial to } \\
\text { learn about other } \\
\text { professions } \\
\text { B: Brought } \\
\text { clarity to future } \\
\text { practice } \\
\text { B: Social time } \\
\text { was the most } \\
\text { beneficial } \\
\text { B: Prior rural } \\
\text { experience was } \\
\text { the most helpful } \\
\text { V: More time } \\
\text { B: Rural practice } \\
\text { is rewarding } \\
\text { A: Inclusive } \\
\text { A: Enjoyment } \\
\text { B: Living } \\
\text { together was the } \\
\text { best part } \\
\text { B: Different } \\
\text { schedules was } \\
\text { challenging } \\
\text { B: Re-framed } \\
\text { perspective of } \\
\text { rural }\end{array}$ \\
\hline
\end{tabular}




\begin{tabular}{|c|c|c|}
\hline $\begin{array}{l}\text { of. I did really enjoy my time here in Coos Bay } \\
\text { and learning about the local community. }{ }^{2} \\
\text { I completely agree. Having other students coming } \\
\text { and going while working on the project did make } \\
\text { some details difficult. I also agree that the best part } \\
\text { of the interprofessional experience was just living } \\
\text { and hanging out together. } \\
\text { I also was surprised by the size of the Coos Bay } \\
\text { community! It is certainly larger than what I } \\
\text { picture when I think of rural communities. } \\
\text { Although, Coos Bay is somewhat isolated from } \\
\text { any large cities. }{ }^{1} \text { I have also been impressed with } \\
\text { all the support }{ }^{1} \text { in place here. They have done a } \\
\text { great job with the resources they have! }\end{array}$ & & \\
\hline $\begin{array}{l}\text { Participant 25: The most helpful part of the rural } \\
\text { campus was the opportunity to live with peers } \\
\text { from different professions. }{ }^{2} \text { It was around the } \\
\text { dining room table that the most interesting } \\
\text { conversations occurred, learning about each other's } \\
\text { programs, roles, and experiences. }{ }^{2} \text { I've always } \\
\text { looked forward to a career that would allow me to } \\
\text { collaborate }{ }^{1} \text { with and learn from other professions, } \\
\text { and this experience has confirmed that desire. } \\
\text { Understanding that everyone for the most part } \\
\text { shares the same goals of improving the lives of } \\
\text { their patients as well as themselves makes } \\
\text { professional work enjoyable. }{ }^{2} \text { The biggest } \\
\text { challenge was collaborating with students from } \\
\text { other programs simply because our schedules did } \\
\text { not line up, }{ }^{2} \text { so we were constantly losing } \\
\text { members of the team or gaining new ones, making } \\
\text { it difficult to keep everyone on the same page. } \\
\text { Even so, the few chances we had to all work } \\
\text { together were enjoyable. }{ }^{2} \text { My biggest surprise in } \\
\text { coming to this community was that it didn't feel all } \\
\text { that rural. While the community certainly has its } \\
\text { needs, I feel that those needs are met with an } \\
\text { abundance of resources and support systems, }{ }^{2} \\
\text { which makes rural practice more appealing. I did } \\
\text { enjoy working within a multidisciplinary clinic } \\
\text { and seeing my preceptor not hesitate to utilize the } \\
\text { expertise of those around her. I had planned on } \\
\text { working in a rural community before this } \\
\text { rotation and this experience confirmed that plan. } \\
\text { Yes. To everything. I thought time outside of class } \\
\text { with other students was the best part of the } \\
\text { experience too, and where I learned the most. }{ }^{2} \\
\text { And you're right - I think the best part of rural } \\
\text { practice is getting to be an integral part of }\end{array}$ & Collaborative & $\begin{array}{l}\text { V: Living with } \\
\text { peers } \\
\text { B: Organic } \\
\text { conversations } \\
\text { yielded the most } \\
\text { A: Confirming } \\
\text { V: Common } \\
\text { goals } \\
\text { B: Different } \\
\text { schedules were a } \\
\text { hindrance to IPE } \\
\text { A: Pleasant } \\
\text { A: Amazed } \\
\text { B: Not as rural as } \\
\text { labeled } \\
\text { B: Needs met } \\
\text { through } \\
\text { supportive } \\
\text { environment } \\
\text { A: Enjoyment } \\
\text { B: IPP utilizes } \\
\text { the expertise } \\
\text { around you } \\
\text { A: Confirming } \\
\text { V: More time }\end{array}$ \\
\hline
\end{tabular}




\begin{tabular}{|c|c|c|c|}
\hline $\begin{array}{l}\text { something, and that's impossible to get in such a } \\
\text { short amount of time. We'll have to graduate and } \\
\text { find out for ourselves! }\end{array}$ & & & \\
\hline $\begin{array}{l}\text { Participant 26: This entire external rotation, class, } \\
\text { and project has been a very eye opening } \\
\text { experience. }{ }^{2} \text { Even though dental professionals are } \\
\text { medical professionals, a lot of the medical issues } \\
\text { covered in our exercises and discussions are a tad } \\
\text { bit foreign to me and I enjoy just sitting back and } \\
\text { absorbing the information presented to me and that } \\
\text { is discussed. What I have gathered from all these } \\
\text { discussions is that I surely need to focus on my } \\
\text { patient's overall health and be in discussion with } \\
\text { their other health providers to ensure that their } \\
\text { entire being is being cared for and not just their } \\
\text { oral cavity. } \\
\\
\text { Rural IPE experiences has shown that working in } \\
\text { the rural community has a different flavor in that } \\
\text { health professionals often have expanded roles } \\
\text { compared to their counterparts in an urban } \\
\text { setting. }{ }^{1,2} \text { There aren't as many specialists, so they } \\
\text { need to cover more ground }{ }^{1} \text { in order to treat all of } \\
\text { their patients' needs. } \\
\text { Yes I have very much enjoyed our interactions } \\
\text { outside of the IPE course and coursework. } \\
\text { Hanging out as fellow students or even just } \\
\text { humans has been fun to discuss different } \\
\text { upbringings and experiences experienced while on } \\
\text { rotation or in school. When it boils down to the } \\
\text { basics, it shows that we are all having similar } \\
\text { struggles and strengths in our respective programs, } \\
\text { and it is refreshing to be around fresh faces and be } \\
\text { able to discuss professional school experiences. } \\
\end{array}$ & Dental & $\begin{array}{l}\text { Expanded role } \\
\text { Cover more } \\
\text { ground } \\
\text { Lack diversity }\end{array}$ & $\begin{array}{l}\text { B: Rural IPE } \\
\text { expands thinking } \\
\text { A: Teachable } \\
\text { V: Holistic view } \\
\text { of the patient } \\
\text { B: Rural } \\
\text { providers have } \\
\text { an enlarged role } \\
\text { V: Social } \\
\text { interactions } \\
\text { V: Fresh } \\
\text { perspectives } \\
\text { A: Enjoyable } \\
\text { A: Sarcastic } \\
\text { A: Agreement } \\
\text { B: Not so rural }\end{array}$ \\
\hline
\end{tabular}




\begin{tabular}{|c|c|c|c|}
\hline $\begin{array}{l}\text { Participant 27: I think that working with other } \\
\text { professions has been a great way to better } \\
\text { understand the nature of their work, }{ }^{2} \text { especially in } \\
\text { a rural setting. }{ }^{2} \text { It has been great to work on our } \\
\text { rural campus project together and to get to know } \\
\text { the medical and dental students in a more casual } \\
\text { setting like home or out for food. }{ }^{2} \text { Each profession } \\
\text { had their own unique set of skills to bring to our } \\
\text { IPE project and it was a delight getting to see } \\
\text { everyone contribute in a slightly different way. }{ }^{2} \text { In } \\
\text { terms of future work, having a clinical rotation } \\
\text { with a physician, NP and psychologist has has } \\
\text { been such a positive experience that I almost } \\
\text { demand for my future job a multidisciplinary team } \\
\text { like that. }{ }^{2} \text { It can only facilitate better patient care } \\
\text { and provider interactions. } \\
\text { I had always planned on working in a rural } \\
\text { location. I have to say that this rotation certainly } \\
\text { helped cement that belief, especially after such a } \\
\text { positive clinical and IPE experience. }\end{array}$ & & Proud & $\begin{array}{l}\text { B: Rural IPE is } \\
\text { wonderful } \\
\text { V: Social } \\
\text { interactions } \\
\text { B: The course is } \\
\text { a great } \\
\text { mechanism for } \\
\text { IPE } \\
\text { A: Happiness } \\
\text { A: Affirmative } \\
\text { B: Will seek IPP } \\
\text { as a provider } \\
\text { B: Varying } \\
\text { schedules is a } \\
\text { barrier } \\
\text { A: Pleased }\end{array}$ \\
\hline $\begin{array}{l}\text { Participant 28: Working on this project with PA's } \\
\text { and Med students has been great. }{ }^{2} \text { My teammates } \\
\text { are smart and insightful people who I know will } \\
\text { make a great difference in healthcare. }{ }^{2} \text { It really is a } \\
\text { team effort for total health and we can all feed off } \\
\text { of each other and offer support for each other in } \\
\text { complex cases. }{ }^{2} \text { And sure I think the oral cavity is } \\
\text { a very important section of the human anatomy, } \\
\text { but I can't cure it all and not even } 1 / 10 \text { of } \\
\text { someone's body. }{ }^{2} \text { So it's important to work in } \\
\text { teams especially in rural communities. }{ }^{2} \text { I love } \\
\text { smaller }{ }^{1} \text { communities because when you want to } \\
\text { make a difference, it actually seems to help a lot } \\
\text { more than if it were a large town and what you } \\
\text { actually accomplished was a rain drop in the } \\
\text { ocean. Here it seems to matter more. } \\
\text { Overall my rural experience with Klamath } \\
\text { Advantage has been amazing. I am really proud of } \\
\text { the work I've achieved here. }{ }^{2} \text { I was able to be a }\end{array}$ & Dental & Smaller & $\begin{array}{l}\text { A: Positive } \\
\text { A: Appreciation } \\
\text { V: Whole group } \\
\text { contribution } \\
\text { B: Need other } \\
\text { providers for } \\
\text { good care } \\
\text { B: Team-based } \\
\text { care is needed in } \\
\text { rural } \\
\text { B: Greater } \\
\text { impact in rural } \\
\text { A: Gratified } \\
\text { V: Making a } \\
\text { difference }\end{array}$ \\
\hline
\end{tabular}




\begin{tabular}{|c|c|c|c|}
\hline $\begin{array}{l}\text { part of the standard of care and help set that bar: be } \\
\text { a larger drop of water in the ocean. }\end{array}$ & & & \\
\hline $\begin{array}{l}\text { Participant 29: Working with students studying } \\
\text { different fields within the health profession has } \\
\text { reinforced my belief that health care should be an } \\
\text { open and fluid system. } .^{2} \text { In order to provide the best } \\
\text { health care for every individual, I believe that a } \\
\text { patient's doctors, physical therapists, nurses, } \\
\text { physician's assistants, and dentists should be aware } \\
\text { of the entire picture. } .^{2} \text { A health care provider } \\
\text { cannot expect to provide the best possible care for } \\
\text { a patient if they do not take every other aspect of } \\
\text { their patient's health into account. }{ }^{2} \text { Working with } \\
\text { this group of students has been eye opening. }{ }^{2} \\
\text { There is a real connection between every } \\
\text { provider. }{ }^{2} \text { Everyone has been open and interested } \\
\text { in feedback. }{ }^{2} \text { There has been a real give and take } \\
\text { between every member of the team. }{ }^{2} \text { We are all } \\
\text { equals, but we each bring something different to } \\
\text { the team. I can only hope that in the future my } \\
\text { experience with people from other health } \\
\text { professions is as strong and positive. } \\
\\
\text { Working in the rural community has opened my } \\
\text { mind up to the possibility of one day working in } \\
\text { this setting. }{ }^{2} \text { The IPE experience has shown me } \\
\text { that there is a lot of need in rural communities. }{ }^{1} \\
\text { Studying the kinds of issues that are predominate } \\
\text { in this community is essential to realizing the } \\
\text { needs that are lacking }{ }^{1} \text { in this community. I want } \\
\text { to be a dentist who does good work for people in } \\
\text { need. If I happen to have the opportunity in } \\
\text { Klamath Falls again or in another rural setting, I } \\
\text { would not be opposed to it. }{ }^{2}\end{array}$ & Dental & $\begin{array}{l}\text { A lot of need } \\
\text { Needs are } \\
\text { lacking }\end{array}$ & $\begin{array}{l}\text { B: Health care } \\
\text { should be } \\
\text { available and } \\
\text { easy to navigate } \\
\text { B: } \\
\text { Communication } \\
\text { and collaboration } \\
\text { are essential } \\
\text { V: Holistic care } \\
\text { A: Eye-opening } \\
\text { B: Provider } \\
\text { connectedness } \\
\text { B: Reciprocal } \\
\text { give and take } \\
\text { B: Everyone is } \\
\text { teachable } \\
\text { V: Feedback } \\
\text { A: Upbeat } \\
\text { A: Open-minded } \\
\text { B: Rural } \\
\text { communities } \\
\text { have big needs } \\
\text { B: Need to } \\
\text { provide informed } \\
\text { care }\end{array}$ \\
\hline $\begin{array}{l}\text { Participant 30: The opportunity to work with a } \\
\text { team of interprofessional students has been a } \\
\text { chance to learn from and learn how to better } \\
\text { support people in different professions as we } \\
\text { continue to move forward in our careers. }{ }^{2} \text { In } \\
\text { discussing }^{2} \text { this project specifically, I had a better } \\
\text { understanding of the training involved with each } \\
\text { profession and the skill set that each brought with } \\
\text { them. }{ }^{2} \text { In talking less formally, it was wonderful to } \\
\text { connect over shared experiences in health care but } \\
\text { also to hear the daily ups and downs that students } \\
\text { of different professions face. }{ }^{2} \text { It gave me a better } \\
\text { sense of my limitations and realms of expertise in } \\
\text { the broad field that is health care and recognize } \\
\text { when another's perspective or advice would be } \\
\text { helpful. }{ }^{2} \text { It also helped me to realize what } \\
\text { behaviors and strategies I can use in the future to }\end{array}$ & & $\begin{array}{l}\text { Strong ties } \\
\text { Interdependent } \\
\text { upon one } \\
\text { another }\end{array}$ & $\begin{array}{l}\text { V: Learning } \\
\text { opportunities } \\
\text { B: } \\
\text { Communication } \\
\text { is learning } \\
\text { A: Ideal } \\
\text { B: Informal } \\
\text { communication } \\
\text { is beneficial } \\
\text { A: Self- } \\
\text { realization } \\
\text { A: Absorbing } \\
\text { B: Improved } \\
\text { understanding of } \\
\text { support needed } \\
\text { B: Rural health } \\
\text { is interconnected }\end{array}$ \\
\hline
\end{tabular}




\begin{tabular}{|c|c|}
\hline $\begin{array}{l}\text { ensure other health care staff are supported. } \\
\text { The rural IPE experience has strengthened my } \\
\text { understanding of community support in a rural } \\
\text { setting. }{ }^{2} \text { The partners with whom we work on this } \\
\text { project, the ties each of the team members have in } \\
\text { the community, and the influence of my rotation } \\
\text { on my work on this research all seem to have } \\
\text { multiple connections in this health care network. } \\
\text { While I think this also exists in a more urban } \\
\text { setting, I feel that these ties are somehow stronger, } \\
\text { more interdependent }{ }^{2} \text { upon one another because of } \\
\text { the setting. }{ }^{1} \text { Communication and partnership } \\
\text { somehow seems more personal. }{ }^{2} \text { I think that is one } \\
\text { of the aspects I have enjoyed the most about this } \\
\text { experience. It has made working in a rural setting a } \\
\text { goal for my future. }{ }^{2}\end{array}$ & $\begin{array}{l}\text { B: Rural health } \\
\text { is more } \\
\text { interdependent } \\
\mathrm{B} \text { : } \\
\text { Communication } \\
\text { is more personal } \\
\text { A: Desire for } \\
\text { rural }\end{array}$ \\
\hline
\end{tabular}




\section{APPENDIX D}

Values coding Categorization Table

\begin{tabular}{|c|c|}
\hline Values & \\
\hline Social time & \\
\hline Multiple professions & \\
\hline IPE & \\
\hline Hanging out & \\
\hline Community project & \\
\hline Working with other professions & \\
\hline Community project & Key \\
\hline Living with others students & \\
\hline $\begin{array}{l}\text { Collaborative environment } \\
\text { Distinctive }\end{array}$ & Code - Social Connectedness \\
\hline Collective & Code - Role Appreciation \\
\hline Personal interaction & Code - Collegiality \\
\hline Making a difference & Code - Rural Appeal \\
\hline Living with other students & Code - Patient Centered \\
\hline Drive to succeed & Code - Education \\
\hline More interprofessional & Code-Challenges \\
\hline Stable housing & \\
\hline Matching skill sets & \\
\hline IPE work & \\
\hline Learning about other professions & \\
\hline Deeper level of care & \\
\hline Available resources & \\
\hline Patient's point of view & \\
\hline Rural learning environment & \\
\hline Family planning & \\
\hline Living together & \\
\hline Learned about others & \\
\hline Professional learning & \\
\hline Making a difference & \\
\hline Engaged provider & \\
\hline Professional interaction & \\
\hline Personal mentorship & \\
\hline Nonclinical interactions & \\
\hline Strong professional relationships & \\
\hline Collegiality & \\
\hline Mentor's involvement & \\
\hline Learning about other professions & \\
\hline Experience separate from IPE & \\
\hline Working together in clinic & \\
\hline Living with classmates & \\
\hline
\end{tabular}




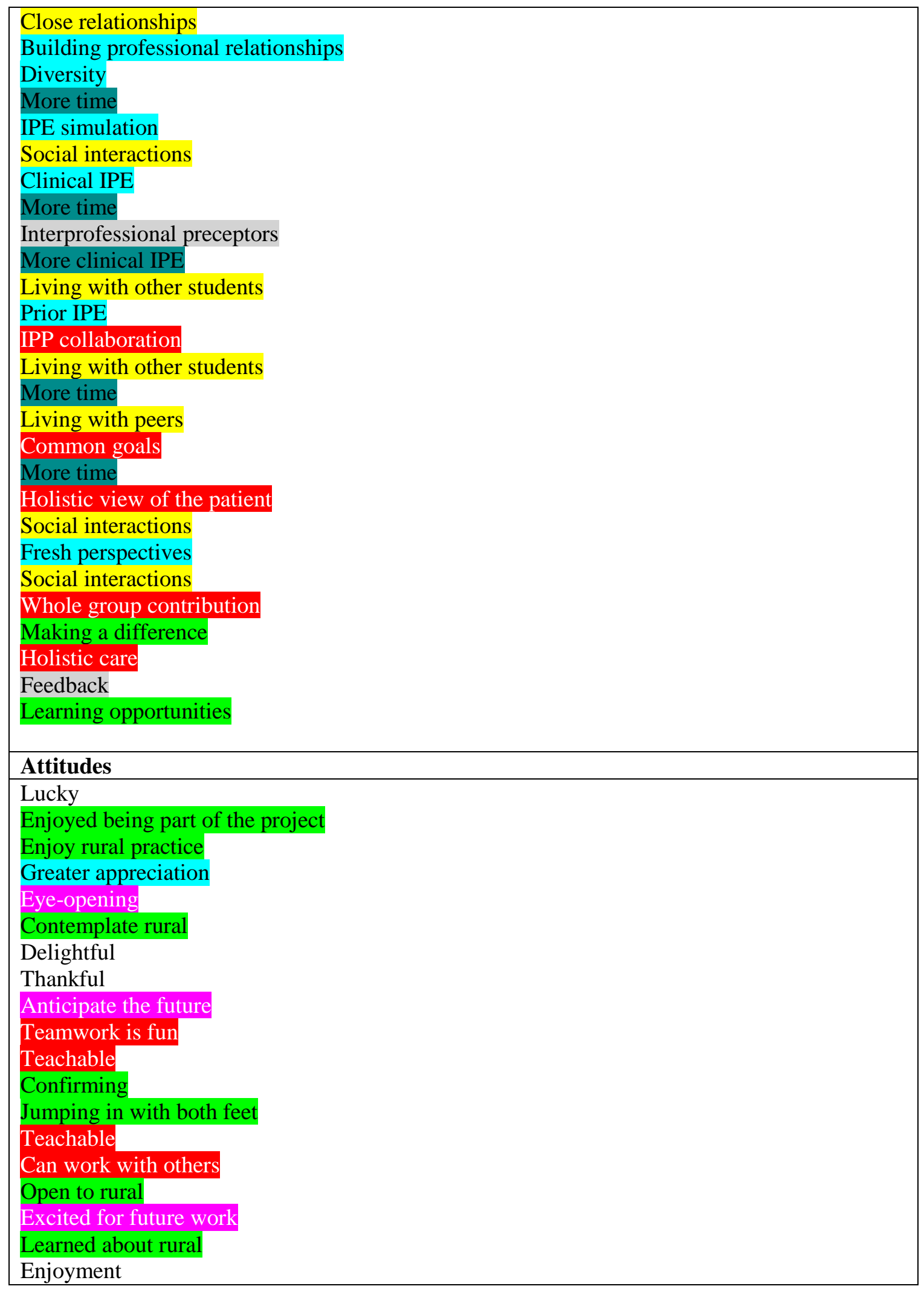




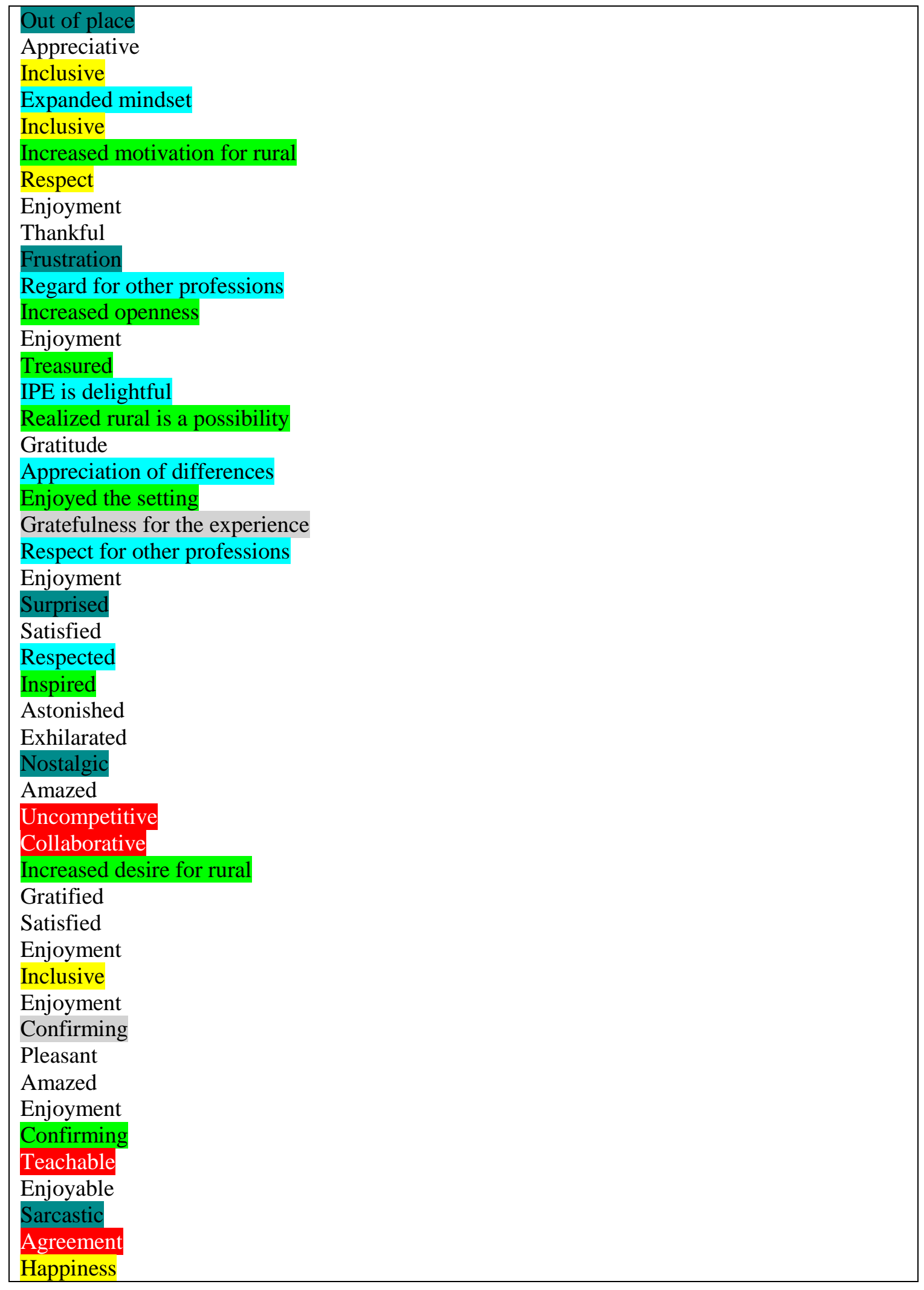




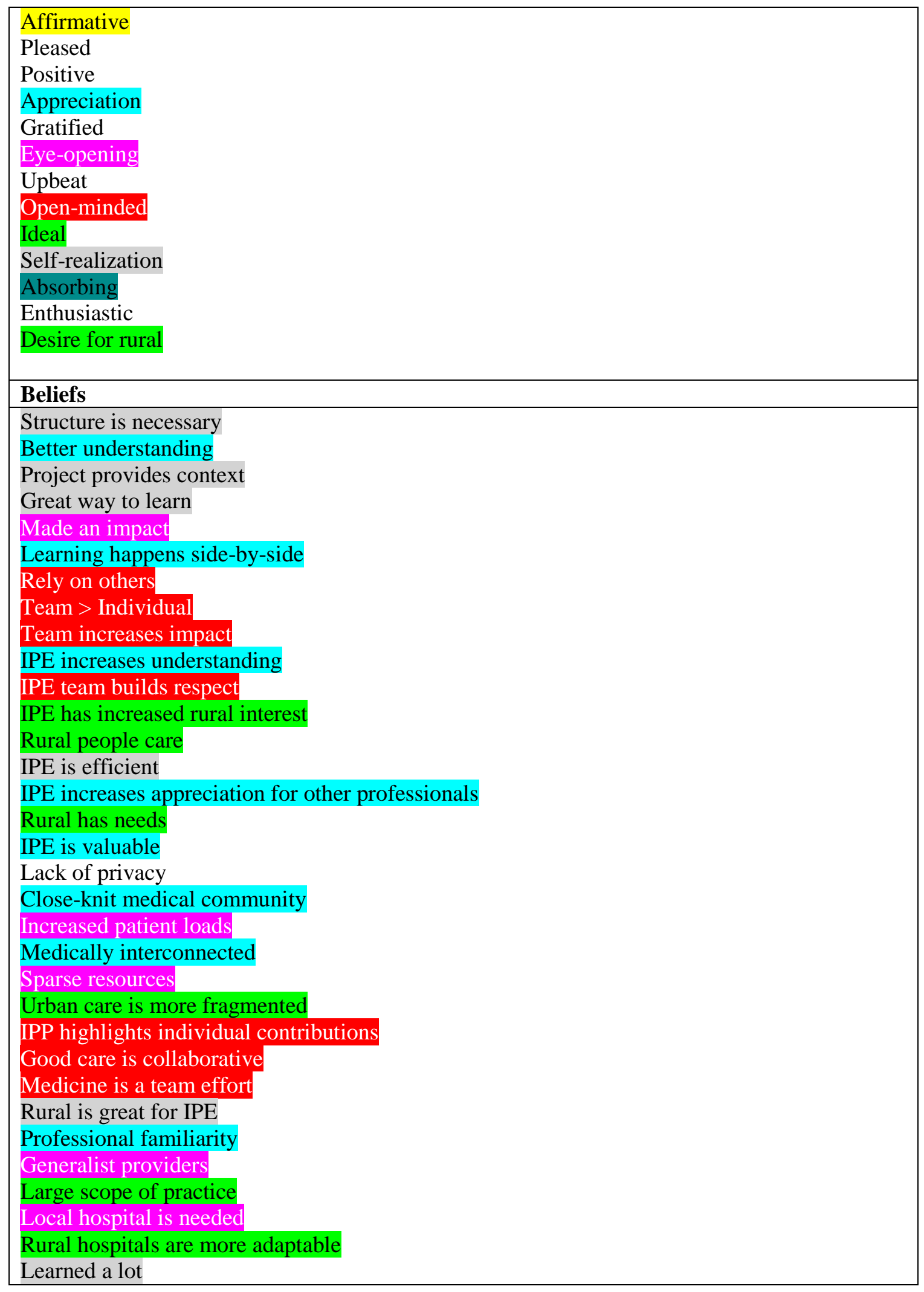




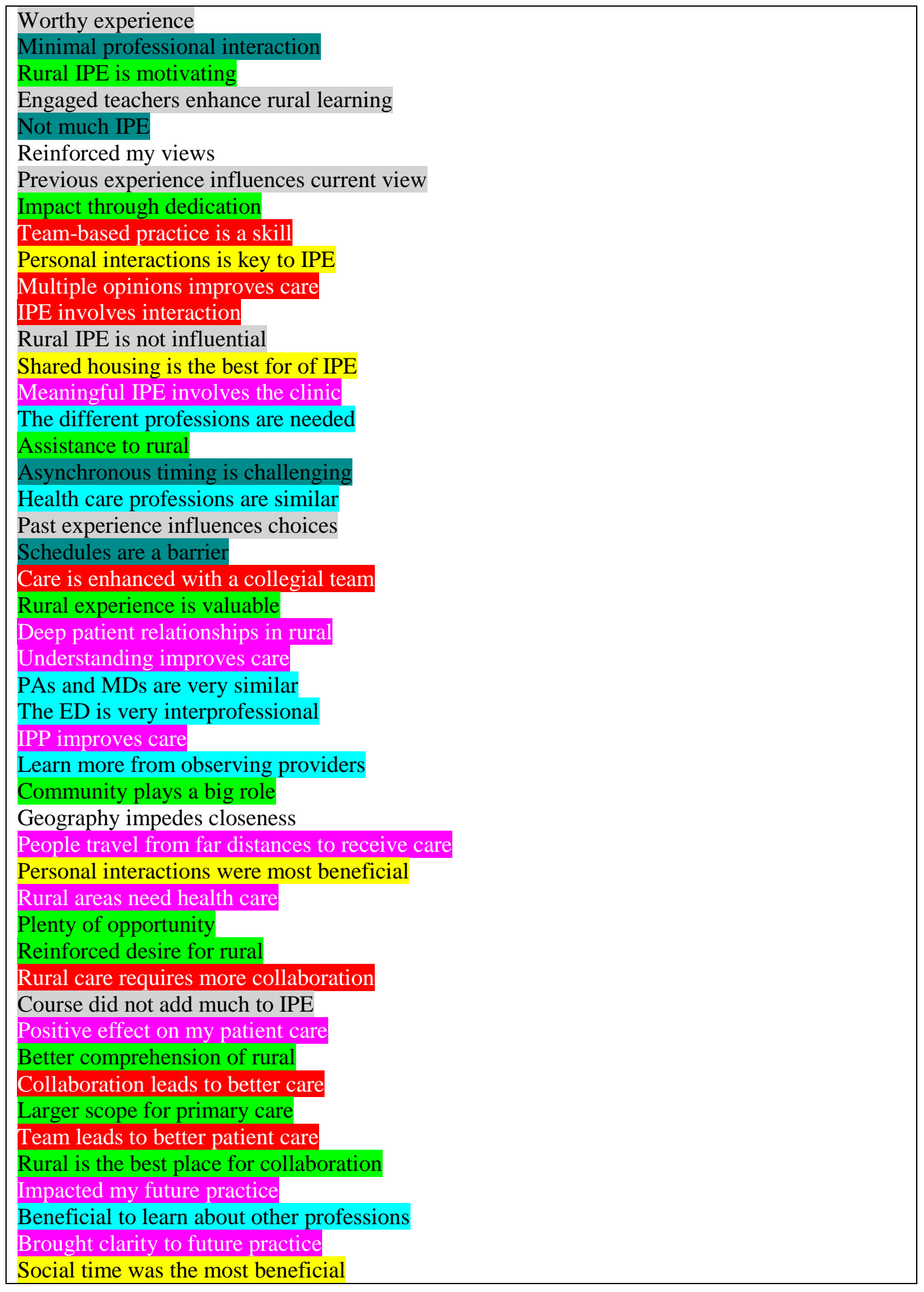




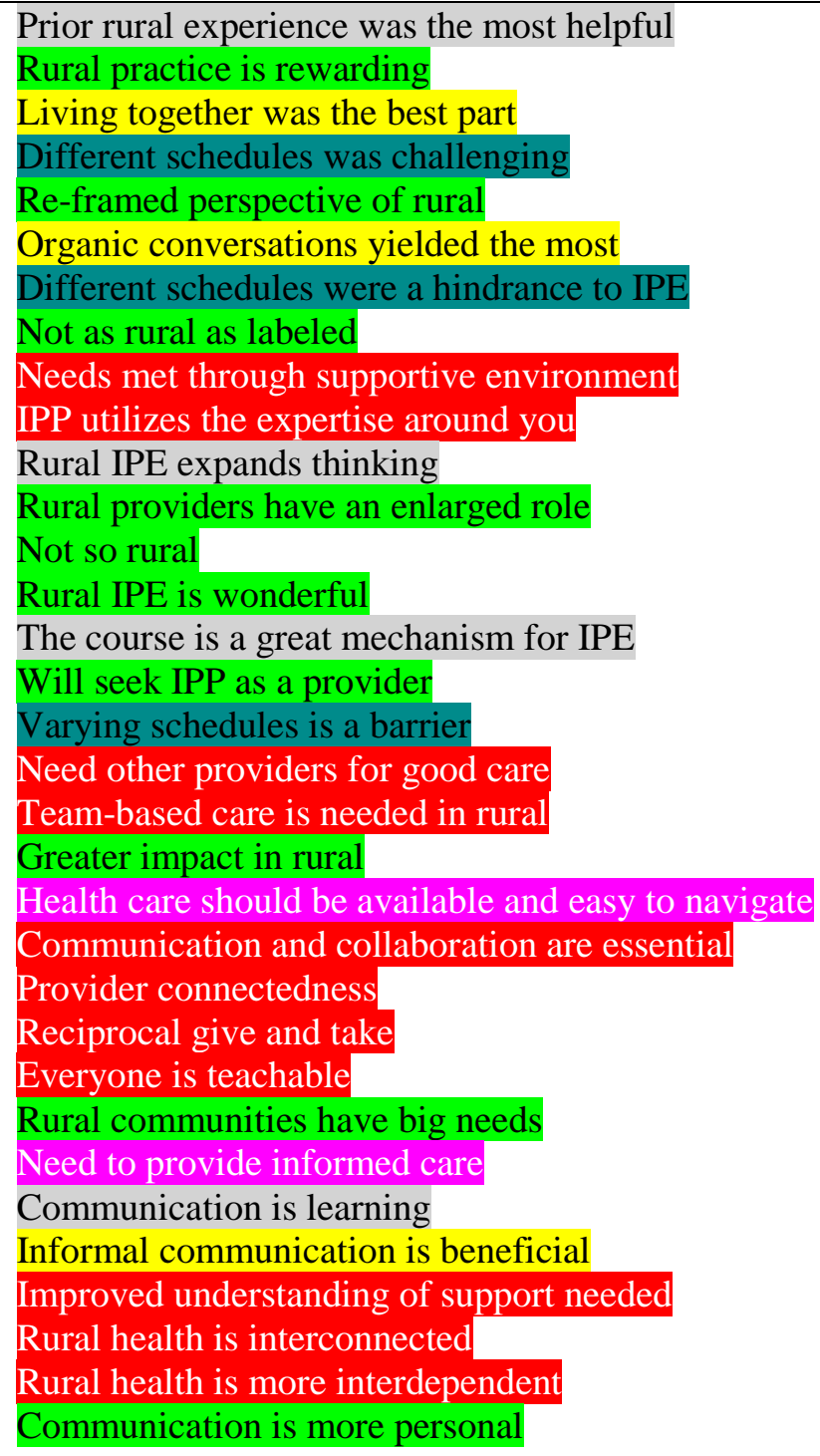




\section{APPENDIX E}

\section{Example of Completed Q Sort and Corresponding Email}

flashe.

Somebody

Some street 100

Some city

Please send this printout to address mentioned above. Thanks for you help.

\begin{tabular}{|c|c|c|c|}
\hline $\begin{array}{l}\text { Study: } \\
11-1611: 18\end{array}$ & $\begin{array}{l}\text { Rural Interprofessional Health Care Education: } \\
\text { NEG: } 11\end{array}$ & A Study of Student Perspectives 1.0 & Date:2016- \\
\hline User-id: & - ne- & 345 & $\begin{array}{l}\text { NEU: } 14 \\
\text { POS: } 11\end{array}$ \\
\hline
\end{tabular}

\begin{tabular}{|l|l|l|l|l|l|l|l|l|l|l|l|l|}
\hline $\mathbf{- 5}$ & $-\mathbf{4}$ & $\mathbf{- 3}$ & $\mathbf{- 2}$ & $\mathbf{- 1}$ & $\mathbf{0}$ & $\mathbf{+ 1}$ & $\mathbf{+ 2}$ & $\mathbf{+ 3}$ & $\mathbf{+ 4}$ & $\mathbf{+ 5}$ \\
\hline & 12 & 10 & 20 & 23 & 14 & 1 & 11 & 7 & 31 & 32 & 18 \\
\hline & 19 & 29 & 8 & 26 & 24 & 5 & 30 & 4 & 13 & \\
\hline & & 2 & 25 & 28 & 15 & 27 & 22 & 33 & \\
\hline & & 34 & 36 & 9 & 3 & 35 & & \\
& & & 17 & 16 & 21 & & & \\
& & & & & & &
\end{tabular}

form0: 1975
form 1: 2
form2: 1
form3: 1
form4: 1
form5: 이1|이이이0
form6: 1

form6: 1 


\section{Curt Stilp}

\section{From: \\ Sent: \\ To:}

Subject:

\section{Curt Stilp}

Wednesday, November 16, 2016 11:19 AM

Curt Stilp

FlashQ/Rural Interprofessional Health Care Education: A Study of Student Perspectives 1.0

Thank you for participating in our survey. Please do not modify the following text:

name: Rural Interprofessional Health Care Education: A Study of Student Perspectives 1.0 sort: $0|-3|+1|+3|+1|0|+2|-2| 0|-4|+1|-5|+4|-1| 0|0|-1|+5|-4|-3|+1|+2|-2|0|-2|-1|+1|-1|-3|+2|+3|+4|+3 \mid-$

$2|+2|-1$

nneg: 11

nneu: 14

npos: 11

form0: 1975

form 1: 2

form 2: 1

form $3: 1$

form $4: 1$

form5: $01110|0| 0 \mid 0$

form6: 1

duro: 345

dur1: 68

dur2: 82

dur3: 13

dur4: 0

dur5: 180

Mail generated by FlashQ 


\section{APPENDIX F}

The Un-Rotated Factor Matrix

\begin{tabular}{|c|c|c|c|c|c|c|c|c|}
\hline & \multicolumn{8}{|c|}{ Factors } \\
\hline $\begin{array}{c}\mathrm{Q} \\
\text { Sort }\end{array}$ & 1 & 2 & 3 & 4 & 5 & 6 & 7 & 8 \\
\hline 1 & 0.4801 & 0.6118 & -0.0594 & -0.0426 & 0.1095 & -0.1291 & -0.1377 & 0.0757 \\
\hline 2 & 0.6547 & -0.2351 & -0.0458 & 0.3994 & 0.0140 & -0.1303 & 0.2766 & 0.0282 \\
\hline 3 & 0.5630 & 0.0404 & 0.0111 & 0.4102 & -0.2915 & 0.2126 & -0.4136 & -0.0117 \\
\hline 4 & 0.7624 & -0.1681 & 0.2092 & 0.0183 & 0.1251 & 0.0476 & -0.0449 & 0.1045 \\
\hline 5 & 0.5621 & 0.4013 & -0.3238 & -0.0302 & -0.0921 & -0.1476 & -0.1235 & 0.4038 \\
\hline 6 & 0.3976 & 0.1529 & -0.0870 & 0.1160 & -0.3891 & -0.5088 & -0.0258 & 0.2872 \\
\hline 7 & 0.3296 & 0.3810 & -0.0819 & 0.5227 & 0.1384 & 0.3340 & -0.0800 & 0.1612 \\
\hline 8 & 0.6214 & 0.0238 & 0.1345 & 0.2473 & 0.5072 & -0.1063 & 0.1833 & 0.2783 \\
\hline 9 & 0.5580 & -0.4677 & 0.0689 & 0.3507 & -0.1133 & 0.3138 & 0.0274 & 0.0657 \\
\hline 10 & 0.4692 & 0.5772 & -0.0323 & -0.0928 & -0.0799 & 0.0932 & 0.2310 & 0.2151 \\
\hline 11 & 0.7605 & 0.1022 & 0.1153 & 0.1637 & 0.1188 & -0.1175 & -0.1698 & -0.0902 \\
\hline 12 & 0.3079 & 0.4688 & -0.0582 & -0.2634 & -0.0878 & 0.2603 & 0.2504 & 0.3552 \\
\hline 13 & 0.6958 & -0.0150 & -0.3227 & -0.1998 & 0.2261 & -0.1396 & -0.0996 & -0.2083 \\
\hline 14 & 0.7480 & 0.2451 & 0.1143 & -0.1960 & -0.1085 & 0.1081 & -0.2299 & -0.0933 \\
\hline 15 & 0.4480 & 0.5459 & 0.5029 & -0.0888 & 0.0730 & -0.0331 & 0.1278 & -0.2797 \\
\hline 16 & 0.6857 & 0.2472 & 0.0344 & -0.2987 & 0.1915 & -0.1453 & -0.1667 & -0.0466 \\
\hline 17 & 0.6174 & -0.3580 & 0.2875 & -0.2381 & 0.1929 & -0.0003 & 0.1438 & 0.0047 \\
\hline 18 & 0.4480 & 0.5459 & 0.5029 & -0.0888 & 0.0730 & -0.0331 & 0.1278 & -0.2797 \\
\hline 19 & 0.7137 & -0.1886 & 0.0309 & -0.3033 & 0.2092 & 0.0071 & -0.0420 & -0.0361 \\
\hline 20 & 0.6961 & 0.3115 & 0.2835 & 0.1866 & -0.1142 & -0.1935 & 0.0183 & 0.0156 \\
\hline 21 & 0.3151 & 0.3870 & 0.2614 & 0.2155 & -0.0398 & 0.4855 & 0.0484 & -0.1422 \\
\hline 22 & 0.7746 & -0.1465 & -0.3087 & 0.1295 & -0.1598 & 0.1269 & 0.0156 & -0.0760 \\
\hline 23 & 0.7601 & -0.0863 & -0.1786 & 0.1058 & 0.0622 & 0.0844 & -0.0751 & 0.2483 \\
\hline 24 & -0.1583 & 0.4504 & -0.5659 & 0.1467 & 0.4440 & 0.1616 & -0.0125 & 0.0690 \\
\hline 25 & 0.5385 & -0.0239 & -0.2044 & -0.2283 & 0.0480 & -0.1856 & -0.2509 & -0.1528 \\
\hline 26 & 0.3697 & -0.5041 & 0.0129 & 0.1293 & 0.4534 & 0.3126 & 0.0913 & -0.0959 \\
\hline 27 & 0.7637 & -0.1333 & -0.3167 & -0.3275 & -0.0984 & -0.0536 & 0.0218 & 0.0504 \\
\hline 28 & 0.6325 & -0.2754 & -0.3311 & -0.3372 & -0.1341 & 0.0525 & 0.1886 & 0.1058 \\
\hline 29 & 0.6165 & 0.2271 & -0.1235 & 0.0724 & -0.3206 & -0.0135 & -0.1946 & -0.2204 \\
\hline 30 & 0.7364 & -0.0512 & -0.1539 & -0.2043 & 0.0980 & 0.1512 & -0.2231 & 0.2179 \\
\hline 31 & 0.7818 & 0.2691 & -0.1388 & -0.2074 & 0.1271 & 0.0392 & 0.0052 & -0.0896 \\
\hline 32 & 0.6762 & -0.1613 & 0.2129 & 0.0495 & 0.0763 & -0.1816 & 0.2749 & -0.1704 \\
\hline 33 & 0.6161 & -0.4229 & 0.0314 & 0.0658 & -0.2729 & 0.0019 & 0.2785 & 0.1169 \\
\hline 34 & 0.7232 & -0.3400 & 0.1322 & 0.1547 & 0.0835 & -0.1551 & 0.1056 & 0.0731 \\
\hline 35 & 0.2593 & 0.2097 & 0.6151 & -0.1667 & -0.1154 & 0.0254 & -0.0549 & 0.3305 \\
\hline 36 & 0.6484 & -0.3196 & 0.1171 & -0.3130 & 0.3676 & 0.0807 & -0.0404 & 0.1391 \\
\hline 37 & 0.4970 & -0.2495 & 0.4596 & 0.2474 & -0.1805 & 0.1819 & -0.1222 & 0.1406 \\
\hline 38 & 0.6037 & -0.1722 & -0.5608 & 0.1496 & -0.1090 & 0.0280 & 0.0835 & -0.1655 \\
\hline 39 & 0.7435 & -0.1913 & -0.1637 & 0.0644 & -0.3470 & -0.0144 & -0.0060 & -0.2085 \\
\hline 40 & 0.7025 & -0.2304 & -0.0094 & -0.0961 & -0.2891 & 0.0021 & 0.3662 & -0.0717 \\
\hline 41 & 0.4757 & 0.0732 & -0.0642 & 0.4807 & 0.2186 & -0.2253 & -0.3602 & -0.1002 \\
\hline 42 & -0.0121 & 0.7261 & -0.1098 & 0.2100 & -0.0616 & -0.0648 & 0.4016 & 0.0194 \\
\hline
\end{tabular}




\begin{tabular}{|l|rrrrrrrr|}
\hline 43 & 0.7815 & 0.0474 & 0.2535 & 0.0301 & -0.0567 & -0.0777 & -0.0309 & -0.2294 \\
44 & 0.0634 & 0.0358 & 0.1231 & -0.5078 & -0.2753 & 0.4378 & -0.2470 & 0.0034 \\
45 & 0.3217 & 0.4356 & -0.4580 & -0.0083 & 0.0047 & 0.2586 & 0.2977 & -0.3219 \\
\hline
\end{tabular}




\section{APPENDIX G}

\section{Group A Factor Loadings}

Group A factor loadings with the single statistically significant loading (> .43) flagged with an " $X$ " to distinguish the defining participant sort for each factor

\begin{tabular}{|c|l|c|c|}
\hline Sorts & Factor 1 & Factor 2 & Factor 3 \\
\hline Participant 1 & 0.1010 & $0.7254 \mathrm{X}$ & 0.2681 \\
Participant 2 & $0.6815 \mathrm{X}$ & 0.1063 & 0.1014 \\
Participant 3 & $0.4546 \mathrm{X}$ & 0.2685 & 0.2001 \\
Participant 4 & $0.7025 \mathrm{X}$ & 0.1054 & 0.3854 \\
Participant 5 & 0.3155 & $0.6945 \mathrm{X}$ & -0.0039 \\
Participant 6 & 0.2705 & 0.3284 & 0.0898 \\
Participant 7 & 0.0952 & $0.4827 \mathrm{X}$ & 0.1360 \\
Participant 8 & $0.4952 \mathrm{X}$ & 0.2308 & 0.3259 \\
Participant 9 & $0.7029 \mathrm{X}$ & -0.1694 & 0.1103 \\
Participant 10 & 0.1058 & $0.6819 \mathrm{X}$ & 0.2796 \\
Participant 11 & $0.5755 \mathrm{X}$ & 0.3615 & 0.3744 \\
Participant 12 & 0.0284 & $0.5354 \mathrm{X}$ & 0.1749 \\
Participant 13 & $0.6421 \mathrm{X}$ & 0.4128 & -0.0757 \\
Participant 14 & 0.4917 & 0.4727 & 0.4092 \\
Participant 15 & 0.0290 & 0.4347 & $0.7496 \mathrm{X}$ \\
Participant 16 & 0.4491 & 0.4796 & 0.3175 \\
Participant 17 & $0.6662 \mathrm{X}$ & -0.1419 & 0.3577 \\
Participant 18 & 0.0290 & 0.4347 & $0.7496 \mathrm{X}$ \\
Participant 19 & $0.6968 \mathrm{X}$ & 0.1388 & 0.2025 \\
Participant 20 & 0.3900 & 0.4373 & 0.5645 \\
Participant 21 & 0.0317 & 0.3449 & $0.4443 \mathrm{X}$ \\
Participant 22 & $0.7744 \mathrm{X}$ & 0.3340 & -0.0744 \\
Participant 23 & $0.7130 \mathrm{X}$ & 0.3250 & 0.0556 \\
Participant 24 & -0.2858 & 0.5234 & -0.4387 \\
Participant 25 & $0.4970 \mathrm{X}$ & 0.2914 & -0.0208 \\
Participant 26 & $0.5699 \mathrm{X}$ & -0.2571 & -0.0104 \\
Participant 27 & $0.7595 \mathrm{X}$ & 0.3432 & -0.0814 \\
Participant 28 & $0.7233 \mathrm{X}$ & 0.1776 & -0.1756 \\
Participant 29 & 0.4229 & $0.4965 \mathrm{X}$ & 0.1468 \\
Participant 30 & $0.6714 \mathrm{X}$ & 0.3336 & 0.0803 \\
Participant 31 & 0.5435 & 0.6072 & 0.1970 \\
Participant 32 & $0.6256 \mathrm{X}$ & 0.0727 & 0.3632 \\
Participant 33 & $0.7343 \mathrm{X}$ & -0.0934 & 0.1071 \\
Participant 34 & $0.7684 \mathrm{X}$ & -0.0204 & 0.2555 \\
Participant 35 & 0.0259 & 0.0365 & $0.6982 \mathrm{X}$ \\
Participant 36 & $0.6967 \mathrm{X}$ & -0.0297 & 0.2237 \\
Participant 37 & 0.4845 & -0.1735 & 0.5056 \\
Participant 38 & $0.6781 \mathrm{X}$ & 0.3405 & -0.3644 \\
Participant 39 & $0.7507 \mathrm{X}$ & 0.2267 & 0.0348 \\
Participant 40 & $0.7145 \mathrm{X}$ & 0.1161 & 0.1509 \\
Participant 41 & 0.3743 & 0.2878 & 0.1131 \\
Participant 42 & -0.3674 & $0.6285 \mathrm{X}$ & 0.0976 \\
\hline
\end{tabular}




\begin{tabular}{|l|llc|}
\hline Participant 43 & 0.6020 & 0.2710 & 0.4913 \\
Participant 44 & 0.0181 & 0.0072 & 0.1417 \\
Participant 45 & 0.1131 & $0.6732 X$ & -0.1925 \\
\hline
\end{tabular}




\section{APPENDIX $\mathrm{H}$}

\section{The Complete Factor Array for the Q Sort}

\begin{tabular}{|c|c|c|c|c|}
\hline & Statement & $\begin{array}{c}\text { Factor } \\
1\end{array}$ & $\begin{array}{c}\text { Factor } \\
2\end{array}$ & $\begin{array}{c}\text { Factor } \\
3\end{array}$ \\
\hline 1. & $\begin{array}{l}\text { The rural setting makes me feel comfortable and } \\
\text { at ease. }\end{array}$ & 2 & 1 & -5 \\
\hline 2. & $\begin{array}{l}\text { The social challenges rural patients face make it } \\
\text { hard for me to provide care }\end{array}$ & -2 & 1 & 1 \\
\hline 3. & $\begin{array}{l}\text { I noticed the people seem happy in spite of } \\
\text { significant disadvantages. }\end{array}$ & 0 & 0 & 1 \\
\hline 4. & $\begin{array}{l}\text { Time and sustained presence in a community } \\
\text { helped build trust and familiarity. }\end{array}$ & 3 & 3 & 3 \\
\hline 5. & $\begin{array}{l}\text { Working on a community project provides the } \\
\text { most suitable platform for learning how to } \\
\text { communicate with other members of the health } \\
\text { care team. }\end{array}$ & -1 & -5 & -2 \\
\hline 6. & $\begin{array}{l}\text { Seeing patients together combines our } \\
\text { knowledge and strength to provide care. }\end{array}$ & 0 & 0 & 0 \\
\hline 7. & $\begin{array}{l}\text { Working together in the clinic serves as great } \\
\text { "peer" support that is needed. }\end{array}$ & 1 & -1 & -2 \\
\hline 8. & $\begin{array}{l}\text { The nature in which care is delivered in a rural } \\
\text { setting lends itself to team-based patient- } \\
\text { centered care. }\end{array}$ & 3 & 0 & -1 \\
\hline 9. & $\begin{array}{l}\text { IPE leads to a greater understanding of my own } \\
\text { role on the health care team. }\end{array}$ & 0 & -2 & 0 \\
\hline 10. & $\begin{array}{l}\text { Returning to something that is familiar is the } \\
\text { most important reason I would choose a rural } \\
\text { community. }\end{array}$ & -2 & -3 & -3 \\
\hline 11. & $\begin{array}{l}\text { Knowledge and experience with rural } \\
\text { recreational activities lead to acceptance by the } \\
\text { community. }\end{array}$ & 0 & 2 & 1 \\
\hline 12. & $\begin{array}{l}\text { As an outsider to a rural community, the best } \\
\text { approach is through humility, curiosity, and } \\
\text { good intention. }\end{array}$ & 5 & 3 & 2 \\
\hline 13. & $\begin{array}{l}\text { Having no familiarity with a rural community is } \\
\text { a disadvantage when providing care. }\end{array}$ & 0 & 3 & 4 \\
\hline 14. & $\begin{array}{l}\text { Time spent in a rural setting does not lead to a } \\
\text { greater understanding of rural life. }\end{array}$ & -4 & -4 & -4 \\
\hline 15. & $\begin{array}{l}\text { Rural communities have limited funds which } \\
\text { restrict what care can be provided. }\end{array}$ & 0 & 1 & -1 \\
\hline 16. & $\begin{array}{l}\text { The most important role of a health care } \\
\text { provider is community engagement. }\end{array}$ & -1 & -4 & 0 \\
\hline 17. & $\begin{array}{l}\text { Rural culture is one where community-minded } \\
\text { individuals value resilience and practicality. }\end{array}$ & 1 & 2 & 0 \\
\hline 18. & $\begin{array}{l}\text { A rural community provides ample opportunities } \\
\text { for creativity, meaning, variety, and autonomy. }\end{array}$ & 4 & 0 & 0 \\
\hline 19. & $\begin{array}{l}\text { The rural IPE experience helped me answer } \\
\text { questions about rural life. }\end{array}$ & 1 & -3 & 5 \\
\hline
\end{tabular}




\begin{tabular}{|c|c|c|c|c|}
\hline 20. & $\begin{array}{l}\text { My exposure to rural practice had generated an } \\
\text { interest in a rural community. }\end{array}$ & 2 & 1 & -2 \\
\hline 21. & $\begin{array}{l}\text { By being exposed to a rural clinical experience, } \\
\text { I gained understanding about how my interests } \\
\text { and desires could be met in a rural setting. }\end{array}$ & 4 & 2 & 3 \\
\hline 22. & $\begin{array}{l}\text { Certain health professions come with a } \\
\text { responsibility to care for a rural community. }\end{array}$ & -1 & 0 & 3 \\
\hline 23. & $\begin{array}{l}\text { The rural IPE experience did not expand my } \\
\text { understanding of the respective health care } \\
\text { professions. }\end{array}$ & -4 & 1 & -2 \\
\hline 24. & $\begin{array}{l}\text { Feeling professionally isolated is common in a } \\
\text { rural community. }\end{array}$ & -3 & 0 & 2 \\
\hline 25. & $\begin{array}{l}\text { Rural healthcare practice does not allow time } \\
\text { away from your patients. }\end{array}$ & -3 & -1 & 0 \\
\hline 26. & $\begin{array}{l}\text { The availability of outdoor activities attracts me } \\
\text { to the rural setting. }\end{array}$ & 2 & 4 & 1 \\
\hline 27. & $\begin{array}{l}\text { The most important aspect of rural IPE is living } \\
\text { together with other health professions students. }\end{array}$ & -1 & -2 & 1 \\
\hline 28 . & I want my children to grow up in a rural area. & 1 & -1 & -4 \\
\hline 29. & $\begin{array}{l}\text { I felt judged for not having views and beliefs } \\
\text { similar to my patients. }\end{array}$ & -5 & -1 & -1 \\
\hline 30. & $\begin{array}{l}\text { Isolation from family and friends is a major } \\
\text { reason for not choosing to live in a rural } \\
\text { community. }\end{array}$ & -2 & 5 & 4 \\
\hline 31. & $\begin{array}{l}\text { The most effective rural IPE allows for } \\
\text { engagement in the community. }\end{array}$ & 3 & 4 & 2 \\
\hline 32. & $\begin{array}{l}\text { The rural clinical setting provides the best } \\
\text { opportunity to learn about other health care } \\
\text { professions. }\end{array}$ & -2 & -3 & -1 \\
\hline 33. & $\begin{array}{l}\text { The rural setting is not a good place to apply the } \\
\text { IPE model. }\end{array}$ & -3 & -2 & -3 \\
\hline 34. & $\begin{array}{l}\text { Seeing patients together with another students } \\
\text { provided a great way for me to learn. }\end{array}$ & -1 & -2 & -3 \\
\hline 35. & $\begin{array}{l}\text { The rural IPE experience harnessed the potential } \\
\text { of rural services to promote my interprofessional } \\
\text { capability. }\end{array}$ & 1 & -1 & -1 \\
\hline 36. & $\begin{array}{l}\text { Feeling a connection to a rural community } \\
\text { makes it more likely to return after graduation. }\end{array}$ & 2 & 2 & 2 \\
\hline
\end{tabular}

